\title{
II. DIE NACHLASSENDE ATTRAKTIVITÄT DER GERICHTE
}

\section{INSTITUTIONELlER PluRALISMUS UND ANGEBotstheORIE DES STREITVERHALTENS}

Warum gehen Menschen überhaupt vor Gericht? Warum prozessieren sie einmal bereitwillig, ja geradezu mit Hingabe, dann hingegen nur widerstrebend und erst nachdem alle anderen Möglichkeiten erschöpft sind? Wie kommt es, daß die Klagefreudigkeit im Laufe der Zeiten und zwischen den nationalen Rechtskulturen offenbar erheblichen Schwankungen unterliegt? Das Konfliktverhalten der Menschen zu ergründen, gehört zu den schwierigsten Aufgaben einer Kulturgeschichte des Rechts. Will man sich nicht mit der Erzählung einzelner Fälle begnügen oder mit der schlichten Auskunft zufriedengeben, daß bestimmte Völker, Gruppen oder Individuen eben ,streitsüchtiger' seien als andere, kommt man um komplexere Erklärungsversuche nicht herum. Eine notwendige, wenn auch nicht hinreichende Vorbedingung dafür ist die statistische Erhebung der Klagetätigkeit und der Klageerfolge, wenn möglich differenziert nach Gerichten, nach Art der Klagen und nach sozialer Position und Geschlecht von Klägern und Beklagten. Für Arbeitsstreitigkeiten im England des Industriezeitalters liegen justizstatistische Untersuchungen bisher nur in Form von Fallstudien zu einzelnen Gesetzen vor. Dabei stand vornehmlich der Zeitraum bis $1875 \mathrm{im}$ Mittelpunkt. In den folgenden Abschnitten wird versucht, für die Zeit von 1850 bis zum Beginn zwanziger Jahre des 20 . Jahrhunderts einem Gesamtüberblick näherzukommen. Neben der ordentlichen Lokalgerichtsbarkeit werden dabei auch freiwillige Schieds- und Einigungsinstanzen berücksichtigt.

Diesem Vorhaben sind allerdings durch die Quellenlage Grenzen gesetzt. Offizielle Justizstatistiken, unterteilt in eine strafrechtliche und eine zivilrechtliche Serie, gibt es in Großbritannien seit 1857. Sie wurden in den Parliamentary Papers veröffentlicht, waren bis zum Ersten Weltkrieg vergleichsweise ausführlich und sind - bei allen quellenkritischen Vorbehalten, die man gegen zeitgenössische Statistiken anmelden muß - einigermaßen verläßlich. ${ }^{1}$ Leider enthalten diese Statistiken über weite Strecken nicht das,

1 Für die Jahre 1858 bis 1913 erschienen die Justizstatistiken regelmäßig ein bis zwei Jahre später in den Parliamentary Papers, während des Ersten Weltkrieges wurden die Statistiken im 
was den Sozialhistoriker interessiert. Die Streitgegenstände erscheinen dort nicht für alle Gerichte spezifiziert, und wo dies der Fall ist, werden oft juristische Kategorien wie zum Beispiel breach of contract verwendet, die keine Rückschlüsse auf die Fakten des Falles und die Art der Beziehung zwischen den Beteiligten erlauben. Erfolgsquoten sind ebenfalls meist nur pauschal ausgewiesen, und sozialgeschichtlich verwertbare Angaben zu Klägern und Beklagten finden sich selten. Immerhin sind aber für einige zweifelsfrei als Arbeitskonflikte identifizierbare Klagetypen (wrongful dismissal, Klagen unter den Master and Servant Acts, Employers' Liability und Workmen's Compensation Acts) Zahlenangaben vorhanden, aus denen sich langfristige Veränderungen der Prozeßhäufigkeit und zum Teil auch die Prozeßergebnisse ablesen lassen. Für darüber hinausgehende Fragen bin ich auf eigene Zählungen und Schätzungen angewiesen, die sich auf mein aus Gerichtsakten und publizierten Fallberichten gewonnenes Sample stützen.

Trotz der damit verbundenen, unvermeidlichen Unsicherheiten kann ein Befund als gesichert gelten: Gemessen an der Klagetätigkeit insgesamt nahm die Zahl der Arbeitsstreitigkeiten vor den ordentlichen Lokalgerichten im Laufe des Untersuchungszeitraums ab. Bei manchen Klagetypen, so insbesondere bei Klagen unter dem Employers and Workmen Act, ist seit Mitte der siebziger Jahre des 19. Jahrhunderts sogar ein Rückgang in absoluten Zahlen zu verzeichnen, was angesichts der zunehmenden Beschäftigtenzahl, und damit der zunehmenden Zahl potentiell rechtsrelevanter Konflikte, darauf hindeutet, daß die ordentlichen Lokalgerichte (Friedensrichter, Grafschaftsgerichte) als Instanzen der Konfliktregelung immer mehr an Attraktivität einbüßten. Der Oberste Gerichtshof fiel als Ort für Arbeitsstreitigkeiten quantitativ nicht ins Gewicht und braucht daher in diesem Kapitel nicht eigens behandelt zu werden. ${ }^{2}$ Seine Bedeutung lag primär in der Funk-

Umfang erheblich reduziert und für einige Jahre nicht in den Parliamentary Papers veröffentlicht. Nach dem Krieg wurden vor allem die Civil Judicial Statistics nur noch in stark vermindertem Umfang und in veränderter Form fortgeführt. Eine Auflistung der Fundorte der Justizstatistiken in den Parliamentary Papers findet sich bei: P. Ford u. G. Ford, Select List of British Parliamentary Papers, 1833-1899, Shannon (Ireland) 1969, App. IV, S. 149; dies., A Breviate of Parliamentary Papers, 1900-1916, Shannon (Ireland) 1969, S. 458 f. (für 1900 bis 1938). Für die Siglen der Microfiche-Edition bis 1898 siehe: Peter Cockton, Subject Catalogue of the House of Commons Parliamentary Papers 1801-1900, Bd. 1, Cambridge 1991, S. 610f. Außer bei wörtlichen Zitaten oder direkten Bezugnahmen auf eine einzelne Statistik wird auf Nachweise verzichtet.

2 Was erstinstanzliche Arbeitsstreitigkeiten vor dem Obersten Gerichtshof (bis 1873/75 den Common law-Gerichten) in London angeht, so lassen sich den offiziellen Justizstatistiken immerhin für einen wichtigen Klagegegenstand (wrongful dismissal) Zahlenangaben entnehmen. Danach machten Prozesse wegen ungerechtfertigter Entlassung im Zeitraum von 1867 bis 1898 stets etwa ein Prozent aller Klagen vor dem Obersten Gerichtshof aus. In absoluten 
tion als Berufungsinstanz, die durch ihre Entscheidungen die Normen des Common law veränderte und so mittelbar auch die Praxis der Lokalgerichte lenkte. Auf diese qualitativen Aspekte der Rechtsprechung der höheren Gerichte wird in späteren Kapiteln eingegangen.

Unter quantitativem Gesichtspunkt kann man insgesamt durchaus von einer Flucht englischer Arbeitnehmer und Arbeitgeber aus dem Recht, das heißt dem gewöhnlichen Recht der ordentlichen Gerichtsbarkeit, sprechen. Dieser Befund ist um so bemerkenswerter, wenn man zum Vergleich die aus offiziellen Statistiken ermittelbaren Zahlen zur Spruchtätigkeit der deutschen Gewerbe-, Kaufmanns- und Arbeitsgerichte zwischen 1890 und 1929 dagegenhält. Hier kam es, wie zu zeigen sein wird, zu einem steilen Anstieg der Klagetätigkeit, der durch den Ersten Weltkrieg nur kurzzeitig unterbrochen wurde. Im Verhältnis zur Zahl der Beschäftigten, die jeweils unter die Jurisdiktion fielen, klagten deutsche Arbeitnehmer und Arbeitgeber in den Jahren vor dem Ersten Weltkrieg vor den Gewerbe- und Kaufmannsgerichten etwa fünfzehn mal so häufig wie englische Arbeitnehmer und Arbeitgeber vor den Friedens- und Grafschaftsgerichten. ${ }^{3}$ Bedenkt man, daß in Deutschland zusätzlich auch die ordentlichen Gerichte (Amtsgerichte, Landgerichte) sowie Innungsschiedsgerichte mit Arbeitsstreitigkeiten befaßt waren, wird der Abstand zwischen den beiden Rechtskulturen noch größer. Andere justizförmige Institutionen, die auf englischer Seite in den Vergleich einbezogen werden müßten, fehlen; die freiwilligen Schieds- und Einigungsstellen blieben, wie sich zeigen wird, als Instanz zur Lösung von Individualkonflikten wenig bedeutsam, und eine den Gewerbegerichten vergleichbare Sondergerichtsbarkeit gab es nicht.

Wie ist es zur Flucht aus dem Recht und damit zur fortschreitenden Entrechtlichung der Arbeitsbeziehungen in England gekommen? Waren englische Arbeitnehmer und Arbeitgeber weniger, streitsüchtig als die deutschen, oder waren ihre Beziehungen tatsächlich konfliktärmer, so daß sich der enorme Unterschied bei der Prozeßhäufigkeit auf diese Weise - sozusagen von der Nachfrageseite her - erklären ließe? Abgesehen davon, daß Phänomene wie Streitsucht oder die Konflikthaltigkeit von Situationen als

Zahlen waren das nie mehr als $30 \mathrm{Klagen}$ pro Jahr. Hinzu kamen noch etwa ein bis maximal zwei Dutzend Fälle, die vor den in den Provinzen rundreisenden Common law-Richtern in den courts of assize entschieden wurden. So weit sich den Law Reports entnehmen läßt, handelte es sich bei den Klägern vor allem um leitende Angestellte (Manager, Filialleiter, Geschäftsreisende) sowie Schauspieler, Journalisten, Schuldirektoren und andere höher qualifizierte Arbeitnehmer, bei denen die Streitwerte im Fall der Entlassung über den für die Grafschaftsgerichte geltenden Grenzen lagen.

3 Vgl. die Grafiken 2.3, 3.1 und 5.2. und die vergleichende Analyse der Zahlen in Kap. II.5. 
Massenerscheinung schwer nachzuweisen sind, gibt es gute Gründe dafür, zunächst nach einer eher angebotsorientierten, das heißt vor allem institutionengeschichtlichen Erklärung des Konfliktverhaltens zu suchen. Das gilt übrigens nicht nur für England im 19. und frühen 20. Jahrhundert, sondern generell. ${ }^{4}$ Ob Streitigkeiten mithilfe der ordentlichen Justiz oder auf anderem Wege gelöst werden, hängt dieser Ausgangsvermutung zufolge zu einem guten Teil davon ab, wie weit die zur Verfügung stehenden Institutionen fähig sind, den spezifischen Bedürfnissen der Streitenden entgegenzukommen. Im Falle Englands mögen unter anderem der strenge Formalismus des Common law, die unterschiedslose Behandlung von Arbeitsverträgen als gewöhnliche Verträge zwischen gleichen Partnern, die geringe Flexibilität des Verfahrens und nicht zuletzt die hohen Prozeßkosten viele potentiell klagebereite Arbeitnehmer und Arbeitgeber von einem Gang zum Gericht abgehalten haben. Für die in Westminster angesiedelten höchsten Gerichte und ihre regionalen Ableger, die nur an jeweils wenigen Tagen pro Jahr in bestimmten Provinzstädten tagenden Assizengerichte (courts of assize), kam als zusätzlicher Hinderungsgrund die große räumliche und zeitliche Distanz zum Streitgeschehen hinzu. Die Common law-Richter konnten aufgrund ihrer Ausbildung und ihres Gesichtskreises nicht die Sachkenntnis besitzen, die sie in den Augen rechtssuchender Geschäftsleute oder Arbeitnehmer benötigten.

Lassen sich für die fehlende Anziehungskraft der Common law-Gerichte allerhand plausible Gründe benennen, vor allem die hohen Kosten, ist es nicht ohne weiteres einzusehen, warum auch die lokalen Friedens- und Grafschaftsgerichte für klagende Arbeitnehmer und Arbeitgeber so unattraktiv gewesen sein sollen. Beide Institutionen waren dicht genug gestreut und nahe genug am Geschehen, um auf lokale Besonderheiten eingehen und sich mit den typischen Konflikten ortsansässiger Industrien vertraut machen zu können. Beide Gerichte waren zwar theoretisch an das Common law gebunden, es ist jedoch fraglich, wie weit sich Friedensrichter und Grafschaftsrichter tatsächlich an dessen rigide Formalismen hielten. Die bisher vorliegenden Fallstudien zu beiden lokalen Gerichtstypen zeigen eher eine uneinheitliche, örtlichen Gewohnheiten verpflichtete, manchmal bis hin zur Idiosynkrasie neigende Spruchpraxis. Unter den Berufsfriedensrichtern und Grafschaftsrichtern gab es durchaus populäre Figuren, manche von ihnen waren als Schlichter bei Arbeitskämpfen sehr geschätzt, vielfach

4 Vgl. Blankenburg, Mobilisierung des Rechts, S. 27-30 u. 95-105; ders., Prozeßflut und Prozeßebbe. Über die Fähigkeit der Gerichte, mit Rechtsstreitigkeiten fertig zu werden, in: ders. (Hg.), Prozeßflut?, S. 9-20, hier bes. S. 11 ff. 
nahmen auch die Gerichtsprozesse den Charakter von informellen Verhandlungen an. Für einen allgemeinen Vertrauensverlust in den Gerechtigkeitssinn der lokalen Rechtsprechungsorgane finden sich, jedenfalls bis zu den siebziger Jahren des 19. Jahrhunderts, nur wenig Anzeichen.

Allerdings, das muß betont werden, sind unter diesem Aspekt bisher vorwiegend die frühen und mittleren Jahrzehnte des 19. Jahrhunderts untersucht worden. Die eigentliche Abkehr von den ordentlichen Gerichten auf lokaler Ebene setzte bei englischen Arbeitnehmern und Arbeitgebern erst später, im letzten Drittel des 19. Jahrhunderts, ein. Vorher waren die lokalen Gerichte noch Bestandteile eines Systems gewesen, das man mit dem Begriff legal pluralism bezeichnet hat. ${ }^{5}$ Unter, rechtlichem Pluralismus' hat man ein System zu verstehen, in dem verschiedene Institutionen der Konfliktregulierung, rechtliche sowohl als außerrechtliche, um die Gunst (oder wenn man so will: die Kundschaft) potentieller Streitparteien konkurrieren. Im viktorianischen England war die ordentliche, dem Common law verpflichtete Justiz nur eine dieser Institutionen. Daneben gab es eine Vielzahl von freiwilligen Schiedsstellen und lokalen Sondergerichtsbarkeiten aller Art, zu denen sich im Laufe des 19. und frühen 20. Jahrhunderts als neue Erscheinung auch administrative Instanzen mit quasi-judikativen Funktionen gesellten, beispielsweise die Fabrikinspektoren, die Railway and Canal Commission oder die National Insurance Commissioners. ${ }^{6} \mathrm{Ob}$ man für die Zeit bis zur Mitte des 19. Jahrhunderts überhaupt von einer, ordentlichen' lokalen Gerichtsbarkeit in England sprechen sollte, ist bezweifelt worden.? Die Friedensgerichte unterschieden sich in den Details der Organisation und vor allem in ihrer Tätigkeit erheblich voneinander. Ähnliches scheint

5 Hierzu vor allem: Arthurs, Without the Law'. Allgemein zum Ansatz des legal pluralism: Marc Galanter, Justice in Many Rooms, in: Journal of Legal Pluralism 1 (1981), S. 1-48.

6 Vgl. hierzu neben der Publikation von Arthurs, ,Without the Law', auch die frühe Arbeit von Otto Koellreutter, Verwaltungsrecht und Verwaltungsrechtsprechung im modernen England. Eine rechtsvergleichende Studie, Tübingen 1912. Über Koellreutters spätere Rolle im Nationalsozialismus: Michael Stolleis, Recht im Unrecht. Studien zur Rechtsgeschichte des Nationalsozialismus, Frankfurt/Main 1994, bes. S. $116 \mathrm{ff}$. u. $138 \mathrm{ff}$. Für Arbeitsstreitigkeiten besaßen die administrativen Spruchinstanzen nur eine begrenzte Bedeutung. Wichtig wurden die innerbehördlichen, oft undurchschaubaren, weil kaum gesetzlich geregelten Beschwerdeund Konfliktlösungsprozeduren besonders für Angestellte der Lokalverwaltungen sowie Lehrer. Kritisch dazu aus Sicht der zeitgenössischen Juristenschaft: W. J. L. Ambrose, The New Judiciary, in: Law Quarterly Review 26 (1910), S. 203-214. Zu den Lehrern siehe auch unten, Kap. III.3.

7 Siehe Arthurs, ,Without the Law', S. $32 \mathrm{ff}$. u. $38 \mathrm{ff} . ;$ ders., Special Courts, Special Law: Legal Pluralism in Nineteenth-Century England, in: G.R. Rubin u. David Sugarman (Hg.), Law, Economy and Society, 1750-1914: Essays in the History of English Law, Abingdon 1984, S. 380-411. 
auch noch bei den frühen Grafschaftsgerichten der Fall gewesen zu sein, wenngleich diese im Jahr 1847 im Prinzip einheitlich für ganz England und Wales, mit Ausnahme der City of London, eingerichtet wurden. Eine gröBere Uniformität der Praxis scheint aber auch hier erst um die siebziger Jahre des 19. Jahrhunderts eingekehrt zu sein. Überdies besaßen Friedensrichter und Grafschaftsgerichte etwa im Bereich der Arbeitsstreitigkeiten, aber nicht nur dort, zum Teil eine konkurrierende Rechtsprechung. Schließlich glichen selbst die höchsten Gerichtshöfe in Westminster bis zur großen Justizreform von 1873-75 eher einer vielköpfigen Hydra als einem rational strukturierten, einheitlichen Bau; ihre Entscheidungstätigkeit basierte zum Teil auf unterschiedlichen Prinzipien, Common law und equity, bevor beide Rechtsmaterien durch die Justizreform für den gesamten neugeschaffenen Obersten Gerichtshof zu verbindlichen Traditionen erklärt wurden. ${ }^{8}$ Kurzum, wer prozessieren wollte, konnte im England des 19. Jahrhunderts unter einer großen Zahl von Institutionen der Konfliktregulierung wählen. Vor allem auf lokaler Ebene bestand dabei ein fließender Übergang zwischen justizförmigen Institutionen, die ihre Normen zumindest der Theorie nach vom Common law bezogen, und anderen Einrichtungen, deren Urteilsmaßstäbe nur zum Teil den strengen Maßstäben des Rechts genügten. Wie sich der Pluralismus der Institutionen auf die Prozeßfreudigkeit auswirkte, wie er die Erfolgschancen verschiedener sozialer Gruppen positiv oder negativ beeinflußte, ist bisher nur in sehr allgemeiner Form erörtert worden. Die folgenden Abschnitte versuchen, diese Fragen im Hinblick auf Arbeitnehmer und Arbeitgeber genauer zu beantworten. Dazu wird die in der Rechts- und Sozialgeschichte übliche, lediglich auf einzelne Gesetze oder einzelne Gerichtstypen zentrierte Betrachtungsweise verlassen und durch den Blick auf das Wechselspiel der Institutionen ersetzt.

Nun gibt es in der zweiten Hälfte des 19. Jahrhunderts Anzeichen für eine Verminderung pluralistischer Elemente im System der im weitesten Sinne rechtsprechenden Instanzen. Der wohl wichtigste Schritt auf diesem Weg zu mehr Uniformität war die Schaffung der Grafschaftsgerichte (1847), der zweite große Schritt war dann die Reform der Spitze der ordentlichen Gerichtsbarkeit in den Jahren 1873-75. Durch verschiedene Reformen des Berufungswesens und andere Maßnahmen wurden im Laufe der zweiten

8 Zur großen Justizreform, zur Organisation und Arbeitsweise der höheren Gerichte vor und nach 1875 gibt es gute Überblicksdarstellungen, weshalb hier nicht näher darauf eingegangen werden muß. Vgl. zuletzt mit Literaturhinweisen: Cornish u. Clark, Law and Society, S. 18-28, 40-45, 92 ff.; Konrad Zweigert u. Hein Kötz, Einführung in die Rechtsvergleichung auf dem Gebiete des Privatrechts, 3. neubearb. Aufl., Tübingen 1996, S. $195 \mathrm{ff}$. u. $204 \mathrm{ff}$. 
Jahrhunderthälfte die Friedens- und Grafschaftsrichter einer effektiveren Aufsicht durch die Common law-Gerichte und das Amt des Lordkanzlers, welches als eine Art Justizministerium fungierte, unterworfen. ${ }^{9}$ Beide Schienen der Lokalgerichtsbarkeit gerieten so zunehmend unter die Kontrolle des Common law; sie wurden normalisiert, uniformisiert und professionalisiert. Die Friedensrichter verloren zudem im Laufe des 19. Jahrhunderts den größten Teil ihrer administrativen Befugnisse, was sie eindeutiger als zuvor zu Organen der Rechtsprechung werden ließ. Zwar blieben die Friedensrichter selbst überwiegend Laien, aber überall sonst in den Lokalgerichten wuchs die Bedeutung professioneller, im Common law geschulter Juristen. Das Laienelement, insbesondere die Einrichtung der Geschworenen, wurde immer weiter zurückgedrängt.

Am Ende des 19. Jahrhunderts war das Gesamtsystem der konfliktregulierenden Institutionen klarer als zuvor in zwei voneinander getrennte Bereiche gespalten: einen rechtlichen Bereich, der die ordentliche Gerichtsbarkeit auf nationaler und lokaler Ebene umfaßte, und einen außerrechtlichen Bereich, dem freiwillige Schiedsorgane, administrative Spruchinstanzen und alle anderen Formen mehr oder weniger informeller Streitschlichtung angehörten. Das Gesamtsystem blieb pluralistisch, aber innerhalb dessen, was nun das ,gewöhnliche Recht' (ordinary law) genannt wurde, gab es weniger Vielfalt. Das ,gewöhnliche Recht' sollte für alle Personen und für alle Situationen das gleiche sein. Für Sonderrechte, spezielle Gerichte, lokale Abweichungen sollte im Recht kein Platz mehr sein. Was sich dem gewöhnlichen Recht nicht fügte, gehörte nun begrifflich nicht mehr zum ,Recht', es galt als etwas anderes, als Nicht-Recht, und außerdem als etwas der englischen Tradition Fremdes. Wieder war es Albert V. Dicey, der dieser Auffassung zum Durchbruch verhalf, nicht nur unter den Common law-Juristen, sondern darüber hinaus auch in weiten Kreisen der britischen Öffentlichkeit. ${ }^{10}$ Diceys definitorische Schärfung des Begriffs ordinary law richtete sich vor allem gegen die administrativen Spruchinstanzen, die Fabrikinspektoren, die Railway and Canal Commission, die National Insurance Commissioners, die verschiedenen mit quasi-judikativen Aufgaben betrauten Behörden und Ministerialabteilungen. Diese Instanzen maßten sich in seinen Augen Funktionen an, die eigentlich dem gewöhnlichen Recht zu-

9 Hierzu unten, Kap. II.2. u. II.3.

$10 \mathrm{Vgl}$. Albert V. Dicey, Introduction to the Study of the Law of the Constitution (1885), 6. Aufl., London 1902, hier bes. S. $183 \mathrm{f}$, 189f., 198f., 322-349, 485-492. Vgl. zum folgenden und zur Nachwirkung von Diceys Konzept des rule of law auch Cosgrove, Rule of Law, S. 78-90. 
standen. Dicey verurteilte das Bestreben der Politiker und Beamten in den Verwaltungsinstanzen, sich durch sogenannte, privative` Klauseln in Gesetzen sogar der letztinstanzlichen Kontrolle durch den Obersten Gerichtshof entziehen zu wollen. Für ihn waren diese Bestrebungen ein Verstoß gegen den rule of law. Die Möglichkeit, daß man die administrativen Spruchinstanzen selbst durch rechtsstaatliche Garantien, Öffentlichkeit des Verfahrens usw. rationalisieren, dabei aber als Sondergerichtsbarkeiten bestehen lassen könnte, zog Dicey nicht in Betracht. Dieser, aus deutscher Sicht ganz naheliegende Gedanke war für ihn, der nur die französischen Verhältnisse als Gegenbild zu England beobachtete, offensichtlich unfaßbar. ${ }^{11}$ Mit ihrer begrifflichen Engführung dessen, was ,Recht' sein sollte, schlossen Dicey und mit ihm die große Mehrheit der Juristen und der britischen Öffentlichkeit jede Möglichkeit für die Anerkennung von Sondergerichtsbarkeiten als vollwertige Instanzen der Rechtsprechung aus. Eine Konstruktion wie die deutschen Gewerbegerichte und später die Arbeitsgerichte konnte unter diesen begrifflichen Voraussetzungen in den Köpfen der britischen Entscheidungsträger nur schwer gedeihen. Eine nennenswerte Rezeption der deutschen Einrichtungen fand in England nicht statt. ${ }^{12}$

Die Engführung des Rechts war aber nicht nur eine begriffliche Angelegenheit, sie hatte auch Auswirkungen auf die alltägliche Praxis im Gerichtssaal, vor allem auf lokaler Ebene. Dort wurde die Rechtsprechung nun nach den Kriterien des Common law einheitlicher und professioneller gehandhabt. Sie wurde damit im Sinne des formalen Gleichheitsgrundsatzes zweifellos gerechter, dennoch aber (oder gerade deshalb) aus der Sicht der Streitparteien oft als mechanisch, realitätsfern und letztlich ungerecht empfunden. Vielleicht liegt hier eine Erklärung dafür, daß Arbeitnehmer und Arbeitgeber sich von den Friedens- und Grafschaftsgerichten immer mehr abwandten. Alternativen in Form von Schiedsgerichten oder anderen speziellen Instanzen, die in Arbeitsstreitigkeiten rechtskräftige Urteile fällen konnten, standen, wie gesagt, nicht zur Verfügung. So blieb in vielen Fällen,

11 Für kritische Stimmen gegen Diceys irrige Auffassung des französischen droit administratif und die englische Diskussion über die rechtliche Kontrolle der Verwaltung siehe William A. Robson, Administrative Law, in: Morris Ginsberg ( $\mathrm{Hg}$. ), Law and Opinion in England in the 20th Century, London 1959, S. 193-214; Cosgrove, Rule of Law, S. 91-103; John W. F. Allison, A Continental Distinction in the Common Law: A Historical and Comparative Perspective on English Public Law, Oxford 1996; ders., Cultural Difference, the Separation of Powers and the Public-Private Divide, in: Revue Européenne de Droit Public/European Review of Public Law/Europäische Zeitschrift des öffentlichen Rechts 9 (1997), S. 305-333.

12 Siehe unten Kap. II.5. 
auch denen, die nur eine Person oder wenige Individuen betrafen, als einziger Ausweg die informelle Verhandlung oder der Arbeitskampf.

Folgt man diesem Gedankengang, wäre das in Großbritannien im 20. Jahrhundert dominierende System des freien kollektiven Verhandelns nicht so sehr das gezielt angestrebte Resultat einer starken Gewerkschaftsbewegung und der sie stützenden politischen Kräfte, sondern eher eine aus der Not geborene Lösung in Ermangelung adäquater rechtlicher Konfliktlösungsformen. Wenn diese These zutrifft, enthielte die Meistererzählung der Arbeiterbewegung ein starkes Element von Wunschdenken, welches im 20. Jahrhundert zur Stabilisierung der einmal entstandenen Verhältnisse beigetragen hätte. In anderer Weise erwiese sich dann auch die Meistererzählung der Common law-Juristen als Faktor im Prozeß der Entrechtlichung der britischen Arbeitsbeziehungen: Indem die Juristen alle aufgrund legislativer Eingriffe oder kollektiver Vereinbarung zustandegekommenen quasi-rechtlichen Konfliktlösungsformen dem Bereich des Nicht-Rechts zuordneten, sprachen sie diesen Einrichtungen von vornherein die Legititmität ab, die zu ihrer Weiterentwicklung nötig gewesen wäre. Der Versuch, das ,gewöhnliche Recht' von fremden Elementen reinzuhalten, die begriffliche Engführung des Rechts durch die Common law-Juristen, hätten dann im Feld der Arbeitsbeziehungen letztlich zur Selbstmarginalisierung der Justiz geführt. In den folgenden Abschnitten soll geprüft werden, ob sich für diese Umdeutung der Meistererzählungen in der Geschichte der mit Arbeitsstreitigkeiten befaßten Institutionen Anhaltspunkte finden lassen.

\section{FRIEDENSRICHTER}

\section{SUMMARISCHE RECHTSPRECHUNG UND RELATIVE AUTONOMIE}

Der Friedensrichter (magistrate) war mindestens bis zur Mitte des 19. Jahrhunderts für die meisten Engländer die erste und einzige Stelle, an der sie mit dem Recht in Berührung kamen. Nach der Jahrhundertmitte traten für zivile Streitigkeiten die Grafschaftsgerichte hinzu, doch der magistrate's court blieb wegen der vergleichsweise niedrigen Gebühren und aufgrund seiner schnellen Erreichbarkeit das Arme-Leute-Gericht par excellence. ${ }^{13}$ Diese typisch englische Institution, in der Laien über ihresgleichen zu Ge-

13 Vgl. W.A. Hunter, Mr. Cross's Labour Bills, in: Fortnightly Review 18 (1875), S. 217-227, S. $225 \mathrm{f}$.: "The magistrate's court is the poor man's court, and only through that court does the bulk of the people ever come to know anything of the law". 
richt sitzen, hat bisher alle ihre Kritiker überdauert und existiert, wenn auch in gewandelter Form, bis heute. ${ }^{14}$ Ursprünglich zur Aufrechterhaltung der öffentlichen Ordnung ins Leben gerufen, waren die Friedensrichter seit jeher vor allem mit der Ausübung der Strafgewalt betraut. Daneben besaßen sie auch im Bereich des Zivilrechts Befugnisse, so unter anderem die Rechtsprechung unter dem Employers and Workmen Act. Außerdem erfüllten sie eine Fülle administrativer Aufgaben, angefangen von der Lizenzvergabe für Schankwirtschaften über die Verwaltung der Lokalsteuern bis hin zur Aufsicht über Straßen- und Brückenbau, Polizei, Gefängnisse und Irren- und Armenanstalten. Damit waren die magistrates im 18. und frühen 19. Jahrhundert nicht nur Richter, sondern zugleich auch die Hauptorgane der Lokalverwaltung. Diese administrativen Kompetenzen brauchen hier nicht weiter $\mathrm{zu}$ interessieren, zumal sie den Friedensrichtern im Laufe des 19. Jahrhunderts durch eine Serie von Reformen zum größten Teil genommen und statt dessen gewählten Körperschaften oder staatlichen Organen übertragen wurden. ${ }^{15}$ Die richterlichen Funktionen rückten so in den Städten ab 1835, in den Grafschaften ab 1888 in den Mittelpunkt der Tätigkeit der magistrates.

Hier war es nun vor allem die Strafgewalt, die den Friedensrichtern Autorität verlieh und ihr Erscheinungsbild in der Öffentlichkeit prägte. Viermal pro Jahr, bei Bedarf öfter, traten die Friedensrichter in den Grafschaften und boroughs zu sogenannten quarter sessions zusammen, um dort unterstützt von den Geschworenen über alle Straftaten zu urteilen, mit Ausnahme der Fälle, bei denen die Todesstrafe vorgeschrieben war; diese mußten vor den courts of assize verhandelt werden. Das umständliche Verfahren mit jury fand jedoch nur bei schweren Strafsachen, den sogenannten indictable offences, Anwendung. Bei einer großen Zahl kleinerer Vergehen und Ordnungswidrigkeiten, darunter auch Verstößen gegen die Master and Servant Acts, waren die Friedensrichter befugt, allein oder zu zweit in sogenannten petty sessions Strafen auszusprechen und Anordnungen zu treffen. Man sprach hier von der, summarischen Rechtsprechung' (summary juris-

14 Zur Geschichte der Friedensrichter: Esther Moir, British Institutions. The Justice of the Peace, Harmondsworth 1969; Sir Thomas Skyrme, History of the Justices of the Peace, 3 Bde., Chichester 1991 (eine umfangreiche, aber in den Details nicht immer verläßliche Darstellung). Zu den Reformen der jüngsten Vergangenheit: Jackson's Machinery of Justice, ed. J. R. Spencer, Cambridge 1989 (= 7. rev. Aufl. von: R.M. Jackson, The Machinery of Justice in England, zuerst 1940), S. 184-193 u. 403-419.

15 Die wichtigsten Stationen des Kompetenzverlusts: 1829 (Metropolitan Police), 1834 (Poor Law), 1835 (Municipal Corporations), 1839/56 (County Police, Borough Police), 1835/77 (Prisons), 1888 (County Councils). 
diction) der Friedensrichter. Der Umfang dieser summarischen Rechtsprechung war durch Statutes definiert und wuchs vom 18. bis zum 20. Jahrhundert immer weiter an. Sie hatte vor allem den Vorteil, schnell zu sein: petty sessions konnten jederzeit anberaumt werden und tagten in Großstädten nahezu täglich. Die Friedensrichter in petty sessions waren auch zuständig für die Voruntersuchungen bei schweren Straftaten, wobei sie allerdings nicht wie deutsche Untersuchungsrichter - selbständig Beweise beschafften, sondern lediglich vorgelegte Beweise daraufhin beurteilten, ob sie für eine Überstellung zur Verhandlung vor den quarter sessions oder den courts of assize ausreichten. Die Verfolgung, Beweissicherung und Anklageerhebung war im übrigen in England eine Angelegenheit der Privatleute. Bei Straftaten übernahm im Laufe des 19. Jahrhunderts zunehmend die Polizei diese Rolle, vielfach mußten aber nach wie vor die Bürger selber tätig werden, sofern nicht administrative Organe wie Fabrikinspektoren oder Lokalverwaltungen hilfsweise eingriffen. Eine der deutschen Staatsanwaltschaft vergleichbare Behörde gab und gibt es in England nicht. ${ }^{16}$

Sorgte bei den schweren Kriminalfällen schon das öffentliche Aufsehen dafür, daß die Friedensrichter stets mit einer Überprüfung ihrer Urteilssprüche rechnen mußten, besaßen sie bei den summarisch verhandelten Routinesachen ein viel höheres $\mathrm{Ma}$ an Autonomie. Im summarischen Verfahren wurden außer kleinen Diebstählen, Störungen der öffentlichen Ordnung und Verkehrsdelikten auch fast alle Verstöße gegen die im ersten Kapitel genannten Master and Servant Acts, Truck Acts, Factory Acts, Mines Acts usw. geahndet. Die Berufungsmöglichkeiten für die Streitparteien waren durch diese Arbeitsgesetze zum Teil stark beschnitten. Der Master and Servant Act von 1823 schloß die Berufung an höhere Gerichte ganz aus, die Fabrikgesetze ab 1844 sowie die meisten anderen Arbeitsgesetze nach der Jahrhundertmitte ließen lediglich eine Berufung an die quarter sessions zu. ${ }^{17}$ Der Summary Jurisdiction Act von 1848, der eine Art rudimentärer Prozeßordnung für das summarische Verfahren darstellte, kannte ebenfalls

16 Im Jahr 1879 wurde das Amt eines Director of Public Prosecutions eingerichtet, doch blieb seine Rolle im 19. und frühen 20. Jahrhundert im wesentlichen beschränkt auf die Beratung des Innenministeriums und der Polizeibehörden bei der Verfolgung der schwerwiegendsten Verbechen. Erst im Jahr 1985 wurde diesem Amt mit dem Crown Prosecution Service ein personeller Unterbau gegeben, aber nach wie vor liegt die Entscheidung, ob es überhaupt zu einer Strafverfolgung kommt, bei der Polizei oder anderen Behörden und Privatleuten. Anders als die deutschen Staatsanwälte haben die Beamten des Crown Prosecution Service vor Gericht nicht das Anklagerecht.

174 Geo. 4, c. 34 (1823), s. 5 (mand every Order or Determination of such Justice or Justices made under this Act shall be final and conclusive“); $7 \& 8$ Vict., c. 15 (1844), ss. 69 u. 70. 
über die quarter sessions hinaus kein Berufungsrecht. ${ }^{18}$ Einer Prozeßpartei, die sich ungerecht behandelt fühlte, war mit einer Berufung an die quarter sessions allerdings kaum gedient, denn dort blieben die Friedensrichter unter sich; die Wahrscheinlichkeit war gering, daß sie das Urteil eines Kollegen, der noch dazu meistens anwesend war, kassierten.

Jenseits der quarter sessions bestand im Prinzip die Möglichkeit, daß ein Common law-Gericht, in der Regel die King's Bench, von sich aus oder auf Betreiben einer Prozeßpartei oder dritter Personen ein Verfahren an sich zog. Das konnte durch den sogenannten writ of certiorari und andere richterliche Verfügungen (writs) geschehen. ${ }^{19}$ Einige Arbeitsgesetze schlossen auch diese Möglichkeit kategorisch aus, so noch der Master and Servant Act von 1867.20 Andere Gesetze legten fest, daß formale Verfahrensfehler nicht ausreichen sollten, um einen writ of certiorari zu erlassen, so etwa der Truck Act von 1831, das Bergwerksgesetz von 1842 und die Fabrikgesetze ab 1844.21 Damit sollte verhindert werden, daß eine Prozeßpartei unter rein

$1811 \& 12$ Vict., c. 43 (1848), s. 27. Dieses Gesetz regulierte auch das Verfahren unter dem Master and Servant Act neu. Deshalb ist die in der Sekundärliteratur immer wieder zu lesende Behauptung, daß die unter dem Master and Servant Act angeklagten Arbeiter kein Recht auf Verteidigung und Darstellung ihres Falles gehabt hätten, für die Zeit nach 1848 unzutreffend. Vgl. ebd., s. 12 (,and the Party against whom such Complaint is made or Information laid shall be admitted to make his full Answer and Defence thereto, and to have the Witnesses examined and cross-examined by Counsel or Attorney on his Behalf") u. s. 14 (" and he shall be asked if he have any Cause to show why he should not be convicted, or why an Order should not be made against him“). Die irrige Auffassung wird zum Beispiel vertreten von D.C. Woods, The Operation of the Master and Servant Act in the Black Country, 1858-1875, in: Midland History 7 (1982), S. 93-115, S. 93 u. 104 („a worker prosecuted by an employer could not give evidence on his own behalf"). Richtig ist, daß Angeklagte bis 1867 nicht als Zengen unter Eid in eigener Sache aussagen durften.

19 Der berühmteste writ war habeas corpus, durch den die Rechtmäßigkeit einer Gefangennahme überprüft und eine Freilassung erwirkt werden konnte. Der writ of certiorari ermöglichte die Revision untergerichtlicher Urteile im Hinblick auf Rechts- und Verfahrensfehler. Urteile von magistrates konnten auf diese Weise kassiert werden oder mit der Auflage an die magistrates zurückgehen, sie den Vorgaben des höheren Gerichts entsprechend zu ändern. Daneben kam auch noch der writ of mandamus in Frage, durch den ein Untergericht gezwungen werden konnte, einen Fall anzuhören, dessen Behandlung es verweigert hatte. Der Review of Justices Decisions Act, 35 \& 36 Vict., c. 26 (1872) erleichterte es Friedensrichtern, ihre Entscheidung zu verteidigen. Sie brauchten nun nicht mehr persönlich zu erscheinen oder sich durch einen Anwalt vertreten zu lassen, sondern konnten per Post eine beeidete Erklärung mit ihren Urteilsgründen einsenden.

2030 \& 31 Vict., c. 141 (1867), s. 23: "No Writ of Certiorari or other Process shall issue to remove any Proceedings under this Act into any Superior Court."

$211 \& 2$ Will. 4, c. 37 (1831), s. 17: „And be it further enacted, That no Conviction, Order, or Adjudication made by any Justices of the Peace under the Provisions of this Act shall be quashed for Want of Form, nor be removed by Certiorari or otherwise into any of His Majesty's superior Courts of Record“". Zu den frühen Fabrik- und Bergwerksgesetzen vgl. Arthurs, ,Without the Law', S. 146. Auch der Factory and Workshop Act von 1901 (1 Edw. 7, 
technischen Vorwänden eine Revision der ursprünglichen Entscheidung erlangen konnte. Wenn im Gesetz nichts gesagt war, hatten die Common lawGerichte theoretisch freie Hand, Verfahren an sich zu ziehen. Das war zum Beispiel beim Employers and Workmen Act von 1875 der Fall, so daß man für den Bereich der Master and Servant-Gesetzgebung von einer zunehmenden Überwachung der Friedensrichter durch die Common law-Richter sprechen kann. In der Praxis wurde jedoch hier, wie auch bei anderen Streitigkeiten unter den Arbeitsgesetzen, nur selten von writs of certiorari $\mathrm{Ge}$ brauch gemacht. Von sich aus wurden die höchsten Gerichte nur bei krassen Fehlentscheidungen mit entsprechendem öffentlichen Aufsehen tätig. Die Mobilisierung eines Common law-Gerichts verlangte entweder potente Fürsprecher oder eine Hartnäckigkeit und finanzielle Vorleistungen, zu denen mittellose Individualkläger in aller Regel nicht willens oder fähig waren.

Außer durch writ of certiorari konnten ,summarisch' zu entscheidende Streitsachen noch auf andere Weise vor ein Common law-Gericht gelangen, nämlich dann, wenn die magistrates selber einen Fall für so bedeutend oder schwierig hielten, daß sie ihn nicht endgültig entscheiden mochten. Hierfür sah das Gesetz ab 1857 den Weg by case stated vor. Diese Prozedur sah so aus, daß der Friedensrichter auf Antrag einer der Prozeßparteien die wichtigsten Punkte des Falles zusammenfaßte und für diesen so dargelegten Fall (case stated) die Meinung des höheren Gerichts einholte. ${ }^{22} \mathrm{Ob}$ ein solcher case stated gewährt wurde, hing freilich zunächst vom einzelnen Friedensrichter ab.23 Bei zweifelhaften Fällen mit exemplarischer Bedeutung für größere Personengruppen scheint die Bereitschaft dazu im Laufe des Untersuchungszeitraums gewachsen zu sein. Nur wenige Friedensrichter waren so sehr von missionarischem Eifer besessen, daß sie ihre eigene Auffassung partout durchsetzen wollten, und wo dies der Fall war, konnte der Druck der lokalen Öffentlichkeit und, wenn nichts anderes fruchtete, die Drohung mit einem Antrag an den Obersten Gerichtshof ein Einlenken herbeiführen. ${ }^{24}$

c. 22, s. 146) enthielt noch eine ähnlich lautende Klausel wie die oben zitierte aus dem Truck Act 1831.

22 Summary Proceedings Act, $20 \& 21$ Vict., c. 43 (1857), ss. 2 u. 6; ergänzt durch Summary Jurisdiction Act, $42 \& 43$ Vict., c. 49 (1879), s. 33.

$2320 \& 21$ Vict., c. 43 (1857), s. 4: „If the Justice or Justices be of opinion that the Application is merely frivolous, but not otherwise, he or they may refuse to state a Case ...". Ein Beispiel für die Verweigerung eines case stated: Colliery Guardian, 10. Juli 1858, S. 24.

24 $20 \& 21$ Vict., c. 43 (1857), s. 5. 
Insgesamt läßt sich somit in der zweiten Hälfte des 19. Jahrhunderts eine bescheidene Erweiterung der Berufungs- und Revisionsmöglichkeiten beobachten. Von einem regulären Instanzenzug oder einer vollständigen Lenkung der Friedensrichter durch die Common law-Gerichte kann jedoch auch im frühen 20. Jahrhundert noch nicht die Rede sein. In ihrer summarischen Rechtsprechung blieben die Friedensrichter weitgehend autonom. Das galt also auch für weite Bereiche des statutarischen Arbeitsrechts. Dessen Auslegung wurde vom Common law nur sporadisch und indirekt, durch Präzedenzfälle, beeinflußt. Die Masse der Fälle wurde entschieden, ohne daß das Common law bemüht wurde und ohne daß höhere Gerichte davon Kenntnis nahmen. Die Eventualität einer Kontrolle von seiten der King's Bench brauchte die Friedensrichter kaum zu beunruhigen; viel bedrängender war für die meisten von ihnen die Normalität der Kontrolle durch die öffentliche Meinung vor Ort.

\section{SOZIALE ZUSAMMENSETZUNG UND ANSEHEN DER LAIENFRIEDENSRICHTER}

Angesichts ihres großen Entscheidungsspielraums war es um so wichtiger, wer die Friedensrichter waren und wie sie berufen wurden. In der politischen Auseinandersetzung nahm dieses Thema breiten Raum ein. Die Arbeiterbewegung interessierte sich für die Personalfrage weit mehr als für eine Reform der Institution selbst. Die Parteilichkeit der Laienfriedensrichter schien sich in vielen Fällen direkt aus ihrer sozialen, religiösen und politischen Herkunft ableiten zu lassen. Der Austausch der Personen bot sich daher als scheinbar leichtester Weg an, um das Übel der ,Klassenjustiz' zu bekämpfen. Diese Interessenlage spiegelt sich auch in der Geschichtsschreibung, so daß wir, vor allem was das 19. Jahrhundert angeht, über ein relativ genaues Bild der Zusammensetzung der Friedensrichterschaft verfügen. Hier sollen die Veränderungen nur in groben Linien skizziert werden.

Die Friedensrichter wurden im Namen der Krone vom Lordkanzler auf Lebenszeit ernannt. In den Grafschaften folgte der Lordkanzler faktisch den Vorschlägen des Lord Lieutenant, des höchsten Würdenträgers der county, in den Städten und boroughs spielten die Empfehlungen der Korporationen beziehungsweise der gewählten Stadträte eine Rolle. Der Bürgermeister einer Stadt war in der Regel für die Dauer seiner Amtszeit und ein weiteres Jahr darauf ex officio Friedensrichter. Bis zur Reform von 1835 kooptierten sich die städtischen Friedensrichter praktisch selbst. Aufgrund ihrer engen personellen Verflechtung mit der oligarchischen, manchmal korrupten Obrigkeit besaßen sie in den letzten Jahrzehnten vor der Reform 
häufig nur geringes Ansehen. ${ }^{25}$ In den Grafschaften dagegen stammten die Friedensrichter aus den höheren Rängen der vermögenden gentry und erfreuten sich durchweg eines hohen Sozialprestiges. Seit 1731 war hier ein jährliches Einkommen aus Landbesitz von $£ 100$ Voraussetzung für das Amt; ab 1875 konnten auch Besitzer oder Mieter eines Wohnhauses, dessen Mietwert von der lokalen Steuerbehörde auf $£ 100$ taxiert worden war, zum Friedensrichter ernannt werden. ${ }^{26}$ Diese Eigentumsqualifikationen fielen durch Gesetz im Jahr 1906, hatten aber schon lange vorher für Angehörige der gehobenen Mittelklassen kein ernsthaftes Hindernis mehr dargestellt. ${ }^{27}$ Frauen erhielten 1919 den Zugang zum Friedensrichteramt, ihr Anteil blieb jedoch, schon wegen der Praxis lebenslänglicher Ernennungen, lange Zeit gering. ${ }^{28}$

Magistrates wurden und werden für ihre Tätigkeit nicht bezahlt, weshalb man sie in polemischen Zusammenhängen als "The Great Unpaid" bezeichnete. ${ }^{29}$ Für Arbeiter und kleine Angestellte kam das Amt schon aus diesem Grund nicht in Frage, daran änderte auch die Abschaffung der Eigentumsqualifikation nichts. Nach 1906 gelangten jedoch in nicht unerheblichem Umfang Gewerkschaftsfunktionäre und Politiker der Labour Party auf die Friedensrichterbänke. Waren vorher die liberalen und konservativen Eliten unter sich gewesen, zeichnete sich nun ein Trend zur Politisierung des Amtes ab. Diese Tendenz wurde verstärkt durch eine Reform der Nominierungspraxis, die im Jahr 1910, nach vorausgegangener öffentlicher Debatte

25 Vgl. Moir, Justice of the Peace, S. 169-178; Skyrme, History of the Justices, Bd. 1, S. 266 u. $273 \mathrm{f}$.

265 Geo. 2, c. 18 (1732), ergänzt durch 18 Geo. 2, c. 20 (1744); 38 \& 39 Vict., c. 54 (1875).

$276 \mathrm{Edw} .7$, c. 16 (1906). Zur praktischen Bedeutungslosigkeit der Besitzqualifikationen für das reiche Bürgertum vgl. Hartmut Berghoff, Englische Unternehmer 1870-1914. Eine Kollektivbiographie führender Wirtschaftsbürger in Birmingham, Bristol und Manchester, Göttingen 1991, S. 165.

28 Nach Jackson's Machinery of Justice, S. 406, lag der Frauenanteil im Jahr 1947 bei eins zu 3,5; vgl. auch Skyrme, History of the Justices, Bd. 2, S. 232-236 u. Bd. 3, S. 297-327 (Liste der ersten im Jahr 1920 ernannten weiblichen Friedensrichter). Im Jahr 1925 gab es 1293 weibliche Friedensrichter in Großbritannien; vgl. The Magistrate. A Quarterly Bulletin of the Magistrates' Association, No. 7 (April 1925), S. 76.

29 Vgl. etwa Hunter, Mr. Cross's Labour Bills, S. 225, der die Abschaffung der ,amateur administration of justice" und die Ersetzung der "Great Unpaid" durch "skilled and paid judges" fordert. Etwas versöhnlicher: Henry Crompton, The Workmen's Victory, in: Fortnightly Review 18 (1875), S. 399-406, S. 403: "The unpaid' is used as a term of reproach, when it ought to be a title of honour." Crompton, der Rechtsberater des TUC, schlug in diesem Artikel eine Vermehrung der professionellen magistrates vor, nicht jedoch die komplette Abschaffung des Systems der Laienrichter. Karl Marx, Das Kapital, MEW 23, S. 306 (MEGA ${ }^{2}$ II.5., S. 229), gibt als Quelle für diesen Wortgebrauch den englischen Radikalen William Cobbett an. 
und einem Bericht einer Royal Commission, erfolgte. Der Bericht fand vor allem auf dem Lande ein starkes Übergewicht konservativer und der anglikanischen Kirche angehörender Friedensrichter. ${ }^{30}$ Man folgte der Empfehlung der Kommission, das Vorschlagsrecht sogenannten advisory committees zu übertragen. Diesen beratenden Komitees obliegt bis heute die Nominierung der Friedensrichter. Die Mitglieder wurden vom Lordkanzler bestellt, ihre Zusammensetzung war (und ist) geheim, doch achtete man dabei insbesondere auf den Parteienproporz, mit der Folge, daß auch die Nominierungen zunehmend nach politischen Proporzgesichtspunkten stattfanden. In manchen Fällen scheint man auf die sonstige Befähigung der Kandidaten wenig Rücksicht genommen zu haben; vielfach wurde das Amt offenbar als Belohnung für verdiente Lokalpolitiker und Vereinsfunktionäre mißverstanden. Jedenfalls stand das öffentliche Ansehen der Friedensrichter in den Jahrzehnten zwischen den Weltkriegen auf einem Tiefpunkt. Bemängelt wurde einmal der ,Amateurismus' vieler magistrates, ihre unprofessionelle Verhandlungsführung, dann auch oft ihr zuweilen weit fortgeschrittenes Alter. Es kursierten Anekdoten über achtzig- oder gar hundertjährige, halbtaube, geistig abwesende Friedensrichter, die reihenweise Fehlentscheidungen trafen. ${ }^{31}$

Daß die Kritik an den Unregelmäßigkeiten des Verfahrens und an der $\mathrm{Zu}$ fälligkeit vieler Urteile gerade in den zwanziger und dreißiger Jahren des 20. Jahrhunderts lauter wurde, hatte aber auch einen anderen Grund. Zum erstenmal erschienen nun Angehörige der Mittelklassen in größerer Zahl als Angeklagte vor den Friedensrichtern und wurden zu Opfern von deren vermeintlich neuer - Inkompetenz. Das hing in erster Linie mit der Motorisierung und der wachsenden Zahl der Verkehrsdelikte zusammen. Hatten diese in den Jahren vor 1914 nur etwa 10 Prozent aller vor den magistrates verhandelten Fälle ausgemacht, stieg ihre Zahl bis 1938 auf fast 60 Prozent. ${ }^{32}$ Justizkritiker aus dem Umkreis der Arbeiterbewegung wiesen nicht ohne Ironie darauf hin, daß die Arbeiter und die Armen schon immer unter

30 Report of the Royal Commission on the Selection of Justices of the Peace, Cd. 5250, London 1910, S. 8 u. 14; Minutes of Evidence taken by the Royal Commission on the Selection of Justices of the Peace, Cd. 5358, London 1910, Appendix II, S. 237f. Vgl. auch Skyrme, History of the Justices, Bd. 2, S. 223-230.

31 Die schärfsten Kritiken der Zwischenkriegszeit stammten von zwei anonymen Autoren: Solicitor, English Justice, London 1932, hier bes. S. 20-24; A Barrister, Justice in England, London 1938, hier bes. S. $14 \mathrm{f}$.

32 Vgl. Jackson's Machinery of Justice, S. 402. Ausführlich zu den polizeilichen, juristischen und sozialen Problemen der Verkehrsregulierung: Clive Emsley, ,Mother, what did policemen do when there weren't any motors?' The law, the police and the regulation of motor traffic in England, 1900-1939, in: Historical Journal 36 (1993), S. 357-381. 
der Laienjustiz der Friedensrichter gelitten hätten. Die Mittelklassen hätten davon nur nichts gemerkt, weil sie selber nicht betroffen gewesen seien. Nun werde es endlich auch ihnen kar, daß eine billige Justiz eine schlechte Justiz sei. Früher hingegen hätten sie das System der, großen Unbezahlten' gerne akzeptiert, um Kosten zu sparen: „Warum“, so hätten sie gefragt, „soll Geld verschwendet werden, um den Arbeiterklassen teure Richter zu geben, sie sind ja schließlich auch kein teures Essen gewöhnt?"33 Die fehlende Professionalität der Friedensrichter, ihr juristischer Dilettantismus, avancierte nun zum Hauptkritikpunkt; der Vorwurf der klassenbedingten Voreingenommenheit, gegründet auf die personelle Zusammensetzung der Friedensrichterschaft, trat nach dem Ersten Weltkrieg langsam in den Hintergrund. Klassenjustiz in diesem Sinne wurde nun eher als eine Sache der Vergangenheit angesehen.

Wie weit aber ist der im 19. Jahrhundert immer wieder zu hörende Vorwurf zutreffend, daß im Bereich der Master and Servant-Gesetze und Fabrikgesetze Arbeitgeber über ihre eigenen Untergebenen beziehungsweise sich selbst zu Gericht saßen? Was läßt sich aufgrund der sozialen Herkunft der Friedensrichter über ihre mögliche Parteilichkeit aussagen? Nach den vorliegenden Lokalstudien kann es als gesichert gelten, daß es in den Jahrzehnten zwischen 1830 und 1870 in manchen Industrieregionen des Nordens und der Midlands einen regelrechten Run der örtlichen Unternehmer auf die Friedensrichterbänke gegeben hat. In der Grafschaft Staffordshire zum Beispiel, zu großen Teilen identisch mit dem sogenannten Black Country, einem Kohle- und Eisenrevier westlich von Birmingham, gehörten noch 1835 fast 60 Prozent der Friedensrichter dem Adel und der Gentry an, weitere 13 Prozent waren Kleriker. Nur knapp zwanzig Jahre später, im Jahr 1854, waren bereits über 50 Prozent aller Friedensrichter Kohlengrubenund Eisenwerkbesitzer, nur noch 11 Prozent gehörten zum Adel und zur Gentry. Hier läßt sich, wie Roger Swift gezeigt hat, die Übernahme der Friedensrichterbänke durch die Industriellen durchaus als bewußte Reaktion auf eine den Arbeitern gegenüber als zu wohlmeinend und zu paternalistisch empfundene Rechtsprechung der Grundbesitzer und Kleriker erkennen. ${ }^{34}$ Gerade die anglikanischen Geistlichen scheinen als magistrates

33 Barrister, Justice in England, S. 19, vgl. auch ebd., S. 47.

34 Roger Swift, The English urban magistracy and the administration of justice during the early nineteenth century: Wolverhamton 1815-1860, in: Midland History 17 (1992), S. 75-92; zur Rolle der Friedensrichter im Black Country außerdem: David Philips, The Black Country magistracy 1835-60. A changing elite and the exercise of its power, in: Midland History 3 (1976), S. 161-196; ders., Crime and Authority in Victorian England: The Black Country 
vielerorts mit einer gewissen Sympathie für die klagenden oder angeklagten Industriearbeiter geurteilt $\mathrm{zu}$ haben, zumindest solange es sich nicht um kriminelle Handlungen im eigentlichen Sinne handelte. Die Webbs schätzten, daß Kleriker in den Jahrzehnten vor 1830 bis zu einem Viertel der aktiven Friedensrichterschaft stellten. ${ }^{35}$ Selbst wenn dies für die urbanisierten und industrialisierten Regionen übertrieben scheint, ist es richtig, daß die Geistlichen häufiger als andere zu den Sessionen erschienen und dort oft auch den Vorsitz einnahmen, so daß ihre Spruchpraxis den Industriellen ein Dorn im Auge war. Die parteipolitische Antipathie gegen die zum größeren Teil den Tories zuneigenden Grundbesitzer und Kleriker mag ein weiterer Grund für das aktivere Engagement der Unternehmerschaft auf den Friedensrichterbänken gewesen sein.

Das Black Country stach insofern heraus, als dort die Industriellen schon um 1850 die county magistracy beherrschten. In anderen Industrieregionen war die Präsenz der Unternehmer zu dieser Zeit noch stärker auf die Städte und boroughs eingegrenzt, so etwa in den Textilbezirken von Lancashire und in der von Kohle, Maschinen- und Schiffsbau geprägten Tyneside-Region um Newcastle. Erst in der zweiten Hälfte des 19. Jahrhunderts gelang es den Unternehmern in einigen weiteren Grafschaften, die Mehrheit auf den Friedensrichterbänken zu erorbern, so etwa in Cheshire. ${ }^{36}$ Auf Grafschaftsebene behielten die grundbesitzenden gentlemen aber fast überall bis zum späten 19. Jahrhundert die Oberhand, auch in Mittel- und Nordengland. Sie beherrschten damit weiterhin die quarter sessions und bis 1888 die Lokalverwaltung, jedoch nicht unbedingt sämtliche petty sessions, die ja für Streitigkeiten $z$ wischen masters und servants die entscheidende Instanz waren. Das anhaltende Übergewicht des Grundbesitzes in der county magistracy ist zum Teil eine Folge der Verwaltungsgrenzen. Nur wenige Grafschaften deckten sich so weitgehend mit einem Industrierevier wie Staffordshire. Im benachbarten Warwickshire zum Beispiel, einer ebenfalls indu-

1835-1860, London 1977; Richard H. Trainor, Black Country Élites. The Exercise of Authority in an Industrialized Area 1830-1900, Oxford 1993, bes. S. 138-151 u. 166-174.

35 Zit. Moir, Justice of the Peace, $106 \mathrm{f}$. Vgl. die damit übereinstimmenden Zahlenangaben bei Carl H. E. Zangerl, The Social Composition of the County Magistracy in England and Wales, 1831-1887, in: Journal of British Studies 11, 1 (Nov. 1971), S. 113-125, S. 118.

36 Vgl. Clive Emsley, Crime and Society in England, 1750-1900, London u. New York 1987, S. 157 (zu Wigan/Lancashire); H. I. Dutton, u. J.E. King, The limits of paternalism: the cotton tyrants of North Lancashire, 1836-54, in: Social History 7 (1982), S. 59-74, bes. S. $65 \mathrm{ff}$. (zu Preston u. Blackburn); Norman McCord, The Government of Tyneside, 1800-1850, in: Transactions of the Royal Historical Society, Fifth Series, Bd. 20, London 1970, S. 5-30, hier S. 17-21; J.M. Lee, Social Leaders and Public Persons. A Study of County Government in Cheshire since 1888, Oxford 1963, bes. S. $5 \mathrm{ff}$. 
strialisierten, aber stärker von ländlichen Zonen durchsetzten Grafschaft dominierten um die Mitte des 19. Jahrhunderts noch die Grundbesitzer, und in einer fast ganz landwirtschaftlichen Grafschaft wie Lincolnshire gehörten noch im Jahr 1876 von den insgesamt 183 Friedensrichtern 55 dem Klerus und 20 den führenden Adelsfamilien an, der Rest waren gentlemen. ${ }^{37}$ So läßt sich wohl auch der Befund, daß in den englischen Grafschaften insgesamt im Jahr 1887 immer noch über 70 Prozent der Friedensrichter Mitglieder des Hochadels und der lokalen squirearchy waren, zum Teil auf Grenzveränderungen zurückführen. ${ }^{38}$ Zahlreiche Städte wurden in den Jahrzehnten nach 1835 inkorporiert und fielen damit aus der Jurisdiktion und Administration der Grafschafts-Friedensrichter heraus. Andere Städte und urbanisierte Bezirke machten von der seit 1835 bestehenden Möglichkeit Gebrauch, einen bezahlten Friedensrichter einzustellen, so daß sie für die summarische Rechtsprechung ebenfalls nicht mehr auf die GrafschaftsFriedensrichter angewiesen waren. Ferner ist zu berücksichtigen, daß sich unter den zeitgenössisch als gentlemen oder baronet figurierenden Personen manche Industrielle befunden haben, die sich aus dem aktiven Geschäftsleben zurückgezogen hatten oder geadelt worden waren, nun im Umland der Städte lebten und dort die Rechtsprechung ausübten. ${ }^{39}$ Auf der untersten Ebene der Rechtsprechung, in den petty sessions, machte sich somit in den verstädterten Regionen die Dominanz des Grundbesitzes weniger bemerkbar als es nach den Zahlen für die Grafschaften den Anschein haben könnte.

In den Städten und boroughs selbst schließlich stieg der Anteil der Friedensrichter, die den ,Mittelklassen' zugerechnet wurden, zwischen 1842 und 1887 von 43 auf 71 Prozent. ${ }^{40} \mathrm{Daß}$ sich unter diesen zahlreiche Geschäftsleute befunden haben, zeigt Hartmut Berghoffs Studie zu Birmingham, Manchester und Bristol zwischen 1870 und 1914. Mehr als 40 Prozent der von ihm untersuchten Unternehmer in den drei Städten, insgesamt 571

37 Roland Quinault, The Warwickshire County Magistracy and Public Order, c. 1830-70, in: ders. u. John Stevenson (Hg.), Popular Protest and Public Order. Six Studies in British History, 1790-1920, London 1974, S. 181-214; Moir, Justice of the Peace, S. 160 (zu Lincolnshire).

38 Vgl. die Tabelle bei Zangerl, County Magistracy, S. 115.

39 Zur Nobilitierung von Unternehmern vgl. Hartmut Berghoff, Aristokratisierung des Bürgertums? Zur Sozialgeschichte der Nobilitierung von Unternehmern in Preußen und Großbritannien 1870 bis 1918, in: Vierteljahrschrift für Sozial- und Wirtschaftsgeschichte 81 (1994), S. 178-204; ders., Adel und Bürgertum in England 1770-1850. Ergebnisse der neueren Elitenforschung, in: Elisabeth Fehrenbach ( $\mathrm{Hg}$.$) , Adel und Bürgertum in Deutschland$ 1770-1848, München 1994, S. 95-127.

40 Siehe Zangerl, County Magistracy, S. 115. 
Personen, waren Friedensrichter, manche sogar im Laufe ihrer Karriere an mehreren Stellen. Sie übten ihr Amt teils innerhalb der Städte, teils im Umland aus, wobei die erfolgreicheren Industriellen den prestigefördernden Sprung in die county magistracy schafften, während die kleineren Unternehmer in den Städten zu Gericht saßen. ${ }^{41}$ Insgesamt waren also Arbeitgeber auf den Friedensrichterbänken in hohem Maße präsent, und, so ist hinzuzufügen, sie waren es jeweils dort, wo ihre wirtschaftlichen Interessen lagen und ihre Beschäftigten arbeiteten. Grundbesitzer dominierten auf dem Land, Geschäftsleute, Bankiers und Inhaber kleinerer Betriebe in den Städten, Großindustrielle in den industrialisierten Teilen der Grafschaften.

Die Gefahr einer Verletzung der richterlichen Neutralität war somit durchaus vorhanden. Wenn ein arbeitgebernahes Fachorgan wie der „Colliery Guardian“ 1858 schrieb, daß ,respektable Bergwerksbesitzer keine Hilfe von einseitigen Magistrates benötigten, so war dies ein Eingeständnis, daß es parteiliche Friedensrichter gab. ${ }^{42}$ Unbestreitbar hat es Einzelfälle gegeben, in denen Arbeitgeber oder ihre Verwandten bei Streitigkeiten mit den eigenen Arbeitern oder bei Auseinandersetzungen mit den Fabrikinspektoren in eigener Sache zu Gericht saßen. Die Tatsache, daß es nötig schien, in die Fabrik- und Bergwerksgesetze entsprechende Ausschlußklauseln hineinzuschreiben, ist ein Indiz dafür, daß es hier zu Mißbräuchen gekommen ist. ${ }^{43}$ Extreme Fälle von Privatjustiz sind jedoch nur aus den Jahrzehnten vor 1875 bekannt. Die Schamschwellen gegenüber einer Vermischung von wirtschaftlichem Interesse und richterlicher Tätigkeit erhöhten sich im Laufe der viktorianischen Zeit. Das Befangenheitsgefühl ging aber nicht so weit, daß Unternehmer auch davor zurückschreckten, in Fällen zu urteilen, die zwar nicht die eigene Firma, wohl aber die eigene Industriebranche betrafen. Hier galt ihnen die Konkurrenz innerhalb der Branche als ausreichendes Argument, um Forderungen nach einer Erweiterung der Unvereinbarkeitsklauseln zurückzuweisen.

Tatsächlich sollte man die Solidarität unter Arbeitgebern nicht überschätzen. Im Fall der Fabrik-, Bergwerks- und Truckgesetze hatten die vorbild-

41 Berghoff, Englische Unternehmer, S. 163-169.

42 Colliery Guardian, 2. Okt. 1858, S. 211 f.: „Respectable colliery owners derive no advantage from illegal practices, and need no assistance from one sided magistrates".

43 Vgl. Arthurs, ,Without the Law', S. 103-112. Vgl. etwa Colliery Guardian, 2. Okt. 1858, S. $216 \mathrm{f}$. Zwei Friedensrichter wurden hier von einem Anwalt als befangen abgelehnt, weil sie als Aktionäre bzw. über Verwandte an den Firmen beteiligt waren, gegen die eine Klage unter dem Truck Act lief. Noch 1875 war es unklar, ob Friedensrichter in solch einem Fall daran gehindert waren, zu Gericht zu sitzen, vgl. Justice of the Peace, 29. Mai 1875, S. 350 (Leseranfrage). 
lichen Unternehmer ein Interesse daran, daß die von ihnen selbst eingehaltenen Standards nicht von anderen unterlaufen wurden. Die Inhaber der etablierteren, erfolgreichen Firmen konnten sich Gesetzestreue eher leisten, und oft waren sie es, die als Friedensrichter über Verstöße in kleinen, schlecht geführten Fabriken und Kohlengruben zu urteilen hatten. Solidarität konnte sich in solchen Fällen in einer gewissen Nachsicht bei der Höhe der verhängten Strafen äußern, aber daß bei eindeutig nachgewiesenen Verstößen ein Schuldspruch glatt verweigert wurde, kam nur selten vor. ${ }^{44}$ Ähnliches gilt für individuelle Lohnklagen von Arbeitnehmern. Diese richteten sich häufig gegen die Schwächeren der Branche, gegen Subunternehmer, kleine Meister mit wenigen Beschäftigten, Firmen mit zweifelhafter Kreditwürdigkeit. Größere Unternehmer, die ihre Leute regelmäßig und gut bezahlten, hatten als Friedensrichter nicht unbedingt Mitleid mit diesen Beklagten, bloß weil sie auch Arbeitgeber waren. Auf dem Lande bestand ebenfalls oft eine soziale Distanz zwischen den großen Grundbesitzern, die zu Gericht saßen, und den Pächtern und Farmern, die ihre Streitigkeiten mit Gesinde und Landarbeitern vor Gericht austrugen. Die Neigung zur Solidarität unter Arbeitgebern wurde somit partiell konterkariert durch das Motiv der wirtschaftlichen Konkurrenz und ein gewisses moralisches Überlegenheitsgefühl auf Seiten der Friedensrichter gegenüber ihren vor Gericht erscheinenden vermeintlichen Standesgenossen.

Etwas anders sah es aus, wenn Straftaten und Vertragsbrüche von Arbeitnehmern geahndet werden sollten. Arbeiter, die des Diebstahls an Materialresten oder anderem Betriebseigentum überführt worden waren, konnten keineswegs mit Milde rechnen, nur weil zufällig der lokale Konkurrent betroffen war. Gegen die Praxis des ,Mitgehenlassens' und ,Unterschlagens (pilfering, embezzlement) schlossen sich die Arbeitgeber vielerorts zu Assoziationen zusammen, deren Zweck es war, jeden Vorfall konsequent zu verfolgen. ${ }^{45}$ Solidarität zeigten die Arbeitgeber auch in außergewöhnlichen

44 Vgl. etwa Colliery Guardian, 13. Febr. 1858, S. 106, "Colliery Informations“ (Fallbericht); 20. Febr. 1858, S. 115, „Colliery Mismanagement" (Leitartikel).

45 Die London Chamber of Commerce gründete am 17. Januar 1901 ein Pilferage Committee, das vor allem über polizeiliche Maßnahmen zur Bekämpfung der fortgesetzten Diebstähle von Dockarbeitern beriet. Guildhall Library, MS 16643/5, ff. 35-38, 60, 63, 67. Ansonsten verließen sich die Londoner Unternehmer vorzugsweise auf periodische Razzien und Prozeß-Kampagnen zur Abschreckung und auf informelle Maßnahmen am Arbeitsplatz, insbesondere natürlich die fristlose Entlassung. Vgl. Jennifer Davis, Prosecutions and Their Context. The Use of the Criminal Law in Later Nineteenth-Century London, in: Douglas Hay u. Francis Snyder ( $\mathrm{Hg}$.), Policing and Prosecution in Britain 1750-1850, Oxford 1989, S. 397-426, hier S. 401-413. Wesentlich systematischer gingen die Kammgarnfabrikanten von West Yorkshire vor. Sie hatten schon im späten 18. Jahrhundert einen privaten Detektiv- 
Konfliktsituationen, bei großen Streiks und Aussperrungen. Die Friedensrichter nutzten dann ihren Ermessensspielraum, um exemplarisch harte Strafen zu verhängen. Ein Kontraktbruch, der in ruhigen Zeiten vielleicht nur zu einer Verwarnung geführt hätte, wurde in solchen Situationen als schwerer Fall gewertet, der die Höchststrafe, drei Monate Gefängnis mit hard labour, verdiente. Es waren vor allem solche situativ bedingten, extremen Ausschläge bei der Strafzumessung, die den Laien-Friedensrichtern den Vorwurf der Klassenjustiz einbrachten. Um Rechtsbeugungen im juristischen Sinne handelte es sich dabei jedoch nicht. Die Gesetze selber machten es möglich, daß Gesetzesübertretungen der Arbeiter oft mit übertriebener Härte, dann wieder mit Milde und Mitleid behandelt wurden. Ebenso ließen sie es zu, daß Arbeitgeberverstöße gegen Arbeiterschutzmaßnahmen meistens mit nominellen Strafen, hin und wieder aber auch mit der Höchststrafe bedacht wurden.

\section{INKONSEQUENTE PROFESSIONALISIERUNG}

In der zweiten Hälfte des 19. Jahrhunderts waren verschiedene Tendenzen wirksam, die den Spielraum der Laienfriedensrichter bei der Urteilsfindung allmählich einengten und insgesamt im Laufe der Zeit ein höheres Maß an Gleichförmigkeit der Spruchpraxis herbeiführten. Außer den erwähnten Veränderungen im materiellen Recht und im Verfahrensrecht (Berufungsmöglichkeiten) sind vor allem zwei Faktoren zu nennen: zum einen die Publizität der Gerichtsverhandlungen, zum anderen der zunehmende Einfluß von Personen mit juristischer Ausbildung im Justizalltag. Das enorme Anwachsen und die vielfältigen Formen der journalistischen Berichterstattung von den Lokalgerichten nach 1850 werden uns in einem späteren Kapitel noch näher beschäftigen. ${ }^{46}$ Hier sei zunächst nur bemerkt, daß die gesteigerte Aufmerksamkeit der Presse schon von sich aus eine normierende Wirkung entfaltete. Je ausführlicher die Berichterstattung wurde, desto stärker gerieten extrem abweichende Entscheidungen ins Blickfeld einer regionalen sowie - zunehmend - auch branchen- und fachbezogenen nationalen Öffentlichkeit. Die Berichte und Kommentare in der Presse stellten Maßstäbe

und Strafverfolgungsdienst, das Worsted Committee, ins Leben gerufen. Dieses Komitee richtete sich zunächst gegen das sogenannte embezzlement bei Heimarbeitern, später auch Fabrikarbeitern, und übernahm im späteren 19. Jahrhundert auch die Funktion einer Rechtsschutz- und Lobbyorganisation der Unternehmer. Vgl. hierzu: Barry Godfrey, Private Policing: A Nineteenth Century Example, unpubl. paper, Nene College, 1994; Karl Ittmann, Work, Gender and Family in Victorian England, Basingstoke 1995, S. $66 \mathrm{ff}$. 
bereit für das, was als normale oder eben noch vertretbare Urteilspraxis gelten konnte. Über den so entstehenden Konsens über das ,Normale' konnten sich auch die Laienfriedensrichter auf Dauer nicht hinwegsetzen.

Der zweite eben genannte Faktor, die erhöhte Präsenz juristisch-professioneller Elemente in den Friedensgerichten, machte sich am nachdrücklichsten in den Städten bemerkbar. Die ersten Berufsfriedensrichter gab es in London, wo die Kriminalitätsbekämpfung im 18. Jahrhundert besonders im Argen gelegen hatte. Hier wurden bereits im Jahr 1792 per Gesetz sieben ,Polizeiämter' geschaffen und mit je drei bezahlten Richtern (stipendiary magistrates) besetzt, denen je sechs bezahlte Polizisten unterstellt wurden. ${ }^{47}$ Diese Einrichtung folgte dem Vorbild eines schon bestehenden Polizeiamts in der Bow Street, das seine Existenz der privaten Initiative von Bürgern, darunter Henry und John Fielding, verdankte und sich zunächst nur aus Belohnungen für die Ergreifung von Straftätern und Gerichtsgebühren finanziert hatte. ${ }^{48}$ Weitere Polizeiämter wurden in den folgenden Jahrzehnten eingerichtet. Im Jahr 1839 erhielten dann die Londoner police courts, wie sie nun genannt wurden, ihre bis auf weiteres endgültige Form, die im wesentlichen bis nach dem Zweiten Weltkrieg unverändert geblieben ist. Durch die Reform wurden Polizei und Justiz voneinander getrennt. ${ }^{49}$ Die police courts wurden zu reinen Gerichten, denen praktisch die gesamte summarische Rechtsprechung für das innere Stadtgebiet von London mit Ausnahme der City, wo der Lord Mayor und die Aldermen als Friedensrichter fungierten, anvertraut wurde. Die mit Laien-Friedensrichtern besetzten Londoner petty sessions erfüllten daneben nur noch geringfügige, hauptsächlich administrative Aufgaben, aber die quarter sessions blieben, wie überall sonst im Lande, für die schweren Straftaten und in Berufungsangelegenheiten zuständig. Bis 1850 war die Zahl der Londoner police courts auf 13 und die Zahl der stipendiary magistrates auf 23 angewachsen. Sie mußten barristers mit mindestens sieben Jahren Berufspraxis sein, wurden mit £ 1400 pro Jahr verhältnismäßig gut bezahlt und waren stadtbekannte, zum Teil herausragende Persönlichkeiten.

Zeitgenössische Beobachter bewerteten die Arbeit der Londoner police court magistrates in der zweiten Hälfte des 19. Jahrhunderts überwiegend positiv, und die Historiker sind ihnen darin gefolgt. Die meisten Londoner

32 Geo. 3, c. 53 (1792).

48 Zur Frühgeschichte der Londoner Police Courts siehe Cornish u. Clark, Law and Society, S. 554f. u. 587f.; John M. Beattie, Crime and the Courts in England 1660-1800, Oxford 1986, S. 58 u. 65 ff.; Skyrme, History of the Justices, Bd. 2, S. 135-149.

49 London Police Court Act, 2 \& 3 Vict., c. 71 (1839); Metropolitan Police Act, 2 \& 3 Vict., c. 47 (1839). 
Polizeirichter sahen ihre Aufgabe nicht nur in der schnellen Aburteilung von Straftätern, sondern verstanden ihre Arbeit als umfassendes Angebot der Konfliktregelung für die zum größten Teil arme Klientel, die sich an sie wandte. ${ }^{50}$ Bemerkenswert ist die hohe Zahl und die große Vielfalt der von ihnen erledigten Fälle. In den späten fünfziger Jahren des 19. Jahrhunderts wurden im Metropolitan Police District an die 100000 Fälle pro Jahr summarisch verhandelt, in den achtziger Jahren waren es im Schnitt etwa 125000 und in den Jahren vor dem Ersten Weltkrieg über 150000.51 Greifen wir zur Veranschaulichung der Bandbreite der behandelten Gegenstände ein beliebiges Jahr heraus, das Jahr 1892.52 In diesem Jahr standen in London fast 143000 Fälle zur summarischen Verhandlung an. Mehr als ein Fünftel davon, gut 30000, hatte mit Trunkenheit zu tun (drunk and disorderly). Die beiden nächsthäufigen Kategorien mit je etwa 18000 Fällen waren Verstöße gegen die Elementary Education Acts (dahinter verbargen sich vor allem Vorladungen von Eltern, deren Kinder nicht zur Schule erschienen waren) und gewöhnliche tätliche Angriffe (common assaults). Es folgten etliche Fallgruppen mit mehr als tausend Verstößen, angefangen bei Diebstählen verschiedener Art und Vergehen gegen die Police Acts, über Verstöße gegen die Stage and Hackney Carriage Acts, Widerstand gegen Beamte, Tierquälerei, nicht bezahlte Hundesteuern, Prostitution, Bettelei, Sachbeschädigungen, Vernachlässigung von Frauen und Kindern, unerlaubter Besitz von Gegenständen, bis hin zur Nicht-Beseitigung von Müll, lästigen Gerüchen und Verunreinigungen (nuisances). Schließlich gab es noch viele andere Kategorien mit weniger als tausend Fällen, darunter auch 733 Fälle unter dem Employers and Workmen Act, 436 Veruntreuungen (embezzlements), 149 Verstöße gegen die Factory Acts und 14 Verstöße unter dem Conspiracy and Protection of Property Act.

Mit der Erledigung all dieser Fälle war aber die Tätigkeit der Londoner magistrates längst nicht erschöpft. Hinzu kamen noch die Voruntersuchungen der schwereren Straftaten, die Prüfung der Anträge auf Haftbefehle und gerichtliche Vorladungen sowie - statistisch nicht erfaßbar, aber durch zeitgenössische Schilderungen gut belegt - die Beantwortung zahlreicher

so Vgl. Jennifer Davis, A Poor Man's System of Justice: The London Police Courts in the Second Half of the Nineteenth Century, in: Historical Journal 27, 2 (1984), S. 309-335.

51 Für die Jahre bis 1892: Criminal Statistics, Tab. 7 (für die Fundorte in den Parliamentary Papers siehe oben S. 155 f., Fn. 1); für die Jahre 1906-1913: London Statistics, hg. v. London County Council, Bd. 18 (1907-08) - Bd. 25 (1914-15), Abschnitt „Police and Justice“. Der Metropolitan Police Court District blieb in diesem Zeitraum bis auf kleine Grenzkorrekturen unverändert; vgl. Skyrme, History of the Justices, Bd. 2, S. $149 \mathrm{f}$.

52 Criminal Statistics 1892, PP 1893-94, CIII, Tab. 7, hier S. 28. 
Rechtsfragen, Bitten und Hilfsgesuche. Die Beschäftigung mit diesen Anträgen, Fragen und Bitten eröffnete in der Regel den Arbeitstag des Polizeirichters; es war dies die sogenannte application time, und nach dem Bericht Hugh Gamons, der im Jahr 1907 im Auftrag des Toynbee Trust eine Sozialreportage über die Londoner police courts verfaßte, erschienen viele des Rechts unkundige arme Leute vor dem Polizeirichter, ohne eine klare Vorstellung von dem zu haben, was sie wollten. Sie hatten ein Problem, Ärger mit dem Vermieter oder dem Arbeitgeber oder dem Ehemann, und fragten den Richter, was sie tun sollten: „Please, sir, tell me what I am to do.“53 Diese Form der kostenlosen Rechtsberatung hatte sich bei den Londoner police courts als Gewohnheit eingebürgert und unterschied sie von den Friedensgerichten in der Provinz, wo es, glaubt man Hugh Gamon, eine vergleichbare Praxis nicht gab. Das relativ große Vertrauen der Arbeiterschaft und der Armen in die Londoner Polizeirichter beruhte nicht zuletzt auf diesem Angebot, auf der Offenheit für Klagen, die zunächst nicht in juristisch einwandfreier Form vorgebracht wurden, und auf der Bereitschaft der Richter, bei der Suche nach adäquaten Problemlösungen behilflich zu sein, so weit es ihr Zeitbudget erlaubte. Die Londoner Polizeigerichte waren somit ein Beispiel dafür, daß die Professionalisierung der Justiz nicht notwendigerweise mit einer Formalisierung der Rechtsprechung im Sinne mechanischer Normanwendung einhergehen mußte. Obwohl sie ausgebildete barristers waren, hatte die Spruchpraxis der Polizeirichter nichts von dem technischen Charakter der Common law-Rechtsprechung an sich. Auch Kritiker der Friedensrichterschaft aus dem Umkreis der Arbeiterbewegung fanden für die Londoner police court magistrates freundliche Worte. ${ }^{54}$

Außer in London gab es bezahlte Friedensrichter auch in einigen größeren Provinzstädten und städtischen Ballungsräumen, so zuerst 1813 in Manchester. Der Municipal Corporations Act von 1835 gestattete es den Stadträten, einen Antrag an den Innenminister auf Ernennung eines stipendiary magistrate zu stellen. ${ }^{55}$ Für Städte und Ballungsräume außerhalb des Geltungsbereichs des Municipal Corporations Act konnte die Ernennung eines bezahlten Friedensrichters durch spezielles Gesetz erwirkt werden. In beiden Fällen mußten jedoch die Städte selbst für das Gehalt des Richters aufkommen, weshalb von dieser Möglichkeit nur zögernd Gebrauch ge-

53 Hugh R.P. Gamon, The London Police Court To-day \& To-morrow, London 1907, S. 80 f.

54 Vgl. Henry Crompton, The Reform of the Magistracy, in: Fortnightly Review 18 (1875), S. 688-698, S. 696: "It seems to amount to this, that while the country justices have exhibited the greatest incompetency, the London and some of the Northern stipendiaries have done parts of their work in the most admirable and efficient manner."

55 5 \& 6 Will 4, c. 76 (1835), s. 99. 
macht wurde. Der stipendiary magistrate mußte, wie in London, barrister mit mindestens sieben Jahren Berufspraxis sein, die Ernennung erfolgte durch die Krone jeweils auf Lebenszeit, danach mußte die Wiederbesetzung erneut beantragt werden. Bis 1900 hatte es an 23 Orten, bis zum Ende des Zweiten Weltkrieg an 26 Orten bezahlte Friedensrichter gegeben, allerdings nicht überall durchgehend. ${ }^{56}$ In so bedeutenden Städten wie Newcastle, Sheffield und Brighton amtierte 1946 kein stipendiary magistrate mehr, obwohl es vorher eine Stelle gegeben hatte; andere Großstädte wie Bristol, Coventry oder Norwich hatten nie einen Antrag gestellt. Verglichen mit den Polizeirichtern in London besaßen die Berufsfriedensrichter in der Provinz eine schwächere Stellung. Sie konnten zwar allein in petty sessions zu Gericht sitzen, aber nichts hinderte die örtlichen Laienfriedensrichter, zu den Sitzungen zu erscheinen, und in diesem Fall entschied die Mehrheit. Der stipendiary magistrate in der Provinz übte seine Tätigkeit konkurrierend mit den Laien aus. In größeren Städten wie Birmingham konnte er oft nur ein Drittel oder die Hälfte der anfallenden Arbeit bewältigen. Er war somit bestenfalls primus inter pares, und gegenläufige Entscheidungspraktiken waren möglich. Dennoch hatte er als Berufsjurist natürlich eine gewisse Leitbildfunktion, besonders bei schwierigen Fällen. ${ }^{57}$

Überall dort, wo es keine Berufsrichter gab, also vor allem auf dem Lande und in den Kleinstädten, waren die Sekretäre der Friedensrichter (clerks) oft die einzigen Personen im Gerichtssaal mit juristischer Ausbildung. Der clerk of the petty sessions mußte Berufsjurist sein, der bei den quarter sessions tätige clerk of the peace brauchte es nicht zu sein, war es aber faktisch in den meisten Fällen. Bezahlt wurden die clerks aus lokalen Steuermitteln. Ihre Aufgabe ging weit über die eines Schreibers hinaus. Sie bestand nicht nur in der Protokollführung, Ausstellung von Vorladungen und Haftbefehlen, Vorbereitung der Sitzungen und Gebührenverwaltung, sondern auch in der Beratung der Richter (und manchmal der Prozeßparteien) zu allen Rechts- und Verfahrensfragen. Auf den petty sessions wurde auch die Zeu-

56 Hierzu und zum folgenden: R. M. Jackson, Stipendiary Magistrates and Lay Justices, in: Modern Law Review 9 (1946), S. 1-12, hier S. 2 f.

57 Eine weitere Gruppe professioneller Juristen im System der Friedensrichter bildeten die sogenannten recorder. Es gab sie nur in Städten und borougbs. Ihre Funktion entsprach derjenigen des Richterkollegiums auf den quarter sessions. Mit der summarischen Rechtsprechung waren die recorder nur als Berufungsinstanz befaßt; sie sind daher hier nur am Rande von Interesse. Die recorder wurden auf Antrag des jeweiligen borough ernannt und lokal finanziert, hielten ihre Gerichtstage viermal im Jahr ab und praktizierten daneben oft noch privat als barristers. Einige von ihnen waren gleichzeitig auch Grafschaftsrichter. Im Jahr 1910 gab es 108 solcher recorder-Gerichte. Ausführlich hierzu: Heinrich B. Gerland, Die Englische Gerichtsverfassung. Eine systematische Darstellung, Leipzig 1910, S. 123-132. 
genvernehmung oft durch den clerk durchgeführt. Ein guter clerk, erzog seine Friedensrichter, ohne sich selbst in den Vordergrund zu spielen, ein schlechter konnte sich zur dominierenden Person im Gerichtssaal aufschwingen und so die Autorität des Gerichts untergraben. ${ }^{58}$ In jedem Fall war der clerk in den meisten Friedensgerichten das einzige Bindeglied zwischen den staatlichen Normen - Common law und Statute law - und der lokalen Rechtsprechungspraxis. In der Schriftführung wurde er dabei unterstützt durch eine wachsende Zahl von vorgedruckten Formularen, die für häufig wiederkehrende Vorgänge, zum Beispiel Vorladungen unter bestimmten Gesetzen, einen Standardtext bereitstellten, bei dem oft nur noch Namen, Daten und Details des Sachverhalts eingetragen werden mußten. ${ }^{59}$

Die professionellen Elemente im System der Friedensgerichte nahmen somit im Untersuchungszeitraum insgesamt zu, aber der Professionalisierungsgrad variierte regional sehr stark. Es gab ein deutliches Stadt-LandGefälle. Daß das System der Laienrichter toleriert wurde, hatte hauptsächlich Kostengründe. Die lokalen Steuerzahler waren vielfach nicht bereit, für eine Justiz viel Geld auszugeben, von der sie nur in Ausnahmefällen als Angeklagte negativ betroffen waren. Romantisch-nationale Vorstellungen wie die, daß es sich um die ,englischste' Institution unter allen Regierungseinrichtungen handele, dienten daneben allenfalls der ideologischen Verbrämung. 60

Der Ausnahmefall der Londoner police court magistrates zeigt, daß ein staatlich finanziertes System von Berufsrichtern sogar bei den Arbeiterklassen und Armen eine gewisse Popularität erlangen konnte, vorausgesetzt es hielt sich fern von juristischem Formalismus. Damit die Popularität erhalten blieb, war freilich eine ausreichende personelle Ausstattung notwendig. Und hier lag ein Schwachpunkt, der, wie Jennifer Davis nachgewiesen hat, ab etwa 1880 auch in London zu einer Abwendung der Arbeiterklassen von den police courts geführt hat. ${ }^{61}$ Die Geschäftsüberhäufung der stipendiary magistrates nahm bei gleichbleibender Richterzahl derartig zu, daß die vor-

58 Die Kritik an der Rolle der clerks wuchs besonders in der Zwischenkriegszeit; vgl. Jackson, Stipendiary Magistrates, S. 10 ff.; Solicitor, English Justice, S. 25-28.

59 Zum Teil wurden die Formulartexte in den Anhängen von Gesetzen veröffentlicht; vgl. etwa Masters and Servant Act, $30 \& 31$ Vict., c. 141 (1867), Schedule 3. Formularsammlungen, vorgedruckte Protokollbücher und Einzelblatt-Formulare konnten von darauf spezialisierten Druck- und Verlagshäusern in London bezogen werden. Hilfestellung boten Handbücher wie z. B. George C. Oke, The Magisterial Formulist: Being A Complete Collection of Forms and Precedents for Practical Use, London 1850, 2. Aufl. London 1856 (zahlreiche weitere Auflagen).

60 Vgl. Moir, Justice of the Peace, S. 9 (mit Zitaten von F.W. Maitland und Sir Edward Coke).

61 Davis, Poor Man's System, S. $333 \mathrm{f}$. 
dringliche Aufgabe der Kriminalitätsbekämpfung (und später der Aburteilung von Verkehrssündern) immer stärker in den Vordergrund rückte; für andere Dinge, insbesondere die Bitt- und Hilfsgesuche, blieb den Richtern immer weniger Zeit. Die Gerichte glichen zunehmend Maschinen, in denen im Schnellgerichtsverfahren hunderte von Fällen regelrecht durchgepeitscht wurden. Für die in der Regel komplizierten und zeitraubenden Auseinandersetzungen um Arbeitsverträge, Kündigungsbedingungen oder Lohnzahlungsmodalitäten waren die Friedensgerichte unter solchen Umständen kaum noch der geeignete Platz. Zudem waren die Streitigkeiten unter dem Employers and Workmen Act als, zivile' Angelegenheiten ein Fremdkörper in den sonst fast nur mit Strafsachen und Ordnungswidrigkeiten befaßten police courts. Was für London zutraf, galt ähnlich auch für die Verhältnisse in den großen Provinzstädten und Industrieregionen. Die hier aufgezählten institutionellen Mängel dürften zur nachlassenden Attraktivität der Friedensgerichte für klagende Arbeitnehmer und Arbeitgeber beigetragen haben. Die fehlende Professionalität der magistrates auf dem Lande, die übermäßige Hast und das routinemäßige Abarbeiten der Fälle in den Städten haben vermutlich mehr potentielle Kläger abgeschreckt als die vielbeschworene Klassenjustiz. Vor allem den stipendiary magistrates in London kann man Unfairness gegenüber Arbeitern kaum vorwerfen, dennoch stagnierte auch hier, trotz wachsender Beschäftigtenzahlen, die Zahl der Klagen unter den Arbeitsgesetzen. Die Erfahrung der, Klassenjustiz' kann zumindest in London nicht der Hauptgrund für diese Entwicklung gewesen sein.

\section{AKTENFÜHRUNG UND JUSTIZSTATISTIKEN}

Es bedarf kaum der Erwähnung, daß die offiziellen, in den Parliamentary Papers publizierten Justizstatistiken nur wenig über das tatsächliche Konfliktpotential in der englischen Gesellschaft aussagen. Ebensowenig läßt sich daraus Genaues über das tatsächliche Ausmaß der Kriminalität ablesen. ${ }^{62}$ Was gezählt wurde, sind allein die der Polizei bekannt gewordenen und in irgendeiner Form vor Gericht verhandelten Fälle. Bei diesen han-

62 Ausführlich zum Aufbau und zu den Möglichkeiten des Gebrauchs der englischen Kriminalstatistiken als Indikator für die tatsächliche Kriminalität und die Effektivität ihrer Bekämpfung: V. A. C. Gatrell u. T. B. Hadden, Criminal statistics and their interpretation, in: E. A. Wrigley (Hg.), Nineteenth-century society. Essays in the use of quantitative methods for the study of social data, Cambridge 1972, S. 336-396; V. A. C. Gatrell, The Decline of Theft and Violence in Victorian and Edwardian England, in: ders., Bruce Lenman u. Geoffrey Parker (Hg.), Crime and the Law. The Social History of Crime in Western Europe since 1500, London 1980, S. 238-370; Emsley, Crime and Society, S. 18-47. 
delte es sich um sichtbare Ereignisse, die im Prinzip leicht zählbar waren. Dennoch sind, gerade was die summarische Rechtsprechung angeht, gewisse Zweifel im Hinblick auf die Genauigkeit der Zahlen angebracht. Der Grund sind vor allem Unregelmäßigkeiten bei der Datenerhebung an der Basis. Die gesamte Spruchtätigkeit der Friedensrichter wurde in den Kriminalstatistiken erfaßt, auch die zivilrechtlichen Angelegenheiten. ${ }^{63} \mathrm{Die}$ Statistiken für die summarische Rechtsprechung beruhten auf jährlichen Rückmeldungen, die von der örtlichen Polizei für den jeweiligen Polizeidistrikt, ab 1893 dann für die jeweilige Grafschaft zusammengestellt und ans Home Office gesandt wurden. ${ }^{64}$ Dabei war die Polizei natürlich auf die Amtshilfe der clerks an den petty sessions und police courts angewiesen. Das war besonders wichtig für diejenigen Bereiche der summarischen Rechtsprechung, mit denen die Polizei allenfalls am Rande zu tun hatte, also zum Beispiel die Klagen unter den verschiedenen Arbeitsgesetzen. Hier lag bereits eine erste Fehlerquelle, die noch dadurch verstärkt wurde, daß es vor 1893 keine festen Richtlinien für die Datenerhebung gab. Das führte etwa dazu, daß einige lokale Polizeibehörden die Urteilssprüche unter dem Employers and Workmen Act nach 1875 anfangs nicht in ihre Meldungen aufnahmen, weil es sich dabei strenggenommen nicht um Verurteilungen im straftrechtlichen Sinne (convictions) handelte. ${ }^{65}$ Die Reform der Statistik im Jahr 1893 behob diesen Mangel, indem nun die Fälle unter dem Employers and Workmen Act in einer gesonderten Rubrik unter der Überschrift „Proceedings in QuasiCriminal Matters" ausgewiesen wurden und entsprechende Richtlinien an die Polizeibehörden ergingen.

Eine zweite Fehlerquelle ergab sich aus der begrenzten Schriftlichkeit in den petty sessions selbst. Die Aktenführung auf dieser untersten Ebene der englischen Justiz war alles andere als regelmäßig. Das gilt besonders für den Zeitraum bis zum Ende der siebziger Jahre des 19. Jahrhunderts. Wenn die

63 Für meine Zwecke relevant sind vor allem die folgenden Tabellen der jährlichen Criminal Statistics: Bis einschließlich 1892 Tab. 7 („Offences Determined Summarily. Total number of Persons proceeded against before Justices, in each Police District") und Tab. 8 („Offences Determined Summarily. Total of the Offences of each Class for which Persons were Proceeded against Summarily before Justices“ - gibt die Prozeßresultate); ab 1893 Tab. XI („Courts of Summary Jurisdiction. Number of Persons Tried, Nature of Offences, Results of Proceedings, and Length of Sentences" - entspricht im wesentlichen der alten Tabelle 8) und Tab. XIV ("Courts of Summary Jurisdiction. Proceedings in Quasi-Criminal Matters" enthält u. a. die Zahlen für Fälle unter dem Employers and Workmen Act, aber nur Gesamtzahlen für ganz England und Wales).

64 Einige Angaben zu Defiziten in der Praxis dieser Rückmeldungen finden sich im Bericht der Reformkommission der Kriminalstatistik: Report of the Committee Appointed to Revise 65 the Criminal Portion of the Judicial Statistics (Dez. 1892), PP 1895, CVIII, hier S. 18-21.

Ebd., S. 19. 
Aktenüberlieferung aus dieser Zeit ein getreues Abbild der Praxis des Aufschreibens vermittelt, muß man mit unvollständigen Meldungen von den petty sessions an die Datensammler bei der Polizei rechnen. Es ist davon auszugehen, daß nicht alle Verhandlungsergebnisse in den petty sessions protokolliert wurden. Ein Minimum an schriftlichem Niederschlag gab es auf jeden Fall bei Verurteilungen (convictions). Insofern war hier die Wahrscheinlichkeit einer Weitergabe der Information an die Polizei höher als bei den Fällen, in denen es nicht zu einer Verurteilung kam. Der Summary Jurisdiction Act von 1848 schrieb vor, daß über jede Verurteilung eine Protokollnotiz angefertigt werden mußte, die anschließend kopiert und mit Siegel versehen an den clerk of the peace weiterzuleiten war und bei etwaigen Revisionen oder Berufungsverfahren als Beweismittel dienen konnte. ${ }^{66}$ Hierfür wurden in der Praxis meist vorgedruckte Formulare verwendet. Solche Formulare gab es auch für Fälle unter dem Master and Servant Act. ${ }^{67}$ Es kam hinzu, daß die Polizei über die Gefängnisinsassen ohnehin aus direkter Kenntnis informiert war und daß an den petty sessions über Strafen und Bußgelder gesondert Buch geführt werden mußte. ${ }^{68}$ Grobe Unstimmigkeiten bei den Zahlen für convictions mußten also auffallen. Insgesamt kann man somit die offiziellen Statistiken, was die Zahlen für convictions angeht, als brauchbar bewerten.

Weniger gut sah es bei abgewiesenen Klagen oder sonstigen Prozeßausgängen aus, also etwa bei gütlichen Einigungen oder ,Rückziehern' von sei-

$6611 \& 12$ Vict., c. 43 (1848), ss. 14 u. 17.

67 Northamptonshire RO, Acc No. 1967/170, Box X 3918, Northampton Petty Sessions, Informations and Examinations, 1858. Hierbei handelt es sich um ein Bündel mit Anzeigen und Niederschriften der Aussagen von Klägern und Zeugen zu 242 Fällen, darunter zwei Master and Servant-Fälle. Auf der Außenseite der vorgedruckten Anzeigenformulare (informations) ist jeweils handschriftlich das Prozeßergebnis festgehalten. Im Fall Thomas Smith, Farmer v. John Bettle, Servant in Husbandry, angeklagt wegen „Leavg. Service“, lau-

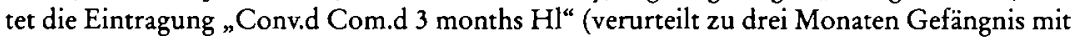
bard labour); Im Fall Thomas Pell, Farmer v. Thomas Pettit, Servant in Husbandry, angeklagt als „Run away Servant “ lautet die Eintragung „Settled“, was man wohl mit ,erledigt” übersetzen müßte, ohne daß damit klar ist, in welcher Weise der Prozeß ,erledigt' wurde; jedenfalls kam der Angeklagte glimpflich, das heißt ohne Strafe, davon.

Northamptonshire RO, Box 4920, Northampton Petty Sessions, Record of Convictions, 1850-1861. Hierbei handelt es sich um ein Buch, in dem insgesamt 2044 Verurteilungen aufgelistet sind. Darunter befinden sich auch 20 Master and Servant-Fälle, sämtlich Arbeitgeberklagen, darunter auch der oben (Fn. 67) erwähnte Fall des zu drei Monaten Haft mit hard labour verurteilten John Bettle. In dem Buch nicht festgehalten ist hingegen der ,erledigte Fall des weggelaufenen Knechts Thomas Pettit (siehe Fn. 67). Man fragt sich, ob und wie der clerk und die Polizei in Northampton solche, erledigten'Fälle und die grundsätzlich nie mit einer conviction enden könnenden Arbeitnehmerklagen bei der Anfertigung ihrer statistischen Meldungen berücksichtigt haben. 
ten des Klägers. Hier muß man bis zum Ende der siebziger Jahre des 19. Jahrhunderts mit unzuverlässigen Angaben rechnen. Das Gesetz von 1848 überließ es dem einzelnen Friedensrichter, ob er die Abweisung einer Klage schriftlich festhalten ließ oder nicht; von anderen denkbaren Ausgängen war im Gesetz erst gar nicht die Rede. ${ }^{69}$ Es hing also von den Gepflogenheiten am Ort ab, wie man zum Beispiel bei einer mündlich erhobenen Klage gegen einen Arbeiter verfuhr, die nach kurzer Diskussion unter Zusicherung zukünftigen Wohlverhaltens zurückgezogen wurde. Presseberichte zeigen, daß derlei Fälle keineswegs selten waren.$^{70} \mathrm{Ob}$ sie aber überhaupt aktenkundig und damit eventuell statistisch relevant wurden, war eine Sache zufälliger Entscheidungen. Wenn eine Aktennotiz gemacht wurde, war es immer noch zweifelhaft, wie weiter verfahren wurde. Sollte man den Fall als förmlichen Freispruch werten und als solchen weitermelden?71 Oder sollte man ihn dem vorgerichtlichen Stadium zurechnen und unter den Tisch fallen lassen? Hier lag die Entscheidung allein in den Händen des Friedensrichters und seines clerk. An manchen petty sessions scheint man die Prozeßergebnisse einigermaßen konsequent dokumentiert zu haben, hier benutzten die clerks für Freisprüche und gütliche Einigungen die gleichen Formulare wie für convictions. ${ }^{72}$ An anderen petty sessions verließen sich die clerks auf eigene, mehr oder weniger sorgfältige Aufzeichnungen. Kurzum, es ist davon auszugehen, daß die frühen Statistiken, was erfolglose Klagen und sonstige Prozeßresultate angeht, weniger zuverlässig sind als für convictions.

Eine stärkere Normierung der Verschriftlichungspraxis in den petty sessions und police courts ergab sich infolge des Summary Jurisdiction Act von 1879. Dieser verlangte, daß überall sogenannte register of summary jurisdiction geführt werden sollten, in denen nicht nur convictions, sondern auch andere Verhandlungsergebnisse nach bestimmten, von Zeit zu Zeit veränderbaren Regeln verzeichnet werden sollten. ${ }^{73} \mathrm{Da}$ diese Regeln im großen und ganzen eingehalten wurden, zeigen die überlieferten Register. Sie sind einander sehr ähnlich. Die Fälle sind durchnumeriert, Namen (zum Teil auch Wohnorte und Berufe) von Klägern und Beklagten sind angegeben, die Tatbestände werden in Stichworten umschrieben, und die Prozeßausgänge

$6911 \& 12$ Vict., c. 43 (1848), s. 14.

70 Vgl. etwa Colliery Guardian, 9. Okt. 1858, S. 231, „Breach of Contract“; ähnliche Fälle: ebd., 24. Juli 1858, S. 55; ebd., 27. Nov. 1858, S. 344; Northampton Mercury, 7. Aug. 1858, „Farm Labourers absconding from Service“. Bis 1892 kannte die Statistik nur zwei Prozeßausgänge: Schuldspruch oder Freispruch.

72 Das war offenbar in Northampton der Fall (siehe oben Fn. 67).

$7342 \& 43$ Vict., c. 49 (1879), s. 22. 
sind ebenfalls knapp festgehalten. Zwei Beispiele für typische Einträge, der eine aus Sutton Coldfield bei Birmingham, der andere aus Brackley in Northamptonshire, seien hier zitiert:

24 Jan. 1905; James Colley v. Frank James Lea; Claim for 14/- Wages; Judgment for Plaintiff for 14/- \& 5/- costs and on counterclaim for defendant for $5 /-\& 2 /$ - costs. ${ }^{74}$

23 Feb. 1891; Thomas Jarvis, Middleton Cheney, Butcher v. Thomas Gascoigne Junior, Middleton Cheney, Labourer; Breach of Employer's and Workmen's Act. Leaving Plaintiff's service without notice on Thursday the 15th January 1891 he being a weekly servant from Saturday to Saturday; Judgment for Plaintiff. Defendant ordered to pay $5 \mathrm{~s} /$ - for damages $\& 11 / 6$ costs. ${ }^{75}$

Mit diesen Registern hatte sich die Basis für verläßliche und einheitliche statistische Erhebungen auf der untersten Ebene der englischen Justiz verbessert. Es ist davon auszugehen, daß auch Freisprüche, abgewiesene Klagen und ,Rückzieher' aufgrund der fortlaufenden Buchführung nun vollständiger erfaßt wurden. In der Statistik erschienen diese Prozeßausgänge bis einschließlich 1892 (wenn überhaupt) unter der Rubrik ,Freisprüche`. Ab 1893 wurde dann genauer zwischen zurückgezogenen Klagen (charge withdrawn), abgewiesenen Klagen (charge dismissed) und Freisprüchen (defendant discharged) unterschieden. Wenn die statistischen Instrumentarien und Kategorien also zum Ende des 19. Jahrhunderts hin eine differenziertere Erfassung der Fälle gestatteten, blieb als Unsicherheitsfaktor die unterschiedliche Sorgfalt der clerks bestehen. Ein Wechsel der Personen oder übermäßige Routine konnte zu Veränderungen in der Aufschreibepraxis führen. Auf der Ebene der aggregierten Zahlen für ganz England und Wales dürften die dadurch bedingten lokalen Schwankungen jedoch nicht mehr allzu sehr ins Gewicht fallen.

Arbeitsstreitigkeiten tauchten in den Akten der petty sessions vermischt mit allen möglichen anderen Gegenständen der summarischen Rechtsprechung auf. Die Register spiegeln die bunte Reihenfolge, in der die Fälle vor das Gericht gelangten. Sie machen deutlich, daß klagende Arbeitnehmer und Arbeitgeber unter den zahllosen Trunkenbolden, Schlägertypen, Ruhestörern, Schulschwänzern, Landstreichern, Wilderern, Falschfahrern und Taschendieben eine Ausnahme waren. In manchen Gerichtsbezirken wurden nach 1875 zeitweise besondere Protokollbücher, sogenannte Plaint and

74 Birmingham Central Reference Library, Archives Division, PS/SU 3/2, Sutton Coldfield Petty Sessional Division, Register of Court of Summary Jurisdiction, 1904-08 (Reihenfolge und Interpunktion der besseren Lesbarkeit halber leicht geändert).

75 Northamptonshire RO, unverzeichnet, Brackley and Middleton Cheney Petty Sessional Division, Register of Court of Summary Jurisdicition, 1887-1897 (Reihenfolge und Interpunktion der besseren Lesbarkeit halber leicht geändert). 
Minute Books, für Klagen unter dem Employers and Workmen Act geführt. Diese Bücher sind von der Forschung bisher unbeachtet geblieben und werden hier erstmals ausgewertet. Wie verbreitet diese Protokollbücher waren, ist aufgrund der sporadischen Überlieferung schwer zu sagen. Vorgeschrieben waren sie jedenfalls nicht. Es gab sie sowohl in großstädtischen Zentren wie Newcastle als auch in kleineren Industrie- oder Hafenstädten wie St. Helens, Kettering oder Gravesend als auch in überwiegend landwirtschaftlich geprägten Bezirken wie der Reading County Division in Berkshire. ${ }^{76}$ Diese besonderen Plaint and Minute Books ähneln vom Aufbau her den normalen registers of summary jurisdiction, enthalten jedoch zum Teil darüber hinausgehende Informationen. Schon von ihrem äußeren Erscheinungsbild her bestätigen die Protokollbücher, daß Arbeitsstreitigkeiten in den Friedensgerichten immer mehr an den Rand gedrängt wurden. Manche Bücher wurden nur in den ersten Jahren nach ihrer Anschaffung sauber und vollständig geführt, danach gerieten sie anscheinend wegen der Seltenheit der Fälle in Vergessenheit. Es kam zu großen Lücken, und einige Bücher wurden sogar für andere Eintragungen zweckentfremdet. ${ }^{77}$

Als Quellen sind diese Protokollbücher, wie auch die normalen Register, dennoch wertvoll, denn sie erlauben einen genaueren Einblick in die Prozeßresultate als die publizierten Statistiken. Diese zählten nämlich die Klagen unter den Master and Servant Acts und unter dem Employers and Workmen Act nur pauschal, ohne nach Arbeitnehmer- und Arbeitgeberklagen zu differenzieren. Ab 1893 verringerte sich der Informationsgehalt der Statistiken infolge der Reform noch weiter; die Klagen unter dem Employers and Workmen Act wurden nun darstellungstechnisch von den eigentlichen Strafsachen getrennt. Diese Änderung war ein Akt der political correctness, denn die Entkriminalisierung des Kontraktbruchs fand nun endlich auch in der Statistik ihre verspätete Anerkennung. Die Absonderung von den anderen summarischen Tatbeständen hatte aber den Nebeneffekt,

76 Folgende Plaint and Minute Books wurden von mir ausgewertet: Newcastle, 1889-1908: Tyne and Wear Archives Service, MG/Nc/4; St. Helens, 1891-1901: Lancashire Record Office, Preston, PSSH 3/1; Blackburn County, 1876-1915: Lancashire Record Office, Preston, PSBl 4/1; Eddisbury, 1875-1918: Cheshire Record Office, Chester, QPEd 7; Hyde, 1876-1884: Cheshire Record Office, Chester, QPH 3; Kettering and Little Bowdes, 1877-1887: Northamptonshire Record Office, unverzeichnet, shelf 58a; Reading County, 1876-1898: Berkshire Record Office, Reading PS/RC/9/1; Maidenhead, 1890-1938: Berkshire Record Office, Reading, PS/M/9/1; Gravesend, 1875-1881: Centre for Kentish Studies, Maidstone, PS/Gr/Sz/1; Maidstone, 1898-1905: Centre for Kentish Studies, Maidstone, PS/Md/Sv; Sheerness, 1880-1902: Centre for Kentish Studies, Maidstone, PS/Shz/4.

77 Im Buch von Maidenhead Borough tauchten zum Beispiel des öfteren Klagen des lokalen Steuerbeamten wegen Nichtzahlung der Lokalsteuern auf. 
daß nun nur noch Zahlen für England und Wales insgesamt gegeben wurden. Es entfiel die bis dahin übliche, nach Orten differenzierende Statistik der Streitigkeiten unter dem Employers and Workmen Act. Insgesamt wurden die Statistiken zur summarischen Rechtsprechung zum Ende des 19. Jahrhunderts hin zwar zuverlässiger, aber für meinen Untersuchungszweck weniger informativ.

\section{NUTZUNG DER FRIEDENSGERICHTE DURCH ARBEITNEHMER UND ARBEITGEBER: LANGFRISTIGE VERÄNDERUNGEN}

Trotz aller Einschränkungen im Hinblick auf Verläßlichkeit und Aussagekraft der Justizstatistiken ist der Haupttrend unbezweifelbar. Nach einem Höhepunkt in den frühen siebziger Jahren des 19. Jahrhunderts verloren die Friedensgerichte für Streitigkeiten aus dem Arbeitsvertrag an Bedeutung. Hatte die Zahl der Fälle bis 1875 im Durchschnitt etwas über 10800 betragen, stagnierte sie in den Jahrzehnten danach um einen Mittelwert von 6700. Nach dem Ersten Weltkrieg fand keine Wiederbelebung der Klageaktivität statt. Im Jahr 1923 klagten nur noch weniger als halb so viele Arbeitnehmer und Arbeitgeber vor den Friedensgerichten wie 1913 (Grafik 2.1).

Wie sehr die Streitigkeiten aus dem Arbeitsvertrag im alltäglichen Geschäft der Friedensrichter marginalisiert wurden, zeigt sich, wenn man die Klagen unter den Master and Servant-Gesetzen in Relation zur Gesamtzahl aller summarisch verhandelten Fälle setzt. Bis einschließlich 1875 machten die Master and Servant-Fälle im Schnitt 2,25 Prozent aller summarischen Fälle aus, nach 1875 pendelte dieser Wert um eine Marke von etwa einem Prozent, in den frühen zwanziger Jahren des 20. Jahrhunderts bei einem halben Prozent (Grafik 2.2). ${ }^{78}$

Der Rückgang der Klagetätigkeit wird noch deutlicher, wenn man ihn zur Zahl der potentiellen Kläger oder Beklagten unter den genannten Gesetzen, also Handarbeitern, in Beziehung setzt. Kamen um 1870 auf 100000 handarbeitend Beschäftigte noch knapp 150 Klagen pro Jahr, waren es zwanzig Jahre später nur noch halb soviele und nach dem Ersten Weltkrieg gerade

78 Dabei ist zu berücksichtigen, daß sich durch die Reform der Statistik im Jahr 1893 die Berechnungsgrundlage für die summarischen Fälle insgesamt dergestalt änderte, daß bestimmte Kategorien von Fällen, die vorher mitgezählt worden waren, nun separat gezählt wurden. Die Gesamtzahl der summarischen Fälle reduzierte sich dadurch von 1892 auf 1893 erheblich - nach Schätzungen der Statistiker um etwa 62000 (vgl. Criminal Statistics 1893, PP 1895, CVIII, Introduction, S. 99f.). Um dieser Veränderung Rechnung zu tragen, müßte man die Prozentwerte für Master and Servant-Fälle ab 1893 noch leicht nach unten revidieren. 
Grafik 2.1: Friedensgerichte England und Wales, 1857-1923: Klagen unter den Master and Servant Acts (MES) und dem Employers and Workmen Act (EEW)

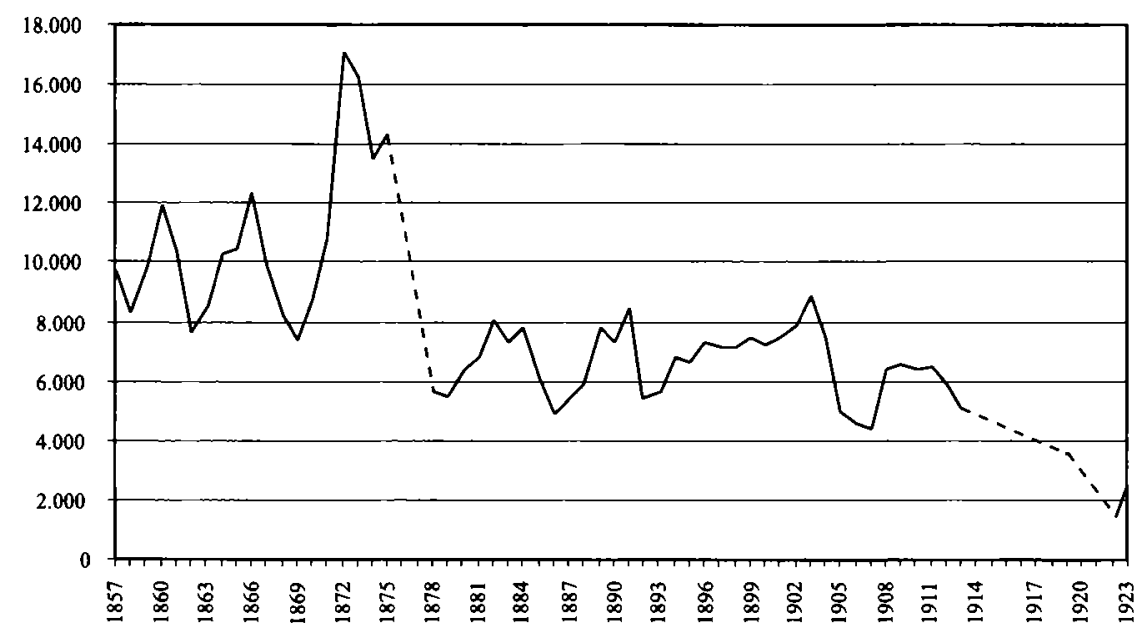

Quelle: Criminal Statistics, Tab. 7 (bis 1892), Tab. XI u. XIV (ab 1893)

Grafik 2.2: Friedensgerichte England und Wales, 1857-1923: Gesamtzabl aller summarisch verhandelten Fälle und Prozentanteil unter den Master and Servant-Gesetzen (MES, EEW) und dem Conspiracy and Protection of Property Act (CEPP)

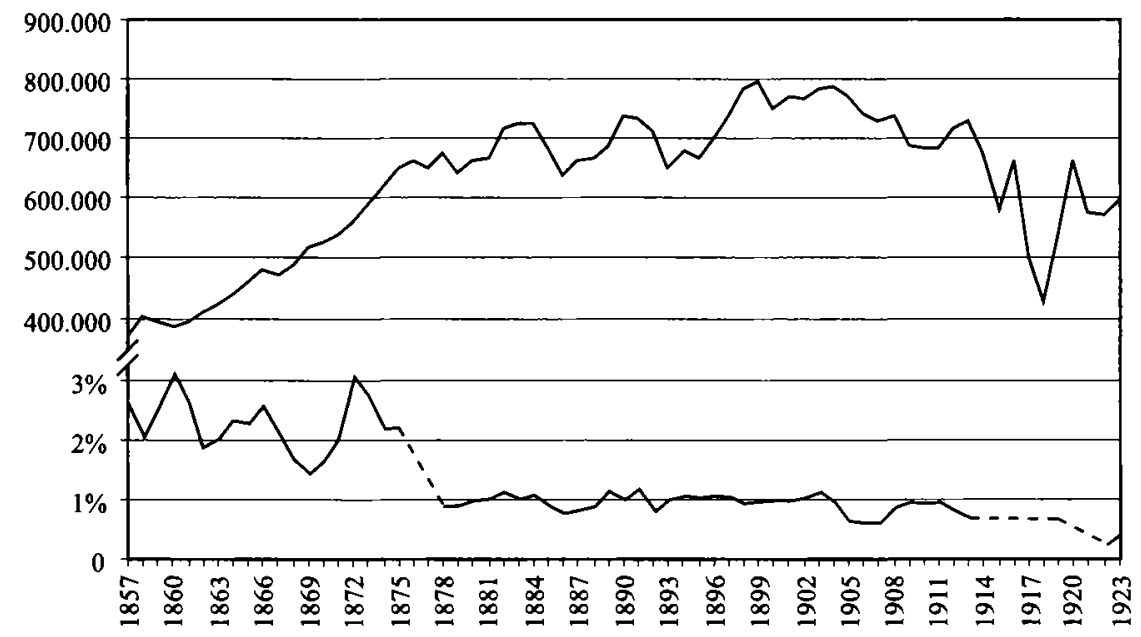

Quelle: Criminal Statistics, Tab. 7 (bis 1892), Tab. XI u. XIV (ab 1893), Comparative Tab. C 1920 u. 1924 
einmal zwei Dutzend (Grafik 2.3). Die Wahrscheinlichkeit für einen einzelnen Arbeiter oder Arbeitgeber, in einen Fall unter den betreffenden Gesetzen verwickelt zu werden, lag danach um 1870 bei $675 \mathrm{zu} 1$, um 1890 bei 1350 zu 1 und um 1920 nur noch bei etwa 4300 zu 1. Die zunehmende Distanz zwischen Arbeitswelt und ordentlicher Justiz, hier den Friedensgerichten, kommt in diesen Zahlen deutlich zum Ausdruck.

Lassen sich die langfristigen Trends des Klageverhaltens und der Inzidenz von Gerichtsprozessen für potentiell Betroffene aufgrund des publizierten Zahlenmaterials gut rekonstruieren, ist es weitaus schwieriger, die zum Teil erheblichen kurzfristigen Schwankungen bei der Zahl der Klagen zu erklären. Man hat versucht, die kurzfristigen Schwankungen mit Konjunkturzyklen in Verbindung zu bringen. Theoretisch gibt es dafür gute Gründe. Gute Konjunkturen führten im viktorianischen England in der Regel innerhalb kurzer Zeit zu erhöhter Streikbereitschaft der Trade Unions und zu größerer Fluktuation auf dem Arbeitsmarkt. Beides, das Bemühen der Gewerkschaften, die günstige Lage auszunutzen, und der Versuch einzelner Arbeiter, durch einen Wechsel des Arbeitsplatzes die eigene Lage zu verbessern, ließ die Zahl der Kontraktbrüche in die Höhe schnellen. Arbeitgeber reagierten darauf, so die Theorie, indem sie verstärkt Strafanträge unter den Master and Servant-Gesetzen stellten. Dieser Konnex funktionierte solange, wie das Gesetz primär von Arbeitgebern als Instrument der Abschreckung eingesetzt werden konnte. Das war bis 1875 der Fall. Vor 1875 war die Abwehr von Lohnforderungen und Streiks in den Augen der Arbeitgeber ein wesentlicher Zweck des Gesetzes. Der Höhepunkt der Klagetätigkeit in den frühen siebziger Jahren des 19. Jahrhunderts ist denn auch durchaus als Begleiterscheinung des wirtschaftlichen Booms dieser Jahre interpretierbar. ${ }^{79}$ Die politische Agitation um die Reform der Labour laws in diesen Jahren mag ein übriges getan haben, um die propagandistische Nutzung des Master and Servant Act auf beiden Seiten anzureizen. Statistisch nachweisbar ist dieses politische Motiv natürlich nicht, durch Zeitungsartikel läßt es sich aber belegen. ${ }^{80}$

79 Vgl. Simon, Master and Servant, S. 186 u. 190; Woods, Operation, S. 98. Nicht haltbar ist Daphne Simons These, daß der Master and Servant Act im wesentlichen nur von kleinen masters benutzt worden sei.

80 Vgl. etwa den hysterischen Leitartikel über den, Terrorismus' der Gewerkschaften und Mittel zu ihrer Bekämpfung in: Colliery Guardian, 10. Juni 1870, S.603; siehe auch ebd., 24. Juni 1870, S. 659: Bericht über einen Fall von angeblicher Einschüchterung von NichtGewerkschaftsmitgliedern durch Angehörige der South Yorkshire Miners' Association. Der Anwalt der Gewerkschaftler sah hier ein ,abgekartetes Spiel' der Kläger - „that they had set out with the intention of going into certain localities and raising a disturbance, in order that they might bring some unionist before the magistrates". 
Grafik 2.3: Friedensgerichte England und Wales, 1857-1923: Klagen unter den MESGesetzen pro 100000 handarbeitend Beschäftigte

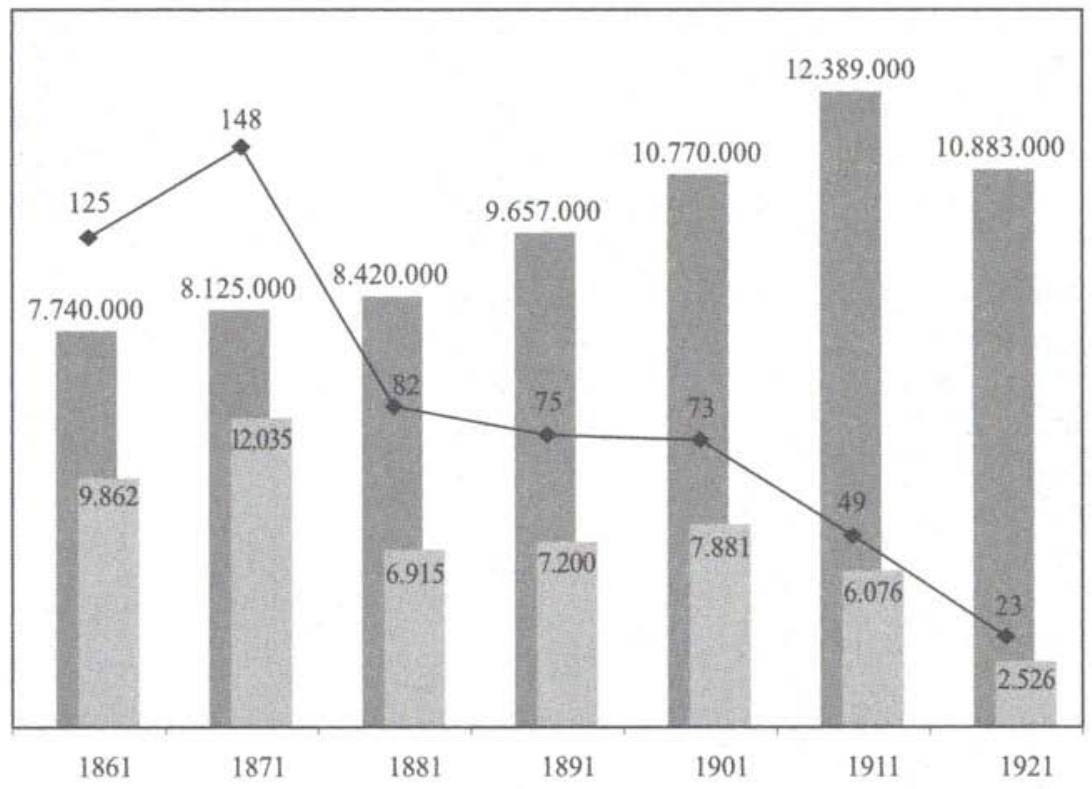

\section{Handarbeitend Beschäftigte}

Klagen

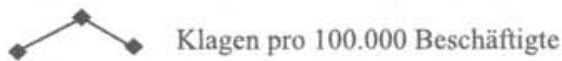

Erläuterung: 1. Die Zahlen für "Klagen “ von 1861 bis 1911 sind Fünfjahresdurchschnitte, zentriert auf die Zensusjahre. Die Zahl für Klagen 1921 ist der Durchschnitt aus den Klagezahlen für 1919, 1922 und 1923.

2. Die Zahl der ,handarbeitend Beschäftigten ' wurde ermittelt, indem jeweils von der im Zensus angegebenen Gesamtbevölkerungszahl (bzw. ab 1891 vom „Total aged 10 years and upwards“) die Zahlen für die Kategorien "General or Local Government“/„Public Administration“, "Armed Forces ${ }^{\prime} /$ "Defence“, „Professional Occupations", ,Domestic Offices and Personal Services“, „Buying and Selling “/”Commercial Occupations" and „Domestic Offices“/”Persons of Rank and Property "/,Persons supported by the Community"/ ${ }_{n}$ Scholars, children unproductive "/„Indefinite and nonproductive“/, Retired or unoccupied " (= Kinder, Hausfrauen, sonstige im Haus lebende Verwandte, Adlige, Empfänger von Armenunterstützung, Rentner, Schüler usw.) subtrahiert wurden. Das ist zwar nur ein sehr ungenauer Indikator, kommt jedoch der Zahl der potentiellen Kläger und Beklagten unter den M\&S-Gesetzen immer noch näher als wenn man die Gesamtzahl der Beschäftigten oder gar nur Bevölkerungszahlen nähme.

Quellen: Criminal Statistics, Tab. 7 (bis 1892), Tab. XI u. XIV (ab 1893), Comparative Tab. C 1920 u. 1924; Census of England and Wales 1861, 1871, 1881, 1891, 1901, 1911, 1921 
Nach der Beseitigung der Strafklauseln für Kontraktbruch im Jahr 1875 war das Gesetz als Abschreckungsinstrument nur noch bedingt verwendbar, und so kann man den Absturz der Klagezahlen nach Inkrafttreten des Employers and Workmen Act zum Teil auf nachlassende Attraktivität des Gesetzes für Arbeitgeber zurückführen. ${ }^{81}$ Auch wenn somit manches für einen Zusammenhang zwischen Konjunkturzyklen, Arbeitsmarktschwankungen, Kontraktbrüchen und Klagetätigkeit der Arbeitgeber spricht, scheint es kaum möglich, alle kurzfristigen Schwankungen bei der Zahl der Master and Servant-Fälle auf diese Weise zu erklären. Zudem sind die nationalen Statistiken für eine sichere Beweisführung zu grob. Selbst auf der Ebene einzelner Polizeibezirke ist eine rein ökonomisch-konjunkturelle Erklärung plötzlicher Schwankungen des Streitverhaltens wegen der unterschiedlichen Konjunkturverläufe in verschiedenen Industriebranchen wenig sinnvoll.

Auch ein Zusammenhang zwischen Streikwellen und Schwankungen bei den Klagezahlen läßt sich nicht sicher nachweisen. Große Streiks oder Aussperrungen waren zwar immer von gerichtlichen Auseinandersetzungen begleitet, quantitativ fielen diese aber nicht unbedingt ins Gewicht. Gerade die berühmtesten Arbeitskämpfe, die in den Annalen der Arbeiterbewegung den meisten Raum einnehmen, waren eher Zeiten, in denen weniger Klagen anfielen, wie man an den Beispielen der großen Aussperrung im Londoner Baugewerbe von 1859-60 und des Streiks der Dockarbeiter von 1889 sehen kann; bei beiden Gelegenheiten ist keine Erhöhung der Klagen unter dem Master and Servant Act beziehungsweise dem Employers and Workmen Act in London festzustellen. ${ }^{82}$ Auch während der ganz Großbritannien erfassenden Streikbewegung im Bergbau 1911-12 ist gegenüber den Vorjahren kein signifikanter Anstieg oder Rückgang der Klagen zu verzeichnen.

Konjunkturen und große kollektive Arbeitskämpfe mögen im Einzelfall zu härteren Auseinandersetzungen in den Gerichten geführt haben, sie wirkten sich aber in der Statistik der Individualklagen - außer in den frühen siebziger Jahren des 19. Jahrhunderts - nicht erkennbar aus. Erklärungen für die kurzfristigen Schwankungen müssen an anderer Stelle ansetzen. Wie

81 Weitere Faktoren, die zwar nicht für den plötzlichen Rückgang nach 1875, wohl aber für die langfristige Stagnation mitverantwortlich gewesen sein könnten, waren die Tendenz zu Arbeitsverträgen mit kürzeren Kündigungsfristen und die zunehmende Selbstdisziplin der Gewerkschaften, die darauf achteten, daß Streiks nur unter Beachtung der Kündigungsfrist, also ohne Kontraktbruch, stattfanden: vgl. Simon, Master and Servant, S. 190 f.; Lujo Brentano, Einleitung, in: ders. ( $\mathrm{Hg}$.), Arbeitseinstellungen und Fortbildung des Arbeitsvertrags (Schriften des Vereins für Socialpolitik 45), Leipzig 1890, S. IX-LXXVIII, S. LXf.

82 Siehe Grafik 2.5, S. 197. 
sich aus Presseberichten und Protokollbüchern ablesen läßt, waren es eher kleine, spontane, örtlich begrenzte Arbeitsniederlegungen, bei denen Arbeitgeber sich nicht anders zu helfen wußten, als daß sie die Wortführer oder sogar alle beteiligten Arbeiter auf einmal vor den Friedensrichter bringen ließen. Diese Vorfälle hatten lokale und branchenspezifische Ursachen, die sich auf der Ebene national aggregierter Daten über Konjunkturen, Arbeitsmarkt oder Streikwellen kaum studieren lassen. Statistisch schlugen die kleinen, oft aus geringfügigem Anlaß entstandenen Streitigkeiten dennoch $\mathrm{zu}$ Buche, denn manchmal waren dutzende, ja sogar hunderte von Arbeitern in sie verwickelt.

Beispiele für solche Kollektiv- oder Massenklagen finden sich im gesamten Untersuchungszeitraum. Sie nahmen aber im späten 19. Jahrhundert stark zu, und es waren vor allem sehr viel mehr Arbeiter in sie involviert als in früheren Jahrzehnten. Oft fungierten die magistrates in diesen Situationen als eine Art Clearing-Stelle, indem sie nach Anhörung beider Seiten auf eine außergerichtliche Einigung drängten und den Fall vertagten, um den Parteien Gelegenheit zu weiteren Verhandlungen zu geben. So geschah es etwa am 29. September 1858 in Wolverhampton, als neun Bergleute wegen Arbeitsniederlegung ohne Einhaltung der vierzehntägigen Kündigungsfrist vor Gericht standen. ${ }^{83}$ Ein anderes Mal verhielten sich die Friedensrichter eher im Sinne der Arbeitgeber, so zwei Tage vorher im benachbarten Dudley, wo zehn wegen des gleichen Delikts angeklagte Grubenarbeiter vor die Wahl gestellt wurden, entweder zu den vom Arbeitgeber diktierten Bedingungen zur Arbeit zurückzukehren oder für einen Monat ins Gefängnis zu gehen. ${ }^{84}$ Eine mögliche Lösung konnte auch so aussehen, daß ein Fall als test case herausgegriffen wurde, dessen Entscheidung für alle anderen akzeptiert werden sollte, so geschehen am 6. Mai 1893 in Castle Eden (County Durham), als 187 Bergleute wegen Kontraktbruchs unter dem Employers and Workmen Act verklagt wurden. ${ }^{85}$ Schließlich gab es Massenklagen, bei denen sich die Friedensrichter nicht scheuten, in jedem Einzelfall zu entscheiden, so etwa am 10. März 1923 in Pontypool (Wales), wo gegen 52 kontraktbrüchige Bergarbeiter eine Strafe von jeweils 26 Shilling verhängt wurde. ${ }^{86}$

Die beiden zuletzt genannten Beispiele von 1893 und 1923 machen im übrigen deutlich, daß der Employers and Workmen Act trotz des Wegfalls

83 Colliery Guardian, 2. Okt. 1858, S. 216.

84 Ebd., S. 217.

85 Labour Gazette, Juni 1893, S. 42.

86 The Times, 12.März.1923, S. 9. 
der Strafandrohung für Arbeitgeber nützlich bleiben konnte. In gewisser Weise war es sogar risikoloser, leichter und weniger anstößig, eine große Zahl von Arbeitern zu kleinen Schadensersatzsummen verurteilen zu lassen als die halbe Belegschaft eines Werks ins Gefängnis zu schicken. Eine Grenze der Nutzungsmöglichkeit war eher durch die Kapazität der Gerichte gegeben, wie ein extremer Fall vom Februar-März 1923 aus dem Kohlengebiet um South Shields verdeutlicht. Hier erwirkte eine einzige Coal Company gegen sage und schreibe 980 Arbeiter Vorladungen; die Beratungen der Anwälte beider Seiten an dem extra anberaumten Gerichtstermin, einem Samstag, führten zu dem allseits geteilten Wunsch einer außergerichtlichen Lösung, die schließlich auch gefunden wurde. ${ }^{87}$ Massenklagen wurden nicht nur von Arbeitgebern angestrengt. Auch Arbeiter nutzten gelegentlich dieses Mittel. Oft war dies für sie der einzige Weg, um einen Arbeitgeber, dessen Finanzlage prekär schien, zur Zahlung zu zwingen, so etwa in einem Fall von 30 Eisenbahnbauarbeitern an der West Riding Railway, die im November 1847 vor den Friedensrichtern in Halifax erfolgreich ausstehende Löhne einklagten. ${ }^{8}$ Manchmal wurde die Kollektivklage auch als Zwischenschritt oder Ersatzhandlung im Rahmen von Tarifstreitigkeiten eingesetzt, so bei einer Klage von 174 Dockarbeitern in Birkenhead, deren am 15. Juni 1893 erhobene Forderung nach jeweils 2 Shilling Wartegeld und 2 Shilling Überstundengeld "gemäß den Regeln ihrer Union" vom Friedensrichter zurückgewiesen wurde, mit der Begründung, daß in den Arbeitsverträgen der Leute von diesen Gewerkschaftsregeln nichts zu finden sei. ${ }^{89}$ Am extremsten war wohl ein Fall im Jahr 1884, bei dem $1126 \mathrm{Ar}$ beiter separat ihren Arbeitgeber auf exakt die gleiche Summe Lohn verklagen mußten, weil dieser sich nicht auf einen Testfall einließ.90 Hier mußten also über eintausendmal Gebühren vorgestreckt werden, um einen Anspruch durchzusetzen.

Angesichts der genannten Beispiele für Mehrfach- und Massenklagen stellt sich mit Blick auf die Statistik erneut die Frage, wie die clerks an den Friedensgerichten diese Fälle bewerteten. Notierten sie jeden Fall einzeln? Hielten sie nur den einen test case im Protokollbuch fest? Und als wieviele ,Fälle ${ }^{c}$ wurden die Vorkommnisse weitergemeldet? Nach dem Plaint and

87 Iron and Coal Trades Review, 16. Febr. 1923, S. 251; 23. Febr. 1923, S. 297; 2. März 1923, S. 330. Insgesamt waren es, wie der Zeitungsbericht vermerkte, sogar 5.168 Vorladungen. Der Fall der 980 Arbeiter betraf nur eine Zechenbelegschaft.

89 Labour Gazette, Juli 1893, S. 63.

90 Über diesen Fall berichtete ein Mr. Crawford vor dem TUC-Kongreß: Seventeenth Annual Trades' Union Congress, Aberdeen 1884, S. 11 (Microfilm edition). 
Minute Book vom Friedensgericht in Newcastle zu urteilen, scheint es üblich gewesen zu sein, bei Massenklagen jeden einzelnen Fall zu notieren und weiterzumelden. Das führte auf lokaler Ebene zu erheblichen Ausschlägen in der Statistik. Wurden für Newcastle-on-Tyne City im Jahr 1889 nur 11 Fälle unter dem Employers and Workmen Act gemeldet, waren es im folgenden Jahr 108 Fälle, und im darauffolgenden Jahr wieder nur 20 Fälle. Die extrem hohe Zahl für 1890 war, wie das Protokollbuch zeigt, auf eine einzige Klage der Elswick Coal Company gegen 86 Kohlenhauer zurückzuführen, die fast alle zu 10 oder 15 Shilling Schadenersatz und Gerichtskosten verurteilt wurden. ${ }^{91}$ Ähnliche scheinbar rätselhafte ,Ausreißer für einzelne Polizeidistrikte finden sich in der publizierten Justizstatistik immer wieder, und sie dürften auf ähnliche Weise zu erklären sein.92 Bei einer Gesamtzahl von (nach 1875) durchschnittlich nur etwa 6700 Klagen pro Jahr für ganz England und Wales konnte eine zufällige Häufung solcher Massenklagen an mehreren Orten in einem bestimmten Jahr bereits zu erheblichen Verschiebungen in der nationalen Statistik führen.

Diese Bemerkungen sollten davor warnen, in die kurzfristigen Schwankungen bei den Klagezahlen allzu viel hineinzuinterpretieren. Die nationale Statistik eignet sich vor allem für die Beschreibung langfristiger Trends. Über die Gründe für plötzliche $\mathrm{Zu}$ - oder Abnahmen läßt sich hingegen aufgrund der nationalen Zahlen allenfalls spekulieren. Nur auf der Ebene einzelner Orte und Industriebranchen ließe sich ermitteln, wie die Gesamtzahlen zustandekamen. Politische Agitation, günstige Konjunkturen für lokale Produkte, Lohnkämpfe, ein jahrelang sich hinziehender Streit um eine gewerbespezifische ,Gewohnheit', aber auch Personen und Zufälle - ein bekannt arbeitgeberfreundlicher Friedensrichter hier, ein notorisch gewerkschaftsfeindlicher Unternehmer dort - mögen örtlich zu einem Ansteigen oder Abschwellen der Klagetätigkeit geführt haben. Grenzveränderungen von Gerichtsbezirken und die lokal differierende Praxis des Aufschreibens und Weitermeldens der Fälle konnten zusätzlich Verzerrungen bewirken. Der abnehmende Gesamtrend blieb jedoch von alldem unberührt und ist auf nationaler Ebene gut erkennbar.

91 Tyne and Wear Archives Service, Newcastle, MG/Nc/4, Plaints and Minutes under the Employers' and Workmen's Act, 1889-1908, Eintrag vom 14. Okt. 1889. In der Kriminalstatistik tauchten diese 86 Fälle erst im Jahr 1890 auf, weil bis zur Reform der Statistik das Berechnungsjahr jeweils am 29. September endete.

92 Extreme Ausschläge gibt es z. B. für Preston in den sechziger Jahren und für Warrington in den achtziger Jahren des 19. Jahrhunderts. Preston: 1863 - 38 Fälle, 1865 - 285 Fälle, 1866 498 Fälle, 1868 - 58 Fälle. Warrington: 1882 - 199 Fälle, 1883 - 69 Fälle, 1884 - 149 Fälle, 1885 - 84 Fälle, 1887 - 22 Fälle. 
$\mathrm{Zu}$ fragen bleibt, ob es lokale Abweichungen gab, die zugleich etwas über die Verteilung der Klagetätigkeit auf Industriezweige aussagen. Was den Employers and Workmen Act angeht, kann diese Frage aufgrund der Reform der Statistik nur für den Zeitraum bis 1892 beantwortet werden. Auch ist zu berücksichtigen, daß die Polizeidistrikte in vielen Fällen zu groß waren, als daß eine exakte Zurechnung der Klagen zu bestimmten Industriezweigen möglich wäre. Dennoch erlauben die Zahlen für einige ausgewählte Regionen und Orte gewisse Rückschlüsse auf lokale und branchenspezifische Schwerpunkte der Nutzung (Grafiken 2.4 und 2.5). Es zeigen sich erhebliche regionale Divergenzen. In der agrarischen Grafschaft Berkshire, in der teils ländlichen, teils von Heimindustrie geprägten Grafschaft Northamptonshire, in der Messer- und Klingenstadt Sheffield sowie in Staffordshire folgte die Klageentwicklung ungefähr dem nationalen Trend.

Grafik 2.4: Friedensgerichte England und Wales 1858-1892: Klagen unter den MES-Gesetzen in Lancashire ${ }^{\mathrm{a}}$, West Yorkshire ${ }^{\mathrm{b}}$, County Durham ${ }^{\mathrm{c}}$ und Staffordshire ${ }^{\mathrm{d}}$

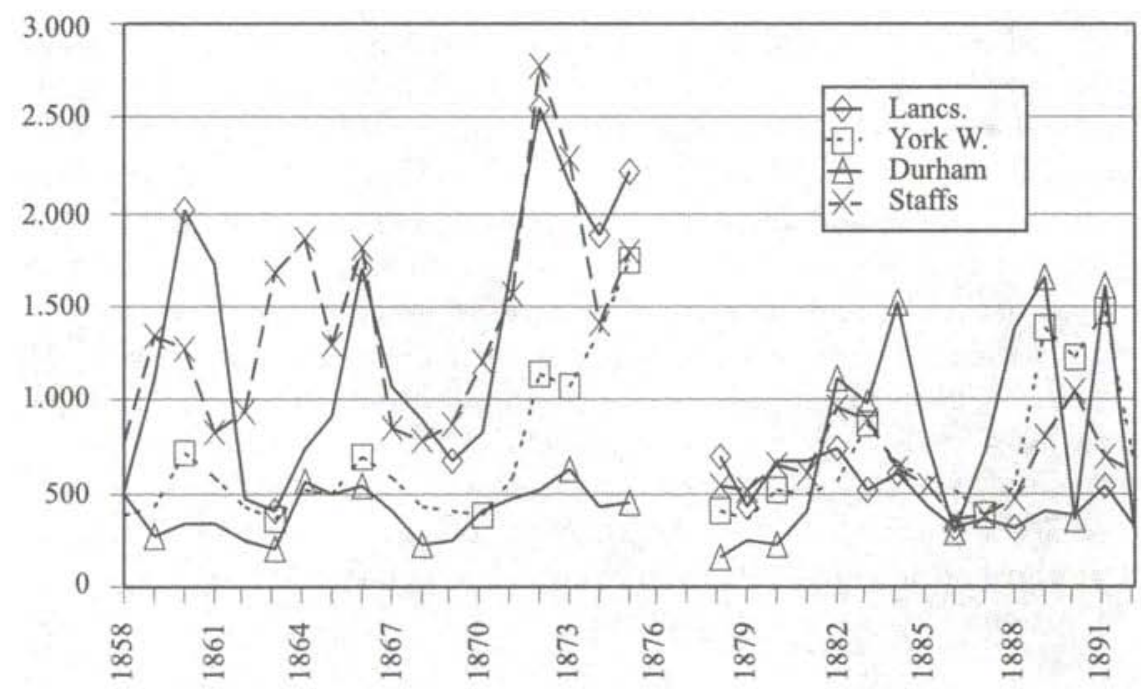

${ }^{2}$ Lancashire: einschließlich Ashton-under-Lyme Borough, Blackburn B., Bolton B., Manchester City, Oldham B., Preston B., Rochdale B., Staleybridge B., Warrington B., Wigan B.; ab 1882 auch Accrington B.; ab 1887 auch Bacup B. u. Burnley B.

b West Yorkshire: ohne einliegende Boroughs

c Durham County: ohne einliegende Boroughs

d Staffordshire: einschließlich Wolverhampton B. und Walsall B.

Quelle: Criminal Statistics, Tab. 7 
Grafik 2.5: Friedensgerichte England und Wales 1858-1892: Klagen unter den MES-Gesetzen in Berkshire ${ }^{2}$, Northamptonshire ${ }^{\mathrm{b}}$, Sheffield und London ${ }^{\mathrm{c}}$

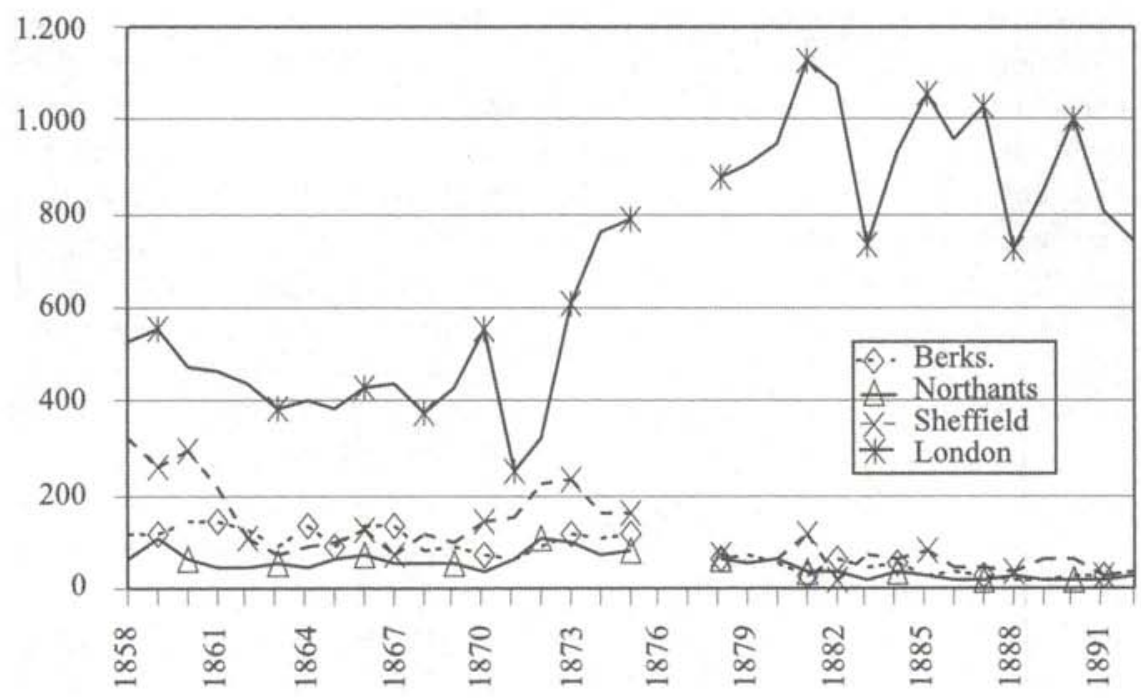

a Berkshire: ohne einliegende Boroughs

b Northamptonshire: einschließlich Northampton Borough und Daventry Borough

c Metropolitan Police District

Quelle: Criminal Statistics, Tab.7

Dagegen ergab sich ein überproportionaler Einbruch in den Baumwollbezirken von Lancashire. Dort war es in den fünfziger und sechziger Jahren im Zusammenhang mit lokalen Konflikten um Löhne und Arbeitsbedingungen zu regelrechten Prozeßlawinen gekommen, die sich bis in die nationale Statistik hinein bemerkbar machten. Nach 1875 verstetigte sich die Klagetätigkeit in Lancashire auf vergleichsweise niedrigem Niveau mit sinkender Tendenz. Diese Entwicklung dürfte vor allem auf ein nachlassendes Interesse der Arbeitgeber an den Friedensgerichten zurückzuführen sein. Für die Cotton Lords mit ihren in Fabriken zentrierten, meist weiblichen Arbeitskräften lohnte es nach dem Wegfall der Strafbestimmungen offenbar kaum noch der Mühe, die Friedensrichter anzurufen. ${ }^{93}$ Nennenswerte

93 Darauf könnte auch die Tatsache hindeuten, daß in der Statistik zwischen 1878 und 1880 für Lancashire extrem hohe Werte für Klagen unter dem Conspiracy and Protection of Property Act angegeben wurden, während bis 1880 überhaupt keine Zahlen für Klagen unter dem Employers and Workmen Act erschienen. Zwar dürfte diese Unregelmäßigkeit vor allem auf die Irritation der örtlichen Polizeibehörden und der clerks zurückzuführen sein, die offen- 
Schadensersatzsummen waren von den Beschäftigten in der Baumwollindustrie kaum einzutreiben. Außerdem unterlagen die Löhne der Kinder und Frauen ab 1875 einem besonderen gesetzlichen Schutz: Auch im Falle eines Kontraktbruchs konnten Fabrikarbeiterinnen und Kinder ihren bis dahin erarbeiteten Lohn behalten; die sonst übliche Verwirkung (forfeiture) fand nicht statt. ${ }^{94}$ Die Baumwollunternehmer von Lancashire konnten somit die Friedensgerichte im wesentlichen nur noch für symbolische Lektionen gegen ihre Beschäftigten nutzen. Neben dem verringerten Nutzen des Rechtswegs für Arbeitgeber sorgte auch der Ausbau des Systems der kollektiven Verhandlungs- und Konfliktlösungsformen und die damit einhergehende Disziplinierung der Arbeiterschaft in Lancashire dafür, daß die typischen Kontraktbruchklagen hier nach 1875 seltener wurden. ${ }^{95}$

Anders sah es im benachbarten West Yorkshire aus. Dort fiel der landesweite Rückgang der Klagetätigkeit nach 1875 weniger deutlich aus, und in den späten achtziger und frühen neunziger Jahren waren fast wieder die Höchstwerte der frühen siebziger Jahre erreicht. Relativ gesehen rückte West Yorkshire damit in die Reihe der Regionen mit dem höchsten Klageaufkommen in ganz England und Wales auf. Man kann daraus den Schluß ziehen, daß der Employers and Workmen Act für die dortigen Woll- und Kammgarnfabrikanten nützlich war. Gegen die zum größeren Teil männlichen, häufig in einer Art von Pseudo-Selbständigkeit gehaltenen Beschäftigten dieser Branche waren Schadensersatzklagen erfolgversprechender als gegen die überwiegend weiblichen und jugendlichen Arbeitskräfte in den Baumwollfabriken. Zudem waren auch die Firmengrößen in West Yorkshire erheblich kleiner, die Unternehmer weniger finanzkräftig und zum Teil selbst in hohem Maße abhängig von der schwankenden Nachfrage der Textilkaufleute. Auch die Arbeiter hatten somit in West Yorkshire mehr Gründe für Klagen. Schließlich war das System der industriellen Beziehungen hier bei weitem nicht so hoch entwickelt wie in Lancashire. Die kollektiven Konflikte waren lokal begrenzter, spontaner und auf beiden Seiten aggressiver und weniger diszipliniert. ${ }^{96}$ Auffällig ist jedenfalls, daß die beiden

sichtlich an vielen Orten nicht recht wußten, wie sie die Fälle unter den neuen Gesetzen rückmelden sollten. Aber es wäre auch denkbar, daß viele Unternehmer in Lancashire tatsächlich zunächst versuchten, die verbliebenen strafrechtlichen Möglichkeiten des Conspiracy and Protection of Property Act auszuloten, bevor sie sich damit abfanden, daß die neue Rechtslage bei Kontraktbruch nur noch in Ausnahmefällen Strafen erlaubte.

$9438 \& 39$ Vict., c. 90 (1875), s. 11.

95 Zur Stabilisierung der Konfliktmuster in Lancashire in diesem Zeitraum: Joyce, Work, Society and Politics, S. 64-73.

96 Vgl. ebd., S. 73-79. Ausführlicher zur Konfliktgeladenheit der Arbeitsbeziehungen in der Woll- und Kammgarnindustrie um Bradford im letzten Viertel des 19. Jahrhunderts: Itt- 
großen, ähnlich strukturierten nordenglischen Textilregionen eine gegenläufige Entwicklung durchliefen: Während die Baumwollarbeiter und -fabrikanten von Lancashire dazu übergingen, ihre Konflikte auf andere Weise zu lösen, behielt der neue Employers and Workmen Act trotz des Wegfalls der Strafbestimmungen für Unternehmer und Arbeiter in West Yorkshire seine Bedeutung.

Generell machten die Arbeitgeber von der Möglichkeit der Zivilklage gegen einzelne Arbeiter offenbar am bereitwilligsten dort Gebrauch, wo sie es mit einer männlichen, fachlich qualifizierten, in kleineren Betrieben oder in scheinselbständigen Formen tätigen Arbeiterschaft zu tun hatten. Umgekehrt waren diese Arbeiter auch eher in der Lage, ihrerseits vorenthaltenen Lohn oder Schadensersatz gerichtlich einzuklagen. Daß die Klagezahlen für London im Gegensarz zum übrigen Land nach 1875 weiter anstiegen und dann auf höherem Niveau stagnierten, ist zum Teil auf diese Weise zu erklären; in der hauptstädtischen Industrie dominierten kleine, handwerkliche Betriebe mit einem hohen Anteil qualifizierter Arbeiter. ${ }^{97} \mathrm{Zu}$ berücksichtigen ist hierbei natürlich auch die allgemein zunehmende Beschäftigtenzahl in London. Allerdings gehörten die expandierenden Außenbezirke nicht zum Metropolitan Police District, und das wachsende Heer der im Dienstleistungssektor Angestellten fiel nicht unter den Employers and Workmen Act. Deshalb genügt der Verweis auf das allgemeine Beschäftigungsniveau nicht, um die relativ hohen Klagezahlen für London nach $1875 \mathrm{zu}$ erklären.

Eine andere Erklärung wurde bereits angedeutet. Diese würde weniger von der Nachfrageseite als vielmehr vom Angebot an juristischen Dienstleistungen her argumentieren. In London war dieses Angebot, was die Friedensgerichte angeht, zweifellos attraktiver als in der Provinz. Die Professionalität und Unparteilichkeit der Polizeirichter und die später noch zu behandelnden Einrichtungen der Rechtsberatung dürften viel dazu beigetragen haben, daß die Friedensgerichte in London keinen so einschneidenden Rückgang bei den Arbeitsstreitigkeiten erlebten wie andernorts. ${ }^{98}$

Außer für London, Lancashire und West Yorkshire zeigen die Grafiken vor allem für die von Kohleabbau geprägte Grafschaft Durham eine atypi-

mann, Work, Gender and Family, S. 46f. u. 57-72. Die relative Zunahme der Klagen in West Yorkshire könnte auch auf ein geändertes Klageverhalten der dortigen Kohlengrubenbesitzer zurückzuführen sein.

97 Zur Wirtschafts- und Beschäftigungsstruktur Londons: P.G. Hall, The Industries of London since 1861, London 1962; Geoffrey Crossick, An Arrisan Elite in Victorian Society. Kentish London 1840-1880, London u. Totowa N.J. 1978; Paul Johnson, Economic Development and Industrial Dynamism in Victorian London, in: London Journal 21 (1996), S. 27-37. 
sche Entwicklung. Bis zum Ende der siebziger Jahre des 19. Jahrhunderts wurden hier die Master and Servant-Gesetze zwar regelmäßig, aber für ein so ausgedehntes Bergbaurevier nicht eben häufig genutzt, wenn man zum Beispiel die Zahlen für das Black Country (Staffordshire) dagegenhält. Zu Beginn der achtziger Jahre stieg hingegen die Klagetätigkeit in Durham sprunghaft an, und in der Folge kam es zu extremen periodischen Schwankungen, die - ähnlich wie früher im Falle Lancashires - zu Verzerrungen der nationalen Statistik führten. Bedeutende gesetzliche oder institutionelle Veränderungen gab es in diesem Zeitraum nicht, und die Konjunkturzyklen allein reichen als Erklärung für die erratischen Ausschläge in Durham nicht aus. Der Schlüssel dürfte vielmehr bei der oben erwähnten Praxis der Massenklagen im Rahmen kollektiver Auseinandersetzungen liegen. Nimmt man die journalistische Berichterstattung als Indiz, scheint diese Taktik des Arbeitskampfes mit juristischen Mitteln gerade in der Grafschaft Durham besonders verbreitet gewesen zu sein. ${ }^{99}$ Warum sie dort ausgerechnet seit den frühen achtziger Jahren des 19. Jahrhunderts vermehrt angewendet wurde, könnte nur durch eine Lokalstudie geklärt werden. ${ }^{100}$ Einige allgemeine Bedingungen, die eine Nutzung des Employers and Workmen Act begünstigten, waren in Durham gegeben. Die Bergarbeiterschaft im englischen Nordosten war vergleichsweise hoch bezahlt; das machte es für die Arbeitgeber sinnvoll, den Weg der kollektiven Schadensersatzklage zu ge-

99 Im August 1882 zum Beispiel standen vor dem Durham County Police Court 500 Vorladungen gegen die Bergarbeiter der Brancepeth Colliery zur Diskussion. In diesem Fall wurden die Vorladungen zurückgezogen - die Männer hatten versprochen, zur Arbeit zurückzukehren und ihre ,Repräsentanten' hatten die Gerichtskosten bezahlt (Colliery Guardian, 18. Aug. 1882, S. 267). Es ist gut möglich, daß diese 500 Vorladungen für die extreme Steigerung der Klagezahlen zwischen 1881 (397 Fälle) und 1882 (1117 Fälle) in Durham verantwortlich sind, möglicherweise erschienen diese zurückgezogenen Vorladungen aber auch nicht in der Statistik. Fälle dieser Art, wenngleich nicht immer mit so vielen Beteiligten kamen in County Durham 1882 alle paar Wochen einmal vor. Nur wenige Wochen später wurden z. B. in Bishop Auckland (County Durham) 80 Bergleute zu je 5 Shilling Schadensersatz und Kosten verurteilt (Colliery Guardian, 1. Sept. 1882, S. 339).

100 Die Geschichte der Durbam Miners' Association und ihrer Beziehungen zu den Arbeitgebern in diesen Jahren gibt einige Hinweise auf Gründe, die zu den extremen Schwankungen der Klageaktivität geführt haben könnten. Danach waren die Jahre erhöhter Klagetätigkeit vor allem solche, in denen die zwischen 1877 und 1889 geltende gleitende Lohnskala den veränderten Konjunkturbedingungen angepaßt werden mußte bzw. in die Krise geriet, was auf lokaler Ebene zu zahlreichen Disputen führte; die großen Streikjahre 1879 und 1892 waren dagegen von geringerer Klagetätigkeit vor den Gerichten gekennzeichnet. Vgl. zu den Konflikten um die Skala und den Streiks: Sidney Webb, The Story of the Durham Miners (1662-1921), London 1921, S. 63 f. u. 72 ff. Weitere Einzelheiten zu der gleitenden Lohnskala und den darum geführten Verhandlungen bei: Emil Auerbach, Die Ordnung des Arbeitsverhältnisses in den Kohlengruben von Northumberland und Durham, in: Brentano ( $\mathrm{Hg}$.), Arbeitseinstellungen, S. 1-268. 
hen. Außerdem waren die Durhamer Bergleute gewerkschaftlich gut organisiert, sie waren stolz auf die zum Teil von ihnen selbst mitbestimmte Arbeitsorganisation unter Tage und sie besaßen schon damals ein hohes Traditionsbewußtsein; das bestärkte sie in ihrer Widerstandshaltung gegen alle unternehmerischen Angriffe auf ihr Lohnniveau und ihre ,Gewohnheiten'. ${ }^{101}$ Eine dieser umkämpften Gewohnheiten, die des öfteren Massenklagen der Arbeitgeber hervorrief, war zum Beispiel die Praxis, daß bei Grubenunglücken mit Todesfällen die gesamte Zechenbelegschaft solange die Arbeit niederlegte, bis der Tote geborgen und begraben war. ${ }^{102}$

Die vorstehenden Erläuterungen verdeutlichen vor allem eines: Weder für den nationalen Trend noch für davon abweichende lokale Entwicklungen gibt es eine allgemeingültige Erklärung. Lediglich die Gesetzgebung von 1875 war ein Faktor, der überall zu Buche schlug. Vor allem in der Kohlenbranche wirkte sich die Reform offenbar in der Weise aus, daß die Arbeitgeber seltener gegen einzelne oder einige wenige Arbeiter vorgingen, statt dessen aber in größeren zeitlichen Abständen sehr viele Arbeiter auf einmal verklagten. Was die Verteilung auf Industriezweige angeht, so erlauben die Justizstatistiken zumindest die Feststellung, daß die Streitfreudigkeit in den nordenglischen Textilbezirken, in den Regionen mit Metallverarbeitung und in den Bergbaurevieren besonders ausgeprägt war. In der Baumwollindustrie war sie rückläufig, im Bergbau hingegen blieb sie bis zum Ende des Untersuchungszeitraums ungebrochen. Wie nirgends sonst in England behiehlten die Friedensrichter in den Städten und Siedlungen rund um die Kohlenschächte ihre Funktion als Anlaufstelle bei Arbeitsstreitigkeiten.

Das bestätigt auch ein Blick auf die Nutzung der allgemeinen und branchenspezifischen Arbeiterschutzgesetze, die unter die summarische Jurisdiktion der Friedensrichter fielen, also der Gesetzgebung zu Truck, Bergwerken, Fabriken, Werkstätten und Läden (Grafik 2.6). Die Mines Acts gaben noch während des Ersten Weltkriegs und darüber hinaus Anlaß zu etwa 1000 Klagen pro Jahr, und das trug zur fortdauernden Präsenz der magistrates in den Streitigkeiten zwischen Bergarbeitern und Grubenbesitzern

101 Vgl. Norman Emery, The Coalminers of Durham, Stroud 1992; Dave Douglass, The Durham pitman, in: Raphael Samuel (Hg.), Miners, Quarrymen and Saltworkers, London 1977, S. 205-295.

102 Vgl. Colliery Guardian, 14. Juli 1882, S. 64 (Vorarbeiter von 150 Bergleuten in Rowley); Labour Gazette, April 1894, S. 119 (520 Bergleute in Castle Eden); Labour Gazette, Nov. 1897, S. 346; April 1898, S. 105 (72 Bergleute in Doncaster, West Yorkshire, die zu ihrer Rechtfertigung auf die "custom“ in den benachbarten Grafschaften Durham und Nottinghamshire verwiesen und hier Recht erhielten). 
Grafik 2.6: Friedensgerichte England und Wales 1858-1923: Klagen unter verschiedenen Arbeiterschutzgesetzen (Factory Acts; Mines Acts, Shops Acts, Children Acts, Hosiery Acts und Truck Acts)
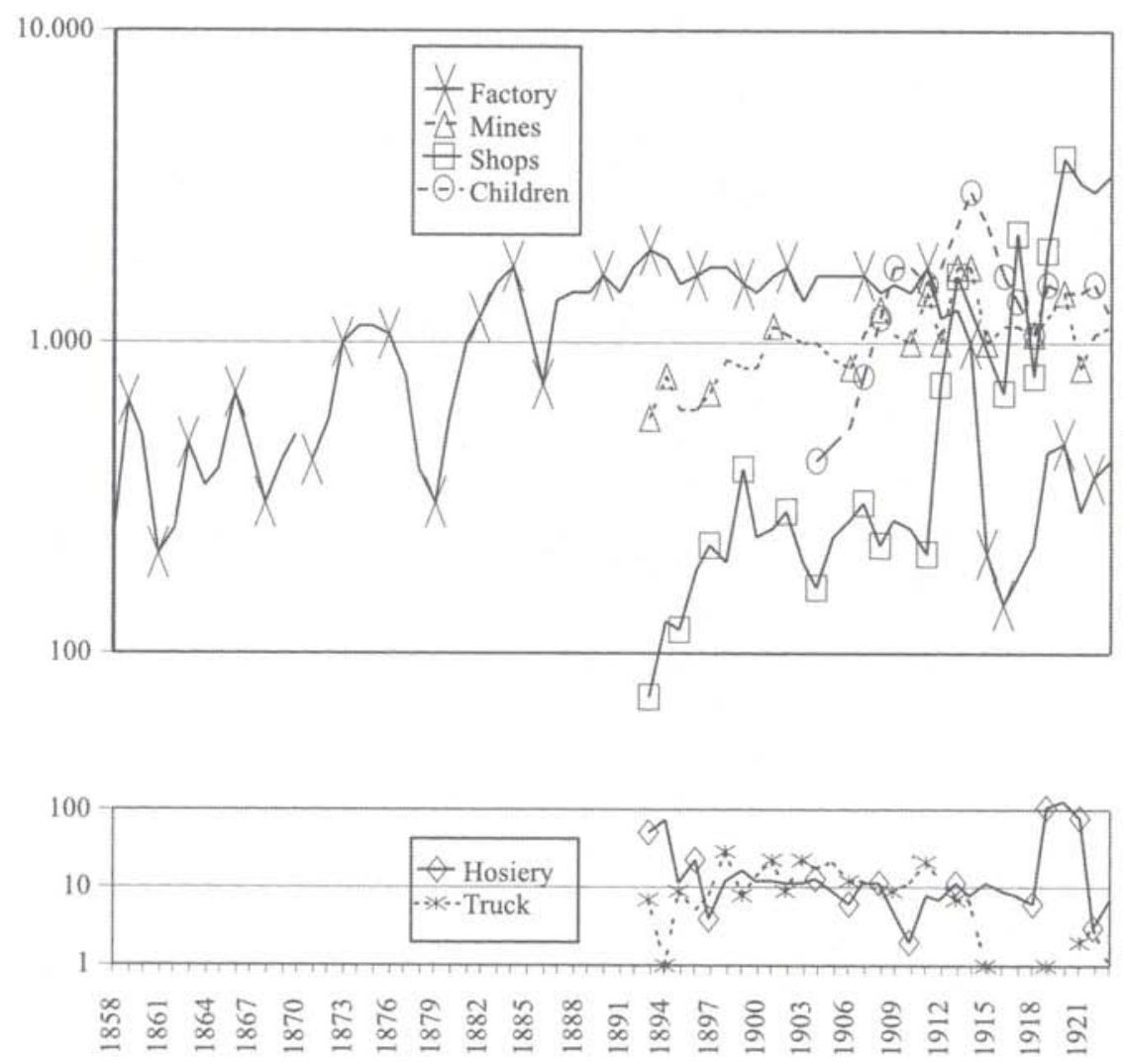

Quellen: Criminal Statistics, Tab. 7 (für 1858-1892); Tab. XI (für 1893-1898), Criminal Statistics 1918, PP 1920 L (Cmd. 684) Comp. Tab. C (für 1899-1918), Criminal Statistics 1923, PP 1924-25 XXVIII (Cmd. 2385) Comp. Tab. C (für 1919-1923)

bei. Der klassische ,Arbeiterschutz' im deutschen Wortsinn war nur ein Teilaspekt der Mines Acts, daneben dienten sie immer auch der Disziplinierung. Aus den vom Home Office bereitgestellten Zahlen geht hervor, daß noch um die Jahrhundertwende stets weit mehr als drei Viertel aller Strafverfolgungen unter den Mines Acts gegen Arbeiter gerichtet waren. Die Summe der gegen sie verhängten Bußgelder lag weitaus höher als die von den Arbeitgebern zu zahlende Summe. ${ }^{103}$ Kläger waren in diesen Fällen oft

103 Vgl. Tenth Abstract of Labour Statistics of the United Kingdom, 1902-1904 (Cd. 2491), 
die Unternehmer selbst, nicht Inspektoren oder Lokalbehörden. Die Bergwerksgesetze riefen somit sehr häufig direkte Konfrontationen zwischen Arbeitgebern und Arbeitern hervor, während bei den übrigen Arbeiterschutzgesetzen die Front zwischen den behördlichen Organen und den Arbeitgebern verlief.

Anders der Trend bei den Fabrikgesetzen. Gegenüber den erbitterten Auseinandersetzungen in der frühen, ,heroischen' Phase der Fabrikgesetzgebung scheint hier im frühen 20. Jahrhundert eine gewisse Entspannung eingetreten zu sein. Mit dem Beginn des Ersten Weltkriegs sank die Zahl der Klagen unter den Factory and Workshop Acts auf wenige hundert pro Jahr, und sie blieb auch in den ersten Jahren nach dem Krieg weit unter dem Vorkriegsniveau (Grafik 2.6). Bedenkt man, daß von den Factory and Workshop Acts im 20. Jahrhundert nicht mehr nur die Textilbranche, sondern eine Vielzahl anderer Betriebe betroffen waren, die sich noch dazu über das ganze Land verteilten, wird offensichtlich, daß die Rechtsprechung unter diesen Gesetzen auf lokaler Ebene kaum noch ins Gewicht fiel.

Der Niedergang der Klagetätigkeit unter den Fabrik- und Werkstättengesetzen - von den Truck Acts gar nicht zu reden - könnte darauf hindeuten, daß die Probleme, um derentwillen diese Gesetze erlassen worden waren, inzwischen nicht mehr existierten. Im Falle des Truck Act, wo die Klagen schon im späten 19. Jahrhundert gegen Null tendierten, ist diese Interpretation naheliegend. Es war nicht mehr die Zahlung des Lohns in Waren, sondern das zu niedrige Lohnniveau und die Praxis der Lohnabzüge, die zu Konflikten führten. Deartige Lohnkonflikte wurden jedoch nunmehr meist auf anderem Wege, durch Verhandlungen, Trade Boards, Schlichtungsinstanzen oder Arbeitskämpfe, gelöst. Bei den Fabrik- und Werkstättengesetzen ist hingegen nicht davon auszugehen, daß die Arbeitgeber, nachdem sie jahrzehntelang versucht hatten, die Gesetze zu umgehen, nun auf einmal lammfromm geworden waren und alle Vorschriften einhielten, so daß die Inspektoren niemanden mehr fanden, den sie hätten verklagen können. Die nach oben weisende Tendenz bei den Zahlen unter den Shops Acts und den Kinderschutzgesetzen spricht dafür, daß es bei englischen Arbeitgebern keinen fundamentalen Sinneswandel im Hinblick auf störende staatliche Eingriffe in betriebsinterne Angelegenheiten gegeben hatte. Der Grund für die rückläufige Beschäftigung der Friedensrichter mit den Fabrik- und Werkstättengesetzen dürfte eher darin liegen, daß die Inspektoren inzwischen über ein erheblich größeres Spektrum an informellen und administrativen

S. 229, Prosecutions under Mines and Quarries Acts during 1903 (mit Vergleichszahlen für 1900-1902). 
Maßregelungen verfügten. Der Gang zum magistrate blieb als allerletzte Option bei ganz und gar uneinsichtigen Arbeitgebern, in den meisten Fällen genügte jedoch die Androhung eines Gerichtsverfahrens, um diese zum Einlenken zu bewegen.

\section{ERFOLGSQUOTEN}

Aus den Justizstatistiken läßt sich über die Erfolge von Arbeitnehmern und Arbeitgebern vor den Friedensgerichten nichts ablesen. Es wurden lediglich pauschale Angaben zur Zahl der Verurteilungen unter den Master and Servant-Gesetzen gegeben. Hierbei zeigen sich im Untersuchungszeitraum zwar starke Schwankungen, aber kein dauerhaft nach oben oder unten weisender Trend. Die Kläger erreichten im Durchschnitt in etwa 60 Prozent aller Fälle ihr Ziel, das heißt eine Verurteilung oder eine gerichtliche Anordnung. Die tatsächliche Erfolgsquote muß jedoch höher veranschlagt werden, denn in vielen Fällen konnte auch ein ,Rückzieher ${ }^{6}$ den Sieg des Klägers bedeuten, nämlich dann, wenn der Beklagte noch vor Abschluß des Verfahrens nachgab oder wenn eine gütliche Einigung zugunsten des Klägers stattfand.

Für eine sozialgeschichtliche Interpretation der Zahlen müßte man wissen, ob und wie sich im Laufe der Zeit das Verhältnis von Arbeitnehmer- zu Arbeitgeberklagen änderte. Mangels offizieller Angaben ist man dafür auf Hochrechnungen, ausgehend von relativ kleinen Fall-Samples, angewiesen. Meine eigene Zählung, basierend auf den von mir gesammelten Zeitungsberichten aus einem breiten Spektrum von Presseorganen für ganz England ergibt für den Zeitraum zwischen 1858 und 1875 ein Verhältnis von 83 Prozent Arbeitgeberklagen zu 17 Prozent Arbeitnehmerklagen. ${ }^{104}$ Eine auf Zeitungsberichten basierende Studie zu der nordwestlich von Birmingham gelegenen Industriestadt Walsall kommt zu einem ähnlichen Resultat. Dort wurden in den Jahren zwischen 1858 und 1875 etwa 87 Prozent aller Klagen von Arbeitgebern und nur 13 Prozent von Arbeitnehmern angestrengt. 105 Mehr als einen ungefähren Anhaltspunkt bieten diese Zählungen nicht, denn es ist wahrscheinlich, daß die Journalisten den Arbeitnehmerklagen, eben weil sie seltener vorkamen, mehr Aufmerksamkeit schenkten. Auf der anderen Seite ist zu bedenken, daß sich die Zeitungen auch die sensationel-

\footnotetext{
104 In absoluten Zahlen: 48 Arbeitnehmerklagen zu 237 Arbeitgeberklagen. Die Erhebung stützt sich auf Fallberichte in Presseorganen für die Stichjahre 1858 und 1870. Bei Mehrfachund Massenklagen habe ich stets jeden einzelnen Fall gezählt.

105 Woods, Operation, S. 102.
} 
len Kollektivklagen der Arbeitgeber in der Regel nicht entgehen ließen, was das Ergebnis in der entgegengesetzten Richtung verzerren würde. Insgesamt treffen die angegebenen Zahlenverhältnisse somit wohl doch ungefähr die Realität. Sicher ist jedenfalls, daß Arbeitgeber bis 1875 weitaus häufiger klagten als Arbeitnehmer.

Was nun die Erfolgsfrage angeht, so fand die erwähnte Lokalstudie zu Walsall Arbeitnehmererfolge in mehr als der Hälfte aller von ihnen initiierten Fälle (57,7\%). ${ }^{106}$ Das deckt sich wiederum in etwa mit dem Ergebnis meiner eigenen Zählung für die Jahre bis 1875: Hier waren Arbeitnehmer in 52 Prozent der von ihnen vorgebrachten Klagen erfolgreich. Klagende Arbeitgeber hingegen waren meinem Presse-Sample zufolge wesentlich häufger erfolgreich, nämlich in 77 Prozent der von ihnen initiierten Fälle. ${ }^{107}$ Die Erfolgsquote der Arbeitgeber lag also höher als diejenige der Arbeitnehmer. Dennoch bestanden für diejenigen Arbeiter, die es erst einmal geschafft hatten, ein Verfahren eröffnen zu lassen, durchaus begründete Hoffnungen auf einen Erfolg. Die Ungleichheit vor Gericht äußerte sich also, abgesehen von der gesetzlich vorgesehenen Asymmetrie der Sanktionen, primär darin, daß so wenige Arbeiter überhaupt dahin gelangten, einen Prozeß führen zu können. Darüber hinaus waren klagende Arbeitnehmer noch aus einem weiteren Grund benachteiligt: Aus ihrer Sicht zählte ein Verfahren in aller Regel nur dann als Erfolg, wenn sie tatsächlich ein vollstreckbares Urteil zu ihren Gunsten erreichten. Die Arbeitgeber hingegen konnten es sich in vielen Fällen leisten, ein Verfahren vorher abzubrechen. Für sie war der Erfolg oft schon erreicht, wenn die Strafe vom Gericht nur angedroht wurde.

Wie entwickelte sich nun das Verhältnis zwischen Arbeitnehmer- und Arbeitgeberklagen nach der Reform von 1875? Die Forschung hat sich mit diesem Thema nicht beschäftigt. Für sie steht es offenbar fest, daß Arbeitgeber nach dem Wegfall der Strafklauseln mit dem Gesetz nichts mehr anzufangen wußten. Die Hypothese, daß Arbeitnehmer ihrerseits in größerem Umfang als zuvor freiwillig die Friedensrichter aufsuchten, scheint den britischen Historikern so abwegig zu sein, daß sie sie gar nicht erst überprüft haben. Dabei wäre dieser Gedanke naheliegend, denn die Eliminierung des Strafrechts aus den individuellen Arbeitsbeziehungen hätte das Arbeitsrecht auch in England längerfristig zu dem machen können, was es in anderen

106 Woods, Operation, S. 109. Die Arbeitnehmer waren hier erfolgreich in 52 von 90 Fällen.

107 In absoluten Zahlen: Arbeitgebererfolge in 183 von 237 Fällen. Als ,Erfolg' habe ich nicht nur Verurteilungen bzw. Zahlungsbefehle (auch Teilzahlungen), sondern auch die ,freiwillige' Rückkehr angeklagter Arbeiter an den Arbeitsplatz und gütliche Einigungen mit Vorteilen für den Kläger gewertet. Die Zeitungsberichte sind in aller Regel genau genug, um ziemlich sicher sagen zu können, wer, gewonnen' hat. 
Nationen schon um die Mitte des 19. Jahrhunderts war und heute überall ist: zu einem Instrument nämlich, das primär von Arbeitnehmern genutzt wird. Im Vergleich zu den industrialisierten Teilen Deutschlands war jedenfalls das Verhältnis von mehr als 80 Prozent Arbeitgeberklagen zu weniger als 20 Prozent Arbeitnehmerklagen, wie es in englischen Friedensgerichten vor 1875 bestand, extrem ungewöhnlich. Wie die Studie von Peter Schöttler zu den rheinischen Fabrikengerichten belegt, wurden dort schon in den vierziger Jahren des 19. Jahrhunderts mehr als zwei Drittel aller Klagen von Arbeitnehmern vorgebracht, und die Gewerbegerichte des wilhelminischen Kaiserreichs waren, wie zu zeigen sein wird, in noch stärkerem Maße beinahe ausschließlich auf die Bedürfnisse der Arbeitnehmer zugeschnitten. ${ }^{108}$

Mit den erhaltenen Protokollbüchern unter dem Employers and Workmen Act und den Registern der summarischen Rechtsprechung verfügen wir für einige englische Gerichtsbezirke über Quellen, die einen genaueren Einblick in die Klagetätigkeit und die Prozeßresultate erlauben. Legt man diese Überlieferung zugrunde, hat es bei der Zahl der Klagen nach 1875 eine leichte Verschiebung zugunsten der Arbeitnehmer gegeben (Tabelle 2.1). Das Verhältnis von Arbeitgeber- zu Arbeitnehmerklagen lag in allen untersuchten Gerichtsbezirken zusammen bei 70 zu 30 Prozent. ${ }^{109}$ Die Erfolgsquote der Arbeitnehmer blieb mit 48 Prozent in etwa konstant, diejenige der Arbeitgeber hingegen sank deutlich ab und lag nun bei 56 Prozent. ${ }^{110}$ Alles in allem also keine dramatischen Veränderungen, aber eine vorsichtige Abschwächung der extremen Unausgewogenheit, die unter dem unreformierten Master and Servant Act geherrscht hatte. Dieses Ergebnis ist freilich nur unter Vorbehalt als repräsentativ anzusehen, denn es wird stark bestimmt durch ein einziges Protokollbuch, dasjenige von Newcastle-onTyne, dem mehr als die Hälfte der Fälle aus den Gerichtsbezirken entstammen. ${ }^{111}$ Newcastle wiederum war einer der Orte, an denen einzelne Unternehmer von Zeit zu Zeit auf das Mittel der Massenanklage zurückgriffen. ${ }^{112}$

108 Schöttler, Die rheinischen Fabrikengerichte, S. 170 u. 179 (71\% Arbeitnehmerklagen in Elberfeld 1844/45). $\mathrm{Zu}$ den Gewerbegerichten siehe unten Kap. II.5.

109 In absoluten Zahlen: 1093 zu 464.

110 Ein Unsicherheitsfaktor ist hier dadurch gegeben, daß die Prozeßresultate nicht in allen Büchern konsequent notiert wurden. Ich habe in diesen Fällen den Ausgang grundsätzlich als ,unbekannt ' gewertet, auch wenn davon auszugehen ist, daß in vielen dieser Fälle die Kläger erfolgreich waren. Insbesondere in St. Helens scheint man anfangs die Prozeßergebnisse nur dann notiert zu haben, wenn sie vom Üblichen, d.h. vom Erfolg des Klägers, abwichen.

111 In absoluten Zahlen: 843 von insgesamt 1557 Fällen.

112 Mehr als die Hälfte aller im Protokollbuch für Newcastle verzeichneten Fälle gingen auf nur vier Massenklagen zurück: 14. Okt. 1889, Elswick Coal Co. gegen 86 Kohlenhauer, alle verurteilt; 25. Febr. 1897, North Eastern Railway Co. gegen 69 Eisenbahnarbeiter, alle zurück- 
Tabelle 2.1: Friedensgerichte England und Wales 1875-1929: Klagen unter dem Employers and Workmen Act. Verbältnis der Streitparteien und Ausgang der Prozesse in ausgewäblten Gerichtsbezirken

\begin{tabular}{|c|c|c|c|c|c|c|c|}
\hline \multirow{2}{*}{$\frac{\text { Kläger }}{\mathrm{AN}}$} & \multicolumn{2}{|c|}{$\begin{array}{l}\text { Prozeßausgang } \\
\text { Erfolg }\end{array}$} & \multicolumn{2}{|c|}{ Mißerfolg } & \multicolumn{2}{|c|}{ Unbekannt } & \multirow{2}{*}{$\begin{array}{c}\text { Summe } \\
464 \\
30 \%\end{array}$} \\
\hline & 225 & $48 \%$ & 166 & $36 \%$ & 73 & $16 \%$ & \\
\hline$A G$ & 613 & $56 \%$ & 348 & $32 \%$ & 132 & $12 \%$ & $\begin{array}{l}30 \% \\
1093 \\
70 \% \\
\end{array}$ \\
\hline Summe & 838 & & 514 & & 205 & & $\begin{array}{l}1557 \\
100 \%\end{array}$ \\
\hline
\end{tabular}

Quellen: Plaint and Minute Books (Employers and Workmen Act): Tyne and Wear Archives Service, MG/Nc/4 (Newcastle, 1889-1908); Lancashire Record Office, PSSH 3/1; PSBl 4/1 (St. Helens, 1891-1901; Blackburn County, 1876-1915); Cheshire Record Office, QPEd 7; QPH 3 (Eddisbury, 1875-1918; Hyde, 1876-1884); Northamptonshire Record Office, unverz., shelf 58a (Kettering and Little Bowdes, 1877-1887); Berkshire Record Office, PS/RC/9/1; PS/M/9/1 (Reading County, 1876-1898; Maidenhead, 1890-1938); Centre for Kentish Studies, PS/Gr/ $\mathrm{Sz} / 1 ; \mathrm{PS} / \mathrm{Md} / \mathrm{Sv} ; \mathrm{PS} / \mathrm{Shz} / 4$ (Gravesend, 1875-1881; Maidstone, 1898-1905; Sheerness, 1880-1902). Summary Jurisdiction Register: Birmingham Central Reference Library, Archives Division, Acc. Ms. 629, 91/14, PS/SU 2/1, 2/7, 2/8, 2/9, 3/2, 3/3 (Sutton Coldfield, 1877-80, 1904-08, 1910-16); Northamptonshire Record Office, unverz. (Brackley, 1880-1911)

Freilich gehörten derartige Massenklagen in vielen industriellen Gerichtsbezirken zum Alltag, so daß ihre gänzliche Eliminierung aus dem Sample ebenfalls in die Irre führen würde.

Eine Kontrolle erlauben in dieser Hinsicht die von mir gesammelten Zeitungsberichte. ${ }^{113}$ Hier zeigt sich bei dem Verhältnis der Arbeitgeber- zu den Arbeitnehmerklagen ebenfalls nur eine ganz leichte Verschiebung gegenüber der Phase vor der Reform: 80 Prozent der Klagen stammten von Arbeitgebern, 20 Prozent von Arbeitnehmern (Tabelle 2.2). Auch hier sind die Berichte über Massenklagen für dieses Ergebnis mitverantwortlich. Bei den Erfolgen ist das aus den Zeitungen zu ziehende Bild für die Arbeitnehmer erfreulicher: Ihre Erfolgsquote stieg auf 66 Prozent, während sich für die Arbeitgeber mit einer Quote von 79 Prozent praktisch nichts änderte.

gezogen; 31. Mai 1902, Elswick Coal Co. gegen 100 Bergleute, alle zurückgezogen; 4./7. Okt. 1907, Walker Coal Co. gegen 201 Bergleute, alle zurückgezogen unter Zahlung von 8s. pro Mann.

113 Die Erhebung stützt sich auf ein breites Spektrum von Presseorganen, konzentriert um die Stichjahre 1882, 1896, 1912, 1917 und 1923. Bei Mehrfach- und Massenklagen habe ich - der in den Protokollbüchern feststellbaren Praxis folgend - stets jeden einzelnen Fall gezählt. 
Tabelle 2.2: Friedensgerichte England und Wales 1875-1923: Klagen unter dem Employers and Workmen Act. Verbältnis der Streitparteien und Ausgang der Prozesse nach Presseberichten

\begin{tabular}{lccccccc}
\hline & \multicolumn{2}{l}{ Prozeßausgang } & & & & \\
Kläger & Erfolg & & \multicolumn{2}{l}{ Mißerfolg } & \multicolumn{2}{c}{ Unbekannt } & Summe \\
\hline AN & 449 & $66 \%$ & 225 & $33 \%$ & 3 & $1 \%$ & 677 \\
& & & & & & & $20 \%$ \\
AG & 2081 & $79 \%$ & 142 & $5 \%$ & 432 & $16 \%$ & 2655 \\
& & & & & & & $80 \%$ \\
\hline Summe & 2530 & & 367 & & 435 & & 3332 \\
& & & & & & & $100 \%$ \\
\hline
\end{tabular}

Quelle: Sample aus Presseberichten, 1875-1923

Trotz aller quellenkritischen Vorbehalte zeigen die Zahlen eine bemerkenswerte Kontinuität über die Reform von 1875 hinweg. Die Entkriminalisierung des Arbeitsvertragsrechts hatte nicht zur Folge, daß aus den englischen Friedensgerichten nun Instanzen wurden, deren Praxis sich etwa derjenigen der deutschen Gewerbegerichte annäherte. Arbeitnehmer stellten weiterhin die Minderheit der Kläger. Insgesamt blieb die Rechtsprechung zum englischen Arbeitsvertragsrecht, so weit sie in die Kompetenz der Friedensrichter fiel, arbeitgeberfreundlicher als in vergleichbaren europäischen Industrieländern.

Eine genauere Analyse einzelner Protokollbücher zeigt jedoch, daß die Nutzung des Employers and Workmen Act in den Gerichtsbezirken höchst unterschiedlichen Mustern folgte. Die nationalen Statistiken und Hochrechnungen spiegeln nicht unbedingt die Rechtswirklichkeit vor Ort. In St. Helens Borough (Lancashire) zum Beispiel stammte das Gros der Klagen von den lokalen Glasfabrikanten, die an das Friedensgericht appellierten, um ihre Lehrlinge zu disziplinieren. Hier wurden recht häufig sogar vierzehntägige Gefängnisstrafen verhängt, was bei Lehrlingen unter dem Employers and Workmen Act zulässig war. Insgesamt gab es in St. Helens im Zeitraum von 1891 bis 1901 nur siebzehn Arbeitnehmerklagen, aber 138 Arbeitgeberklagen. In der ebenfalls in Lancashire gelegenen, von Textilindustrie, Kohleabbau und Landwirtschaft geprägten Blackburn County Division war das Verhältnis hingegen nahezu ausgeglichen: 31 Arbeitnehmerklagen standen hier 32 Arbeitgeberklagen gegenüber. Außerdem läßt sich aus dem Protokollbuch für Blackburn County eine deutliche Entwicklung ablesen. Während in den frühen Jahren der Buchführung - von 1876 bis in die frühen achtziger Jahre des 19. Jahrhunderts - praktisch nur Arbeitgeber 
klagten, waren es in den späteren Jahren zunehmend nur noch Arbeitnehmer, und zwar hauptsächlich Landarbeiter, die das Friedensgericht anriefen. Nach der Jahrhundertwende hatten sie dabei meistens Erfolg, vorher hingegen scheiterten sie sehr oft. In manchen Gerichtsbezirken schließlich überwogen eindeutig die Arbeitnehmerklagen, so zum Beispiel in Sutton Coldfield, einem nördlichen Vorort von Birmingham mit kleinen Werkstätten, Maschinenbau- und Metallverarbeitungsbetrieben, in der an der Themsemündung gelegenen Hafenstadt Sheerness und in der von Handwerk, Verkehr und Geschäften geprägten Kleinstadt Maidstone in Kent.

Wenn die überlieferten Protokollbücher überhaupt verallgemeinernde Schlußfolgerungen zulassen, so waren in Orten mit einer gemischten Wirtschaftsstruktur und handwerklich-kleinbetrieblicher Produktionsweise eher die Arbeitnehmer begünstigt, während überall dort, wo größere Firmen oder ein einziger Industriezweig den Ort dominierten, die betreffenden Arbeitgeber in den Friedensgerichten tonangebend blieben. Letzteres gilt übrigens auch für landwirtschaftliche Bezirke wie etwa die Reading County Division in Berkshire, Eddisbury in Cheshire oder Brackley in Northamptonshire. Vor allem in den ersten Jahren nach Inkraftrreten des Employers and Workmen Act appellierten die Farmer dort wie eh und je besonders in den Ernteperioden an die magistrates, um die zu dieser Jahreszeit begehrten Arbeitskräfte durch die Drohung mit Schadensersatzforderungen und Lohnverlust bei der Stange zu halten. Gerade auf dem Lande scheint indessen seit Mitte der achtziger Jahre des 19. Jahrhunderts ein Attraktivitätsverlust der Friedensgerichte für Farmer eingetreten zu sein: Sie klagten nicht nur seltener, sondern gewannen auch nicht mehr ganz so regelmäßig. Der Rückzug der Farmer löste aber keinen verstärkten Zulauf von Seiten der Landarbeiter aus. Deren Vertrauen in die magistrates war offenbar nicht so gewachsen, daß sie nun vermehrt dort ihr Recht suchten.

Alle quantitativen Befunde weisen somit in die gleiche Richtung. Die veränderte Rechtslage nach 1875 und die etwas ausgewogenere Verteilung der Erfolgsaussichten genügten nicht, um die Arbeitnehmer in wesentlich größerem Umfang als zuvor zu den Friedensgerichten zu locken. Wenn nach 1875 relativ etwas mehr Arbeitnehmer klagten als vorher, so war dies eher auf Zurückhaltung der Arbeitgeber als auf ein neu erwachtes Interesse der Arbeiter an der gerichtlichen Auseinandersetzung zurückzuführen. Obwohl die unausgewogene Spruchpraxis in den Friedensgerichten im späten 19. Jahrhundert etwas nachließ, kam es zu keiner signifikanten Trendwende beim Klageverhalten der Arbeitnehmer. Die Herstellung verfahrensrechtlicher Gleichheit durch den Employers and Workmen Act machte aus dem Recht $z$ war eine neutralere Instanz, aber das war nicht aus- 
reichend, damit die Arbeitnehmer den Rechtsweg in großem Umfang für sich entdeckten.

\section{GRAFSCHAFTSGERICHTE}

\section{EINRICHTUNG UND ZUSTÄNDIGKEIT}

Wenn sich der Erfolg einer Reform an der Langlebigkeit der durch sie geschaffenen Institutionen bemißt, war die Einrichtung der Grafschaftsgerichte im Jahr 1846-47 eine außerordentlich erfolgreiche Maßnahme. ${ }^{114}$ Die county courts bestehen bis heute, und sie bewältigen immer noch, wie schon im viktorianischen Zeitalter, die Masse aller zivilrechtlichen Streitigkeiten in England. Schon in den ersten Jahren nach ihrer Einrichtung wurden dort pro Jahr mehrere hundertausend Klagen bearbeitet, im späten 19. und frühen 20. Jahrhundert waren es mehr als eine Million, und in den achtziger Jahren des 20. Jahrhunderts über 2,5 Millionen Klagen pro Jahr. ${ }^{115}$ Parallel zur Anzahl der Fälle wuchs die Höhe des zulässigen Streitwerts. Lag dieser anfangs bei $£ 20$, wurde er schon nach kurzer Zeit, im Jahr 1850, auf $£ 50$ heraufgesetzt und später, im Jahr 1903, noch einmal auf $£ 100$ erhöht. 116 Diese Grenzwerte galten für alle normalen vertrags- und deliktsrechtlichen Streitigkeiten. Darüber hinaus wurden den Grafschaftsgerichten im Laufe der Zeit eine Reihe von besonderen Kompetenzen übertragen, bei denen die Streitwerte zum Teil höher lagen, so unter anderem die Rechtsprechung unter dem Employers' Liability Act (1880) und unter den Workmen's Compensation Acts (1897/1906). Schon deshalb müssen die Grafschaftsgerichte hier betrachtet werden. Nicht weniger wichtig, wenngleich von der Forschung bisher unbeachtet, war die Zuständigkeit dieser Gerichte für vertragliche

114 Die Rechtsgrundlage war der County Courts Act 9 \& 10 Vict., c. 95 (1846); die Umsetzung der Reform erfolgte im Laufe des Frühjahrs 1847. Im März/April 1847 wurden überall im Land die ersten Gerichtstage abgehalten.

115 Für die Zahlen bis zum Beginn der zwanziger Jahre des 20. Jahrhunderts siehe Tabelle 3.1, S. 211. Zahlen für 1964 in Brian Abel-Smith u. Robert Stevens, Lawyers and the Courts. A Sociological Study of the English Legal System 1750-1965, London 1967, S. 275; Zahlen für 1986 in Jackson's Machinery of Justice, S. 32.

116 County Courts Act, 9 \& 10 Vict., c. 95 (1846), s. 58; County Courts Extension Act, 13 \& 14 Vict., c. 61 (1850), s. 1; County Courts (Amendment) Act, 3 Edw. 7, c. 42 (1903), s. 3. In einem weiteren Schritt wurde die Grenze 1938 auf $£ 200$ heraufgesetzt, allerdings konnte der Beklagte in diesem Fall Einspruch erheben und die Verlagerung des Falls an den Obersten Gerichtshof verlangen; Administration of Justice (Miscellaneous Provisions) Act, $1 \& 2 \mathrm{Geo} .6$, c. 63 (1938), s. 16. 
Tabelle 3.1: Grafschaftsgerichte 1848-1923: Gesamtzabl der Klagen

\begin{tabular}{|c|c|c|c|}
\hline $1848-51$ & $415295^{a}$ & 1890 & 1020356 \\
\hline $1852-56$ & $521007^{a}$ & 1891 & 1063400 \\
\hline 1858 & 738854 & 1892 & 1101075 \\
\hline 1859 & 714562 & 1893 & 1104091 \\
\hline 1860 & 782326 & 1894 & 1167886 \\
\hline 1861 & 903875 & 1895 & 1120726 \\
\hline 1862 & 847783 & 1896 & 1109234 \\
\hline 1863 & 799166 & 1897 & 1119420 \\
\hline 1864 & 738346 & 1898 & 1156642 \\
\hline 1865 & 782686 & 1899 & 1152163 \\
\hline 1866 & 872446 & 1900 & 1180908 \\
\hline 1867 & 941888 & 1901 & 1228710 \\
\hline 1868 & 990306 & 1902 & 1281370 \\
\hline 1869 & 946643 & 1903 & 1324643 \\
\hline 1870 & 924876 & 1904 & 1381463 \\
\hline 1871 & 932221 & 1905 & 1342745 \\
\hline 1872 & 901329 & 1906 & 1323763 \\
\hline 1873 & 865906 & 1907 & 1315141 \\
\hline 1874 & 879400 & 1908 & 1348010 \\
\hline 1875 & 894832 & 1909 & 1368110 \\
\hline 1876 & 965726 & 1910 & 1330315 \\
\hline 1877 & 1044458 & 1911 & 1276510 \\
\hline 1878 & 1052204 & 1912 & 1230805 \\
\hline 1879 & 1067126 & 1913 & 1255542 \\
\hline 1880 & 1119178 & 1914 & 1073417 \\
\hline 1881 & 1060027 & 1915 & 1060814 \\
\hline 1882 & 1046161 & 1916 & 798017 \\
\hline 1883 & 1023234 & 1917 & 609526 \\
\hline 1884 & 979141 & 1918 & 438182 \\
\hline 1885 & 983942 & 1919 & 444155 \\
\hline 1886 & 1004253 & 1920 & 557986 \\
\hline 1887 & 1037454 & 1921 & 672758 \\
\hline 1888 & 1070350 & 1922 & 851084 \\
\hline 1889 & 1062761 & 1923 & 952163 \\
\hline
\end{tabular}

a Durchschnittswert

Quellen: Civil Judicial Statistics (für die Jahre 1848-56: PP 1898 [C. 8838] CIV, Introduction, S. 90; für die Jahre 1913-1923: PP [Cmd. 2277] 1924-25, XXVIII, Comparative Table, S. 4 f. "Proceedings commenced“) 
und deliktsrechtliche Streitigkeiten zwischen Arbeitnehmern und Arbeitgebern bis zur Höhe der angegebenen Streitwerte.

In der englischen Justizgeschichte des 19. Jahrhunderts war die Einrichtung der county courts insofern ungewöhnlich, als mit ihnen eine bedeutende Institution völlig neu geschaffen wurde. Noch dazu geschah dies nicht wie so oft bei anderen Reformen etappenweise, sondern auf einen Schlag und flächendeckend für ganz England und Wales. Diese Neuordnung der niederen Zivilgerichtsbarkeit stellte den wohl größten Erfolg der englischen Rechtsreformbewegung des frühen 19. Jahrhunderts dar. Insbesondere der Name des ehemaligen Lordkanzlers Henry Brougham ist mit der Reform verbunden. ${ }^{117}$ Ein einheitliches System löste damit im Jahr 1847 den unübersichtlichen Wirrwarr, oder positiver ausgedrückt: den Pluralismus, der lokalen Zivilgerichte ab. In vielen Städten und boroughs hatten vor 1847 sogenannte courts of requests für die Eintreibung kleiner Schuldforderungen mehr schlecht als recht funktioniert. Diese Gerichte wurden durch die Reform von 1846-47 entweder in county courts umgewandelt oder im Moment der Etablierung eines county court im jeweiligen Bezirk beseitigt. Es bestehen keine Anzeichen dafür, daß das Publikum diesen lokalen Gerichten nachtrauerte. ${ }^{118} \mathrm{Nur}$ in wenigen Städten überlebten traditionsreiche Stadtgerichte neben den neuen Grafschaftsgerichten, so in Bristol, Liverpool, Norwich und Salford. ${ }^{119}$ Von der Reform ausgenommen blieb allein die City of London, wo der Sheriff's Court, der Mayor's Court und die nahegelegenen Gerichtshöfe in Westminster zunächst konkurrenzlos blieben. Aber auch in der City machte sich die uniformisierende Wirkung der neuen Institution schon nach zwei Jahrzehnten in der Weise bemerkbar, daß der alte Sheriff's Court reformiert und unter dem neuen Namen City of London

$117 \mathrm{Zu}$ den Reformbestrebungen für die untere Zivilgerichtsbarkeit zwischen 1820 und 1846: Arthur Lyon Cross, Old English Local Courts and the Movement for their Reform, in: Michigan Law Review 30 (1931-32), S. 369-385. Allgemein zu den Refomversuchen dieser Jahre, zu denen vor allem die gescheiterten Bemühungen um eine Kodifikation gehören: Lobban, Common Law, bes. S. 185-222.

118 In neueren historischen Arbeiten besteht die Tendenz, die alten courts of requests aufzuwerten und zu betonen, daß sie wegen ihres, informellen' Charakters den Bedürfnissen der Rechtssuchenden entgegengekommen seien. Vgl. insbesondere H. W. Arthurs, Without the Law': Courts of Local and Special Jurisdiction in Nineteenth-Century England, in: Journal of Legal History 5 (1984), S. 130-149; Margot Finn, Debt and Credit in Bath's court of requests, 1829-39, in: Urban History 21 (1994), S. 211-236. Ferner: David A. Kent, Small Businessmen and their Credit Transactions in Early Nineteenth-Century Britain, in: Business History 36 (1994), S. 47-64.

119 Der Tolzey Court of Bristol, der Liverpool Court of Passage, der Norwich Guildhall Court und der Salford Hundred Court blieben bis 1971 aktiv. Vgl. Cornish u. Clarke, Law and Society, S. 30 . 
Court in der Praxis den Grafschaftsgerichten fast vollständig angeglichen wurde. 120

Infolge des County Courts Act von 1846 wurde das ganze Land mit Ausnahme der City in 59 Distrikte eingeteilt. Jedem dieser Distrikte wurde ein Richter vorgestellt. In seinem Distrikt reiste der Grafschaftsrichter in einer regelmäßigen Tournee von Gerichtsort zu Gerichtsort und erledigte die dort aufgelaufenen Fälle. Auf diese Weise wurde an insgesamt etwa 500 Orten in England und Wales wenigstens einmal im Monat Recht gesprochen. Damit drang das zivile Common lawe erstmals in die Tiefen der Provinz vor. Der Richter wurde vom Lordkanzler ernannt, mußte ein barrister mit mindestens sieben Jahren Berufspraxis sein und erhielt ein Jahresgehalt von $£$ 1500.121 Die meisten Fälle entschied er allein, ohne Geschworene. Das Gesetz gab den Prozeßparteien zwar das Recht, eine jury bestehend aus fünf Geschworenen zu beantragen, doch machten nur wenige Streitende von dieser Möglichkeit Gebrauch. Die Zahl der Grafschaftsgerichts-Verfahren mit jury blieb im Untersuchungszeitraum stets unter einem Prozent. ${ }^{122} \mathrm{Un}$ terstützt wurden die Grafschaftsrichter durch einen clerk, der im Jahr 1856 den Titel registrar erhielt. Der registrar mußte ein solicitor sein und war für die gesamte Aktenführung und den Schriftverkehr des Gerichts zuständig. Je nach Größe des Gerichts unterstanden ihm ein oder mehrere Untersekretäre. Im späteren 19. Jahrhundert wurden dem registrar zunehmend auch rechtsprechende Funktionen in Routineangelegenheiten übertragen. ${ }^{123}$

Die in den county courts anzuwendenden Rechtsgrundsätze entsprachen im Prinzip denen des Common law. Tatsächlich ging es jedoch, schon wegen der Menge der anfallenden Streitsachen, weit weniger formalistisch als in den höheren Gerichtshöfen zu. Das Gesetz von 1846 schrieb ein summarisches Anhörungsverfahren ohne das in den Common law-Gerichten übliche formelle pleading vor. Auch in späteren County Courts Acts blieb es bei

12030 \& 31 Vict., c. 142 (1867), ss. 32 u. 35. Im Jahr 1921 wurde dann auch der Mayor's Court mit dem City of London Court amalgamiert, so daß die City fortan nur noch dem Namen nach eine von den normalen Grafschaftsgerichten unterschiedene Zivilgerichtsbarkeit hatte.

121 In den ersten vier Jahren erfolgte die Bezahlung noch aus den Gerichtsgebühren, die demzufolge recht hoch angesetzt waren. Im Jahr 1850 wurde dann die staatliche Bezahlung eingeführt, nachdem sie das Gesetz von 1846 schon als Möglichkeit vorgesehen hatte. Vgl. Cornish u. Clarke, Law and Society, S. 38.

122 Civil Judicial Statistics, Comparative Tables CC. Zum Niedergang des Jury-Verfahrens allgemein: R.M. Jackson, The Incidence of Jury Trial during the Past Century, in: Modern Law Review 1 (1937), S. 132-144, hier bes. $143 \mathrm{f}$.

123 Vgl. P.W.J. Bartrip, County Court and Superior Court Registrars, 1820-1875: The Making of a Judicial Office, in: G.R. Rubin u. David Sugarman (Hg.), Law, Economy and Society, 1750-1914: Essays in the History of English Law, Abingdon 1984, S. 349-379; ferner: Gerland, Englische Gerichtsverfassung, S. 178-181. 
dieser vagen Formulierung, die dem einzelnen Richter einen weiten Gestaltungsspielraum ließ.124 Besonders in den frühen Jahren befanden sich unter den Grafschaftsrichtern etliche zum Teil sehr eigenwillige Persönlichkeiten, die einen idiosynkratischen Verhandlungs- und Urteilsstil an den Tag legten und sich dabei von niemandem hereinreden ließen. Viele von ihnen waren als ehemalige Vorsitzende der älteren courts of requests in den neuen Dienst als Grafschaftsrichter übernommen worden und setzten dort ihre gewohnte Praxis fort. Erst als in den siebziger Jahren des 19. Jahrhunderts die erste Generation der Grafschaftsrichter abzutreten begann, gewannen die Aufsichtsbemühungen und die Personalpolitik des Lord Chancellor's Office an Durchschlagskraft. ${ }^{125} \mathrm{Je}$ ausgedehnter im späten 19. Jahrhundert die Kompetenzen wurden, je mehr Fälle mit hohem Streitwert vor die Grafschaftsgerichte gelangten, je mehr Anwälte, Versicherungsagenten und medizinische Experten sich einschalteten, desto stärker drangen nun auch die Normen des Common law in den Alltag der Gerichtspraxis ein. Vor allem die Fälle unter dem Employers' Liability Act und den Workmen's Compensation Acts trugen zur Juridifizierung im Sinne des Common law bei, denn diese Gesetze produzierten eine Flut höchstrichterlicher Entscheidungen, die von den Grafschaftsrichtern in der Folge nolens volens beachtet werden mußten. Hatten sich somit die frühen Grafschaftsrichter, ähnlich wie die Friedensrichter, sehr oft an ihren eigenen Normvorstellungen und an denen der lokalen Öffentlichkeit orientiert, paßten sie sich im späten 19. und frühen 20. Jahrhundert zunehmend den streng juristischen Maßstäben des Common law an. Das galt vor allem für die komplizierteren Fälle, zu denen auch die Streitigkeiten um Arbeitsunfälle und Kündigungen gehörten.

Bei den Hunderttausenden von Schuldsachen mit geringem Streitwert, darunter auch einfachen Lohnklagen, konnten die Grafschaftsrichter aber auch in späteren Jahren noch relativ unbehelligt von Präzedenzfällen und

$1249 \& 10$ Vict., c. 95 (1846), ss. 58 u. $74 ; 51 \& 52$ Vict., c. 43 (1888), s. 79.

125 Ein farbiges, amüsant zu lesendes Porträt der frühen Grafschaftsrichter zeichnet Patrick Polden, Judicial Selkirks: The County Court Judges and the Press, 1847-80, in: Christopher Brooks u. Michael Lobban (Hg.), Communities and Courts in Britain 1150-1900, London u. Rio Grande 1997, S. 245-262. Zur Überwachung durch das Amt des Lordkanzlers vgl. ders., Judicial Independence and Executive Responsibilities. The Lord Chancellor's Department and the County Court Judges, 1846-1971, in: Anglo-American Law Review 25 (1996), S. 1-38 u. 133-162; ders., Oiling the Machinery: The Lord Chancellor's Office and the County Court Bench, 1927-44, in: Journal of Legal History 19 (1998), S. 224-244. Vgl vom gleichen Autor jetzt auch die Monographie zu allen Aspekten der institutionellen Geschichte der county courts: ders., A History of the County Court, 1846-1971, Cambridge 1999. Diese Arbeit stand mir erst nach Fertigstellung des Manuskripts zur Verfügung und konnte nicht mehr eingearbeitet werden. 
umständlichen rechtlichen Erörterungen entscheiden. Denn die Revisionsund Berufungsmöglichkeiten von den county courts waren, ähnlich wie bei den Friedensrichtern, stark beschränkt. Das Gesetz von 1846 kannte nur den Weg der Verlagerung des Verfahrens an ein Common law-Gericht mittels writ. Bei einem Streitwert von unter fünf Pfund schloß das Gesetz diese Möglichkeit ganz aus, und in den anderen Fällen mußte die betreffende Prozeßpartei von einem Common law-Richter erst eine Erlaubnis einholen und Sicherheit für die Kosten beibringen, bevor ein entsprechender writ ergehen durfte. ${ }^{126}$ Ein Recht auf Berufung in Fragen der Rechtsauslegung wurde 1850 eingeräumt, jedoch galt dies erst für Fälle mit einem Streitwert von über £ 20.127 Bei dieser Grenze blieb es auch nach dem Konsolidierungsgesetz von 1888. Die Hemmschwelle wurde dadurch erhöht, daß diejenige Prozeßpartei, die Berufung einzulegen wünschte oder ahnte, daß eine Berufung nötig werden könnte, den Richter auffordern mußte, alle in der Verhandlung erwähnten juristischen Punkte und die dazugehörigen Tatsachenbeweise schriftlich festzuhalten, eine Pflicht, der sich die Richter wegen ihres angespannten Zeitbudgets nur höchst ungern unterzogen. ${ }^{128}$ Die Reinschrift und weitere Abschriften dieser Notizen mußten überdies von den Prozeßparteien bezahlt werden. ${ }^{129}$ Individualkläger ohne finanziellen Rückhalt besaßen unter diesen Umständen kaum Chancen, ihren Fall von einem höheren Gericht noch einmal aufrollen zu lassen. Es kam hinzu, daß höhere Gerichte grundsätzlich nur das Verfahren und die juristische Argumentation der Untergerichte überprüften; in sogenannten Tatsachenfragen wurde hingegen das, was die Grafschaftsrichter als ,Fakt' gefunden hatten, nicht in Frage gestellt. ${ }^{130}$ Weil aber bei Arbeitsstreitigkeiten fast immer alles

$1269 \& 10$ Vict., c. $95(1846)$, s. 90 .

$12713 \& 14$ Vict., c. $61(1850)$, ss. 14-16.

128 Vgl. den Artikel „Appeals From County Courts“, in: County Courts Chronicle, 1. Juni 1896, S. 481 f.: "Judges there have been known to dislike, possibly even to resent, the time and labour that is involved in recording what passes. Advocates naturally hesitate before even so much as hinting at the possibility of an appeal." Wenn schon die Anwälte sich scheuten, den Richter um Notizen zu bitten, um wieviel schwieriger mußte es für Kläger oder Beklagte ohne Rechtsbeistand sein, dasselbe zu tun?

$12951 \& 52$ Vict., c. 43 (1888), ss. 120 u. 121.

130 Die Formulierung des County Courts Act von 1888 (s. 122) scheint eine ,Uminterpretation“ der vom Grafschaftsrichter gefundenen Fakten zuzulassen: „On the hearing of an appeal the High Court shall have power to draw any inference of fact, and may either order a new trial on such terms as the court shall think just, or may order judgment to be entered for any party, as the case may be, or may make a final or other order on such terms as the High Court may think proper to ensure the determination on the merits of the real questions in controversy between the parties." Vgl. aber die Kritik an der Faktenblindheit der Berufungsinstanzen bei: Barrister, Justice in England, S. $107 \mathrm{f}$. 
von den sogenannten Tatsachen abhing (zum Beispiel: was ist die ,ortsübliche Gewohnheit' in diesem oder jenem Gewerbe?), war der appeal für einen mit dem Urteil unzufriedenen Arbeitnehmer oder Arbeitgeber in vielen Fällen nutzlos.

Ein hohes Maß an Autonomie kennzeichnete somit die Spruchpraxis der Grafschaftsrichter, und bei ihnen entfiel sogar noch die soziale Kontrolle durch ein Kollegium, die bei den Friedensrichtern zumindest gegeben war. Gleichwohl vermittelte die Ziviljustiz in den county courts von Anfang an ein viel einheitlicheres Erscheinungsbild als die Strafjustiz der magistrates. Das lag natürlich zum einen an der ewigen Wiederkehr gleichartiger Fälle, im wesentlichen: unbeglichene Rechnungen und Schulden bei Textilhändlern, Kohlelieferanten, Bäckern, Metzgern, Klempnern, Geldverleihern, Ärzten, städtischen Gasanstalten usw. Das einheitliche Erscheinungsbild rührte aber zum anderen auch daher, daß die Grafschaftsrichter als barristers die gleiche Ausbildung genossen hatten, daß sie zusammen in der Welt der Londoner Inns of Court und der circuit messes in den assize-Städten sozialisiert worden waren und daß sie sich einem gemeinsamen Berufsethos verpflichtet fühlten, in dem Werte wie Prinzipientreue, strikte Regelanwendung und Neutralität gegen jedermann hoch im Kurs standen. ${ }^{131}$ Damit soll keineswegs gesagt sein, daß nicht auch die Justiz der Grafschaftsrichter im Einzelfall als inkonsistent und ungerecht empfunden wurde, doch als Gruppe standen die Grafschaftsrichter viel weniger im Kreuzfeuer der Kritik als die Laienfriedensrichter. Selbst Autoren, die sonst am englischen Rechtssystem kaum ein gutes Haar ließen und mit dem Vorwurf der Klassenjustiz nicht sparten, gaben den Grafschaftsrichtern persönlich gute Noten: „Im ganzen“, so das Urteil eines der Kritiker, „machen sie ihre Sache gut ${ }^{\prime \prime} .132$

Auch bei den Gewerkschaften waren einzelne Grafschaftsrichter hoch angesehen, so zum Beispiel Sir Rupert Kettle, Richter in Wolverhampton und Dudley, der schon auf einem der frühesten Trades Union Congresses anwesend war und dort unter allgemeiner Zustimmung über seine Erfahrungen bei der Schlichtung von Arbeitsstreitigkeiten berichtete. ${ }^{133}$ Oder

$131 \mathrm{Zu}$ Herkunft, Ausbildung, Arbeitsalltag und Wertvorstellungen der viktorianischen barristers: Raymond Cocks, Foundations of the Modern Bar, London 1983.

132 Barrister, Justice in England, S. 110: „On the whole, the County Court judges do the work well ...".

133 Sir Rupert Kettle (1817-1894). Siehe: Report of Proceedings at the Third Annual Trades Union Congress, London 1871, unpag., Diskussion am 9. März 1871 (Microfilm edition). Vgl. auch Rupert Kettle, On Boards of Conciliation and Arbitration between Employers and Employed, and what is required to give them further success, in: Sessional Proceedings 
der den christlichen Sozialisten nahestehende Thomas Hughes, Autor des Erziehungsromans "Tom Brown's Schooldays" (1857) und in seinen späteren Lebensjahren Richter in Ashton-under-Lyme, der häufig als Schlichter bei Tarifkonflikten in Erscheinung trat. ${ }^{134}$ Oder der in Manchester, SüdLondon und Kent als Grafschaftsrichter tätige Edward Abbott Parry, der sich in Büchern und Artikeln kritisch mit dem Justizsystem, vor allem dem unzureichenden Armenrecht, auseinandersetzte und in seiner Praxis unter anderem durch unkonventionelle und deutlich arbeitnehmerfreundliche Urteilssprüche in Workmen's Compensation-Fällen auffiel. ${ }^{135}$ Oder, um ein letztes Beispiel zu nennen, der am Bow County Court im Londoner East End tätige Richter Daniel French, über den anläßlich seines Todes (1902) in der Zeitung von Ben Tillett's Dockarbeiter-Gewerkschaft folgende herzerwärmende Worte zu lesen standen:

We believe him to have done more than any other Judge to command a belief in and respect for the law among the toilers, who have too often great grounds for believing that class prejudice taint even what should be honest and unimpeccable judgments. While the law has lost a great exponent, the poor, and justice itself, have lost a great friend. ${ }^{136}$

\section{DIE GRAFSCHAFTSGERICHTE IM URTEIL DER ARBEITNEHMER, JURISTEN UND UNTERNEHMER}

Wie das Zitat aus der Dockarbeiter-Zeitung belegt, schloß die Hochachtung vor einzelnen Richtern die Kritik an dem System, in dem sie agierten, nicht aus. Die Kritik am System der county courts unterschied sich je nach sozialem Standort. Die Arbeiter und Armen, die in den Schuldfällen die Masse der Beklagten stellten, litten vor allem unter der permanent über ihnen

of the National Association for the Promotion of Social Science for the Year 1870-1, Bd. 4, London 1871, S. 167-188.

134 Thomas Hughes (1822-1896). Vgl. die positive Äußerung des Gewerkschaftlers Henry Broadhurst über Thomas Hughes und andere Grafschaftsrichter: Fifteenth Annual Trades' Union Congress, Manchester 1882, S. 24 (Microfilm edition). Als Schiedsrichter war Hughes in den siebziger Jahren des 19. Jahrhunderts z. B. in der nordenglischen eisenverarbeitenden Industrie und in der Baumwollspinnerei von Yorkshire tätig, vgl. J.H. Porter, Wage Bargaining under Conciliation Agreements, 1860-1914, in: Economic History Review 23 (1970), S. 460-475, S. 463 f.

135 Edward Abbott Parry (1863-1943). Vgl. ders., The Law and the Poor, London 1914, ND New York u. London 1980, bes. S. 76-105 zu seinen eigenen Erfahrungen in Workmen's Compensation-Fällen. Vgl. für ein weiteres Beispiel auch die - in anderer Hinsicht nicht unkritische - Charakterisierung von Richter Francis Greenwell, in: Muir, Justice in a depressed area, S. $104 \mathrm{ff}$.

136 Dockers' Record, No. 7, Aug. 1902, S. 2. Daniel O'Connell French, K.C. (1843-1902), Grafschaftsrichter von 1892 bis 1902. 
schwebenden Drohung des Schuldgefängnisses. Zwar wurde die Praxis des imprisonment for debt im Jahr 1869 per Gesetz abgeschafft, doch ließ das gleiche Gesetz die Schuldhaft durch die Hintertür fortbestehen, indem bei "Zahlungsunwilligkeit" nach wie vor eine Beugehaft bis zu sechs Wochen verhängt und bei Bedarf wiederholt werden konnte, ohne daß die Schuld damit aufgehoben war. ${ }^{137}$ Unter dieser Gesetzeslage hing das Wohl und Wehe der Arbeiterfamilien allein vom Verständnis des einzelnen Richters für deren konjunkturbedingte Konsumgewohnheiten und Anschreibepraktiken $a b$, und nicht alle Grafschaftsrichter kannten diese Lebensumstände so genau wie Richter French im Londoner East End. ${ }^{138}$ Die Schuld- oder Beugehaft für die Armen wurde besonders deshalb als unfair wahrgenommen, weil den reicheren Geschäftsleuten, wenn sie ihre Schulden nicht mehr bezahlen konnten, die Möglichkeit des Bankrotts offenstand. Die Reichen, so hieß es, würden, wenn auch unter öffentlicher Ächtung, von ihrer Schuldenlast befreit, während die Armen in vergleichbarer Situation ins Gefängnis wanderten und ihre Schulden trotzdem behielten. ${ }^{39}$ Tatsächlich wurden noch im Jahr 1906 aus diesem Grund 11986 Personen inhaftiert, danach nahm die Zahl der Inhaftierten deutlich ab und betrug im Jahr 1922 nur noch 1003.140 Die Kritik an diesem Aspekt der Rechtsprechung ging jedoch nicht zu Lasten der Personen oder der Institution, sondern betraf die Gesetzgebung.

Was die Institution selbst angeht, so besaßen die Grafschaftsgerichte bei der englischen Arbeiterschaft unter allen Einrichtungen der ordentlichen Justiz, neben den Londoner police courts, noch am meisten Ansehen. Das kam nicht zuletzt in der Forderung des Trades Union Congress zum Aus-

137 Debtors Act, 32 \& 33 Vict., c. 62 (1869), s. 5. Eine Übersicht über die Rechtslage und die Praxis der Schuldhaft mit Zahlenmaterial bis zum Ende des 19. Jahrhunderts findet sich in den Civil Judicial Statistics 1896, PP 1898 (C. 8838) CIV, Introduction, S. 83-91. Vgl. außerdem: G. R. Rubin, Law, Poverty and Imprisonment for Debt, 1869-1914, in: Rubin u. Sugarman (Hg.), Law, Economy and Society, S. 241-299.

138 Zu den Lebensumständen der Armen im Londoner East End: Gareth Stedman Jones, Outcast London. A Study in the Relationship between Classes in Victorian Society, 2. Aufl. Harmondsworth 1984. Allgemein zu den Konsumgewohnheiten der Arbeiter: Paul Johnson, Saving and Spending: the working-class economy in Britain, 1870-1939, Oxford 1985.

$139 \mathrm{Vgl}$. V. Markham Lester, Bankruptcy, Imprisonment for Debt, and Company Winding-Up in Nineteenth-Century England, Oxford 1995, S. 116-120; Paul Johnson, Creditors, Debtors and the Law in Victorian and Edwardian England, in: Willibald Steinmetz $(\mathrm{Hg}$.), Private Law and Social Inequality in the Industrial Age. Comparing Legal Cultures in Britain, France, Germany and the United States, Oxford 2000, S. 485-504. Ab 1883 stand die Möglichkeit des Bankrotts theoretisch auch kleinen Schuldnern offen, jedoch war es in das Belieben der Grafschaftsrichter gestellt, ob sie entsprechende Anordnungen trafen: Bankruptcy Act, $46 \& 47$ Vict., c. 52 (1883), ss. 103 (5) u. 122 (1).

140 Civil Judicial Statistics 1922, PP 1923 (Cmd. 2001) XXIV, Table XX. (12). 
druck, die erstinstanzliche Rechtsprechung bei Streitigkeiten zwischen Arbeitgebern und Beschäftigten den county courts überall dort zu übertragen, wo es keine stipendiary magistrates gab. ${ }^{141}$ Aus dieser Forderung sprach natürlich in erster Linie das Mißtrauen gegen die Laienfriedensrichter, weniger eine besondere Sympathie für die Grafschaftsgerichte als solche. Der Gesetzgeber trug diesem Ansinnen partiell Rechnung, indem er mit dem Employers and Workmen Act von 1875 ausdrücklich eine konkurrierende Rechtsprechung zwischen Friedensrichtern und Grafschaftsrichtern etablierte - eine Maßnahme, deren Konsequenzen bisher noch nicht untersucht worden sind. Daß diese Veränderung in den Augen des Gesetzgebers keine Nebensache war, zeigt der vollständige Titel des Gesetzes, welcher lautet: „An Act to enlarge the powers of County Courts in respect of disputes between Employers and Workmen, and to give other Courts a limited civil jurisdiction in respect of such disputes. "142 Die Prioritätsverlagerung ist damit klar ausgesprochen. Um so merkwürdiger ist es, daß noch nie danach gefragt worden ist, inwieweit diese Intention des Gesetzgebers realisiert wurde.

Bevor dieser Frage nachgegangen wird, seien die Einstellungen der beiden anderen an den Grafschaftsgerichten interessierten Gruppen charakterisiert. Das waren zum einen die Juristen in ihren Eigenschaften als Richter, Rechtsreformer und freiberufliche Anwälte, zum anderen die Geschäftsleute in ihren Eigenschaften als Gläubiger und Arbeitgeber. Der County Courts Act von 1846 war gegen starke Widerstände aus den Reihen der Rechtsanwälte durchgesetzt worden. Die an den Londoner hohen Gerichtshöfen praktizierenden barristers und die ihnen zuarbeitenden solicitors fürchteten nicht ganz zu Unrecht die Konkurrenz der neuen Grafschaftsgerichte und wehrten sich jahrzehntelang hartnäckig gegen alle Bestrebungen, deren Kompetenzen zu erweitern. Sie verhinderten damit die von vielen, auch vielen Juristen und Politikern, gewünschte Weiterentwicklung der county courts zu einer vollwertigen Repräsentation des Obersten Gerichtshofs in der Provinz - eine Reform, die den kostspieligen Gang nach London

141 Report of Proceedings at the Third Annual Trades Union Congress, London 1871, unpag,, Diskussion am 8. März 1871 (Microfilm edition). Es gab jedoch auch Gegenstimmen, so z.B. auf dem sechsten Trades Union Congress, wo eine Resolution für die Ausdehnung der stipendiary magistrates auf das ganze Land verabschiedet wurde und ein Delegierter aus Darlington erklärte:,.. the less they trusted to county court legislation the better for them. At least his experience taught him this." Sixth Annual Trades' Union Congress, Sheffield 1874, S. 20 (Microfim edition).

$14238 \& 39$ Vict., c. 90 (1875). 
für Kläger und Beklagte aus der Provinz in erster Instanz erübrigt hätte. ${ }^{143}$ Es blieb also dabei, daß die Common law-Gerichte in Westminster direkt angerufen werden konnten. ${ }^{144}$ Der Widerstand der hauptstädtischen Anwaltschaft reichte jedoch nicht aus, um den allgemeinen Bedeutungszuwachs der county courts zu stoppen. Für die solicitors und die zweitrangigen barristers in der Provinz eröffnete sich hier ein, wenn nicht lukratives, so doch auskömmliches Betätigungsfeld, und die Rechtssuchenden selbst bewiesen durch ihren steten Zulauf, daß die Grafschaftsgerichte einen Bedarf erfüllten, den die teure, langsame und formalistische Rechtsprechung des High court und seiner provinziellen Ableger, der courts of assize, nicht erfüllen konnte.

Nachdem es feststand, daß die county courts auch in der Provinz neben dem High court in einer untergeordneten Position bleiben würden, verlagerte sich die innerjuristische Kritik vor allem auf die ungleichmäßige Arbeitsbelastung und die unzureichende Ausstattung der besonders frequentierten county courts. Während die Grafschaftsrichte in manchen entlegenen Gebieten nur wenig zu tun hatten, stöhnten die Richter und registrars in den bevölkerungsreichen Zentren über die Geschäftsüberhäufung. Gerichtstage mit mehr als 200 oder gar mehr als 300 zu erledigenden Fällen waren zum Beispiel in London, aber auch in kleineren Industriestädten wie Walsall oder West Bromwich keine Seltenheit. ${ }^{145}$ Darauf aufbauende Forde-

143 Den Höhepunkt dieser Bestrebungen bildete der zweite Bericht der Judicature Commission, Second Report, Bd. 1, PP 1872 (C. 631) XX; Bd. 2, PP 1872 (C. 631.-I.) XX. Zu den wiederholten und stets nur teilweise erfolgreichen Versuchen einer Reform der Grafschaftsgerichte nach 1846 vgl. Abel-Smith u. Stevens, Lawyers and the Courts, S. 48, 80-84, 90-96.

144 Allerdings gab es seit 1867 eine Abschreckungsklausel, die kleine Streitigkeiten von den höheren Gerichten fernhalten sollte: Wer als Kläger ein Verfahren vor ein höheres Gericht brachte, welches ebensogut vor einem Grafschaftsgericht hätte verhandelt werden können, und vor dem höheren Gericht lediglich eine Summe von unter $£ 20$ (bei Deliktssachen unter $£ 10)$ erstritt, hatte kein Recht auf Erstattung seiner Kosten durch den Beklagten, außer wenn der Richter bestätigte, daß ein besonderer Grund für den Gang zum höheren Gericht vorlag. $30 \& 31$ Vict., c. 142 (1867), s. 5 .

145 Am 8. April 1892 standen im Bow County Court 209 ordinary summonses, 8 defendend default summonses, 6 von früheren Gerichtsterminen vertagte Fälle und 4 Anträge auf der Liste (London Metropolitan Archives, CCT/AK15/8). Immerhin 100 dieser Fälle führten zu einer Anhörung. Allein $165 \mathrm{Klagen}$ stammten von einem einzigen Kläger, der Midland Boot Factory, Limehouse; weitere 34 Klagen von M. Abbott and Co., Coal Merchants. Beide Kläger waren in der entsprechenden Rubrik des Protokollbuchs jeweils durch Stempel eingetragen - ein Zeichen, daß sie nicht das erste Mal vor diesem Gericht erschienen. In Walsall waren am 24 Nov. 1909 sogar 309 ordinary summonses, 16 default summonses, 4 vertagte Fälle, 4 Anträge und 4 Workmen's Compensation-Angelegenheiten zu behandeln (Walsall Local History Centre, AK 28.1). Auch hier gab es mehrere Massenklagen von Textil- und Kohlenhändlern. Ähnlich war es in West Bromwich, wo zwischen Januar und Mai 1909 bei 
rungen nach Grenzkorrekturen, Vermehrung der Richter und Gehaltserhöhungen führten jedoch kaum zu greifbaren Resultaten. Es gab zu keiner Zeit mehr als sechzig Grafschaftsrichter für ganz England und Wales, das war eine im internationalen Vergleich extrem niedrige Zahl. ${ }^{146}$ In der Zwischenkriegszeit wurde die Qualität der Kandidaten für das Grafschaftsrichteramt immer skeptischer beurteilt. Man führte dies vor allem auf das seit der Mitte des 19. Jahrhunderts trotz Nachkriegsinflation unverändert bei £ 1500 liegende Gehalt zurück. Der Posten sei, so meinte man, nur noch für zweitklassige barristers attraktiv, die ein sicheres Auskommen erstrebten; auch politische Gesichtspunkte spielten angeblich bei der Ernennung zunehmend eine Rolle. ${ }^{147}$ Erst 1934/37 fanden die Klagen Gehör; das Gehalt wurde auf $£ 2000$ heraufgesetzt, eine Summe, die schon 1878 von einer parlamentarischen Untersuchungskommission als angemessen bezeichnet worden war. ${ }^{148}$

Als einen Rückschritt empfanden die Befürworter einer Kompetenzerweiterung der county courts nach dem Ersten Weltkrieg die fortdauernde Begrenzung des Streitwerts auf $£ 100$. Die Inflation sorgte dafür, daß etliche Fälle, darunter zum Beispiel die Klagen höherer Angestellter wegen wrongful dismissal, nun wieder sofort vor den High court gebracht werden mußten, nachdem vergleichbare Fälle vor dem Krieg zu allseitiger Zufriedenheit von den county courts gelöst worden waren. Der Rückgang der Klagen vor den county courts nach dem Weltkrieg und der scheinbare Wiederaufstieg des High court und der courts of assize in der Gunst des Publikums sind zu einem guten Teil so zu erklären. ${ }^{149}$ Die Londoner barristers und die großen solicitor-Firmen profitierten davon. Ihr Standardargument, mit dem sie sich schon in der zweiten Hälfte des 19. Jahrhunderts und jetzt wieder gegen eine Erhöhung des Streitwerts wandten, hob darauf ab, daß die Grafschafts-

den meisten Gerichtsterminen mehr als 200 Fälle anstanden (Sandwell Community History and Archives Service, Smethwick, AK 34.19). Diese Beispiele ließen sich beliebig vermehren.

$146 \mathrm{Vgl}$. Gerland, Englische Gerichtsverfassung, S. $268 \mathrm{f}$., der sich an dieser Stelle gegen deutsche Autoren, namentlich Franz Adickes, wendet, die unter Verweis auf die englischen Verhältnisse die Zahl der deutschen Richter an Amts- und Landgerichten für zu hoch hielten. Die niedrige Richterzahl in England sei, so Gerland, „keineswegs die Folge eines Idealzustands weiser Verwaltungsökonomie, sondern vielmehr von unangebrachter Sparsamkeit." Vgl. Franz Adickes, Grundlinien durchgreifender Justizreform. Betrachtungen und Vorschläge unter Verwertung englisch-schottischer Rechtsgedanken, Berlin 1906, bes. S. 36 u. S. 60. Nach Adickes betrug die Zahl der Richter an deutschen Amts-, Land- und Oberlandesgerichten im Jahr 1905 insgesamt 8703. Dagegen hielt er die Zahl von nur 253 Berufsrichtern in England (Richter am High court, Grafschaftsricher, recorder und Polizeirichter).

147 Barrister, Justice in England, S. 41.

$148 \mathrm{Vgl}$. Abel-Smith u. Stevens, Lawyers and the Courts, S. 108.

149 Vgl. ebd., S. 100 f. Zu den Zahlen für Klagen in den county courts siehe Tabelle 3.1, S. 211. 
gerichte ursprünglich für ,arme` Kläger (damit meinten sie die kleinen Ladenbesitzer und Handwerker, nicht die wirklich Armen) geschaffen worden seien; durch eine Erhöhung des Streitwerts und die damit einhergehende Vermehrung komplizierter Fälle drohten diese Kläger an den Rand gedrängt zu werden. ${ }^{150}$ Auch wenn es sich bei diesem Argument offensichtlich um einen Vorwand handelte, hinter dem die handfesten Interessenkämpfe zwischen Provinzanwälten und Londoner Juristen um die lukrative Kundschaft verschleiert wurden, entbehrte es nicht einer gewissen Grundlage. Denn es läßt sich beobachten, daß etwa seit der Jahrhundertwende immer weniger ,kleine Leute vor den Grafschaftsgerichten persönlich als Kläger in Erscheinung traten. Das lag aber nicht, wie die Londoner Juristen unterstellten, an der Erhöhung der Streitwerte, sondern unter anderem daran, daß zunehmend Schuldenaufkäufer, sogenannte debt collection agents, gegen eine gewisse Gebühr die lästige und zeitraubende Aufgabe der gerichtlichen Eintreibung von Zahlungsrückständen für die kleinen Geschäftsleute übernahmen. ${ }^{151}$ Es zeigte sich also in den Grafschaftsgerichten das Phänomen, daß wenige große Massenkläger für das Gros der Fälle verantwortlich waren, aber dahinter verbargen sich bisweilen weiterhin kleine Schuldforderungen kleiner Geschäftsleute. Die wirklich Armen freilich, und dazu gehörten in der Regel die um ihren Lohn klagenden Arbeitnehmer, wurden durch diese Entwicklung in den Grafschaftsgerichten tatsächlich marginalisiert, insofern traf die Kritik von seiten der Londoner Anwaltschaft eine wunden Punkt; allerdings war es nicht der Punkt, den sie gemeint hatten.

Mit den vorstehenden Bemerkungen ist bereits die Hauptfunktion angesprochen, die den Grafschaftsgerichten in den Augen der Geschäftsleute zukam. Es ist die Funktion einer Maschinerie zur Schuldeneintreibung, und es ist diese Funktion, mit der sich die historische Forschung bisher fast aus-

150 Abel-Smith u. Stevens, Lawyers and the Courts, S. 95.

151 Die Praxis begann offenbar in den siebziger Jahren des 19. Jahrhunderts. Zu dieser Zeit rief sie noch Diskussionen unter Richtern und Anwälten hervor; vgl. County Courts Chronicle, 1. März 1875, S.69f., „County Courts Agents" (Leserbrief); ebd., 1. April 1875, S. 90, "Chester County Court. Application against the debt collectors for contempt"; 2. Okt. 1876, S. 461, „Agents in County Courts“. Gegen Ende des Jahrhunderts war das Auftauchen solcher Personen in Grafschaftsgerichten üblich geworden, was sich daran zeigt, daß man im Gericht bereits Stempel für sie parat hatte, um sie mit ihren vielen Klagen rasch in die Protokollbücher eintragen zu können. Vgl. etwa Dudley Public Libraries. Archives and Local History Service, Acc. 8729, AK 64.05, Plaint and Minute Book B, 1890-91, Eintrag für 23. Jan. 1891: ein Richard Walton, Schuldenaufkäufer, trat hier für 7 lokale Händler in insgesamt 68 Fällen auf; ähnliche Einträge von diesem und anderen Schuldenaufkäufern in diesem Buch am 24. März 1891, 28. April 1891, 4. Mai 1891, 8. Mai 1891. Auch 1919-21 war das Muster noch unverändert, vgl. ebd., AK 64.08, Plaint and Minute Book B, 1919-20, Einträge vom 15. Aug. 1919, 9. Okt. 1919, 8. Juni 1920, 1. Febr. 1921. 
schließlich beschäftigt hat. Der County Courts Act von 1846 war Teil der legislativen Bestrebungen der mittleren Jahrzehnte des 19. Jahrhunderts, kommerzielle Transaktionen zu erleichtern und durch ein erhöhtes $\mathrm{Maß}$ an Rechtssicherheit kalkulierbarer zu machen. ${ }^{152}$ Nutznießer des Gesetzes sollten in erster Linie die selbständigen Anbieter von Waren und Dienstleistungen sein, und in der viktorianischen Ära waren es tatsächlich kleinere und mittlere Geschäftsleute, Handwerksmeister und Angehörige der Professionen, die das Gros der Kläger stellten. Dadurch, daß die kleinen Schulden der kleinen Leute in den neuen Gerichten nun schneller und wirksamer eingeklagt werden konnten, verringerte sich für diese Gruppen das Risiko bei der Gewährung kurzfristiger Kredite, bei Vorleistungen ohne sofortige Bezahlung und bei der Praxis des Anschreibens. Das ermöglichte Geschäfte, die sonst nicht getätigt worden wären, und insofern trugen die county courts zweifellos zum Wachstum der britischen Wirtschaft in der zweiten Hälfte des 19. Jahrhunderts bei. Der Titel des Gesetzes sprach aus, daß Schuldeneintreibung die Hauptintention des Gesetzgebers war: „An Act for the more easy recovery of debts and demands in England“. Nach Zahl und Art der in den county courts erledigten Fälle zu urteilen, wurde dieser Zweck des Gesetzes erfüllt. Zahlungsunwillige Konsumenten von Gütern und Dienstleistungen wurden Jahr für Jahr zu Hundertausenden verklagt und regelmäßig in weit über 90 Prozent aller Fälle zur Zahlung verurteilt, sofern sie nicht schon vor Beginn des eigentlichen Verfahrens, freiwillig' gezahlt hatten. Wenn sich trotz der Erfolgsbilanz gelegentlich kritische Stimmen aus der Geschäftswelt gegen den schuldeneintreibenden Aspekt der county court-Justiz vernehmen ließen, so zielten sie darauf, den Prozeß aus der Sicht der Kläger noch effizienter zu gestalten, also die Gerichtsgebühren zu senken und die Prozedur bei Anträgen auf Inhaftierung zahlungsunwilliger Verurteilter zu beschleunigen. ${ }^{153}$ Von einer allgemeinen

152 In diesen Zusammenhang gehören auch die um die Jahrhundertmitte verabschiedeten Gesetze zum Insolvenz- und Gesellschaftsrecht. Die liberalisierende Gesetzgebung zu companies schuf freilich auch neue Gelegenheiten für großangelegten Betrug an Aktionären und Konsumenten; hierzu: George Robb, White-Collar Crime in Modern England. Financial fraud and business morality, 1845-1929, Cambridge 1992; Michael Lobban, Nineteenth Century Frauds in Company Formation: Derry v. Peek in Context, in: Law Quarterly Review 112 (1996), S. 261-334.

153 Beispiele für kritische Stimmen: County Courts Chronicle, 1. Nov. 1848, S. 366, „Correspondence" (Leserbrief eines C.J.G. Eilvart an die Law Times über die hohen Kosten und die Verzögerungen des Verfahrens); ebd., 1. Dez. 1848, S. 389, „Recovery of Debts in the County Courts" (Leitartikel zu den Problemen klagender Geschäftsleute); Clerkenwell News, 6. März 1858, S. 2, „County Court Law“ (Leserbrief): „We pay 10s. for hearing, and can only get five minutes say!... Tradesmen are disgusted with these courts, for they are the dearest in England." 
Unzufriedenheit mit der Leistung der Grafschaftsgerichte in dieser Hinsicht kann aber keinesfalls die Rede sein.

Als weniger geeignet empfanden hingegen die Geschäftsleute die Grafschaftsgerichte für die Lösung ihrer Konflikte untereinander. Das ganze 19. Jahrhundert hindurch wollten die Rufe nach geeigneten Tribunalen für eine nach Möglichkeit einvernehmliche Beilegung kommerzieller Streitigkeiten nicht verstummen. Die Kritiker aus dem Umkreis der Handelskammern und Industriellenverbände konnten sich jedoch zu keiner Zeit einigen, ob man das System der ordentlichen Gerichte - und das hieß in erster Linie die Grafschaftsgerichte - entsprechend adaptieren könne, oder ob man von vornherein auf spezielle Schiedsgerichte außerhalb der ordentlichen Justiz setzen sollte. ${ }^{154} \mathrm{Im}$ Hinblick auf die county courts blieben all diese Debatten letztlich fruchtlos; die county courts änderten ihren Charakter als ordentliche Gerichte kaum. Das lag zum Teil sicherlich an der interessegeleiteten Opposition der Berufsjuristen gegen jede Aufweichung ihres Monopols. Wichtiger aber scheint mir, daß es mit dem in viktorianischer Zeit allseits und gerade auch von den Geschäftsleuten selbst hochgehaltenen Grundsatz der Gleichbehandlung unvereinbar war, prozedurale und institutionelle Sonderkonditionen innerhalb der normalen Justiz nur für eine spezielle $\mathrm{Ka}$ tegorie von Fällen zu fordern. Warum sollten nur die Geschäftsleute für ihre Streitigkeiten untereinander Laien-Beisitzer in den county courts haben dürfen, andere Gruppen aber nicht? Warum sollten nur für sie höhere Streitwerte zugelassen sein? Warum sollten nur sie ausnahmsweise in den Genuß eines weniger streitigen, weniger öffentlichen und weniger strikt nach juristischen Maßstäben durchgeführten Verfahrens kommen? Alle Vorschläge, innerhalb der Grafschaftsgerichte so etwas wie handelsgerichtliche Abteilungen mit eigenen Verfahrensregeln einzurichten, blieben $\mathrm{Ma}-$ kulatur. ${ }^{155}$ Dieses Scheitern verdeutlicht exemplarisch, daß es im viktorianischen England so gut wie unmöglich war, eine Sondergerichtsbarkeit zu verlangen und durchzusetzen, die gleichwohl an die Institutionen der ordentlichen Justiz angebunden blieb, wie es etwa in Deutschland bei den

154 Vgl. W.T.S. Daniel, Is it desirable to establish Tribunals of Commerce, and if so, with what powers?, in: Transactions of the National Association for the Promotion of Social Sciences 1870, London 1871, S. 191-203; W.S. Daglish, On the Same, ebd., S. 203-208, und die anschließende Diskussion, ebd., S. 208-211. Ferner: Arthurs, ,Without the Law', S. 56-88; G. R. Searle, Entrepreneurial Politics in Mid-Victorian Britain, Oxford 1993, S. 130 f. u. 178-181.

155 Einen gewissen Ersatz bedeutete hier die Einführung der Prozedur des default summons, jedoch war dieses Verfahren nur nützlich bei unkomplizierten Fällen, in denen die Schuld im Prinzip unbestritten war. Näheres zum default summons unten, S. 239. 
Handelsgerichten, Gewerbegerichten und Verwaltungsgerichten der Fall war. In England gab es hier nur ein Entweder-Oder: Entweder man unterwarf sich den im Prinzip für alle geltenden Regeln der ordentlichen Justiz, oder man regelte seine Konflikte außergerichtlich und nahm die Nachteile in Kauf, die das für die Vollstreckbarkeit der Urteile und für die Rechtssicherheit mit sich brachte.

Vor einem ähnlichen Dilemma wie die Geschäftsleute standen im viktorianischen England auch die Arbeitnehmer. Keines der etablierten ordentlichen Gerichte kam ihrem Bedürfnis nach einem Tribunal, vor dem sie als Kläger ohne hohe Kosten und mit Aussicht auf Erfolg auftreten konnten, auch nur annähernd entgegen. Wie die Geschäftsleute richteten auch die Arbeitnehmer zeitweise ihre Hoffnung auf die county courts als den noch am ehesten geeigneten Kandidaten für eine Reform. Es ist jedoch nie bis zu vergleichbaren Plänen gekommen, so etwas wie arbeitsgerichtliche Abteilungen an den county courts einzurichten. Bei allen Fragen, welche die institutionelle Seite der Justiz betrafen, verhielt sich die englische Arbeiterbewegung, sehr im Gegensatz zu den deutschen Gewerkschaften und Sozialdemokraten, erstaunlich passiv; sie überließ dieses Diskussionsfeld weitgehend den Reformern aus dem Umkreis der Mittelklassen und den Politikern. Diese hatten verständlicherweise wenig Interesse daran, über verbesserte Klagemöglichkeiten für Arbeitnehmer nachzudenken.

Als Individuen machten Arbeitnehmer dennoch von Anfang an, wie zu zeigen sein wird, in nicht unerheblichem Umfang von den Grafschaftsgerichten Gebrauch. Schon das genügte, um bei den Unternehmern, Geschäftsleuten und manchen Richtern Irritationen hervorzurufen. Hatte es sich anfänglich nur um Klagen wegen ausstehenden Lohns oder ungerechtfertigter Entlassung gehandelt, kamen ab 1880 die Klagen unter dem Arbeitgeberhaftungsgesetz und ab 1897 die Verfahren unter dem Workmen's Compensation Act hinzu. Die county courts wurden damit für die Geschäftsleute, sofern sie Handarbeiter beschäftigten, erstmals zu einer Bedrohung - ein für sie ganz ungewohntes Gefühl. Die Summen, die auf dem Spiel standen, waren insbesondere in Prozessen unter dem Employers' Liability Act erheblich. Für Kleinunternehmer konnten sie durchaus den Ruin bedeuten. Entsprechend ängstlich, ja hysterisch, war zeitweise die unternehmerische Reaktion auf diesen Funktionszuwachs der county courts. Bei allem Respekt, den man den einzelnen Richtern verbal entgegenbrachte, traute man ihnen doch nicht zu, diese Art von Fällen, richtig', das heißt mit der gebotenen Berücksichtigung des Mitverschuldens der Arbeitnehmer an ihrem eigenen Unglück, zu entscheiden. Mehr noch als den Richtern mißtraute man den juries, die in Arbeitgeberhaftungsfällen häufiger als sonst 
hinzugezogen wurden. Das Mitleid mit den Verletzten und Verstümmelten, den Witwen und Waisen getöteter Arbeiter, würde, so fürchtete man, eine sachliche Beurteilung der Fälle durch die Geschworenen stören. ${ }^{156}$ Erst als sich herausstellte, daß die meisten Grafschaftsrichter, nicht zuletzt aufgrund der häufig erfolgenden Berufungen gegen arbeitnehmerfreundliche Urteile, zu einer sehr engen Auslegung des Arbeitgeberhaftungsgesetzes gelangten, ebbte die Unruhe unter den betroffenen Unternehmern ab. ${ }^{157}$

Sie lebte aber schon bald wieder auf, als die Workmen's Compensation Acts von 1897 und 1906 die Beweislasten bei Arbeitsunfällen entscheidend zugunsten der Arbeitnehmer verschoben. Zwar versicherten sich die meisten Unternehmer, wie es der Intention des Gesetzgebers entsprach, gegen das Risiko der Entschädigungszahlung, doch änderte das nichts daran, daß sie den county court zunehmend als Ort erlebten, an dem sie die undankbare Rolle des Beklagten übernehmen mußten. Wie bereits im ersten Kapitel erläutert, sollte das Grafschaftsgericht in Fällen unter dem Workmen's Compensation Act in erster Linie als eine Instanz fungieren, bei der außergerichtlich getroffene Einigungen oder Schiedssprüche zu hinterlegen waren, um ihnen damit Rechtskraft zu verleihen. Nur wenn eine Einigung auf diese Weise nicht zustandekam, sollte der Grafschaftsrichter selbst in Aktion treten, allerdings nicht in dem üblichen, streitigen Verfahren, sondern als Schiedsrichter. ${ }^{158}$ Hier durchbrach der britische Gesetzgeber also ausnahmsweise den Primat des, gewöhnlichen' Rechts innerhalb der ordentlichen Justiz. Für die Workmen's Compensation-Fälle entstand eine Art Sondergerichtsbarkeit im Rahmen der normalen Rechtsprechung. Daß hier zugunsten der Arbeitnehmer ein Verfahren erlaubt wurde, um das sich die Geschäftsleute so oder ähnlich für ihre eigenen kommerziellen Streitigkeiten vergeblich bemüht hatten, erhöhte nicht gerade deren Bereitschaft, sich darauf einzulassen. Ob das Gefühl der Benachteiligung auf seiten der Arbeitgeber dazu beigetragen hat, daß sich die vor den county court als Schiedsgericht gelangenden Workmen's Compensation-Fälle in der Praxis sehr stark dem Modell des normalen, streitigen Gerichtsverfahrens annäherten, läßt

156 Vgl. den ersten Jahresbericht des Vorsitzenden der Builders' Accident Insurance (Limited), abgedruckt in: The Builder, 29. Jul. 1882, S. 156 f.: "We find that in all cases that are contested the sympathies of judges and juries go very strongly with the plaintiff. There is a very great deal of judge-made law on the subject, and we find that the construction put upon the Employers' Liability Act by the judges is very different indeed from that which we were assured would be its scope when it was before Parliament."

157 Vgl. die Kritik an den übertriebenen Befürchtungen des Anfangs in: County Courts Chronicle, 1. Mai 1882, S. 309, „Lay Opinions on Legal Questions. The Employers' Liability Act and its Results."

158 Siehe oben Kap. I.2. 
sich schwer feststellen. Entscheidender für diese Entwicklung dürfte das Bestreben der Versicherungsgesellschaften gewesen sein, jeden aus ihrer Sicht auch nur halbwegs aussichtsreichen Fall bis zur Berufungsinstanz, dem Court of Appeal oder sogar dem House of Lords, durchzufechten. 159 Da sich auch die Gewerkschaften berufen fühlten, ihre Mitglieder in solchen Verfahren notfalls bis zur letzten Instanz zu unterstützen, wurde die ursprüngliche Intention des Gesetzgebers, das Common law aus den Workmen's Compensation-Fällen möglichst herauszuhalten, in ihr Gegenteil verkehrt. Die Workmen's Compensation-Fälle entwickelten sich, wie Charles Muir, ein Kenner der Gerichtspraxis in den nordostenglischen Kohlerevieren, im Jahr 1936 feststellte, „zu den formalistischsten, kostspieligsten, aber auch," so fügte er der Fairness halber hinzu, „zu den am sorgfältigsten behandelten Fällen in den county courts. “160 Trotz seiner Kritik an der „ÜberSubtilität“, mit der Grafschaftsrichter und Berufungsinstanzen viele Entschädigungsanträge bearbeiteten, trat Muir für eine Beibehaltung des normalen Rechtswegs ein, sehr im Unterschied zu den meisten Arbeitnehmerorganisationen, die in den zwanziger und dreißiger Jahren des 20. Jahrhunderts aufgrund der inzwischen gesammelten Erfahrungen immer häufiger für eine administrative Konfliktlösung außerhalb der ordentlichen Justiz plädierten. ${ }^{161}$

Wenn man die öffentliche Diskussion um die Funktion und Arbeitsweise der Grafschaftsgerichte zusammenfassen soll, so ergibt sich für alle drei Interessengruppen ein zwiespältiges Bild. Bei den Juristen verhinderten die Interessenkonflikte zwischen Londoner Anwälten und Provinzjuristen sowie - nicht unbedingt deckungsgleich mit dieser Front - der Gegensatz zwischen Justizreformern und Verteidigern des Supremats des Common law eine eindeutige Haltung. Ein Ausbau der Grafschaftsgerichte zur einzigen erstinstanzlichen Zivilgerichtsbarkeit für ganz England wurde dadurch blockiert. Von den Geschäftsleuten wurde die mit den county courts geschaffene Möglichkeit der effektiven Eintreibung kleiner Schulden dankbar

159 Vgl. dazu: Wilson u. Levy, Workmen's Compensation. Bd. 1, S. 141-156. Dort werden Stellungnahmen der verschiedenen Interessengruppen zu diesem Problem in dem 1919 berufenen Holman Gregory Committee wiedergegeben und kommentiert. Das Holman Gregory Committee sollte u. a. die Frage prüfen, ob ein staatliches Versicherungssystem an die Stelle der Privatversicherungen treten sollte. Für Beispielfälle siehe unten, Kap. III.1.

160 Muir, Justice in a Depressed Area, S. 72; ebd., S. 71: „As has been said, there is no effective appeal from the County Court to a higher Court except in Workmen's Compensation cases, and whether that fact is the explanation or not, it is certainly true that Workmen's Compensation cases are tried in a much more judicial way than any other cases in the County Court."

161 Ebd., S. 148-162. 
angenommen, doch profitierten davon vor allem die handeltreibenden und dienstleistenden Branchen; für die Industriellen hingegen boten die county courts wenig: Bei ihren Vertragsstreitigkeiten ging es um größere Summen, und ihre Schuldforderungen betrafen meist andere Geschäftsleute, mit denen sie aber in der Regel weiter im Geschäft bleiben wollten, weshalb das streitige und öffentliche Verfahren in den county courts ungeeignet war. Überdies waren es auch die Industrieunternehmer, die als Arbeitgeber in erster Linie von den bedrohlichen Schadensersatzforderungen verunglückter Arbeiter betroffen waren. Die Arbeitnehmer schließlich begrüßten es, daß sie für ihre Streitigkeiten mit den Arbeitgebern in den Grafschaftsgerichten eine Alternative $\mathrm{zu}$ den ungeliebten Laien-Friedensrichtern vorfanden, doch erschien dieser Vorzug dadurch getrübt, daß die Arbeiter als Konsumenten unter der rigorosen Verfolgung durch Gläubiger und Schuldeneintreiber zu leiden hatten und daß ihre eigenen, arbeitsrechtlichen Anliegen im Gerichtsalltag der Grafschaftsgerichte eben wegen der Priorität der Schuldsachen allzu oft zu kurz kamen.

\section{KONKURRIERENDE ZUSTÄNDIGKEIT VON GRAFSCHAFTSGERICHTEN UND FRIEDENSRICHTERN}

Sofort nach Inkrafttreten des County Courts Act von 1846 entstand bei vielen Friedensrichtern, ihren clerks und auch bei manchen Grafschaftsrichtern eine erhebliche Konfusion über die Frage, ob sich das neue Gesetz in irgendeiner Weise auf die Jurisdiktion der Friedensrichter bei Fällen unter dem Master and Servant Act auswirkte. Es handelte sich dabei keineswegs um ein theoretisches, abgehobenes Thema für gelehrte Erörterungen, sondern um ein praktisches Problem, das sich im Alltag beider Gerichte immer neu stellte und dort so oder so entschieden werden mußte. Daß dieses Problem virulent wurde, dafür sorgten die klagenden oder beklagten Arbeitnehmer und Arbeitgeber selbst, die sich von Anfang an die Existenz der neuen county courts für ihre $\mathrm{Zwecke}$ zunutze zu machen suchten. Landarbeiter und gewerbliche Arbeiter, die bis dahin nur vor den magistrates ausstehende Löhne hatten einklagen können, versuchten nun ihr Glück vor den Grafschaftsrichtern, von denen sie sich ein unparteiischeres Urteil erhoffen mochten. ${ }^{162}$ Diese mußten sich entscheiden, ob sie die Klage zulas-

162 Vgl. etwa County Courts Chronicle, 1. Jan. 1848, S. 154 (Annon v. Oates and another). Hier versuchte ein irischer Gleisbauarbeiter, vor dem Grafschaftsgericht in Halifax zu klagen, nachdem er von den Friedensrichtern mit der gleichen Klage bereits abgewiesen worden war; vgl. den Bericht über den vorausgegangenen Fall im Halifax Guardian, 13. Nov. 1847, 
sen oder die Arbeiter an die magistrates zurückverweisen wollten. Umgekehrt versuchten auch Arbeitgeber, die vor den magistrates wegen ausstehender Löhne verklagt wurden und eine Verurteilung befürchten mußten, unter Hinweis auf die neuen Grafschaftsgerichte die Zuständigkeit der Friedensrichter in Zweifel zu ziehen. ${ }^{163}$ So sahen sich die magistrates genötigt, ihre vorher unbestrittene Kompetenz gegen die neue Konkurrenz zu behaupten. Die Streitparteien suchten also ihren Vorteil, wo sie konnten, indem sie beide Lokalgerichte gegeneinander ausspielten.

Die Richter und clerks beider Gerichte reagierten verwirrt, weil weder das Gesetz noch höchstrichterliche Urteile eine klare Richtlinie an die Hand gaben, mit der man die Situation bewältigen konnte. Präzedenzfälle, auf die man sich hätte berufen können, waren zu dieser Frage der Kompetenzabgrenzung in den ersten Jahren nach 1846 naturgemäß nicht verfügbar und wegen der niedrigen Streitwerte auch später dünn gesät. 164 Überdies betrafen diese Entscheidungen, wie bei Präzedenzfällen üblich, immer nur den konkreten Fall und seine ganz besonderen Umstände, so daß eine direkte Anwendbarkeit selten gegeben war. Der Gesetzestext selber bot zur Entscheidung der Zuständigkeitsfrage ebenfalls keine Hilfestellung. Das Gesetz von 1846 enthielt nur eine enigmatische Klausel, aus der indirekt hervorging, daß die county courts auch in Angelegenheiten zuständig sein könnten, die nach bisherigem Verständnis in die Kompetenz der magistrates fielen. Diese Klausel lautete:

And be it enacted, That it shall be lawful for any Person under the Age of Twentyone Years to prosecute any Suit in any Court holden under this Act for any Sum of Money not greater than Twenty Pounds which may be due to him for Wages or Piecework, or for Work as a Servant, in the same Manner as if he were of full Age. 165

Im Klartext: Minderjährige sollten bei Lohnklagen vor den county courts die gleichen Rechte besitzen wie Volljährige. ${ }^{166}$ Damit war implizit gesagt,

S. 7. Ähnlich: County Courts Chronicle, 1. Dez. 1847, S. 125 (Diegmore v. Wallace); Justice of the Peace, 6. Nov. 1847, S. 799, „Servants - Recovery of wages after justices' adjudication".

163 Justice of the Peace, 23 Jan. 1847, S. 63: Anfrage eines Abonnenten, vermutlich eines magistrates' clerk, zu einem Fall, in dem der Arbeitgeberanwalt behauptete, die Friedensrichter hätten seit Etablierung der Grafschaftsgerichte keine Kompentenz mehr, Lohnklagen zu entscheiden. Vgl. ähnliche Anfragen ebd., 20. Febr. 1847, S. 126; 22. Mai 1847, S. 378.

164 Ich habe nur zwei einschlägige Fälle ermitteln können: Routledge v. Hislop (1860), 2 E. \& E. 549, E.R. 121, S. 206-209; Hindley v. Haslam (1878) 3 Q.B.D., S. 481-484.

$1659 \& 10$ Vict., c. 95 (1846), s. 64.

166 Diese merkwürdige Klausel ist wahrscheinlich deshalb in das Gesetz gekommen, weil es vor den courts of requests offenbar nicht unüblich gewesen war, daß Eltern für ihre minderjährigen Kinder Löhne einklagten. Vgl. Finn, Debt and Credit, S. 217. 
daß Lohnklagen zulässig waren. Im ganzen Gesetz sucht man aber vergeblich nach näheren Ausführungen zu der Art und Weise, wie mit Lohnklagen von Volljährigen umgegangen werden sollte. Man konnte daraus nur schließen, daß Lohnforderungen in den Grafschaftsgerichten genauso wie alle anderen Arten von Schuldforderungen zu behandeln waren. ${ }^{167}$ Das ließ aber die Frage offen, ob auch diejenigen Arbeiter (volljährig oder nicht), die unter den Master and Servant Act fielen, nun berechtigt sein sollten, wahlweise zum Friedensrichter oder zum Grafschaftsrichter zu gehen. Im Kern ging der Streit um diese Wahlmöglichkeit, an der die betreffenden Arbeiter überall dort ein Interesse haben mußten, wo sie es mit einer in ihren Augen parteiischen Friedensrichterbank zu tun hatten. Der Gesetzgeber hatte dieses Problem schlicht und einfach ignoriert und überließ es den Lokalgerichten, im Einzelfall eine Lösung zu finden.

Wie nicht anders zu erwarten, sahen die Lösungen überall unterschiedlich aus, und es konnte sogar zu dem Fall kommen, daß beide Lokalgerichte sich für unzuständig erklärten, was für den klagenden Arbeiter de facto einer Verweigerung des Rechtswegs gleichkam. ${ }^{168}$ Aber auch wenn ein klagender Arbeiter nur von dem einen Gericht an das andere verwiesen wurde, wie es in späteren Jahrzehnten noch häufig genug vorkam, hatte er zum mindesten bereits einen finanziellen Verlust durch die Gebühren erlitten, die der erste, erfolglose Anlauf gekostet hatte. ${ }^{169} \mathrm{Ob}$ er dann noch einen zweiten Versuch unternahm, war fraglich. Nicht ganz klar war anfangs offenbar auch, ob ein Arbeiter durch eine Lohnklage vor dem county court eine von einem magistrate schon ausgesprochene Verwirkung des Lohns nachträglich korrigieren konnte oder ob er mit einem schon zu seinen Gunsten ergangenen

167 Es gab Leute, die selbst das bezweifelten, so ein Arbeitgeberanwalt in einem Fall vor dem Oldbury County Court, County Courts Chronicle, 2. Mai 1870, S. 119 (Skerton v. Jenkins): "Wages did not constitute a debt, and therefore were not recoverable in the County Court, but before the magistrates."

168 Vgl. den Fall Davies v. Meire, County Courts Chronicle, 2. Aug. 1858, S. 181. Der Grafschaftsrichter erklärte hier, er habe bei Lohnklagen von Landarbeitern keine Jurisdiktion eine eigenwillige Auffassung, die durch das Gesetz oder Präzedenzfälle in keiner Weise gedeckt war. Auf den Einwand des Anwalts des Klägers, die örtlichen Friedensrichter würden bei Lohnklagen von Landarbeitern diese stets an das Grafschaftsgericht verweisen, bemerkte er, daß die Friedensrichter sich offenbar "falsche Begriffe" von ihrer Kompetenz machten. $\mathrm{Da}$ also in diesem Bezirk (Shrewsbury) offenbar beide Lokalrichter ein selbstgemachtes Recht anwendeten, hatten klagende Landarbeiter hier überhaupt keine Chance.

169 Beispielfälle für Verweise vom einen Gericht ans andere: Colliery Guardian, 9. Jan. 1858, S. 23, "Northumberland" (Sanderson v. Blackett); Darlington and Stockton Times, 19. März 1870, S. 3, "Non-Payment of Wages" (Pallister v. Fry, Ianson, and Co.); Colliery Guardian, 21. Jan. 1870, S. 67, "The Mining Customs of Monmouthshire" (Parfitt v. Morgan); Justice of the Peace, 9. Okt. 1875, S. 655 (Leseranfrage); Thomas Holmes, Pictures and Problems from London Police Courts, London 1900, S. 110. 
county court-Urteil in der Hand einer Bestrafung durch den Friedensrichter zuvorkommen konnte. Besonders in ländlichen Gebieten scheint es bei vorzeitigen Beendigungen des Arbeitsverhältnisses vielerorts zu einer Art Wettlauf zwischen Landarbeitern und Farmern zu den Gerichten gekommen zu sein: Während die Arbeiter vor das Grafschaftsgericht zogen, um dort ihren Lohn als zivile Schuld einzuklagen, bemühten sich ihre ,Herren“ vor dem Friedensrichter um den Nachweis, daß ein Fehlverhalten des Arbeiters vorgelegen hatte, was in jedem Fall die Verwirkung des Lohns, eventuell sogar eine Bestrafung nach sich ziehen konnte. ${ }^{170}$ Nach dem Master and Servant Act von 1823 war das Urteil eines magistrate endgültig - „final and conclusive“, wie es im Gesetzestext hieß. ${ }^{171}$ Sofern also aus Sicht des Arbeitgebers ein Kontraktbruch oder ein halbwegs plausibler Grund für die vorzeitige Entlassung vorlag, hatte er ein Interesse daran, so schnell wie möglich zum örtlichen Friedensrichter zu gehen, um dadurch eine Lohnklage seines Arbeiters vor dem Grafschaftsgericht unmöglich zu machen.

Im Resultat trug also die Etablierung der county courts eine gewisse Rechtsunsicherheit in die Beziehungen zwischen Landarbeitern, gewerblichen Arbeitern und ihren Arbeitgebern hinein. Es bestehen keine Anzeichen dafür, daß diese Unsicherheiten vor 1875 behoben wurden. Man darf annehmen, daß die magistrates in der Praxis oft die für den Arbeiter jeweils ungünstigere Interpretation wählten; jedenfalls ist dies der Eindruck, den Zeitungsberichte und die Ratschläge in der Rubrik „Practical Points“ der Fachzeitschrift „The Justice of the Peace“ vermitteln. ${ }^{172}$ Die Grafschaftsgerichte wurden dagegen von den Arbeitern offenbar als weniger unangenehm wahrgenommen. Der Gang zum Grafschaftsrichter bot für sie die Chance, den ungeliebten Laien-Friedensrichtern zu entkommen.

170 Vgl. County Courts Chronicle, 1. Sept. 1847, S. 65 (Granger v. Wade u. Dickins v. Buswell); Northampton Mercury, 17. Dez. 1870, S. 3, „Daventry“ (Cave v. Smith).

1714 Geo. 4, c. 34 (1823), s. 5.

172 Vgl. Justice of the Peace, 10. Juli 1847, S. 510, „Small Debts Act - Jurisdiction of county courts over servants in husbandry" (Leseranfrage mit Fallschilderung): Der Ratgeber vertrat hier die nach dem Gesetzestext völlig unhaltbare Auffassung, daß Grafschaftsgerichte keine Lohnklagen von Volljährigen anhören dürften. Nach 1867 wurde die Unsicherheit sogar noch gesteigert, indem nun einige magistrates die abstruse Auffassung vertraten, daß das Gesetz von 1867 ihnen die Kompetenz für die Entscheidung von Lohnklagen genommen hätte. Zwei Urteile der Queen's Bench auf cases stated rückten dies zurecht, aber man muß wohl davon ausgehen, daß dies nur die Spitze des Eisbergs war und daß möglicherweise an vielen Orten besonders in Nordengland das ,Mißverständnis' der magistrates unkorrigiert blieb und die Arbeiter sogar ihrer einzigen ohnehin schon beschränkten Klagemöglichkeit faktisch beraubte; Vgl. Millett v. Coleman und Dawson v. Coleman, Justice of the Peace, 18. Dez. 1875, S. 805-808; Shaw v. Alderson, Justice of the Peace, 11. Sep. 1875, S. 582. 
Die bis hierher geschilderten Kompetenzkonflikte betrafen, das sei noch einmal betont, nur diejenigen Arbeitnehmer, die unter den Master and Servant Act fielen. Für alle anderen, also das Hauspersonal, höhere Angestellte, Ladengehilfen und generell alle nicht-handarbeitenden Beschäftigten war die alleinige Zuständigkeit der Grafschaftsgerichte unbestritten. Abgrenzungsprobleme gab es freilich auch hier, aber dabei handelte es sich im wesentlichen darum zu definieren, ob die klagende oder beklagte Person ein servant im Sinne des Master and Servant Act war oder nicht. Danach entschied sich dann, ob eine konkurrierende Zuständigkeit der Friedensgerichte bestand oder nicht. Grauzonen gab es insbesondere bei zwei Gruppen. Das war einmal das ländliche Gesinde, dessen Status aufgrund der meist mündlichen Absprachen oft nicht klar zu bestimmen war: Zählte zum Beispiel eine Milchmagd, die sich zugleich auch sonst auf dem Hofe nützlich machen sollte und in einem Verschlag neben dem Haupthaus lebte, zum Hauspersonal oder galt sie als Landarbeiterin? Zum anderen waren es die Heimgewerbetreibenden und Stücklohnarbeiter. Bei deren juristischer Statusdefinition kam es vor allem darauf an, ob sie ihre ganze Arbeitsleistung nur einem Arbeitgeber zur Verfügung stellten oder ob sie aufgrund ihres Arbeitsvertrags (zumindest theoretisch) auch für andere arbeiten konnten. Diese Definitionskämpfe und ihre Implikationen für den Erfolg vor Gericht und das Selbstverständnis der Beteiligten werden Gegenstand eines späteren Kapitels sein. ${ }^{173}$ Hier ist zunächst nur festzuhalten, daß auch in diesem Feld gewisse Unsicherheiten bei der Zuordnung bestanden, die im Einzelfall dazu führten, daß die betreffenden Personen vom einen zum anderen Gericht verwiesen wurden.

An dieser zuletzt genannten Unsicherheit änderte sich durch den $E m$ ployers and Workmen Act von 1875 nichts; nach wie vor mußte jeweils entschieden werden, wer ein workman im Sinne des Gesetzes war und wer nicht. Eindeutig gelöst war aber jetzt die Frage der Zuständigkeit: Bis zu Streitwerten von $£ 10$ konnten die unter das Gesetz fallenden workmen und ihre Arbeitgeber wählen, vor welchem Gericht sie klagen wollten; jenseits dieser Summe mußten sie vor das Grafschaftsgericht gehen. Für alle anderen Beschäftigten blieb es dabei, daß nur die Grafschaftsgerichte oder der Oberste Gerichtshof in Frage kamen. Theoretisch war es nun gleichgültig geworden, welches der beiden Lokalgerichte bemüht wurde, denn das $\mathrm{Ge}-$ setz schrieb (außer bei widerspenstigen Lehrlingen) für Grafschafts- und Friedensgerichte das gleiche Verfahren und die gleichen Sanktionen vor.

173 Siehe unten Kap. V.2. 
Praktisch konnten die Kläger, sofern sie die Wahl hatten, nun abwägen, ob sie sich der billigeren, aber möglicherweise parteiischen Justiz der Friedensrichter anvertrauen wollten oder ob sie lieber die teurere, dafür aber vielleicht neutralere und professionellere Justiz der Grafschaftsrichter in Anspruch nahmen.

\section{EIN GERICHTSTAG IM JAHR 1847}

Am 8. April 1847 wurde der Bow County Court im Londoner East End eröffnet. Auf der Agendaliste, die an diesem ersten Gerichtstag von Richter Henry Storks, Esq., Serjeant at Law, abgearbeitet werden sollte, standen insgesamt 52 Klagen. ${ }^{174}$ Als Nummer sieben auf der Liste wurde der Fall von Elizabeth Clare, einer Minderjährigen, gegen einen gewissen George Blumingback aufgerufen. Laut Eintrag im Minute book ging es dabei um $£ 1$ 1s. 8d. unbezahlten Lohn. Die übrigen Spalten des Minute book, in denen über das Erscheinen der Streitparteien und den Prozeßausgang Buch zu führen war, blieben bei diesem Fall unausgefüllt. Offenbar waren weder die Klägerin noch der Beklagte erschienen. Über die Gründe kann man nur spekulieren. Möglicherweise hatten sich die beiden geeinigt, und die junge Elizabeth, vermutlich ein Hausmädchen, hatte einen Teil ihres Lohns erhalten. Vielleicht hatte sie aber auch inzwischen eine neue Stelle gefunden, womöglich in einem besseren Viertel im Londoner Westen, und sie verzichtete nun darauf, extra ins ferne East End zu reisen, um ihren Streit mit George Blumingback noch zu Ende zu führen. Denkbar wäre auch, daß sich Blumingback, nachdem er die Vorladung erhalten hatte, aus dem Staube gemacht hatte, und daß Elizabeth, die davon erfahren hatte, es nun als zwecklos ansah, die Sache noch weiter zu verfolgen. Es geschah nicht selten, daß Lohnstreitigkeiten auf diese Weise endeten. Die entsprechenden Spalten der Minute books weisen dann entweder Leerstellen auf oder es erscheint der Vermerk ,gestrichen' (struck out). An diesem ersten Gerichtstag des Bow County Court gab es noch eine weitere ergebnislose Lohnklage; es war die Nummer 51 auf der Liste, die Klage eines gewissen Robert Allen gegen Richard Batley, bei der es um Lohn und verkaufte Waren im Gesamtwert von $£ 219 \mathrm{~s}$. ging. Auch hier enthält das Minute book keine weiteren Eintragungen. Das Gericht stellte in solchen Fällen von sich aus keine Nachforschungen an. Die Gebühren für das Einschreiben der Klage und die Ausstellung der Vorladung mußten vom Kläger im voraus entrichtet werden,

174 Vgl. zu den folgenden Fallgeschichten: London Metropolitan Archives, CCT/AK15/1, Minute Book, 1847, Nrn. 1-52. 
insofern bestand für das Gericht keine Veranlassung mehr, der Sache nachzugehen.

Es gab an diesem Tag noch vier weitere Lohnklagen. Hier waren die Kläger erschienen, so daß das Gericht in Aktion trat. Kläger Nummer 31 auf der Liste war James King. Er hatte eine Vorladung gegen einen gewissen George Matterson erwirkt, von dem er 4s. Lohn forderte. Matterson war jedoch nicht erschienen, weil, wie der Eintrag im Minute book ausweist, die Vorladung nicht zugestellt werden konnte. Da James King offenbar auf seinem Recht beharrte, entschloß sich das Gericht, eine neue Vorladung auszustellen, und zwar kostenlos. Diese zweite Vorladung scheint den beklagten Matterson erreicht zu haben, denn gut zwei Wochen später, am nächsten Gerichtstag, dem 26. April 1847, tauchte der gleiche Fall im Minute book unter der laufenden Nummer 94 auf. James King erhielt nun seine 4s. sowie 3s. 4d. Kosten zugesprochen. Diese Summe war laut Minute book am Gerichtstag selbst, also in letzter Minute, vom beklagten Matterson im Gericht eingezahlt worden. Auf diese Weise entging Matterson der lästigen Befragung in der Öffentlichkeit des Gerichtssaals, und er sparte Zeit und zusätzliche Kosten, die eine Anhörung allemal mit sich brachte. Sieben Schilling und vier Pence waren es ihm offenbar nicht wert, seine Sicht des Falles darzustellen. James King konnte das Geld mitnehmen, und er brauchte seinem ehemaligen Arbeitgeber nicht einmal mehr ins Gesicht zu blicken. Auch dies war ein typischer Prozeßausgang; die Verfahrensordnung des county court ermöglichte es, daß Schuldsachen schnell und ohne direkte Konfrontation vor Gericht gelöst wurden, indem der Beklagte die geforderte Summe und die bis dahin angefallenen Gerichtskosten vor Verhandlungsbeginn im Gericht einzahlte. Drei der sechs Lohnklagen dieses Tages wurden also ,abgehakt', ohne daß eine reguläre Verhandlung stattfinden mußte. Das war eine durchaus normale Quote, auch bei anderen Streitgegenständen, und das erklärt, warum die county courts bis zu 200 oder in Extremfällen sogar 300 Fälle pro Tag bewältigen konnten.

Bei den übrigen drei Lohnklagen waren beide Parteien erschienen, so daß der Streit vor Gericht ausgefochten wurde. Eliza Saul, Nummer 36 auf der Liste, forderte von Henry Vincent Garman einen Gesamtbetrag von $£ 19 \mathrm{~s}$. 3d. für unbezahlten Lohn und eine Summe Geldes, die sie an die Frau des Beklagten verliehen hatte. Garman hatte schon vor Verfahrensbeginn, wie es das Gesetz verlangte, dem clerk mitgeteilt, daß er eine sogenannte special defence vorzubringen gedenke, nämlich eine Gegenforderung (set off). ${ }^{175}$

$1759 \& 10$ Vict., c. 95 (1846), s. 76: „And be it enacted, That no Defendant in any Court holden under this Act shall be allowed to set off any Debt or Demand claimed ..., unless such No- 
Einen Teil des von Eliza Saul geforderten Geldes hatte Garman im Gericht eingezahlt, die Restsumme aber bestritt er unter Verweis auf seine Gegenforderung. Wenn die klagende Eliza Saul ein Dienstmädchen war, was wahrscheinlich ist, könnte es sich um eine Ausgleichsforderung wegen zerbrochenen Geschirrs oder anderer angerichteter Schäden handeln; das war bei Konflikten zwischen Hausangestellten und ihren Herren ein häufiger Grund für einen set off. Das Gericht folgte offenbar der Argumentation des Beklagten, denn die Klägerin bekam am Ende lediglich 5s. und 6s. 4d. Kosten zugesprochen: erheblich weniger als sie verlangt hatte und sogar weniger als Garman von sich aus bereits im Gericht eingezahlt hatte. Die nächste Lohnklage auf der Liste war Nummer 47, eine gewisse Louisa Brown, die von einer Sarah Woods 16s. forderte. Hier scheiterte die Klägerin vollständig; es erging ein Urteilsspruch zugunsten der beklagten Sarah Woods, der 2s. 3d. Kosten für ihr Erscheinen zugesprochen wurden. Außerdem mußte Louisa Brown natürlich auch die Gebühr für die Anhörung des Falles (1s. 4d.) an die Gerichtskasse entrichten. Einschließlich der Gebühren für die Ausstellung und Zustellung der Vorladung (11d.), die sie bereits hatte bezahlen müssen, verlor sie also insgesamt $4 \mathrm{~s}$. 6d., mehr als ein Viertel ihrer Forderung. ${ }^{176}$

Als Nummer 50 auf der Liste, kurz vor Ende des Gerichtstags, wurde schließlich noch William Eldridge aufgerufen, der von einem gewissen John Wolmore $£ 2$ 8s. 7d. für Lohn und geleistete Arbeit forderte; die genaue Formulierung im Minute book lautete: "for wages and work and labour". Der Fall scheint komplizierter gewesen zu sein. Die ungewöhnliche Häufung scheinbar gleichartiger Klagegründe deutet darauf hin, daß Eldridge Schwierigkeiten hatte, die Art seiner Arbeitsleistung und sein Verhältnis zum Beklagten, John Wolmore, genau zu definieren. Jedenfalls entschloß sich das Gericht, den Fall auf die nächste Sitzung zu vertagen und die Frage der Kosten ebenfalls erst dann zu entscheiden. Die Entscheidung am nächsten Gerichtstag, dem 26. April 1847, wurde dadurch erleichtert, daß der Beklagte zu diesem zweiten Gerichtstermin trotz ordnungsgemäß zuge-

tice thereof as shall be directed by the Rules made for regulating the Practice of the Court shall have been given to the Clerk of the Court ...". Andere spezielle Verteidigungen', die eigens angemeldet werden mußten, waren zum Beispiel Minderjährigkeit, der Status als nicht schuld- und vertragsfähige Ehefrau (Coverture) und Bankrott.

176 Vgl. die Gebührentabelle im Anhang von 9 \& 10 Vict., c. 95 (1846), Schedule D. Hier wird noch zwischen den Gebühren des Richters, des clerk und des Gerichtsdieners, der für die Zustellung der Vorladungen und das Aufrufen der Fälle zuständig war, unterschieden. Im Jahr 1850 trat eine vereinfachte Gebührenregelung in Kraft, bei der die Gebühren nur noch pauschal, nach Streitwert differenziert, berechnet wurden. 
stellter Vorladung nicht mehr erschien; dies ermöglichte es dem Gericht, ihn in Abwesenheit zu der vollen geforderten Summe und 18s. 2d. Kosten zu verurteilen. Eldridge war somit der einzige von sechs um ihren Lohn klagenden Arbeitnehmern, der seinen Fall in vollem Umfang gewonnen hatte.

Der erste Gerichtstag des Bow County Court war insofern untypisch, als er einen vergleichsweise hohen Anteil an Lohnklagen aufwies. In den folgenden Jahren und Jahrzehnten hatten in Bow nur noch etwa eine bis zwei von hundert Klagen mit Lohnforderungen und Schadensersatz wegen ungerechtfertigter Entlassung zu tun; an vielen anderen Gerichten waren es noch weniger. ${ }^{177}$ Durchaus typisch war hingegen die Art und Weise, mit der die Fälle erledigt wurden. Ähnlich wie geschildert ging es in Bow und andernorts auch im späteren 19. und frühen 20 . Jahrhundert noch zu. ${ }^{178} \mathrm{Im}$ mer blieb ein gewisser Prozentsatz von Fällen unentschieden, weil entweder der Kläger oder der Beklagte oder beide nicht zum Gerichtstermin erschienen. Immer gab es Fälle, die dadurch gelöst wurden, daß der Beklagte die geforderte Summe noch vor Verhandlungsbeginn im Gericht einzahlte. Auch eine Teilzahlung war möglich und konnte den Fall abschließen, wenn der Kläger sich damit zufriedengab. Eine weitere Variante der Beendigung ohne Verhandlung war die Zurücknahme der Klage; im Minute book erschien dann der Vermerk withdrawn. Das konnte verschiedene Gründe haben, über die wir aus den Protokollbüchern nichts erfahren: eine außergerichtliche Einigung oder ein Verzicht oder die Einsicht, daß die Sache zwecklos war. So kam es schließlich immer nur bei einem Teil der Fälle zur direkten Konfrontation vor Gericht, die bei Lohnklagen häufiger als bei Schuldforderungen anderer Art für den Kläger negativ ausging. ${ }^{179}$

\section{NUTZUNG DER GRAFSCHAFTSGERICHTE FÜR ARBEITSSTREITIGKEITEN}

Erhaltene Protokollbücher wie das, auf dessen Basis ich den Verlauf des ersten Gerichtstags in Bow geschildert habe, bilden die einzige verläßliche Quelle für quantifzierende Aussagen zur Nutzung der Grafschaftsgerichte für bestimmte Zwecke. Die offiziellen Justizstatistiken sind für sich genommen wenig hilfreich, denn anders als bei den Friedensgerichten läßt sich daraus nicht ablesen, mit welchen Streitgegenständen sich die county courts

\footnotetext{
$177 \mathrm{Zu}$ den Zahlen siehe Tabelle 3.2, S. $243 \mathrm{f}$.

$178 \mathrm{Vgl}$. die anschauliche Schilderung durch Grafschaftsrichter Kettle in: in: Judicature Commission, Second Report, Bd. 2, Part II, Minutes of Evidence taken before the Commissioners as to County Courts and Local Courts, PP 1872 (C. 631.-I.) XX, S. $319 \mathrm{f}$.

$179 \mathrm{Zu}$ den Erfolgsquoten unten S. $252 \mathrm{ff}$.
} 
beschäftigten. ${ }^{180}$ Es wurden nur pauschale Angaben zum Klageaufkommen, zur Art der Erledigung der Fälle und zu den eingetriebenen Summen und Gebühren gemacht. Betrachtet man jedoch die nationale Statistik zusammen mit den lokal überlieferten Plaint and Minute books, ermöglicht dies Schätzungen für die Klagetätigkeit bei Lohn- und Kündigungsstreitigkeiten in England und Wales. Was die Prozeßergebnisse angeht, können die Berechnungen auf der Basis der Plaint and Minute books zusätzlich durch meine Sammlung von Zeitungsberichten abgestützt werden. Insgesamt lassen sich auf diese Weise die langfristigen Trends grob bestimmen.

Obwohl seit längerem bekannt ist, daß eine nicht unerhebliche Anzahl von Protokollbüchern erhalten geblieben ist, sind diese bisher noch nie systematisch unter einer bestimmten Fragestellung ausgewertet worden. ${ }^{181}$ Noch jüngst hat einer der besten Kenner der county courts behauptet, die wenigen erhaltenen Protokollbücher seien vom Public Record Office an die Grafschaftsgerichte selbst zurückgegeben worden. ${ }^{182}$ Tatsächlich sind die Grafschaftsgerichts-Bestände des Public Record Office an die jeweiligen Lokalarchive abgegeben worden, wo sich überdies, wie meine Nachforschungen ergeben haben, mancherorts noch weitere Akten von Grafschaftsgerichten befinden. Zwar konnte ich längst nicht alle mir bekannten Überlieferungen einsehen, doch beruhen die folgenden Ausführungen auf einem hinreichend großen Sample von Plaint and Minute books aus verschiedenen englischen Regionen, so daß die Befunde als repräsentativ gelten können.

Im Vergleich zu den Friedensgerichten zeichnete sich die Aktenführung bei den Grafschaftsgerichten von vornherein durch ein höheres $\mathrm{Maß}$ an Gleichförmigkeit und Regelmäßigkeit aus. Gewisse Probleme bei der Auswertung entstehen jedoch daraus, daß über verschiedene Aspekte der gerichtlichen Tätigkeit getrennt Buch geführt wurde. Bis zur Mitte der siebziger Jahre existierte an den meisten Grafschaftsgerichten eine Art doppelter Buchführung. Es wurde unterschieden zwischen Plaint books und Minute books. Beide Arten von Büchern enthielten vorgedruckte Spalten, in die $\mathrm{Da}$ -

180 Die Statistik sollte vor allem dem Nachweis dienen, daß die Grafschaftsgerichte effizient und kostengünstig arbeiteten. Welcher Art die Klagen waren, erschien gegenüber der Kosten-Nutzen-Rechnung zweitrangig. Anders als bei der summarischen Jurisdiktion der Friedensrichter sind die Zahlen zu den Grafschaftsgerichten von Anfang an als relativ zuverlässig anzusehen.

181 Lediglich Margot Finn, Women, Consumption and Coverture in England, c. 1760-1860, in: Historical Journal 39 (1996), S. 703-722, S. 717 ff. und Paul Johnson, Small debts and economic distress in England and Wales, 1857-1913, in: Economic History Review 46,1 (1993), S. 65-87, S. 68, haben bisher einige wenige Bücher eingesehen.

182 Gerry R. Rubin, Debtors, Creditors and the County Courts, 1846-1914: Some Source Material, in: Legal History 17 (1996), S. 73-81, S. 77. 
ten, Namen, Zahlen und Fakten handschriftlich eingetragen wurden. Die Plaint books dokumentierten das Stadium bis zum Gerichtstermin, die Minute books hielten den Verlauf und das Ergebnis der eigentlichen Gerichtsverhandlung fest. Laut Gesetz mußte der Gerichtsschreiber jede Klage in ein Buch eintragen, mit einer Nummer versehen und dazu die Namen beider Parteien, ihre Wohnorte und den Gegenstand des Streits festhalten. ${ }^{183}$ Letzteres geschah meist nur mit einem oder zwei Wörtern: goods sold, medical attendance, rent, money lent, nursing of child, breach of contract, commission, work done, wages usw. Auf der Basis des Eintrags im Plaint book erging dann die Vorladung. Die von mir eingesehenen Plaint books enthalten zusätzlich auch oft Berufsangaben. Über die Prozeßausgänge erfährt man hingegen aus den mir bekannten Plaint books nichts, es sei denn, es kam bereits vor dem Verhandlungstermin zu einer Lösung durch Einzahlung der Summe ins Gericht oder durch Verzicht des Klägers. Für den eigentlichen Prozeßverlauf vor Gericht bis hin zum Urteil wurden bis zur Mitte der siebziger Jahre des 19. Jahrhunderts gesonderte Minute books geführt. Auch dies erfolgte auf gesetzlicher Grundlage. ${ }^{184}$ Die Numerierung in den Minute books korrespondierte mit den Plaint books, die Namen der Prozeßparteien und der Streitgegenstand wurden wiederholt, nicht aber die Angaben zu Wohnorten und Berufen. Über die soziale Zusammensetzung der vor Gericht erschienenen Arbeitnehmer und Arbeitgeber kann man also auf der Basis der Minute books allein nichts Genaues sagen. Das Urteil wurde in der Regel nur durch ein Kürzel festgehalten: plt (für den Kläger, dazu in Zahlen die Angabe der Summe und Kosten), deft (für den Beklagten), nonsuit (Abweisung der Klage). Eine Parallelüberlieferung von Plaint books und Minute books gibt es nur in seltenen Fällen, so daß wesentliche Informationen oft fehlen.

Etwa seit den späten siebziger Jahren des 19. Jahrhunderts - der genaue Zeitpunkt läßt sich aufgrund der Lückenhaftigkeit der Überlieferung nicht bestimmen - ging man in den meisten Grafschaftsgerichten zu einer integrierten Form der Dokumentation über. Es wurden nunmehr fast überall Plaint and Minute books verwendet, die den gesamten Verlauf des Verfahrens vom Einschreiben der Klage bis zum Endurteil in einem Buch festhielten. Die vorher getrennt gebotenen Informationen erschienen nun zusammen. Dafür unterschied man aber jetzt zwischen Plaint and Minute books $A, B$ und $C$. Die mit $B$ bezeichneten Bücher waren für ,gewöhnliche Vorladungen' (ordinary summonses), die mit $C$ bezeichneten nur für sogenannte

$1839 \& 10$ Vict., c. 95 (1846), s. 59; 51 \& 52 Vict., c. 43 (1888), s. 73.

$1849 \& 10$ Vict., c. 95 (1846), s. 111; 51 \& 52 Vict., c. 43 (1888), s. 28. 
default summonses gedacht. In den mit $A$ bezeichneten Büchern wurden beide Typen von summonses zusammen verzeichnet. Die default summonses waren eine Form der Vorladung, die den Klägern seit 1875 zur Verfügung stand und bei der ein automatisches Urteil zugunsten des Klägers erfolgte, wenn der Beklagte nicht innerhalb von sechzehn Tagen nach $\mathrm{Zu}-$ stellung der Zahlungsaufforderung schriftlich erklärte, daß er den Fall zu verteidigen gedenke. Bei Streitwerten unter fünf Pfund war dieses Verfahren allerdings nicht zulässig, außer wenn es um verkaufte und gelieferte $\mathrm{Wa}$ ren ging. ${ }^{185}$ Es blieb den Gerichten überlassen, ob sie ein Plaint and Minute book $A$ führten oder ob sie eine nach ordinary summonses (Buch $B$ ) und default summonses (Buch $C$ ) getrennte Buchführung wählten. Die meisten Gerichte entschieden sich für die getrennte Lösung. Da es kaum Parallelüberlieferungen von Büchern $B$ und $C$ gibt, kann in diesen Fällen bei der Auswertung als Bezugsgröße zu den Arbeitsstreitigkeiten jeweils nur die Zahl der ordinary summonses (zuzüglich der verteidigten default summonses) oder der default summonses, nicht die Gesamtzahl aller Klagen vor dem betreffenden Gericht angegeben werden.

Bei allen soeben beschriebenen Protokollbüchern handelt es sich um standardisierte Ergebnisprotokolle, die nur die allernotwendigsten Informationen zu den Gerichtsfällen bieten. Diese Form der laufenden Aktenführung war dem Schnellverfahren in den Grafschaftsgerichten angepaßt. Andere Aufzeichnungen, aus denen sich wenigstens annäherungsweise die Argumentation der Beteiligten oder gar der Wortlaut des vor Gericht Gesprochenen rekonstruieren ließen, sind nur in Ausnahmefällen überliefert. ${ }^{186}$ Presseberichte sind für diese Fragen wesentlich ergiebiger. Die Kargheit der Gerichtsakten hat zur Folge, daß manche Streitigkeiten, hinter denen sich tatsächlich Arbeitskonflikte verborgen haben mögen, nicht als solche identifiziert werden können. Absolut sicher identifizierbar sind allein die Fälle, bei denen in der Spalte zum Streitgegenstand Wörter wie wages, wages in lieu of notice oder salary auftauchen. Gelegentlich finden sich ausführlichere Beschreibungen des Streitgegenstands, die auf Arbeitskonflikte

$18538 \& 39$ Vict., c. 50 (1875), s. 1. Für verkaufte und gelieferte Waren war dieses Verfahren schon 1867 ermöglicht worden. Die Berufsangaben in den Plaint and Minute books C deuten darauf hin, daß default summonses vor allem von Geschäftsleuten für ihre Streitigkeiten untereinander verwendet wurden. Die typischen Kläger waren Großhändler und Industrielle, die typischen Beklagten Kleinhändler und Handwerksmeister.

186 Notizbücher des Richters mit stichpunktartigen Mitschriften der Aussagen sind zum Beispiel überliefert für Dorking County Court, 1847-58 u. 1911-19 (Surrey County Record Office, Kingston, 615/- unverzeichnet, 3 Bde.). Ihr Aussagewert für meine Zwecke ist aber gering, da längst nicht alle Fälle notiert wurden. 
hindeuten, zum Beispiel die folgenden Einträge aus Maidstone (Kent), Bow (Ost-London) und Kettering (Northamptonshire):

2-3 Dec. 1850 / Ann Gibbons (by attorney) v. Christopher Morgan (def. service proved) / [Claim:] Work done as a schoolmistress and materials provided, board \& lodging provided and money paid, \& 20 2s. 8d. / [Judgment or Order of Court:] Plt. $£ 202$ s. $8 \mathrm{~d}$., $£ 518 \mathrm{~s}$. $4 \mathrm{~d}$. costs, by instalments of one pound per month, attorney allowed. ${ }^{187}$

2 Dec. 1872 / Cornelius Daley (person, attorney Mr. Wilson) v. Charles Ross (person, attorney Mr. Wood) / [Claim:] Damages for that the deft. by his foreman employed plt for a job $\&$ in consequence of deft. not supplying a barge the plt. has sustained loss, 6s. 3d. / [Judgment or Order of Court:] Deft., 2s. costs, on 16th instant, hearing fee 2 s. 188

21 Dec. 1882 / George Evans Abbott and Thomas Bird, Kettering, Shoemanufacturers (person) v. Palmer Timpson, 13 Wellington Place, Northampton, Traveller (person) / [Claim:] Money had and received for Plaintiff's use \& 5 9s. 3d. / [Judgment or Order of Court:] Plt, $\{5$ 9s. 3d. sol. costs etc. $£ 11$ 16s., total costs $£ 2$ 15s., Pay.t in a month. ${ }^{189}$

Hätten hier die Einträge in der Rubrik claim lediglich auf work done, damages und money had and received gelautet - alles Einträge, die häufig vorkamen -, wäre eine Identifikation als Arbeitsstreitigkeit nicht möglich. In Verbindung mit Berufsangaben lassen aber auch Kurzbeschreibungen eine Arbeitsstreitigkeit erkennen, so zum Beispiel bei dem folgenden Eintrag aus Dudley:

13 Jun. 1911 / Eliza Tinsley \& Co., Old Hill, Chain Manufacturers v. Ezra Smith, 21 Hollybush St, Cradley Heath, Chainmaker (wife) / [Claim:] Value of iron, and money advanced 11s. 7d. / [Judgment or Order of Court:] Plt 11s. 7d., 2s. costs, 1s./6d. every 28 days, by consent, fee $1 \mathrm{~s} .{ }^{190}$

Hier hatte offensichtlich eine Kettenherstellerin einem auf Werkvertragsbasis arbeitenden Kettenmacher Materialien und Geld vorgestreckt, ohne daß die erwartete Gegenleistung erbracht wurde. Die vom Gericht angeordnete, sehr niedrige Ratenzahlung von nur einem Shilling und Sixpence alle 28 Tage deutet auf die extreme Armut des beklagten Kettenmachers hin, der

187 Centre for Kentish Studies, Maidstone County Court, Minute Book, Okt. 1849 - März 1851 (unverzeichnet). Meine Zitierweise weicht der besseren Lesbarkeit halber von der Reihenfolge der Spalten in den Büchern etwas ab.

188 London Metropolitan Archives, CCT/AK15/6, Bow County Court, Minute Book, 1872-73.

189 Northamptonshire Record Office, Kettering County Court, Plaint and Minute Book A (unverzeichnet), Nr. K 1049.

190 Dudley Archives and Local History Centre, AK 64.07, Dudley County Court, Plaint and Minute Book B, Ordinary Summonses Aug. 1910 - Jul. 1911. 
sich vor Gericht durch seine Ehefrau vertreten ließ. Ein weiteres Beispiel sei zitiert, bei dem Kläger und Beklagter eher der gehobenen Mittelschicht zuzurechnen sind:

15 Oct. 1919/ William Ford, Maidstone, Dentist v. Sydney Walter Waldby, dentists Mechanic / [Claim:] Damages and Injunction, $\mathfrak{£} 50$ / Withdrawn. ${ }^{191}$

Hier handelte es sich um eine Konkurrenzklausel-Klage eines Arbeitgebers, in diesem Falle eines Zahnarztes, gegen seinen ehemaligen Assistenten, der sich verpflichtet hatte, nach Beendigung seines Dienstverhältnisses nicht am gleichen Ort in dem betreffenden Gewerbe tätig zu werden. Wie die Beispiele zeigen, kann sich theoretisch hinter allen möglichen Kurzformeln eine Arbeitsstreitigkeit verbergen. Bei meinen Zählungen habe ich jedoch nur Lohn- und Gehaltsklagen, wages in lieu of notice-Fälle sowie sicher identifizierbare Fälle wie die soeben zitierten aufgenommen.

Ein besonderes Problem bereiten Einträge wie work done oder work and labour, die in den Protokollbüchern recht häufig vorkommen. Mit derartigen Formulierungen konnte sowohl die einmalige Arbeitsleistung eines Selbständigen gemeint sein, zum Beispiel die Reparatur eines gebrochenen Rohres durch einen Klempner oder das Anfertigen eines Mantels nach Maß, als auch das Herstellen von Werkstücken oder spezifische Dienste für einen bestimmten Arbeitgeber auf mehr oder weniger regelmäßiger Basis, also etwa das Zurechtschneiden von Textilien in Heimarbeit oder das Abernten von Getreidefeldern in einer vorgeschriebenen Zeit oder die kurzfristige Beschäftigung eines Gelegenheitsarbeiters im Hafen oder auf dem Bau. Ohne begleitende Berufsangaben ist nicht feststellbar, in welchem Grad von Abhängigkeit sich die arbeitende Person zu ihrem Arbeitgeber befand, und auch mit Berufsangaben läßt sich die Statusfrage nicht immer sicher entscheiden. Während die Wörter wages und salary eindeutig ein Dienstverhältnis umschreiben, bei dem die ganze persönliche Arbeitskraft einem Arbeitgeber zur Verfügung gestellt wurde, also das, was man in deutscher Terminologie einen Dienstvertrag nennen würde, deuten die Formulierungen work done und work and labour eher auf ein Beschäftigungsverhältnis, das man im Deutschen als Werkvertrag bezeichnen müßte. In der Realität der Arbeitswelt waren die Übergänge zwischen echter Selbständigkeit, Scheinselbständigkeit und völliger Abhängigkeit fließend. Wenn ein Bergarbeiter in Gateshead von einem Bergwerksbesitzer $£ 1$ für work and labour forderte oder ein Arbeiter einen Steinbruchbetreiber auf $£ 11$ für work and

191 Centre for Kentish Studies, Maidstone County Court, Plaint and Minute Book, Ordinary Summonses, Aug. 1918 - Feb. 1920 (unverzeichnet). 
Tabelle 3.2: Grafschaftsgerichte 1847-1925: Anteil der Arbeitsstreitigkeiten a ausgewählten Gerichtsorten

\begin{tabular}{|c|c|c|c|c|}
\hline County Court & Zeitraum & $\begin{array}{l}\text { Arbeits- } \\
\text { streitigkeiten }\end{array}$ & Alle Klagen & Prozent \\
\hline \multirow[t]{7}{*}{ Bow (London) } & 1847 & 16 & 1331 & $1,20 \%$ \\
\hline & $1861-62$ & 65 & 4381 & $1,48 \%$ \\
\hline & $1872-73$ & 59 & 4107 & $1,43 \%$ \\
\hline & $1881-82$ & 72 & $4698^{c}$ & $1,53 \%$ \\
\hline & 1892 & 50 & $4490^{c}$ & $1,11 \%$ \\
\hline & 1912 & 49 & $3725^{c}$ & $1,31 \%$ \\
\hline & 1922 & 30 & $3552^{\mathrm{c}}$ & $0,84 \%$ \\
\hline \multirow[t]{3}{*}{ West London } & $1847-48$ & 52 & 2571 & $2,02 \%$ \\
\hline & 1886 & 93 & $2501^{c}$ & $3,72 \%$ \\
\hline & 1913 & 30 & $755^{b}$ & $3,97 \%$ \\
\hline Croydon & 1884 & 22 & 1029 & $2,14 \%$ \\
\hline Kingston-upon-Thames & $1912-17$ & 40 & $2501^{d}$ & $1,60 \%$ \\
\hline \multirow[t]{4}{*}{ Guildford/Godalming } & $1898-99$ & 15 & $966^{c}$ & $1,55 \%$ \\
\hline & $1911-12$ & 7 & $965^{c}$ & $0,72 \%$ \\
\hline & $1916-21$ & 3 & $924 d$ & $0,32 \%$ \\
\hline & $1923-24$ & 15 & $828^{c}$ & $1,81 \%$ \\
\hline \multirow[t]{3}{*}{ Dorking } & $1852-56$ & 14 & 541 & $2,59 \%$ \\
\hline & $1896-99$ & 15 & 1125 & $1,33 \%$ \\
\hline & $1913-22$ & 7 & 1010 & $0,69 \%$ \\
\hline \multirow[t]{9}{*}{ Maidstone } & $1849-51$ & 13 & 1361 & $0,96 \%$ \\
\hline & $1868-69$ & 13 & 1338 & $0,97 \%$ \\
\hline & $1877-78$ & 10 & 1251 & $0,80 \%$ \\
\hline & $1896-98$ & 1 & $1020^{d}$ & $0,09 \%$ \\
\hline & $1898-99$ & 6 & 1727 & $0,38 \%$ \\
\hline & $1905-07$ & 2 & $951^{d}$ & $0,21 \%$ \\
\hline & 1910 & 5 & $1740^{c}$ & $0,28 \%$ \\
\hline & $1918-20$ & 22 & $1319^{c}$ & $1,67 \%$ \\
\hline & $1919-22$ & 0 & $890^{d}$ & $0,00 \%$ \\
\hline \multirow[t]{6}{*}{ Kettering } & 1856 & 4 & 310 & $1,29 \%$ \\
\hline & $1881-82$ & 7 & 1170 & $0,60 \%$ \\
\hline & $1891-92$ & 16 & 1127 & $1,42 \%$ \\
\hline & $1901-02$ & 10 & 1263 & $0,79 \%$ \\
\hline & $1908-12$ & 1 & $1290^{d}$ & $0,08 \%$ \\
\hline & $1921-26$ & 0 & $1056^{d}$ & $0,00 \%$ \\
\hline \multirow[t]{2}{*}{ Brackley } & $1883-90$ & 33 & 1604 & $2,06 \%$ \\
\hline & $1891-95$ & 7 & 921 & $0,76 \%$ \\
\hline \multirow[t]{8}{*}{ (West) Hartlepool } & $1857-58$ & 17 & 1452 & $1,17 \%$ \\
\hline & $1875-76$ & 8 & 1541 & $0,52 \%$ \\
\hline & $1879-86$ & 3 & $1417^{d}$ & $0,21 \%$ \\
\hline & $1896-1900$ & 0 & $1765^{d}$ & $0,00 \%$ \\
\hline & $1907-12$ & 2 & $1687^{d}$ & $0,12 \%$ \\
\hline & 1910 & 5 & $1553^{b}$ & $0,32 \%$ \\
\hline & 1918-24 & 1 & $1489 d$ & $0,07 \%$ \\
\hline & $1919-20$ & 1 & $1641^{b}$ & $0,06 \%$ \\
\hline Gateshead & $1862-63$ & 21 & 2752 & $0,76 \%$ \\
\hline
\end{tabular}


Tabelle 3.2: Grafschaftsgerichte 1847-1925: Anteil der Arbeitsstreitigkeiten a ausgewäblten Gerichtsorten (Forts.)

\begin{tabular}{|c|c|c|c|c|}
\hline County Court & Zeitraum & $\begin{array}{l}\text { Arbeits- } \\
\text { streitigkeiten }\end{array}$ & Alle Klagen & Prozent \\
\hline & $1868-70$ & 40 & 4928 & $0,81 \%$ \\
\hline & 1897 & 10 & $1532^{c}$ & $0,65 \%$ \\
\hline & 1907 & 3 & $1512^{\mathrm{c}}$ & $0,20 \%$ \\
\hline \multirow[t]{2}{*}{ Walsall } & 1909-10 & 6 & $2336^{\mathrm{b}}$ & $0,25 \%$ \\
\hline & $1909-10$ & 3 & $2172^{d}$ & $0,14 \%$ \\
\hline \multirow[t]{11}{*}{ Dudley } & $1847-48$ & 45 & 3169 & $1,42 \%$ \\
\hline & $1853-54$ & 47 & 3083 & $1,52 \%$ \\
\hline & 1857 & 15 & 2104 & $0,71 \%$ \\
\hline & $1868-69$ & 46 & 6045 & $0,76 \%$ \\
\hline & $1869-70$ & 38 & 2353 & $1,61 \%$ \\
\hline & $1872-73$ & 20 & 2351 & $0,85 \%$ \\
\hline & 1881 & 16 & $2481^{c}$ & $0,64 \%$ \\
\hline & $1890-91$ & 18 & $2735^{c}$ & $0,66 \%$ \\
\hline & $1910-11$ & 13 & $4023^{c}$ & $0,32 \%$ \\
\hline & $1919-21$ & 24 & $2009 c$ & $1,19 \%$ \\
\hline & $1921-25$ & 2 & $4280^{d}$ & $0,05 \%$ \\
\hline \multirow[t]{7}{*}{ Oldbury/West Bromwich } & 1859 & 19 & 1904 & $1,00 \%$ \\
\hline & $1877-80$ & 5 & $1692^{d}$ & $0,29 \%$ \\
\hline & $1887-89$ & 1 & $1607^{d}$ & $0,06 \%$ \\
\hline & $1906-08$ & 4 & $1668^{d}$ & $0,24 \%$ \\
\hline & 1909 & 2 & $4046^{c}$ & $0,05 \%$ \\
\hline & $1917-21$ & 1 & $1737 \mathrm{~d}$ & $0,05 \%$ \\
\hline & $1919-20$ & 7 & $2037^{c}$ & $0,34 \%$ \\
\hline \multirow[t]{2}{*}{ Clitheroe } & 1847 & 4 & 458 & $0,87 \%$ \\
\hline & 1858 & 4 & 523 & $0,76 \%$ \\
\hline \multirow[t]{2}{*}{ Blackburn } & 1907 & 16 & $1970^{c}$ & $0,81 \%$ \\
\hline & $1917-18$ & 17 & $2046^{c}$ & $0,83 \%$ \\
\hline Chorley & 1917-19 & 16 & $640^{\mathrm{b}}$ & $2,50 \%$ \\
\hline Summe & & 1304 & 145076 & $0,90 \%$ \\
\hline
\end{tabular}

a Ohne Employers' Liability und Workmen's Compensation-Fälle

b Ordinary summonses

c Ordinary summonses $u$. defended default summonses

d Default summonses

Quellen: Protokollbücher: LMA CCT/AK15/1,5-8,10-11 (Bow); LMA CCT/AK43/1,10,20 (West London); Surrey County RO 3543/3 (Croydon); Surrey County RO 3545/6 (Kingstonupon-Thames); Surrey County RO 3544/1-3,7 (Guildford/Godalming); Surrey County RO 615/- unverz. (Dorking); Centre for Kentish Studies, unverz. (Maidstone); Northamptonshire RO shelf 59k, unverz. (Kettering); Northamptonshire RO shelf $58 \mathrm{p}$, unverz. (Brackley); Cleveland County Archives AK19/1,3-5,7,9-11 (West Hartlepool); Tyne and Wear Archives Service Acc 2160/1/1-2 u. Acc 2160/2/1,4-5 (Gateshead); Walsall Local History Centre AK28/1-2 (Walsall); Dudley Archives and Local History Service Acc. 8729 AK64/03,05,07-08,13-16, 20-21,24,31,34-35,40,42-43 (Dudley); Sandwell Community History and Archives Service Acc. 8932 AK34/6,10,13,18-21 (West Bromwich); Lancashire RO CYC 1/29,34 (Clitheroe); Lancashire RO CYBN 8/1/1-2 (Blackburn); Lancashire RO CYCh 3/1 (Chorley) 
labour verklagte, so kann man mit einiger Sicherheit von einem Abhängigkeitsverhältnis ausgehen. ${ }^{192}$ Englischen Rechtstheoretikern war zwar der römisch-rechtliche Unterschied zwischen Dienstverträgen und Werkverträgen bekannt, ${ }^{193}$ aber bei den Notizen in den Plaint and Minute books der Grafschaftsgerichte ist nicht davon auszugehen, daß von den clerks immer scharfe rechtliche Unterscheidungskriterien angewandt wurden. Die Gerichtsschreiber waren bei der Aufnahme des Falles auf die Aussagen der Beteiligten, in erster Linie diejenigen des Klägers, angewiesen, und die meisten Anbieter und Käufer der Ware ,Arbeit' dürften sich frühestens in dem Moment Gedanken um die Statusfrage gemacht haben, wenn sie vom clerk aufgefordert wurden, den Grund ihrer Klage zu benennen. Ob ihre Klage dann auf wages oder auf work done lautete, hing von ihrem eigenen Verständnis der Wörter, eventuell auch von den Ratschlägen eines Anwalts und von den Gepflogenheiten des clerk ab. ${ }^{194}$ Dennoch war es juristisch nicht unerheblich, wie die Schuldforderung und damit indirekt der Status der arbeitenden Person definiert wurden; es sind Fälle bekannt, die wegen falscher Benennung des Klagegegenstands zurückgewiesen wurden. ${ }^{195}$

Für die quantifizierende Auswertung der Protokollbücher mußte eine Grenze gezogen werden, und ich habe mich entschlossen, Einträge mit Formulierungen wie work done, work and labour und ähnlichem grundsätzlich nicht mitzuzählen, außer wenn begleitende Berufsangaben und andere Indizien ein Abhängigkeitsverhältnis klar erkennen lassen. Insgesamt wurden somit nur sicher identifizierbare Fälle gezählt. Deshalb sind meine Zahlenangaben zu Arbeitsstreitigkeiten in ausgewählten Grafschaftsgerichten (ohne Employers' Liability- und Workmen's Compensation-Fälle) als Mindestzahlen anzusehen (Tabelle 3.2).

Aus den Klagezahlen für die einzelnen Gerichtsorte geht zweierlei hervor. Erstens: Lohn- und Kündigungsstreitigkeiten nahmen im Alltag der Grafschaftsgerichte generell nur eine Randposition ein. Nirgends machten sie mehr als vier Prozent aller Streitsachen aus, an vielen Gerichtsorten sogar weniger als ein Prozent. Zweitens: ihre Bedeutung relativ zu allen anderen Streitsachen nahm zum Ersten Weltkrieg hin fast überall ab. Nur in London blieben die Zahlen in etwa konstant. Der in der unmittelbaren

192 Tyne and Wear Archives Service, Newcastle, 2160/1/2, Gateshead County Court, Plaint Book, 1869-70, Nrn. W 1038 u. X 476.

193 Zur Rezeption des römischen Vertragsrechts in England: Simpson, Innovation.

194 Die Tatsache, daß auch ein Eintrag wie "Wages for work done“ möglich war, läßt darauf schließen, daß die Begriffe auch bei den clerks nicht festgefügt waren. London Metropolitan Archives, CCT/AK15/7, Bow County Court, Minute Book, 1881-82, No. K 2047.

195 Vgl. etwa Northampton Mercury, 15. Okt. 1870, S. 8 (Hilyard v. Waite). 
Nachkriegszeit an einzelnen Orten (Guildford, Maidstone, Dudley) beobachtbare relative Wiederanstieg ist hauptsächlich darauf zurückzuführen, $\mathrm{daß}$ in dieser Zeit die Klagetätigkeit insgesamt wesentlich niedriger lag als vor 1914.

Eine grobe Einteilung in drei Zeitabschnitte (1847-1876, 1877-1900, 1901-1925) ergibt, bezogen auf alle Klagen in den ausgewählten Gerichtsorten, einen stabilen Anteil von etwas über einem Prozent Lohn- und Kündigungsstreitigkeiten bis zur Jahrhundertwende und einen niedrigeren Wert von etwas über einem halben Prozent für das erste Viertel des 20. Jahrhunderts (Tabelle 3.3).

Tabelle 3.3: Grafschaftsgerichte 1847-1925: Anteil der Arbeitsstreitigkeitena an allen ausgewäblten Gerichtsorten nach Zeitabschnitten

\begin{tabular}{lccl}
\hline Zeitraum & Alle Klagen & Arbeitsstreitigkeiten & Prozent \\
\hline $1847-1876$ & 48603 & 560 & $1,15 \%$ \\
$1877-1900$ & 36858 & 400 & $1,09 \%$ \\
$1901-1925$ & 59615 & 344 & $0,58 \%$ \\
\hline Gesamt & 145076 & 1304 & $0,90 \%$ \\
\hline
\end{tabular}

a Ohne Employers' Liability und Workmen's Compensation-Fälle Quellen: Protokollbücher (wie Tabelle 3.2)

Obwohl die absoluten Fallzahlen in den einzelnen Gerichten klein waren, haben wir es national gesehen keineswegs mit einem vernachlässigenswerten Phänomen zu tun. Dies zeigt sich, wenn man die für die drei Zeitabschnitte ermittelten Prozentwerte zu den Zahlen der offiziellen Justizstatistik für die Gesamtzahl der Klagen in allen englischen Grafschaftsgerichten in Beziehung setzt. Da in den county courts zwischen den späten siebziger Jahren des 19. Jahrhunderts und 1914 jährlich im Durchschnitt weit über eine Million Klagen erledigt wurden, ergeben selbst Werte von etwas über einem Prozent für das letzte Viertel des 19. Jahrhunderts stets mehr als 10000 Arbeitsstreitigkeiten pro Jahr. Das sind deutlich mehr Fälle als in den Friedensgerichten nach 1875 unter dem Employers and Workmen Act bearbeitet wurden. In den größeren Grafschaftsgerichten, wo Arbeitslasten von 150 oder 200 Fällen pro Gerichtstag üblich waren, kann man demnach um 1890 mit etwa ein bis zwei Lohn- und Kündigungsfällen in jeder Sitzung rechnen. Legt man den aus den Protokollbüchern für das erste Viertel des 20. Jahrhunderts ermittelten Wert von etwas über einem halben Prozent zu- 
grunde, müßte man für die Jahre vor dem Ersten Weltkrieg immer noch mit über 7000 Lohn- und Kündigungsklagen pro Jahr und - nach dem kriegsbedingten Einbruch - mit einem langsamen Wiederanstieg auf etwa $5500 \mathrm{Kla}$ gen im Jahr 1923 rechnen. ${ }^{196}$

Diese Schätzungen können selbstverständlich nicht mehr als einen groben Anhaltspunkt für die Größenordnungen bieten, mit denen wir es zu tun haben. Immerhin lassen sie in Verbindung mit den Zahlen für die einzelnen Gerichtsorte erkennen, daß etwa um die Jahrhundertwende - an manchen Orten früher, an anderen später - ein Rückgang der Lohn- und Kündigungsklagen vor den Grafschaftsgerichten einsetzte. Auch hier gab es also eine Abkehr der Arbeitnehmer und Arbeitgeber von der Justiz, doch machte sie sich erst später als in den Friedensgerichten bemerkbar.

Die nachlassende Attraktivität der Grafschaftsgerichte für Streitigkeiten aus dem Arbeitsvertrag fällt noch deutlicher ins Auge, wenn man die geschätzten Klagezahlen in Relation zur Gesamtzahl der Beschäftigten, also der potentiellen Kläger oder Beklagten, setzt. In den sechziger, siebziger und achtziger Jahren des 19. Jahrhunderts kamen auf 100000 Beschäftigte pro Jahr etwa 100 Klagen, kurz vor dem Ersten Weltkrieg waren es nur noch 50, und bis zum Beginn der zwanziger Jahre halbierte sich die Zahl noch einmal (Grafik 3.1). Die Wahrscheinlichkeit für einen einzelnen Arbeitnehmer oder Arbeitgeber, in eine Arbeitsstreitigkeit vor einem Grafschaftsgericht verwickelt zu werden, lag demnach bis zu den späten achtziger Jahren des 19. Jahrhunderts bei etwa 1000 zu 1, kurz vor dem Ersten Weltkrieg bei $2150 \mathrm{zu}$ 1, und in der Nachkriegszeit nur noch bei $4200 \mathrm{zu} 1$.

Wenn soeben von einer um die Jahrhundertwende einsetzenden Abkehr von den Grafschaftsgerichten die Rede war, so ist zu berücksichtigen, daß im gleichen Zeitraum die Verfahren unter dem Workmen's Compensation Act zunahmen. Dadurch blieben die Grafschaftsgerichte im Alltag der Arbeitnehmer und Arbeitgeber präsent. In den meisten englischen Regionen, vielleicht mit Ausnahme der Bergbaureviere, waren die Grafschaftsgerichte damit ab 1900 für Individualarbeitskonflikte wichtiger geworden als die Friedensgerichte.

Mögliche Gründe für die nachlassende Klagefreudigkeit der Arbeitnehmer und Arbeitgeber in den Grafschaftsgerichten sind ebenso schwer zu benennen wie im Falle der Friedensgerichte. Legislative Veränderungen scheiden als Erklärung aus, denn abgesehen von der Unfallgesetzgebung kam es nach 1875 weder im materiellen Arbeitsvertragsrecht noch im Bereich des

196 Vgl. Grafik 3.1. 
Grafik 3.1: Grafschaftsgerichte 1848-1923: Arbeitsstreitigkeiten ${ }^{\mathrm{a}}$ pro 100000 Beschäftigte
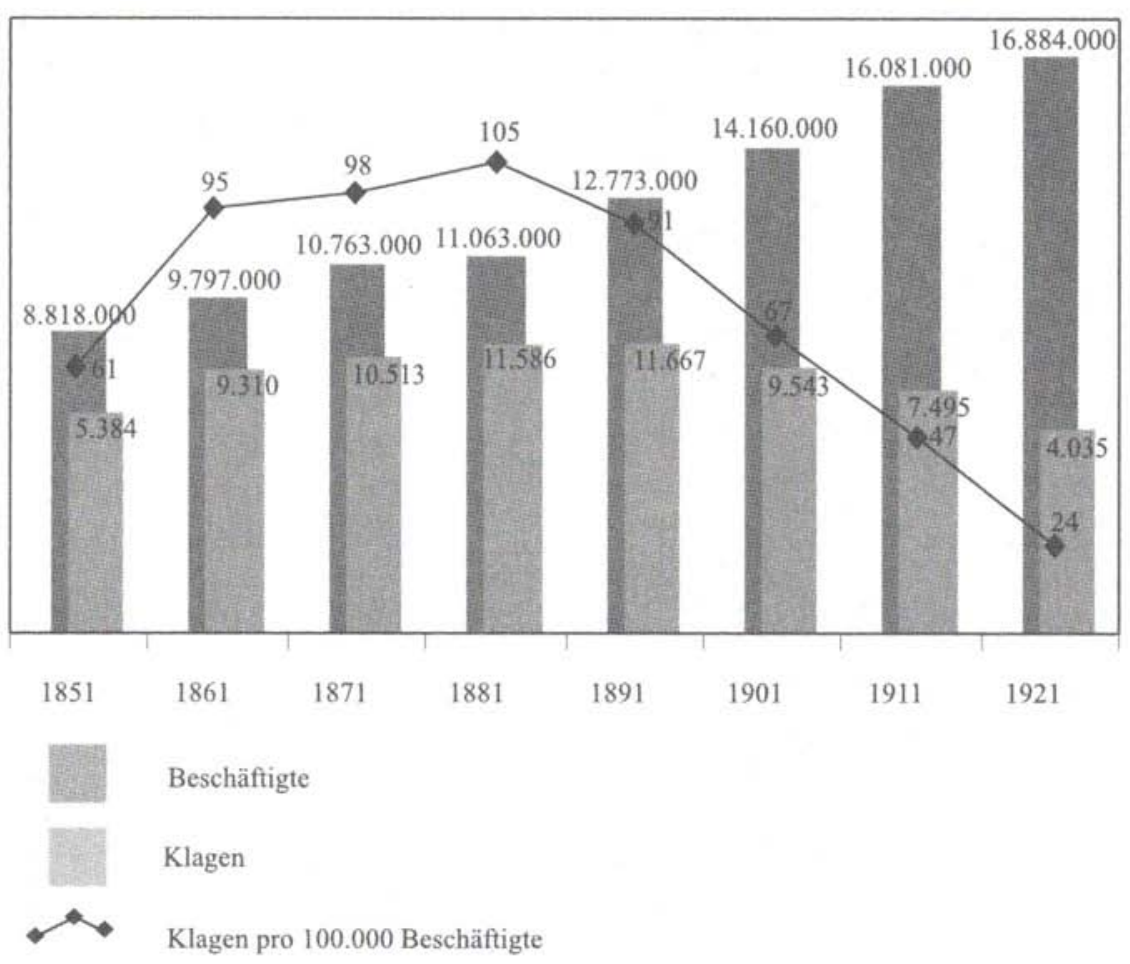

a Ohne Employers' Liability und Workmen's Compensation-Fälle

Erläuterung: 1. Die Zahlen für ,Klagen' wurden ermittelt, indem die in Tabelle 3.2 für die drei Zeitabschnitte ausgewiesenen Prozentanteile für Arbeitsstreitigkeiten mit den Zahlen für sämtliche Klagen vor den Grafschaftsgerichten aus den Justizstatistiken multipliziert wurden. Hierbei wurden (wie bei Grafik 2.3) Fünfjahresdurchschnitte, zentriert auf die Zensusjahre, gebildet. Die Zahl für 1851 beruht auf einem Neunjahresdurchschnitt für 1848-56.

2. Die Zahl der ,Beschäftigten' wurde ermittelt, indem jeweils von der im Zensus angegebenen Gesamtbevölkerungszahl (bzw. ab 1891 vom „Total aged 10 years and upwards") die Zahlen für die Kategorien „Defence“/„Armed Forces", „Domestic Offices“/„Persons supported by the Community“/„Scholars, children, unproductive“/”Indefinite and non-productive“/,Retired or unoccupied" (= Kinder, Hausfrauen, sonstige im Haus lebende Verwandte, Rentner, Schüler usw.) subtrahiert wurden.

Quellen: Protokollbücher (wie Tabelle 3.2); Civil Judicial Statistics (für 1848-56; PP 1898 [C. 8838] CIV, Introduction, S. 90; für 1913-1923: PP 1924-25 [Cmd. 2277] XXVIII, Comp. Tab., S. $4 \mathrm{f}$. "Proceedings commenced "); Census of Great Britain, 1851; Census of England and Wales $1861,1871,1881,1891,1901,1911$ u. 1921 
Zivilprozeßrechts zu einschneidenden Neuerungen. Wenn überhaupt, hätte man aufgrund der Gesetzeslage sogar eine Zunahme der Lohn- und Kündigungsklagen in Grafschaftsgerichten erwarten können, weil der Employers and Workmen Act den Handarbeitern und ihren Arbeitgebern ausdrücklich etwas gestattete, was vorher stets umstritten gewesen war: die freie Wahl zwischen Friedens- und Grafschaftsgerichten.

Untersucht man jedoch die berufliche Zusammensetzung der Streitparteien - so weit sie sich aufgrund der Protokollbücher ermitteln läßt -, so scheinen sich die in Handwerk, Bau, Bergbau, Industrie und Landwirtschaft beschäftigten Handarbeiter im späten 19. und frühen 20. Jahrhundert von den Grafschaftsgerichten zurückgezogen zu haben. Waren Handarbeiter zwischen 1847 und den frühen siebziger Jahren des 19. Jahrhunderts unter den Streitenden noch recht gut vertreten, lag ihr Anteil im späten 19. und frühen 20. Jahrhundert fast überall niedriger. Auch in den nord- und mittelenglischen Industrierevieren stellten nun die Beschäftigten aus dem Dienstleistungsbereich etwa die Hälfte, mancherorts auch die große Mehrheit der Prozeßparteien (Tabelle 3.4). Im reichen Westen Londons gehörten schon Mitte der achtziger Jahre des 19. Jahrhunderts über 80 Prozent der Streitparteien dienstleistenden Berufen an, wobei hier allein das - überwiegend weibliche - Hauspersonal (Dienstmädchen, Gouvernanten, Butler, Chauffeure) die Hälfte aller Kläger und Beklagten stellte. Im armen Osten Londons waren Beschäftigte in den Transportgewerben, im Einzelhandel, Gehilfen in Gaststätten, Pubs und Coffee shops sowie im privaten Dienstleistungssektor (Wäscherinnen, Friseure, Krankenschwestern) stärker vertreten. Neben diesen Gruppen traten in den Industrieregionen Nord- und Mittelenglands die Handlungsreisenden, Büroangestellten und höheren technischen Angestellten sowie Theaterleute und Artisten als profilierte Gruppen in Erscheinung. Der berühmteste Kläger unter der letztgenannten Gruppe war Charlie Chaplin, der im April 1909, gerade zwanzig Jahre alt geworden, im Grafschaftsgericht von West Hartlepool den Schatzmeister einer Seemannsmission auf $£ 14$ 10s. für „Wages \& hire of cinematograph \& films" verklagte. ${ }^{197}$ Tatsächlich befand sich Ted Karnos Vaudeville-Theater-

197 Cleveland County Archives, AK 19/7, Plaint and Minute Book C, 1907-12, Nr. N 117. Der volle Eintrag lautet: „28. Apr. 1909; Charles Chaplin, 61 Scarborough St, West Hpool, Layhelper v. Stuart C. Knox, The Secretary and Treasurer, and Sir Thomas Fowell Buxton, Chairman of Committee of the Missions to seamen sued on their own behalf $\&$ on behalf of all other members of the Committee of the said Missions to Seamen, 11 Buckingham Street, Strand, London, Missioners; Claim: Wages \& hire of cinematograph \& films $£ 1410$ s., sol. costs charged on the Summons 18s. 2d., fee on entering plaint 15s., fees Schedule B 4s. Date fixed for hearing 11 Jun. 1909, defence filed 13 Mai 1909 by S.C. Knox, 21 Mai 1909 by Solcrs to Sir T.F. Buxton." Leider konnte ich nicht ermitteln, wie der Fall ausgegangen ist. 


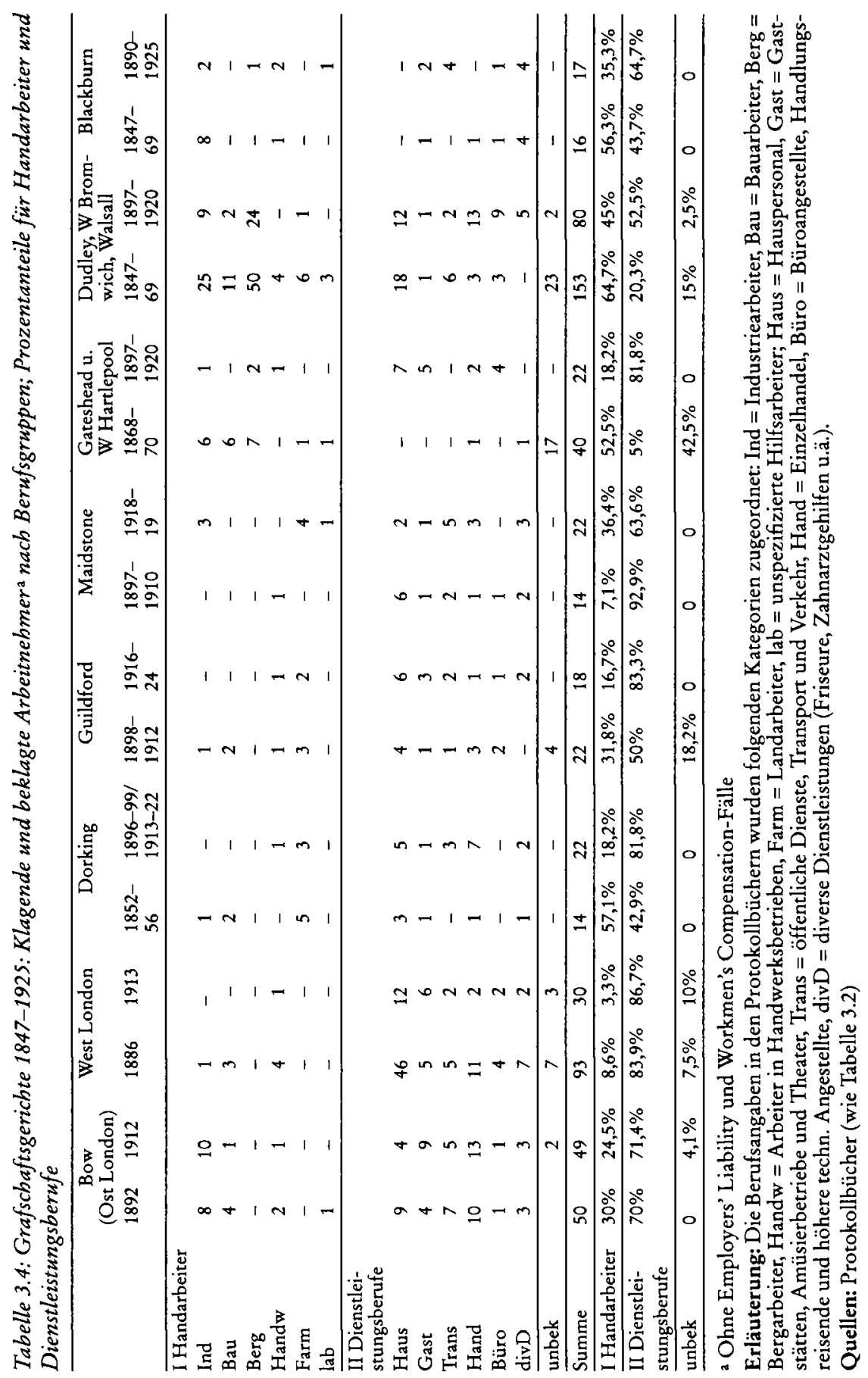


gruppe, bei der Chaplin damals engagiert war, im April 1909 in Hartlepool und Umgebung auf Tournee. ${ }^{198}$ Wie sich der Klage entnehmen läßt, hat Chaplin in seinen freien Stunden offenbar schon damals begonnen, sich seiner späteren Lebensaufgabe, dem Film, zuzuwenden.

Bei aller Vorsicht, die man angesichts der kleinen Fallzahlen walten lassen muß, läßt sich aus Tabelle 3.4 die nachlassende Nutzung der Grafschaftsgerichte durch Handarbeiter und die - relativ - zunehmende Frequentierung durch Beschäftigte im Dienstleistungssektor erkennen. Lediglich Maidstone bildet eine Ausnahme. In den Jahrzehnten vor 1914 stellten dort die dienstleistenden Berufe bereits über 90 Prozent der Streitparteien, am Ende des Krieges waren es nur noch gut 60 Prozent. Wegen der niedrigen Fallzahlen sollte man diesem Gegenbeispiel nicht zuviel Gewicht beimessen. Auch war Maidstone einer der Orte, an denen die Klagetätigkeit am Ende des Ersten Weltkriegs höher lag als vor dem Krieg. Die Tatsache, daß der bekannt arbeitnehmerfreundliche Richter Parry in Maidstone 1918-19 zu Gericht saß, mag dazu geführt haben, daß Landarbeiter und die Arbeiter der ansässigen Munitionsfabriken und Maschinenbaubetriebe sich an diesem Ort wieder vertrauensvoller an das Grafschaftsgericht wandten.

Über die Gründe für die Abkehr der in Handwerk, Landwirtschaft und Industrie tätigen Handarbeiter von den Grafschaftsgerichten kann man nur spekulieren. Außergerichtliche Konfliktlösungen, vor allem die Einrichtung betriebsinterner und branchenspezifischer Verhandlungs-, Schiedsund Einigungsinstanzen mögen insbesondere für die gewerkschaftlich organisierten Industriearbeiter eine Alternative zum Gerichtsverfahren geboten haben. ${ }^{199}$ Daneben kann auch die Angleichung der Verfahren zwischen Friedens- und Grafschaftsgerichten eine Rolle gespielt haben. Vor 1875 hatte sich das zivile Verfahren der Grafschaftsgerichte positiv vom Strafverfahren in den Friedensgerichten abgehoben. Nach 1875 näherte sich hingegen die Praxis beider Gerichte - wenigstens dem Gesetz zufolge - einander an. Sofern sich die Friedensrichter an den Geist des Gesetzes hielten, war es für Handarbeiter nun nicht mehr unmittelbar einleuchtend, warum sie den county courts den Vorzug geben sollten. So ist wohl der Befund zu erklären, $\mathrm{da} ß$ die Grafschaftsgerichts-Klagen in reinen Industriestädten wie Gates-

198 Vgl. Northern Daily Mail (Hartlepool), 6. April 1909, S. 2, „Local Amusements. ... Palace Theatre": „Ted Karno and Co., in their pantomime absurdity, made things very lively, their knockabout business being screamingly funny." Vgl. auch ebd., 10. April 1909, S. 1 (Anzeige).

199 Hierzu unten Kap. II.4. 
head, Hartlepool, West Bromwich oder Walsall stärker zurückgingen als in der Dienstleistungsmetropole London oder in südenglischen Kleinstädten mit mittelständischer Erwerbsstruktur wie Maidstone (Tabelle 3.2).

Was die Streitigkeiten aus dem Arbeitsvertrag, in der Hauptsache Lohnund Kündigungsklagen, angeht, entwickelten sich somit die county courts im späten 19. und frühen 20. Jahrhundert - pointiert gesagt - zu den ErsatzArbeitsgerichten für den tertiären Sektor, und hier waren wiederum besonders Berufe mit geringem gewerkschaftlichen Organisationsgrad und hohem Individualisierungsgrad des Beschäftigungsverhältnisses stark vertreten. Damit erklärt sich auch der im Vergleich zu den Friedensgerichten sehr hohe Anteil von Frauen unter den klagenden Arbeitnehmern in den Grafschaftsgerichten: Der Frauenanteil lag hier seit dem Ende der siebziger Jahre des 19. Jahrhunderts stets bei weit über 30 Prozent (Tabelle 3.5), während klagende oder beklagte Arbeitnehmerinnen in den Friedensgerichten eine Ausnahmeerscheinung blieben. ${ }^{200}$

Tabelle 3.5: Grafschaftsgerichte 1847-1925: Verteilung klagender Arbeitnehmer nach Geschlechtern

\begin{tabular}{lllll}
\hline Zeitraum & $\begin{array}{l}\text { AN-Klagen } \\
\text { gesamt }\end{array}$ & Männer & Frauen & unbekannt \\
\hline $1847-1876$ & 518 & $368=71,04 \%$ & $150=28,96 \%$ & \\
$1877-1900$ & 373 & $212=60,40 \%$ & $139=39,60 \%$ & $22^{\text {a }}$ \\
$1901-1925$ & 308 & $197=63,96 \%$ & $111=36,04 \%$ & \\
\hline
\end{tabular}

a Diese Zahl entstammt dem Protokoll von Croydon County Court, 1884, bei dem ich nur eine pauschale Zählung der Arbeitsstreitigkeiten vorgenommen habe, ohne die Einzelfälle detailliert zu notieren. Bei der Berechnung der Geschlechteranteile in Prozent bleiben diese 22 Fälle unberücksichtigt.

Quelle: Protokollbücher (wie Tabelle 3.2)

200 Meine Zählung aufgrund der Protokollbücher von den Friedensgerichten aus dem Zeitraum 1875-1924 ergab, daß Frauen nur in 45 von 1557 Fällen (2,9\%) als Klägerinnen und in 47 Fällen (3\%) als Beklagte auftraten. Fast alle Fälle mit Frauenbeteiligung fanden in nur zwei Gerichtsbezirken statt, beide in Cheshire: Eddisbury, wo landwirtschaftliche Arbeiterinnen klagten oder verklagt wurden (hier waren Frauen in knapp 30\% aller Fälle beteiligt), und Hyde, wo Textilarbeiterinnen - hauptsächlich als Beklagte - vor Gericht standen (hier waren Frauen sogar in 52\% aller Fälle beteiligt). Für die Quellenangaben siehe Tabelle 2.1, S. 207. 
Die berufs- und geschlechtsspezifischen Differenzierungen vermögen die regionalen Unterschiede des Klageverhaltens zu erklären, helfen aber wenig bei der Beantwortung der Frage, warum die Grafschaftsgerichte insgesamt wenn man von den Unfallangelegenheiten absieht - für klagende Arbeitnehmer und Arbeitgeber unattraktiver wurden. Zwei möglichen Gründen für den Abwärtstrend soll im folgenden nachgegangen werden. Zunächst ist zu prüfen, ob sich aus der Verteilung der Klagetätigkeit auf Arbeitnehmer und Arbeitgeber und aus den jeweiligen Erfolgsquoten weitere Aufschlüsse gewinnen lassen. Gab es in der Urteilspraxis der Grafschaftsrichter Einseitigkeiten, und kam es hier womöglich in den Jahrzehnten vor dem Ersten Weltkrieg zu Verhärtungen, welche die eine oder andere Seite veranlaßt haben könnten, den county courts fernzubleiben? Anschließend wird untersucht, ob sich in der alltäglichen Praxis des Gerichtsalltags Veränderungen ergeben haben, die für die Abkehr der Arbeitnehmer und Arbeitgeber von den county courts verantwortlich gewesen sein könnten. Zeigen sich, mit anderen Worten, Anhaltspunkte, die für eine institutionelle Erklärung der nachlassenden Klagetätigkeit sprechen?

\section{ERFOLGSQUOTEN}

Die county courts waren, da es sich um reine Zivilgerichte handelte, im Prinzip arbeitnehmerfreundlich. Für einen Arbeitgeber war eine Klage dort nur dann sinnvoll, wenn es bei dem betreffenden Arbeitnehmer ,etwas zu holen gab'. Diese Voraussetzung war bei der Masse der Beschäftigten im viktorianischen England kaum gegeben. Nachdem ein Gesetz von 1883 die persönliche Bekleidung, die Betten sowie Werkzeuge bis zu einem Gesamtwert von $£ 20$ vor dem Zugriff der Zwangsvollstreckung schützte, blieb in den meisten Fällen nicht allzu viel zu pfänden übrig. ${ }^{201}$ Auch die Lohnpfändung unterlag seit 1870 starken Beschränkungen. ${ }^{202}$ Es blieb der symbolische Wert einer Verurteilung und die Drohung mit dem Schuldgefängnis bei sogenannter Zahlungsunwilligkeit. Für moralische Belehrungen und symbolische Drohgebärden eignete sich jedoch, soweit es sich um Handarbeiter handelte, die Justiz der Friedensrichter erheblich besser. In den Friedensgerichten waren denn auch, wie im vorigen Kapitel gezeigt wurde, die Arbeit-

201 Bankruptcy Act, 46 \& 47 Vict., c. 52 (1883), ss. 44 (2) u. 122 (4).

202 Wages Attachment Abolition Act, 33 \& 34 Vict., c. 30 (1870). Faktisch griffen Arbeitgeber häufig zur Selbsthilfe, indem sie ausstehenden Lohn einfach einbehielten, auf die Klage des Arbeitnehmers warteten und dann einen set-off als special defence oder counterclaim einreichten. 
geber als Kläger in der Überzahl, und sie blieben dort auch nach der Entkriminalisierung des Kontraktbruchs prominent, wenngleich sich das Muster veränderte: Statt einzelne Arbeiter herauszugreifen, gingen die Arbeitgeber nach 1875 zur Taktik der Massenanklage über. Etwas Vergleichbares ereignete sich in den county courts nicht, obwohl der Employers and Workmen Act dies theoretisch zugelassen hätte. Wohl gab es auch dort häufig Massenklagen gegen hunderte von Personen, doch gingen diese von Händlern und Geldverleihern, sowie gelegentlich von Ärzten oder Wasserwerken aus. Diese Klagen richteten sich gegen Konsumenten, die zwar sehr oft Arbeiter waren, diese aber nicht in ihrer Rolle als Arbeitnehmer betrafen.

Wenn also Arbeitgeber vor den Grafschaftsgerichten gegen Arbeitnehmer klagten, gingen sie fast immer nur gegen Einzelne, höchstens einmal gegen eine kleine Gruppe vor. Im wesentlichen handelte es sich dabei um Schadensersatzklagen wegen versäumter Kündigung (in lieu of notice) und um die Rückforderung vorgestreckter Geldsummen oder Materialien (money had and received, goods sold, iron). Bei dem an zweiter Stelle genannten Typ von Fällen ist jedoch aus den Protokollbüchern in aller Regel nicht zu ersehen, ob eine Arbeitsstreitigkeit vorlag, weshalb ihr wahres Ausmaß im Dunklen bleibt. Das gilt auch für die Fälle, bei denen im Protokollbuch als Grund der Klage lediglich ein nicht näher erläuterter, Vertragsbruch' oder ebenso unspezifizierte ,Schädigungen' (damages) angegeben waren. Bei meiner Auswertung blieben solche unsicheren Fälle grundsätzlich unberücksichtigt.

Trotz der Ungewißheiten steht fest, daß in den Grafschaftsgerichten weitaus mehr Arbeitnehmer als Arbeitgeber klagten. Im gesamten Untersuchungszeitraum gingen stets um die 90 Prozent der Klagen von Arbeitnehmern aus. Erst seit den späten neunziger Jahren des 19. Jahrhunderts zeigt sich eine geringfügige Verschiebung des Verhältnisses zugunsten der Arbeitgeber (Tabelle 3.6). Auch die zur Kontrolle ausgewertete Sammlung von Zeitungsberichten vermittelt ein der Tendenz nach ähnliches Bild, was zugleich ein Beleg dafür ist, daß die Dunkelziffern der aus den Akten nicht erkennbaren Arbeitgeberklagen nicht allzu hoch sein können (Tabelle 3.7). Lediglich die Konkurrenzklausel-Fälle, über die in den Gewerbeblättern und juristischen Fachzeitschriften seit dem Ende des 19. Jahrhunderts ausgiebig berichtet wurde, führen zu einer etwas deutlicheren Ausprägung des Trends zugunsten der Arbeitgeber. An dem Gesamtbild einer überwiegend den Klagebedürfnissen der Arbeitnehmer entgegenkomenden Institution ändert sich jedoch dadurch nichts, und dieser Eindruck würde sich natürlich noch verstärken, wenn man die hier nicht berücksichtigten Schadensersatzklagen infolge von Arbeitsunfällen mit in Rechnung stellte. 
Tabelle 3.6: Grafschaftsgerichte 1847-1925: Verbältnis Arbeitnebmerklagen zu Arbeitgeberklagen an ausgewäblten Gerichtsorten ${ }^{a}$

\begin{tabular}{lccrc}
\hline & AN v. AG & AG v. AN & unbekannt & Gesamt \\
\hline $1847-1876$ & $518=92,50 \%$ & $31=5,54 \%$ & $11=1,96 \%$ & 560 \\
$1877-1900$ & $373=93,25 \%$ & $17=4,25 \%$ & $10=2,50 \%$ & 400 \\
$1901-1924$ & $308=89,54 \%$ & $30=8,72 \%$ & $6=1,74 \%$ & 344 \\
\hline
\end{tabular}

a ohne Employers' Liability- und Workmen's Compensation-Fälle

Quelle: Protokollbücher (wie Tabelle 3.2)

Tabelle 3.7: Grafschaftsgerichte 1847-1925: Verbältnis Arbeitnebmerklagen zu Arbeitgeberklagen nach Presseberichten ${ }^{a}$

\begin{tabular}{lrrrc}
\hline & AN v. AG & AG v. AN & unbekannt & Gesamt \\
\hline $1847-1876$ & $129=93,48 \%$ & $9=6,52 \%$ & - & 138 \\
$1877-1900$ & $152=93,83 \%$ & $10=6,17 \%$ & - & 162 \\
$1901-1924$ & $87=86,14 \%$ & $14=13,86 \%$ & - & 101 \\
\hline
\end{tabular}

a ohne Employers' Liability- und Workmen's Compensation-Fälle

Quelle: Sample aus Presseberichten

Im Hinblick auf die Erfolgsfrage ist zu berücksichtigen, daß längst nicht alle begonnenen Verfahren mit einem Urteil endeten und daß viele Urteile eingetragen wurden, ohne daß eine Anhörung vor Gericht stattfand. Zählt man nur diejenigen Arbeitnehmerklagen, die zu einem Urteil führten (unabhängig davon, ob es zu einer Anhörung kam oder nicht), sowie diejenigen, bei denen die geforderte Summe vor Verhandlungsbeginn im Gericht eingezahlt wurde, so ergibt sich für klagende Arbeitnehmer eine Erfolgsrate, die um einen Mittelwert von 56 Prozent pendelte. ${ }^{203}$ Das entsprach ungefähr dem Wert in den Friedensgerichten, jedoch mit dem entscheidenden Unterschied, daß die county courts viel mehr Arbeitnehmerklagen bearbeiteten (Tabelle 3.8). Die Analyse der Zeitungsberichte unter dem Gesichtspunkt des Klageerfolgs zeigt auch hier im wesentlichen das gleiche Resultat wie es aus den Protokollbüchern zu ermitteln ist. Arbeitnehmer waren den Presseberichten zufolge im Durchschnitt in 61 Prozent der von ihnen angestrengten Klagen erfolgreich (Tabelle 3.9).

203 Auch Teilzahlungen habe ich als, Erfolg' gewertet, wenn sie vom Kläger akzeptiert wurden. Employers' Liability- und Workmen's Compensation-Fälle wurden nicht berücksichtigt. 
Tabelle 3.8: Grafschaftsgerichte 1847-1925: Klageerfolge der Arbeitnebmer an ausgewäblten Gerichtsorten

\begin{tabular}{lcccccc}
\hline Zeitraum & $\begin{array}{l}\text { AN-Klagen } \\
\text { insgesamt }\end{array}$ & $\begin{array}{l}\text { Ausgang } \\
\text { unbekannt }\end{array}$ & $\begin{array}{l}\text { Ausgang } \\
\text { bekannt }\end{array}$ & AN-Erfolg & $\begin{array}{l}\text { AN- } \\
\text { Mißerfolg }\end{array}$ & $\begin{array}{l}\text { "withdrawn“/ } \\
\text { "struck out" }\end{array}$ \\
\hline $1847-1876$ & 518 & 128 & 390 & $223=57,18 \%$ & $86=22,05 \%$ & $81=20,77 \%$ \\
$1877-1900$ & 373 & 88 & 285 & $179=62,81 \%$ & $40=14,03 \%$ & $66=23,16 \%$ \\
$1901-1924$ & 308 & 56 & 252 & $120=47,62 \%$ & $38=15,08 \%$ & $94=37,30 \%$ \\
\hline
\end{tabular}

Quelle: Protokollbücher (wie Tabelle 3.2)

Tabelle 3.9: Grafschaftsgerichte 1847-1925: Klageerfolge der Arbeitnebmer nach Presseberichten

\begin{tabular}{lcccrc}
\hline Zeitraum & $\begin{array}{l}\text { AN-Klagen } \\
\text { insgesamt }\end{array}$ & $\begin{array}{l}\text { Ausgang } \\
\text { unbekannt }\end{array}$ & $\begin{array}{l}\text { Ausgang } \\
\text { bekannt }\end{array}$ & AN-Erfolg & AN-Mißerfolg \\
\hline $1847-1876$ & 129 & 13 & 116 & $58=50,00 \%$ & $58=50,00 \%$ \\
$1877-1900$ & 152 & 1 & 151 & $107=70,86 \%$ & $44=29,14 \%$ \\
$1901-1924$ & 87 & 0 & 87 & $51=58,62 \%$ & $36=41,38 \%$ \\
\hline
\end{tabular}

Quelle: Sample aus Presseberichten

Klagende Arbeitnehmer waren damit allerdings weniger erfolgreich als die Gesamtheit aller Kläger in den county courts. Diese erreichten den Justizstatistiken zufolge stets in mehr als 95 Prozent der entschiedenen Fälle ein für sie günstiges Urteil, und daran änderte sich im gesamten Untersuchungszeitraum nichts. Blieben somit die Erfolgsaussichten für die Gesamtheit aller Kläger konstant hoch, waren sie für klagende Arbeitnehmer gewissen Schwankungen unterworfen. Im letzten Viertel des 19. Jahrhunderts lagen die Erfolgschancen der Arbeitnehmer deutlich über den Durchschnittswerten von 56 beziehungsweise 61 Prozent, im ersten Viertel des 20. Jahrhunderts darunter. Nimmt man hinzu, daß nach 1900 auch die Arbeitgeber etwas häufiger als zuvor als Kläger in Erscheinung traten, läßt sich daraus auf eine gewisse Verhärtung der Rechtsprechung in den Grafschaftsgerichten gegenüber Arbeitnehmern schließen. $\mathrm{Ob}$ freilich diese ex post erkennbare leichte Verschlechterung der Erfolgschancen von den zeitgenössischen Arbeitnehmern überhaupt wahrgenommen werden konnte, erscheint höchst fraglich. Dafür war der Trend denn doch nicht drastisch genug. Als Erklärung für die allmähliche Abkehr von den county courts reicht der Faktor Klageerfolg jedenfalls nicht aus.

Einen Hinweis auf mögliche Gründe liefert jedoch die genauere Analyse des Anteils der ohne Urteil endenden Arbeitnehmerklagen. Dieser Anteil 
stieg im Laufe des Untersuchungszeitraums kontinuierlich an, sehr im Unterschied zum Trend bei der Gesamtheit aller Klagen in den county courts. Während in den county courts insgesamt immer mehr Fälle durch Urteil abgeschlossen wurden, endeten bei den Arbeitsstreitigkeiten mehr und mehr Fälle damit, daß eine vorzeitige Einzahlung ins Gericht stattfand oder daß die Klage ausgestrichen oder zurückgezogen wurde. Arbeitnehmer und Arbeitgeber schreckten offenbar immer öfter davor zurück, einen Streit bis zum bitteren Ende auszufechten (Tabelle 3.10).

Tabelle 3.10: Grafschaftsgerichte 1847-1925: Verbältnis der durch Urteil entscbiedenen Fälle zu den auf andere Weise ("paid ", "struck out ", "withdrawn ", "not served") erledigten Fälle

\begin{tabular}{lccccc}
\hline Zeitraum & $\begin{array}{l}\text { Klagen } \\
\text { insgesamt }\end{array}$ & $\begin{array}{l}\text { Ausgang } \\
\text { unbekannt }\end{array}$ & $\begin{array}{l}\text { Ausgang } \\
\text { bekannt }\end{array}$ & $\begin{array}{l}\text { durch Urteil } \\
\text { entschieden }\end{array}$ & anders erledigt \\
\hline $1847-1876$ & 560 & 135 & 425 & $267(62,82 \%)$ & $158(37,18 \%)$ \\
$1877-1900$ & 400 & 93 & 307 & $144(46,91 \%)$ & $163(53,09 \%)$ \\
$1901-1924$ & 344 & 54 & 290 & $106(36,55 \%)$ & $184(63,45 \%)$ \\
\hline
\end{tabular}

Quelle: Protokollbücher (wie Tabelle 3.2)

Die Zahlen lassen darauf schließen, daß Arbeitnehmer und Arbeitgeber das streitige Verfahren vor einem ordentlichen Gericht zunehmend als ungeeignet zur Lösung ihrer Konflikte empfanden. Sie suchten nach anderen Lösungswegen, aber sie bekamen nur das geboten, was die reguläre Justiz ihnen vorsetzte: ein im Verhältnis zur Streitsumme kostspieliges, oft langwieriges und in jedem Fall für beide Seiten ärgerliches Verfahren, dessen Ausgang ungewiß war und von dem am Ende oft nur die Anwälte profitierten. In den Protokollbüchern der späteren Jahrzehnte finden sich unter den tatsächlich vor Gericht ausgetragenen Verfahren etliche, die wieder und wieder vertagt wurden, sei es aus Zeitmangel, sei es, weil die hinzugezogenen Anwälte komplizierte Fragen aufwarfen, die nicht sogleich entschieden werden konnten. Arbeitgeber wichen dem aus, indem sie lieber gleich bezahlten oder ihre Beschäftigten durch welche Methoden auch immer dazu bewogen, die Klage zurückzuziehen. Zu gewinnen hatten Arbeitgeber in Lohn- oder Kündigungsfällen ohnehin nicht viel, außer vielleicht, wie es ein Rechtsratgeber für Laien formulierte, „die zweifelhafte Ehre, eine bisher ungeklärte Rechtsfrage durch den County Court geklärt zu sehen. “204 Für

204 Anon. [A Barrister-at-Law], The Home Counsellor, London o.J. [nach 1938], S. 233. 
die Arbeitnehmer wiederum war es allemal attraktiver, ein vielleicht nur halb befriedigendes Angebot des Arbeitgebers anzunehmen als das Risiko eines Prozesses mit hohen Kosten und ungewissem Ausgang einzugehen. Bei vielen Arbeitnehmern mag im übrigen genau dies der Hauptzweck der Klage gewesen sein: Sie wollten Druck auf den Arbeitgeber ausüben, ein solches Kompromißangebot zu machen. Erfolgte es, war es gut, erfolgte es nicht, verzichtete man lieber auf weitere Schritte, um nicht noch mehr zu verlieren.

Nicht das Mißtrauen gegen die Richter als Personen, nicht die Annahme einer wie immer gearteten einseitigen Urteilspraxis in den Grafschaftsgerichten, nicht real oder in der Einbildung sinkende Erfolgsaussichten führten zu dieser Entwicklung. Ausschlaggebend, zumindest mitentscheidend für die zunehmende Abkehr vom streitigen Verfahren waren vielmehr Gründe, für die man niemanden persönlich verantwortlich machen konnte. Es waren Gründe, die mit dem schleichenden Funktionswandel der county courts und den daraus resultierenden Veränderungen der alltäglichen Gerichtspraxis zu tun hatten, Gründe mit anderen Worten, die eher in den institutionellen Rahmenbedingungen als in der Entscheidungsgewalt einzelner Personen lagen. Einige Faktoren, die das Erscheinungsbild der Grafschaftsgerichts-Justiz im Untersuchungszeitraum veränderten und die Abkehr vom streitigen Verfahren mitverursacht haben könnten, werden im folgenden benannt.

\section{FUNKTIONSWANDEL DER GRAFSCHAFTSGERICHTE: MARGINALISIERUNG DER INDIVIDUALKLÄGER}

Eine Maschinerie zur Schuldeneintreibung waren die county courts von Anfang an. Notorische Kläger waren die schottischen tallymen: ambulante Textil- und Kurzwarenhändler, die an der Haustür Waren gegen Ratenzahlung verkauften, dann oft nicht pünktlich bezahlt wurden und daher in einer Art symbiotischer Beziehung mit den county courts lebten. ${ }^{205}$ Viele Richter in englischen Industrierevieren betrachteten die tallymen als eine Landplage und scheuten sich nicht, ihnen besonders hohe Beweispflichten aufzuerlegen, wenn sie serienweise Arbeiter und arme Leute wegen angeblicher Zahlungsunwilligkeit ins Gefängnis bringen lassen wollten, um sie zur Zahlung zu zwingen. Tatsächlich standen in diesen Fällen meist die

205 Hierzu: G. R. Rubin, The County Courts and the Tally Trade, 1846-1914, in: ders. u. David Sugarman (Hg.), Law, Economy and Society, S. 321-348. 
Frauen als die eigentlichen Käufer und stellvertretend für ihre Männer vor Gericht.

Aber es waren schon bald nicht mehr nur ambulante Textilhändler, sondern zunehmend auch andere Großhändler, Firmen, Schuldenaufkäufer und halböffentliche Einrichtungen wie Gas- und Wasserwerke, die durch ihre Massenklagen, manchmal bis zu 150 am Tag, die Zeit der Grafschaftsrichter und ihrer registrars fast vollständig in Anspruch nahmen. Ähnlich wie die Verkehrsdelikte die Friedensgerichte überschwemmten, beherrschten diese Massenklagen den Alltag der Grafschaftsgerichte. Auch die Rationalisierung der Protokollführung durch Stempel für häufig wiederkehrende Kläger und für ihren normalen Streitgegenstand (goods sold) konnte die Verstopfung der Gerichte mit derartigen Fällen nicht beseitigen. ${ }^{206}$ Schon am äußeren Erscheinungsbild der Plaint and Minute books läßt sich ablesen, wie die Massenkläger etwa seit den neunziger Jahren des 19. Jahrhunderts im Gerichtsalltag immer mehr in den Vordergrund drängten. Die Leidtragenden waren die Einzelkläger, darunter Arbeitnehmer, deren Fälle aus Zeitmangel vertagt und oft Wochen später gebündeit an einem bestimmten Tag behandelt werden mußten, damit sie nicht ganz untergingen. Daß viele Einzelkläger unter diesen Umständen auf die Fortführung der Angelegenheit oder überhaupt auf eine Klage verzichteten, ist leicht einzusehen.

Ein zweiter Faktor, der sich ähnlich negativ für Einzelkläger auswirkte, war die Kompetenzerweiterung der Grafschaftsgerichte für eine Reihe spezieller und meist komplizierter Rechtsmaterien. Diese Entwicklung machte sich etwa von der Jahrhundertwende an immer stärker bemerkbar. Für Workmen's Compensation-Fälle mit ihren langwierigen Anhörungen technischer Experten und medizinischer Gutachter und ihren wiederkehrenden Anträgen von Arbeitgeber- oder Arbeitnehmerseite auf Überprüfung der wöchentlichen Entschädigungszahlung mußten in den größeren städtischen county courts nun oft ein bis zwei Tage pro Woche reserviert werden. Die Zahl der durch den Grafschaftsrichter als Schiedsrichter zu entscheidenden Workmen's Compensation-Fälle stieg in den Jahren bis zum Ersten Weltkrieg steil an von $1500 \mathrm{im}$ Jahr 1900 auf $8100 \mathrm{im} \mathrm{Jahr} \mathrm{1911;} \mathrm{danach} \mathrm{begann}$ sie wieder zu sinken bis auf $5000 \mathrm{im}$ Jahr 1923. Im gleichen Zeitraum stieg die Zahl der zu registrierenden Memoranden über außergerichtliche Einigungen unter dem Gesetz von 1200 im Jahr 1900 auf 23100 im Jahr 1911, um dann bis 1923 langsam auf 17000 zurückzugehen. ${ }^{207}$ Daneben hatten die

206 Für Beispiele siehe oben, Fn. 145 u. 151.

207 Vgl. die Tabellen für die Jahre bis 1913 bei Bartrip, Workmen's Compensation, S. 20, 22 u. 
größeren Grafschaftsgerichte auch Equity-Angelegenheiten und Bankrotte zu bearbeiten, beides Aktivitäten, für die ebenso wie für Workmen's Compensation-Sachen spezielle Register geführt wurden. Die Notgesetzgebung während des Ersten Weltkriegs, die es den Gerichten erlaubte, Schulden, Mietzahlungen und Vertragserfüllungen für die Dauer des Krieges zurückzustellen, erzeugte vor allem in den ersten Nachkriegsjahren zusätzliche Prozesse, als die Gläubiger ihre Foderungen erneut vorzubringen versuchten. ${ }^{208}$ Prozesse um die Liquidation von Altschulden verstorbener Personen und nicht mehr weitergeführter Betriebe stellten ein weiteres kompliziertes Problem dar. Sehr zeitraubend waren schließlich die im und nach dem Ersten Weltkrieg stark zunehmenden Klagen von Vermietern, Maklern und Kreditanstalten auf Wiederinbesitznahme (possession) von Grundstükken, Häusern und Wohnungen, deren Hypotheken oder Mieten von den Besitzern nicht mehr bezahlt werden konnten. In der Nachkriegszeit mußten auch für diesen Klagetyp vielerorts spezielle Gerichtage reserviert werden.

Infolge dieser Entwicklungen ließ der Zeitdruck im Gerichtsalltag in den frühen zwanziger Jahren des 20. Jahrhunderts nicht nach, obwohl die Anzahl der ,normalen' Klagen weitaus niedriger als in der Vorkriegszeit lag. So kam es vor, daß selbst geringfügige Lohnklagen, bei denen (ausnahmsweise) einmal beide Parteien persönlich erschienen waren, mehrmals verschoben wurden, anstatt am gleichen Tage erledigt zu werden, wie es in viktorianischer Zeit die Regel gewesen war. Neben der Vielzahl spezieller Materien, für die eigene Sitzungen anberaumt werden mußten, war also für das, was urprünglich das ,normale` Geschäft der Grafschaftsgerichte bilden sollte die kleinen Klagen kleiner Leute -, kaum noch Platz. Die county courts nahmen seit dem späten 19. Jahrhundert den Charakter einer Agentur an, in deren unübersichtlichen Verfahren sich nur noch die notorischen Vielkläger und die Anwälte zurechtfanden. Privatkläger brauchten viel Geld und $\mathrm{Ge}$ duld, wenn sie in diesem System zum Ziel kommen wollten. Beides waren Güter, die Arbeitnehmern kaum zur Verfügung standen, es sei denn, sie konnten die Rechtsberatung und -hilfe einer Gewerkschaft in Anspruch nehmen. Die typischen Arbeitnehmerkläger - Dienstmädchen, Verkäuferinnen, Lieferanten, Music-Hall Artisten, Vertreter usw. - konnten dies in

68f. Die Zahlen für 1923 in den Civil Judicial Statistics, PP 1924-25, XXVIII (Cmd. 2277), Table XX (9.), S. 34.

208 Vgl. Courts Emergency Powers Act, $4 \& 5$ Geo. 5, c. 78 (1914) sowie ergänzende und ausdehnende Gesetze von 1916, 1917, 1919 und 1920. Die normale Gerichtspraxis wurde ab September 1923 durch den Expiring Laws Continuance Act, $13 \& 14$ Geo. 5, c. 37 wiederhergestellt. 
der Regel nicht, und so erklärt sich der Rückgang der Arbeitsstreitigkeiten (mit Ausnahme der Workmen's Compensation-Fälle) zum Teil aus den genannten institutionellen Veränderungen. Glaubt man den Justizkritikern und Verbraucherschützern der Gegenwart, hat sich an diesen Mißständen des Systems der county courts seit dem Ersten Weltkrieg nichts geändert; ein Zeitungsbericht von 1993 beschreibt das System als einen „Trümmerhaufen". 209

Der Anspruch der Common law-Juristen, daß das, gewöhnliche Recht ${ }^{\star}$ und die ordentliche Justiz in einer komplexen Industriegesellschaft wie der englischen des 20. Jahrhunderts zur Regelung aller Rechtsprobleme ausreichen müßten, führte also auf der Ebene der niederen Zivilgerichtsbarkeit zu einer Überlastung mit einer Vielfalt von Aufgaben, die, wie zum Beispiel im Fall des Workmen's Compensation Act, oft eher administrativer als juridischer Natur waren. Die personelle und sachliche Ausstattung der Grafschaftsgerichte blieb demgegenüber fast unverändert. Das hatte zur Folge, daß die gewöhnlichen vertrags- und deliktsrechtlichen Streitigkeiten, für welche die county courts ursprünglich eingerichtet worden waren, zur $\mathrm{Ne}$ bensache wurden. Die Abkehr der Arbeitnehmer und Arbeitgeber von den Grafschaftsgerichten läßt sich so zum Teil aus aus dem Funktionswandel der Institution erklären.

\section{SCHIEDS- UND EINIGUNGSSTELLEN}

\section{EIN FUNKTIONALES ÄQUIVALENT FÜR ARBEITSGERICHTE?}

Bis in die siebziger Jahre des 20. Jahrhunderts galt es in Großbritannien als selbstverständlich, daß das Recht und die Gerichte mit der Beilegung von Arbeitsstreitigkeiten möglichst nichts zu tun haben sollten. Je weniger die Juristen sich einmischten, desto besser - so lautete die übereinstimmende Meinung fast aller Beteiligten.210 Dem Hinweis auf die Arbeitsgerichtsbarkeit anderer Länder begegnete man mit dem Argument, daß britische Arbeitnehmer kaum dazu zu bewegen seien, eine mit rechtlichen $Z_{\text {wangsmit- }}$ teln ausgestattete Institution zu akzeptieren. Zur Begründung der abweh-

209 Vgl. Danny Lee, Courts short, in: Time Out, 3.-10. Nov. 1993, S. 13: „Plaintiffs are increasingly finding themselves victims of negligence and maladministration in the shambolic county courts system."

$210 \mathrm{Vgl}$. die einleitenden Sätze in Wedderburn, Worker, S. 13: „Most workers want nothing more of the law than that it should leave them alone. In this they can be said to display an instinct that is fundamental to British industrial relations." 
renden Haltung verwies man auf die Geschichte, genauer auf jene Meistererzählung von der Selbstbefreiung der Arbeiterbewegung aus Klassengesetzgebung und Klassenjustiz, die uns aus dem ersten Kapitel bekannt ist.

In dieser Erzählung geht es freilich nicht nur um die Verdrängung der Justiz aus dem Arbeitsleben. Die Erzählung hat vielmehr auch eine positive Seite. Sie handelt von dem einzigartigen Auf- und Ausbau eines immer perfekteren und umfassenderen Systems der Streitschlichtung und des kollektiven Verhandelns im Laufe des späten 19. und frühen 20. Jahrhunderts. Die Genese dieses Systems ist untrennbar mit dem Aufstieg der britischen Gewerkschaften verbunden. Entsprechend positiv wird das kollektive Verhandeln als typisch britische Methode der Konfliktlösung von den meisten $\mathrm{Hi}$ storikern der Arbeiterbewegung und auch von den Arbeitsrechtlern bewertet. Viele Autoren scheinen davon auszugehen, ohne es immer eigens zu begründen, daß das System des kollektiven Verhandelns eine Art Ersatz für die bis 1964/71 nicht vorhandene Arbeitsgerichtsbarkeit in Großbritannien darstellte. ${ }^{211}$ Es ist jedoch bisher unklar, ob der ausdifferenzierte Einigungsund Schlichtungsapparat im Rahmen des kollektiven Verhandelns tatsächlich jene Aufgaben mitübernahm, die von der ordentlichen Justiz in England offensichtlich nicht (mehr) erfüllt wurden. Kann man wirklich ohne weiteres annehmen, daß die Einigungsausschüsse und Schiedsverfahren, die paritätischen Kommissionen und die informellen Verhandlungs- und Einspruchsprozeduren in den Betrieben den Gang zum Gericht erübrigten? Waren es diese Einrichtungen, die für englische Arbeitnehmer und Arbeitgeber den Rekurs auf den Rechtsweg überflüssig gemacht haben? Mit dieser, in der Forschung eher stillschweigend vorausgesetzten als ernsthaft überprüften Annahme befassen sich die folgenden Überlegungen.

Träfe diese Annahme zu, so wäre eine zusätzliche Erklärung für die beschriebene Abkehr von den Friedens- und Grafschaftsgerichten gewonnen. Die seit den siebziger Jahren des 19. Jahrhunderts sich ausbreitenden Schieds- und Einigungsstellen (arbitration and conciliation boards) hätten dann dafür gesorgt, daß die ordentliche Justiz immer seltener und schließlich nur noch in Ausnahmefällen bemüht werden mußte. Damit wären die freiwilligen britischen Einrichtungen auch als funktionales Äquivalent für die Arbeitsgerichtsbarkeit in anderen Ländern, etwa in Deutschland, zu

211 Am klarsten formuliert wird diese These von Ralf Rogowski u. Adam Tooze, Individuelle Arbeitskonfliktlösung und liberaler Korporatismus. Gewerbe- und Arbeitsgerichte in Frankreich, Großbritannien und Deutschland im historischen Vergleich, in: Vorträge zur Justizforschung, Bd. 1, hrsg. v. Heinz Mohnhaupt u. Dieter Simon, Frankfurt/Main 1992, S. $317-386$, S. 333 u. 377. 
verstehen. So sah es jedenfalls im Jahr 1906 ein deutscher Beobachter, Waldemar Zimmermann, der wie viele andere Deutsche um die Jahrhundertwende nach Großbritannien gereist war, um dort die Methoden der friedlichen Beilegung von Arbeitskonflikten zu studieren und seinen Landsleuten zur Nachahmung zu empfehlen. ${ }^{212}$ Zimmermann betrachtete die von unten herauf gewachsenen britischen Schieds- und Einigungsstellen als Äquivalente zu der von oben herab verordneten deutschen Gewerbegerichtsbarkeit:

Aus der freiwilligen Übereinkunft der beteiligten beiden Lager sind gemeinsame Ausschüsse erwachsen, die die Rechtsstreitigkeiten und Auslegungsschwierigkeiten aus dem Arbeitsvertrage schlichten oder entscheiden, während in Deutschland das die Gewerbegerichte besorgen. ${ }^{213}$

Die Ausführungen des deutschen Autors lassen erkennen, daß er bei seinem Vergleich primär an die Funktion der Gewerbegerichte als Einigungsämter dachte, nicht so sehr an ihre im engeren Sinne gerichtliche Tätigkeit bei individuellen Konflikten, die ja, wie wir noch sehen werden, im Alltag der Gewerbegerichte den weitaus größten Raum einnahmen. Was Zimmermann an den freiwilligen Einigungs- und Schlichtungsstellen in Großbritannien so faszinierte und was sie in seinen Augen vorteilhaft von dem „künstlich von oben geschaffenen Mechanismus" der deutschen Gewerbegerichte (als Einigungsämter) abhob, war die streikverhindernde und erzieherische Wirkung der britischen Einrichtungen. ${ }^{214}$ Das Wunschbild einer befriedeten Arbeitswelt ohne kollektive Arbeitskämpfe durchzieht den gesamten Text und führte bei Zimmermann des öfteren zur Idealisierung der britischen Zustände. Wenn er an der soeben zitierten Stelle von „Rechtsstreitigkeiten und Auslegungsschwierigkeiten aus dem Arbeitsvertrage" sprach, so hatte er dabei nicht in erster Linie Einzelarbeitsverträge vor Augen, sondern das, was andere deutsche Autoren, zum Beispiel Philipp Lotmar, zu diesem Zeitpunkt bereits üblicherweise als Tarifverträge bezeichneten. ${ }^{215}$ Gewiß

212 Waldemar Zimmermann, Gewerbliches Einigungswesen in England und Schottland (Schriften der Gesellschaft für Soziale Reform, Heft 22), Jena 1906. Der Autor berichtete über eine Studienreise nach Großbritannien, an der unter anderem auch Vertreter der HirschDunckerschen und der christlichen Gewerkschaften, darunter Heinrich Imbusch und Adam Stegerwald, teilgenommen hatten. Auch deutsche Arbeitgeber entsandten gelegentlich $\mathrm{Be}-$ obachter nach England, doch waren diese weniger enthusiastisch. Vgl. z. B.: Berichte der von industriellen und wirthschaftlichen Vereinen nach England entsendeten Kommission zur Untersuchung der dortigen Arbeiterverhältnisse, hrsg. von den betreffenden Vereinsvorständen, Berlin 1890.

213 Zimmermann, Einigungswesen, S. 13.

214 Ebd., S. 14.

215 Die Begriffe ,Arbeitsvertrag' und "Tarifvertrag' hatten sich um 1906 in der deutschen Dis- 
traten unterschiedliche Interpretationen von Tarifverträgen häufig an Einzelfällen zutage, insofern hatten es die britischen Schieds- und Einigungsstellen auch mit derlei „Bagatellkonflikten“, wie Zimmermann sie an anderer Stelle abfällig nennt, zu tun. ${ }^{216}$ Aber Zimmermann interessierte sich in seinem Bericht nicht weiter für die Frage, in welcher Weise Tarifverträge zu rechtwirksamen Bestandteilen von Individualarbeitsverträgen werden konnten und wie die englische Praxis in diesem Punkt aussah. Im Gegensatz zur deutschen Rechtswissenschaft, die sich um die Jahrhundertwende intensiv mit diesem Problem zu befassen begann,217 war Zimmermann an scharfen Unterscheidungen zwischen Rechtskonflikten einerseits, rein wirtschaftlichen Interessenkonflikten andererseits gar nicht gelegen. Ebensowenig differenzierte er sorgfältig zwischen individuellen und kollektiven Streitigkeiten. ${ }^{218}$ Vielmehr wollte er gerade zeigen, daß ein Streitschlichtungssystem auch ohne juristische Distinktionen und ohne detaillierte gesetzliche Vorschriften auskam, ja daß ein flexibles System wie das britische besser funktionierte als die überregulierten, an die Gewerbegerichte angegliederten deutschen Einigungsämter.

\section{DER BEGRIFF DES ,DISPUTS‘ UND SEINE FOLGEN FÜR DIE WAHRNEHMUNG INDIVIDUELLER ARBEITSSTREITIGKEITEN}

Die Flexibilität der Prozeduren und die Unschärfe der Definitionen werden in britischen Darstellungen jüngeren Datums als positives Merkmal der industriellen Beziehungen in Großbritannien hervorgehoben. Eine zu starke

kussion noch nicht endgültig verfestigt. Vgl. zur Begriffsgeschichte von ,Arbeitsvertrag;: Rückert, „Frei“ und „sozial“, hier S. 229-243. Hinweise zum Begriff, Tarifvertrag' um 1900 bei: Philipp Lotmar, Die Tarifverträge zwischen Arbeitgebern und Arbeitnehmern, in: Archiv für soziale Gesetzgebung und Statistik 15 (1900), S. 1-122. Sinzheimer sprach in seinem Hauptwerk noch vom „korporativen Arbeitsnormenvertrag“: Hugo Sinzheimer, Der korporative Arbeitsnormenvertrag. Eine privatrechtliche Untersuchung. 2 Teile. Unveränderter Nachdruck der 1. Auflage von 1907/08, Darmstadt 1977. Vgl außerdem: Waldemar Zimmermann, Art. Tarifvertrag, in: Handwörterbuch der Staatswissenschaften, 4. Aufl., Bd. 8, Jena 1928, S. 1-33, hier S. 2 f.; ferner: Peter Ullmann, Tarifverträge und Tarifpolitik in Deutschland bis 1914. Entstehung und Entwicklung, interessenpolitische Bedingungen und Bedeutung des Tarifvertragswesens für die sozialistischen Gewerkschaften, Frankfurt/Main 1977, hier bes. S. 14-19 u. $106 \mathrm{ff}$.

216 Zimmermann, Einigungswesen, S. 69 u. 95.

217 Hierzu im Überblick: Gerd Bender, Strukturen des kollektiven Arbeitsrechts vor 1914, in: Harald Steindl (Hg.), Wege zur Arbeitsrechtsgeschichte, Frankfurt/Main 1984, S. 251-293.

218 Vgl. Zimmermann, Einigungswesen, S. 36. Dort kommt er auf die joint committees im Kohlenbergbau von Northumberland und Durham zu sprechen, die „nur individuelle Streitfragen der einzelnen Gruben, ja einzelner Örter behandeln“ würden. Was er hier „individuelle Streitfragen" nennt, waren natürlich oft kollektive Konflikte. 
Formalisierung oder gar Verrechtlichung der Methoden des Streitschlichtens gilt allgemein als abträglich für den Erfolg. Autoren wie Allan Flanders, Otto Kahn-Freund und K.W. Wedderburn sehen es keineswegs als Nachteil an, daß man im britischen Arbeitsleben auf präzise Unterscheidungen zwischen individuellen und kollektiven Konflikten, zwischen Streitigkeiten aus bestehenden Verträgen und Streitigkeiten um zukünftig zu schließende Verträge immer verzichtet habe. ${ }^{219}$ Eine Ausnahme bildeten einmal mehr Sidney und Beatrice Webb, die in ihrem Hauptwerk „Industrial Democracy" großen Wert auf genaue Definitionen legten und dafür eintraten, Konflikte um neue Vereinbarungen und Konflikte um die Interpretation bestehender Verträge sorgfältig auseinanderzuhalten. ${ }^{220}$ Auch standen die Webbs der Verrechtlichung als gewerkschaftlicher Strategie generell aufgeschlossen gegenüber. Für bestimmte Konfliktfelder, namentlich Fragen der Sicherheit am Arbeitsplatz und der Länge des Arbeitstags, erschien ihnen die Methode des "legal enactment“ angemessener als freiwillige Schiedsverfahren oder freies Verhandeln.221 Ausgiebig kritisierten die Webbs die unpräzisen Begriffe ihrer Zeitgenossen und das planlose Experimentieren mit verschiedenen Formen des Verhandelns und Streitschlichtens. In der Praxis kümmerte man sich aber wenig um die Mahnungen der Webbs. Gewerkschaftssekretäre, Arbeitgeber, Ministerialbeamte und auch der Gesetzgeber sprachen stets nur von, gewerblichen Disputen', ohne danach zu fragen, ob es sich um Rechts- oder Interessenkonflikte handelte, und ohne einen prinzipiellen Unterschied zu sehen, wenn einmal mehrere tausend, dann wieder nur ganz wenige Arbeitnehmer in den ,Disput' verwickelt waren. Typisch für die allgemeine begriffliche Unschärfe war die Definition des Trade Disputes Act von 1906:

In this Act ... the expression ,trade dispute، means any dispute between employers and workmen, or between workmen and workmen, which is connected with the employment or non-employment, or the terms of the employment, or with the conditions of labour, of any person, ....222

219 Allan Flanders, Collective Bargaining, in: ders. u. H.A. Clegg (Hg.), The System of Industrial Relations in Great Britain. Its History, Law and Institutions, Oxford 1954, S. 252-322, S. 254 f.; Kahn-Freund, Legal Framework, S. 97 f.; Wedderburn u. Davies, Employment Grievances, S. 57 f. u. 66.

220 Webb, Industrial Democracy, hier bes. S. $182 \mathrm{ff} ., 191,205,225 \mathrm{f}$. Vgl. auch E.P. Hennock, Lessons from England: Lujo Brentano on British Trade Unionism, in: German History 11 (1993), S. 140-160, S. 151.

221 Webb, Industrial Democracy, S. 255 ff., 796-806 (Abwägung zwischen den Vor- und Nachteilen von collective bargaining und legal enactment).

$2226 \mathrm{Edw} .7$, c. 47 (1906), s. 5 (3). 
Die Formulierung läßt offen, ob mit den hier angesprochenen "terms" und "conditions" vertraglich bereits festgelegte oder noch festzulegende Arbeitsbedingungen gemeint waren; ebenso unterscheidet sie auch nicht zwischen Individual- und Kollektivstreitigkeiten. Ähnlich dehnbare Formulierungen finden sich in den Statuten der boards of conciliation, boards of arbitration und joint committees, die seit den siebziger Jahren des 19. Jahrhunderts in immer mehr Industrien etabliert wurden. Sofern sich diese Gremien schriftliche Regeln gaben, beschränkten sich diese meist darauf, bestimmte Prozeduren bezüglich Zusammensetzung und Beschlußfassung festzulegen. Über die sachliche Zuständigkeit wurde dagegen in der Regel kaum etwas gesagt. ${ }^{223}$ Immerhin läßt sich aus den Namen mancher Gremien ablesen, daß sie ausschließlich mit einem bestimmten Typ von ,Disput ${ }^{\prime}$ zu tun hatten. So befaßte sich etwa das Tyne Shipwrights', Joiners' and Employers' Standing Committee for Demarcation of Work nur mit Konflikten um die Abgrenzung zwischen bestimmten jobs auf den Schiffswerften an der Tynemündung. ${ }^{224}$ Bei den meisten Einigungsausschüssen auf nationaler, regionaler oder lokaler Ebene überwogen aber weitgefaßte Aufgabenbestimmungen. Die 1905 für das britische Baugewerbe verabschiedeten Richtlinien umschrieben den Zweck der zu errichtenden conciliation boards folgendermaßen:

The object of the Conciliation Boards shall be to adjust all questions or disputes relating to hours of labour, rates of wages, working rules and demarcation of work that may from time to time arise and be referred to them either by Employers or

223 Eine Sammlung und Kommentierung der Statuten von 194 boards in: PP 1908 (Cd. 3788) XCVIII: Report on Rules of Voluntary Conciliation and Arbitration Boards and Joint Committees, London 1907. Die Statuten neugegründeter boards sowie Auszüge aus den Tätigkeitsberichten der bestehenden Einrichtungen finden sich regelmäßig in den ab 1889 vom Handelsministerium herausgegebenen und in den Parliamentary Papers publizierten $\mathrm{Be}$ richten über Streiks und Aussperrungen. Die folgenden Beispiele entstammen dem Report on Strikes and Lock-Outs and on Conciliation and Arbitration Boards in the United Kingdom in 1905, PP 1906 [Cd. 3065] CXII. Berichte über einzelne Fälle vor den Schieds- und Einigungsstellen finden sich außerdem regelmäßig in der Labour Gazette unter der Rubrik "Recent Conciliation \& Arbitration Cases and Collective Agreements". Nach diesen Mitteilungen zu urteilen, hätten es die boards nahezu ausschließlich mit kollektiven Auseinandersetzungen um zukünftige Arbeitsbedingungen zu tun gehabt, aber dies spiegelt mehr die Interessen der Berichterstatter als die Realität wider.

224 Report on Strikes and Lock-Outs, 1905, S. 112. Im Jahr 1905 behandelte dieses Komitee lediglich zwei Fälle: „One case was a question as to whether joiners or shipwrights should fit insulation round engine and boiler casings of a certain ship. It was decided that this was a special case and that joiners and shipwrights should do one half each. The other case was a question of stowage ... and this was left in the hands of the manager of the yard affected." 
Operatives with a view to an amicable settlement of the same without resorting to strikes or lock-outs. 225

Das war noch relativ ausführlich. In anderen Statuten hieß es lapidar, daß der betreffende board sich mit „allen Fragen“, welche die Interessen der Beschäftigten und Arbeitgeber berührten, oder einfach mit „allen Fragen“, die mit dem betreffenden Gewerbe zusammenhingen, befassen sollte. ${ }^{226}$

Aufgrund der ungenauen Aufgabenbeschreibung in vielen Statuten ist es nicht leicht, die oben gestellte Frage nach den quasi-gerichtlichen Funktionen der Einigungs- und Schiedsstellen zu beantworten. Nur Einzelstudien können klären, ob die betreffenden boards und committees jeweils auch bei individuellen Streitigkeiten, zum Beispiel bei Kündigungen, in Aktion traten und was sie in solchen Fällen für den einzelnen Beschwerdeführenden leisteten. Weder zeitgenössische Beobachter noch die Forschung haben sich für dieses Problem in nennenswertem Umfang interessiert. ${ }^{227}$ Das erklärt sich zum Teil aus der Entstehungsgeschichte der Schieds- und Einigungsstellen.228 Auf Seiten der Arbeitgeber war die primäre Motivation beim Aufbau dieser Einrichtungen überall die Verhinderung großer Streiks und Aussperrungen. Das Ziel der Domestizierung von Arbeitskämpfen bestimmte auch die Versuche des Staates, das Einigungs- und Schlichtungswesen durch legislative Eingriffe zu fördern.229 Bei den Gewerkschaften ging es zunächst um die Anerkennung als gleichberechtigte Verhandlungspartner durch Arbeitgeber und staatliche Behörden. War dies einmal erreicht, stand die Sicherung größtmöglicher Vorteile für die eigene Mitgliedschaft im Vordergrund. Ins Bewußtsein einer weiteren Öffentlichkeit rückten die Einigungs- und Schlichtungsstellen nur anläßlich größerer Lohnkämpfe und damit verbundener tatsächlicher oder angedrohter Arbeitskampfmaßnahmen. Bei allen unmittelbar oder mittelbar Beteiligten standen also die kollektiven Konflikte im Mittelpunkt der Aufmerksamkeit. Die historische Forschung schließlich hat die verschiedenen Verfahren und Institutionen

225 Ebd., S. 127 (Rules for the Establishment and Governance of Conciliation Boards in the Building Trade).

226 Ebd., S. 129 (Board of Conciliation for the Cumberland Iron Ore Trade) u. 130 (Standing Committee for the Louis XV. Heel Trade).

227 Einzige Ausnahme, allerdings nur bezogen auf die Realität der sechziger Jahre des 20. Jahrhunderts, ist die Studie von Wedderburn u. Davies, Employment Grievances.

228 Siehe dazu: V. L. Allen, The Origins of Industrial Conciliation and Arbitration, International Review of Social History 9 (1964), S. 237-254.

229 Hierzu bes. Roger Davidson, The Board of Trade and Industrial Relations 1896-1914, in: Historical Journal 21 (1978), S. 571-591. Ferner auch: Christoph Cornelißen, Das „Innere Kabinett“. Die höhere Beamtenschaft und der Aufbau des Wohlfahrtsstaates in Großbritannien 1893-1919, Husum 1996, S. 338-348. 
vor allem daraufhin untersucht, ob sie die Schlagkraft der Gewerkschaften förderten oder hemmten und ob die Arbeiternehmer von den jeweiligen Verhandlungsergebnissen materiell profitierten oder nicht. ${ }^{230}$ Unter beiden Gesichtspunkten fällt das Ergebnis für die frühen, bis etwa 1890 vorherrschenden Formen der Konfliktlösung - Schiedssprüche von Unparteiischen, Vereinbarung gleitender Lohnskalen - eher negativ aus. Demgegenüber wird dann die Herausbildung des freien kollektiven Verhandelns in den folgenden Jahrzehnten bis 1914 als Fortschritt gewertet. Die Forschungen laufen, kurz gesagt, darauf hinaus, daß Gewerkschaften und Arbeitnehmer im Schnitt um so bessere Ergebnisse für sich erzielten, je mehr sie die Interventionen von dritter Seite abschütteln konnten, das heißt also sich nicht mehr auf unparteiische Schiedsrichter, anonyme Preisbewegungen oder den Staat verließen, sondern statt dessen ganz auf die eigene Stärke setzten.

Die hier nur summarisch skizzierte Interessenlage der Beteiligten und der Forschung bringt es mit sich, daß individuelle Arbeitsstreitigkeiten nur selten ins Blickfeld derer gerieten, die über das Schieds- und Einigungswesen berichteten. Noch mit am ergiebigsten sind in dieser Hinsicht die älteren deutschen Studien von Schulze-Gaevernitz, Brentano, Auerbach, Lotz und Zimmermann sowie die Beobachtungen der Webbs. ${ }^{231}$ Aus der Sicht der britischen Gewerkschaftsfunktionäre, Verbandssekretäre und Ministerialbeamten waren Individualfälle ,Bagatellsachen', die nur dann Interesse verdienten, wenn sie Anlaß zu größeren, kollektiven ,Disputen' gegeben hatten oder zu geben drohten. Der seit 1889 jährlich erscheinende Report on Strikes and Lock-outs enthielt ab 1894 auch statistische Angaben und Fallberichte zur Tätigkeit der dem Ministerium bekannten conciliation and arbitration boards. In der Statistik der von den boards bearbeiteten und gelösten Fälle wurden hier individuelle Dispute mit wenigen Beteiligten genauso wie größere Arbeitskämpfe mitgezählt; das Interesse der Berichterstatter galt jedoch fast nur den Erfolgen bei der Beilegung von Streiks.

230 Vgl. vor allem: Porter, Wage Bargaining; Jonathan Zeitlin, From Labour History to the History of Industrial Relations, in: Economic History Review 40 (1987), S. 159-184; John G. Treble, Sliding Scales and Conciliation Boards: Risk-Sharing in the late 19th Century British Coal Industry, in: Oxford Economic Papers 39 (1987), S. 679-698.

231 Gerhart von Schulze-Gaevernitz, Zum socialen Frieden. Eine Darstellung der socialpolitischen Erziehung des englischen Volkes im neunzehnten Jahrhundert, 2 Bde., Leipzig 1890, bes. Bd. 2, S. 280-432; Brentano, Einleitung, in: ders. (Hg.), Arbeitseinstellungen; Auerbach, Ordnung des Arbeitsverhältnisses, in: ebd., S. 1-268; Walther Lotz, Das Schieds- und Einigungsverfahren in der Walzeisen- und Stahlindustrie Nordenglands, in: ebd., S. 269-328; Zimmermann, Einigungswesen; Webb, Industrial Democracy, S. 185-206, 231-237, 311-314. 
Typische Individualkonflikte, die gelegentlich Beachtung fanden, weil sie schnell zu Weiterungen führten, waren schikanöse Entlassungen von Gewerkschaftsmitgliedern und Streitigkeiten um die richtigen Maße und Gewichte bei der Lohnzahlung in der Textilindustrie oder im Kohlenbergbau. ${ }^{232}$ Vor allem die letztgenannten Lohnstreitigkeiten hätten theoretisch auch vor Friedens- oder Grafschaftsgerichten verhandelt werden können; Beispiele dafür gibt es in genügender Zahl. ${ }^{233}$ Insofern kann man eine gewisse Konkurrenz zwischen freiwilligen Einigungs- und Schiedsinstanzen und ordentlichen Gerichten voraussetzen. Gerade bei den sogenannten Testfällen dürfte es jedoch oft statt eines Konkurrenzverhältnisses eher eine zeitliche Abfolge der beiden Verfahren gegeben haben. Wenn man noch einmal die Analogie zu den deutschen Gewerbegerichten bemühen will, so könnte man die Verhandlungen vor den außergerichtlichen Gremien in Großbritannien dem Sühneversuch gleichsetzen, der im deutschen Gewerbegerichtsverfahren in jedem Fall zuerst unternommen werden mußte, während der Gang zum Friedens- oder Grafschaftsgericht dem zweiten, streitigen Stadium des deutschen Verfahrens entsprechen würde, das in der Regel mit einem Urteil zugunsten der einen oder anderen Seite endete.234

Trotz der durch unscharfe Begriffe und zeitgenössische Wahrnehmungsdefizite hervorgerufenen Probleme sind auf der Basis des publizierten Materials einige vorläufige Schlußfolgerungen zur Wirksamkeit der Schiedsund Einigungsstellen möglich. Diese seien zunächst kurz zusammengefaßt, bevor sie im Anschluß anhand von Beispielen - der Chronologie folgend näher erläutert werden. An erster Stelle ist daran zu erinnern, daß die Praxis der Schieds- und Einigungsstellen im Umgang mit individuellen Streitigkeiten von Branche zu Branche und von Ort zu Ort variierte. Generalisierende Aussagen stehen daher stets unter dem Vorbehalt, daß es auch Ausnahmen gab. Unbeschadet dessen lassen sich, zweitens, keine Indizien für eine $\mathrm{Zu}-$ nahme des Anteils individueller Rechtskonflikte vor den boards of arbitration and conciliation im Untersuchungszeitraum erkennen. Wenn es also

232 Vgl. etwa Labour Gazette, Sept. 1908, S. 271 (dismissal of fellow workman); Labour Gazette, Nov. 1908, S. 335 (price to be paid for getting coal). Dazu auch die Übersicht über Ursachen und Gegenstände von "Trade Disputes" in: Report on the Strikes and Lock-Outs of 1896, PP 1897 (C. 8643) LXXXIV, S. XVI. Von den 1021 gemeldeten ,Disputen' (Arbeitsniederlegungen) des Jahres 1896 betrafen 570 Lohnfragen, 164 „working arrangements", 103 Fragen der Gewerkschaftszugehörigkeit am Arbeitsplatz und immerhin 43 mit 9104 Beteiligten die Wiedereinstellung von einzelnen entlassenen Arbeitskollegen.

233 Vgl. etwa Labour Gazette, April 1895, S. 121 (Streit um Korrektheit eines Webmusters); April 1896, S. 119; Mai 1896, S. 151; Juni 1896, S. 181 f. (Streitigkeiten um das Wiegen von Kohle).

234 Näheres zum Gewerbegerichtsverfahren unten, Kap. II.5. 
wegen der Konkurrenz dieser Einrichtungen in den Jahrzehnten vor dem Ersten Weltkrieg zu einer Flucht aus der ordentlichen Justiz gekommen sein soll, so müßte man dies hauptsächlich darauf zurückführen, daß die Zahl der Schieds- und Einigungsstellen selber zugenommen hat. ${ }^{235}$ Gegen die Konkurrenz-These spricht aber, drittens, daß wir es bei der Anzahl der insgesamt vor diesen boards und committees verhandelten Fälle, ganz gleich welcher Art, mit relativ geringen Größenordnungen zu tun haben. ${ }^{236}$ Demzufolge müßte man die Bedeutung der Schieds- und Einigungsstellen als direkte Konkurrenten der Friedens- und Grafschaftsgerichte eher gering veranschlagen. Nicht zu unterschätzen ist jedoch, viertens, die Rückwirkung der Schieds- und Einigungsinstanzen sowie der ihnen vorgelagerten informellen Verhandlungen auf das Konfliktverhalten und das Rechtsbewußtsein der Arbeitnehmer selbst. Der informelle und formelle Einigungsund Schlichtungsapparat wirkte wie ein Filter, der vom einzelnen Beschwerdeführenden erst durchlaufen werden mußte, bevor der Rechtsweg überhaupt in Erwägung gezogen wurde. Mehr noch, der extrem weitgefaßte Begriff des ,Disputs' sorgte dafür, daß potentielle Rechtskonflikte von den Beteiligten zunächst gar nicht als solche wahrgenommen und behandelt wurden, sondern einfach als irgendwie zu lösende Fälle. Die vielleicht wichtigste Leistung des britischen Schieds- und Einigungssystems bestand demnach darin, das Denken in juristischen Kategorien und verletzten Rechtsansprüchen von den alltäglichen Konflikten am Arbeitsplatz fernzuhalten. Es kam hinzu, fünftens, daß das gewerkschaftliche Hilfsangebot für einzelne Beschwerdeführende in aller Regel an die Bedingung geknüpft war, daß der Betroffene seinen Fall nicht selbst weiter verfolgte, sondern die Entscheidung über die weitere Art der Behandlung den zuständigen Gremien seiner Trade Union überließ. Die Gewerkschaften, in erster Instanz der lokale oder betriebliche Gewerkschaftssekretär, hatten es also in der Hand, ob sie die Angelegenheit als Interessenkonflikt oder als Rechtskonflikt oder überhaupt nicht weiterführen wollten. Wie verschiedene Trade Unions mit diesem Problem umgingen, wird später, im Zusammenhang mit den Schwellen vor dem Gang zum Gericht, erörtert werden. ${ }^{237}$

235 Die Zahl der dem Board of Trade bekannten ständigen Schieds- und Einigungsstellen (das waren natürlich nicht alle Einrichtungen dieser Art) wuchs von $105 \mathrm{im} \mathrm{Jahr} 1896$ über 164 im Jahr 1905, $296 \mathrm{im} \mathrm{Jahr} 1910$ auf 343 im Jahr 1913. Vgl. Report on the Strikes and LockOuts of 1896, PP 1897 (C. 8643) LXXXIV, S. XLI f.; Report on Strikes and Lock-Outs and on Conciliation and Arbitration Boards in the United Kingdom in 1913, PP 1914-16 (Cd. 7658) XXXVI, S. XXXV.

236 Für Zahlen siehe Grafik 4.1, S. 280.

237 Siehe unten, Kap. III.3. 
Mit den vorstehenden Thesen ist das bereits voll ausgebildete System beschrieben, wie es sich zwischen Jahrhundertwende und Erstem Weltkrieg darstellte und dann nach dem Intermezzo der kriegsbedingten Zwangswirtschaft auf der Basis der Freiwilligkeit weiterentwickelte. Es soll nun zunächst auf die Voraussetzungen und treibenden Kräfte eingegangen werden, die seit der Mitte des 19. Jahrhunderts zur Entstehung dieses spezifischen Schieds- und Einigungswesens geführt haben. Anschließend wird anhand von Beispielen aus einzelnen Branchen die weitere Entwicklung bis zum Ende des Ersten Weltkriegs verfolgt. Dabei wird besonders auf die Bedeutung der Individualfälle und auf das mögliche Konkurrenzverhältnis zur ordentlichen Gerichtsbarkeit geachtet. War die mangelnde Attraktivität des Common law und der Friedens- und Grafschaftsgerichte ein Motiv für die Suche nach alternativen Formen der Streitschlichtung?

\section{DIE ANFÄNGE DES FREIWILLIGEN SCHIEDS- UND EINIGUNGSWESENS}

In einzelnen, hochorganisierten Gewerben existierte bereits zu Beginn des 19. Jahrhunderts eine Maschinerie zur Vereinbarung von Tarifen und zur Schlichtung von Auslegungsdifferenzen. Am bekanntesten ist der Fall der Londoner Schriftsetzer, bei denen es schon 1785 zur Vereinbarung einer ersten Preisliste zwischen Compositors und Master Printers kam, der später so genannten London Scale of Prices. ${ }^{238}$ Wie weit dabei von einer Kontinuität noch älterer, zünftlerischer Traditionen der gewerblichen Streitschlichtung auszugehen ist, braucht hier nicht zu interessieren. ${ }^{239}$ Bei den Schieds- und Einigungsstellen des späteren 19. Jahrhunderts, von denen in diesem Abschnitt die Rede ist, handelt es sich durchweg um Neugründungen, die nach

238 Vgl. Ellic Howe u. Harold E. Waite, The London Society of Compositors (re-established 1848). A Centenary History, London etc. 1948, S. 41-46; Ellic Howe (Hg.), The London Compositor. Documents relating to Wages, Working Conditions and Customs of the London Printing Trade 1785-1900, London 1947, S. 69-94 (Texte der frühen Tarifskalen u. Dokumente zum Entstehungskontext).

239 Zur Regulierung der Arbeitsbeziehungen im Londoner Druckgewerbe bis zum Ende des 18. Jahrhunderts (mit Dokumenten) ebd., S. 10-32; ferner: J.C. Cannon, The Roots of Organization among Journeymen Printers, in Journal of the Printing History Society 4 (1968), S. 91-107. Zur Bedeutung der Stationers' Company, der Zunft des Druck- und Buchgewerbes: Karl Tilman Winkler, Handwerk und Markt. Druckerhandwerk, Vertriebswesen und Tagesschrifttum in London 1695-1750, Stuttgart 1993, S. 45 f. u. 50-56. Die Arbeitsbeziehungen zwischen Meistern und Gesellen werden in diesem umfangreichen Werk kaum thematisiert. Allgemein zur Bedeutung der Zunfttradition für die gewerkschaftliche Entwicklung im englisch-deutschen Vergleich: Christiane Eisenberg, Deutsche und englische Gewerkschaften. Entstehung und Entwicklung bis 1878 im Vergleich, Göttingen 1986, S. $26 \mathrm{ff}$., 51-54 u. $130 \mathrm{ff}$. 
einer mehr oder weniger langen Phase des harten Kampfes zwischen Arbeitgebern und Gewerkschaften ins Leben gerufen wurden und bei denen die Erinnerung an etwaige Zunfttraditionen keine praktische Bedeutung mehr besaß. Grundlegend für die neu geschaffenen Gremien war stets der Gedanke der gegenseitigen Anerkennung und paritätischen Vertretung, mit oder ohne präsidierendem Unparteiischen. So war es auch im Fall der London Society of Compositors, die sich im Februar 1848 als Abspaltung von der National Typographical Association neu konstituierte. Nach einer längeren Periode ständiger Auseinandersetzungen um die London Scale gelang es der Society im Jahr 1856, mit der Master Printers' Association eine Vereinbarung über ein paritätisches Schiedsgremium zu treffen, das aus je drei Arbeitnehmer- und Arbeitgebervertretern bestand und unter dem Vorsitz eines barrister strittige Fragen lösen sollte. Die Regel Nummer eins des neuen Arbitration Committee lautete kurz und bündig: „The Object of the Arbitration Committee: To avoid referring Trade Disputes to Courts of Law." 240

Die Vermeidung von kostspieligen Gerichtsprozessen war also auf beiden Seiten ein erklärtes Motiv für die Einrichtung des Schiedsgremiums der Compositors, aber das Gegenteil trat ein. Schon nach kurzer Zeit, im April 1857, weigerte sich die Society, einen aus ihrer Sicht "unvernünftigen“ Schiedsspruch des vorsitzenden barrister, eines gewissen Mr. Sweet, zu akzeptieren, und verlangte von den Arbeitgebern eine Wiederaufnahme des Falles. ${ }^{241}$ Konkret ging es um die Bezahlung für wiederkehrende Anzeigen in Buchumschlägen und Zeitschriften. Die Befürchtung der Compositors war, daß der "unvernünftige" Schiedsspruch von Mr. Sweet in dem einen Fall nun auf andere umstrittene Fälle dieser Art angewendet werden würde. Genau das war die Interpretation der Arbeitgeber, und sie handelten entsprechend. Diese Präzedenzfall-Wirkung des Schiedsspruchs, durch die eine langjährige Gewohnheit durchbrochen zu werden drohte, war der ei-

240 Ein Exemplar der Regeln des Arbitration Committee in MRC Mss. 28/CO/4/2/1. Bevor ein Fall dem Schiedsgericht zur "final adjudication" vorgelegt werden durfte, mußte er erst in internen Komitees der Gewerkschaft und der Master Printers' Association vorberaten werden. Die Prozedur war also recht umständlich und zeitraubend. Ein Beispiel für einen gelösten Fall vom August 1856 in MRC Mss. 28/CO/4/1/3/13. Vgl. zur Gründung auch Howe u. Waite, Compositors, S. $167 \mathrm{ff}$. Schon 1847 war ein solches Arbitration Committee von den Compositors angeregt worden, kam aber nicht zustande, ebd., S. 121. Auch die Arbeitgeber wollten schon im April 1848 ein sogenanntes Committee of Reference eingerichtet sehen, das aber ausschließlich aus Master Printers bestehen sollte, von denen die Hälfte von den Arbeitgebern, die andere Hälfte von den Compositors gewählt werden sollten; dieser Vorschlag fand natürlich keine Zustimmung bei der Gewerkschaft, vgl. dazu MRC Mss. 28/CO/4/2/1.

241 Hierzu und zu den folgenden Einzelheiten die Quarterly Reports der Gewerkschaft mit eingeklebten Schriftstücken: MRC Mss. 28/CO/1/8/5 (Jan. 1857 - Jan. 1859). Vgl. auch Howe, London Compositor, S. $266 \mathrm{ff}$. 
gentliche Kern des Streits. Die Master Printers lehnten es jedoch indigniert ab, den Fall wiederaufzunehmen, weil die Entscheidung von Mr. Sweet „in strikter Konformität " zu den Regeln des vereinbarten Schiedsverfahrens erfolgt sei. ${ }^{242}$ Daraufhin entschlossen sich die Compositors nach eingehender Beratung durch einen Anwalt, die Angelegenheit vor ein höheres Gericht zu bringen, um dort zunächst klären zu lassen, ob sie die Arbeitgeber trotz des vereinbarten Schiedsverfahrens zu einer Wiederaufnahme des Falles zwingen könnten. Diesem Begehren wurde von Chief Baron Pollock im Court of Exchequer am 3. Juli 1857 stattgegeben; auch erging bereits ein vorläufiges Urteil über die Summe von 3s. 1d. zugunsten des nominellen Klägers, Cornelius Hill, dessen Fall von der Gewerkschaft ausgewählt worden war, um den Streit über die Präzedenzfall-Wirkung des Schiedsspruchs klären zu lassen. Das wesentliche Ergebnis dieser Vorverhandlung war aber zunächst, daß die Arbeitgeber nun gerichtlich gezwungen wurden, einen sogenannten special case durch einen gemeinsam bestellten barrister, einen Mr. Barstow, vorbereiten zu lassen, der dann dem Court of Exchequer zur endgültigen Entscheidung vorzulegen war. Diese endgültige Verhandlung fand am 12. und 25. Februar 1858 statt. ${ }^{243}$ Sowohl in dem konkreten Fall (Hill v. Levy $\mathcal{E}$ Co.) als auch in der entscheidenden Frage nach der Präzedenzfallwirkung des Schiedsspruchs für ähnliche Streitigkeiten um wiederkehrende Anzeigen gab der Richter, Baron Watson, der Gewerkschaft recht. Ausdrücklich stellte Baron Watson fest, daß der Schiedsspruch von Mr. Sweet nur in dem einen Streitfall bindend war, der ihm vorgelegen hatte, nicht aber für alle ähnlichen Fälle, also auch nicht für Hill. Unabhängig davon, so erklärte Baron Watson, könne der Schiedsspruch das Gericht nicht daran hindern, sich in der Sache selbst, nämlich der Interpretation der Scale, sein eigenes Urteil zu bilden:

The opinion of the barrister [Mr. Sweet, W.S.] is entitled to very great weight and consideration, but it does not operate by way of estoppel as being a final and conclusive construction in law.... We are clearly of opinion that it is competent for the Court to entertain the question of construction of the rules [d.h. der Scale, W.S.], and that we are not conclusively bound by the opinion of the barrister. ${ }^{244}$

242 MRC Mss. 28/CO/1/8/5, 36th and 37th Quarterly Reports, April 1857; dazu auch die Darstellung des Falls aus Sicht der Master Printers in einem Bericht des Arbeitgeberkomitees für eine Sitzung der Masters am 6. August 1857: MRC Mss. 28/CO/1/10/1B.

243 Siehe den gedruckten Bericht über das Urteil im Fall Hill v. Levey in den L.S.C. Trade Reports, 1848-1858, MRC Mss. 28/CO/4/1/3/18. Vgl. außerdem die Berichte im County Courts Chronicle, 1. Apr. 1858, S. 79 f. und in den Law Journal Reports, Court of Exchequer, N.S. 27, 1858, S. 259-262.

244 Ebd., S. 261. 
Nach diesem Urteil versuchte die Arbeitgeberseite noch, durch einen writ of error eine Revision zu erreichen. ${ }^{245}$ Im Mai $1858 \mathrm{kam}$ es zu einer weiteren Verhandlung vor sieben Richtern des Court of Queen's Bench und des Court of Common Pleas, doch blieb dieser letzte Vorstoß der Master Printers ohne Erfolg. Der Sieg in diesem über ein Jahr sich hinziehenden Prozeß, bei dem es nominell nur um die lächerliche Summe von 3s. 1d. gegangen war, kam die Gewerkschaft teuer zu stehen. Obwohl die Arbeitgeber verloren hatten und somit das Gros der Kosten tragen mußten, blieb die Society auf $£ 12913 \mathrm{~s}$. 9d. eigenen Anwaltskosten sitzen, die vom taxing master, also dem gerichtlichen Kostenschätzer, nicht anerkannt worden waren.

Ein weiteres, für unseren Zusammenhang wichtigeres Resultat des Falles war, daß die Londoner Master Printers sich von nun an auf Jahrzehnte hinaus weigerten, eine Schiedsinstanz für Streitigkeiten zu akzeptieren. Die Arbeitgeber betrachteten den Gang der Compositors zum ordentlichen Gericht als Vertrauensbruch, der die Grundlage für eine weitere Nutzung des Schiedsverfahrens als Mittel der Konfliktlösung zerstört hätte. ${ }^{246}$ Rechtsstreitigkeiten vor den Friedens- und Grafschaftsgerichten gehörten seitdem wieder zum Alltag im Londoner Druckgewerbe. ${ }^{247}$ Das erst 1856 etablierte Arbitration Committee war nach nur einjährigem Bestehen zusammengebrochen.

Diese Episode verdeutlicht exemplarisch, daß die bindende Kraft und Vollstreckbarkeit von Schiedssprüchen in Großbritannien letztlich allein vom guten Willen der Beteiligten abhing. Es war fast unmöglich, jedenfalls erforderte es erheblichen juristischen Sachverstand, die Regeln eines freiwilligen Schiedsgerichts so zu konstruieren, daß der Rekurs auf das Common law abgeschnitten wurde. Eine bloße gegenseitige Erklärung, sich dem Schiedsspruch unterwerfen zu wollen, genügte nicht, sobald komplizierte Fragen auftauchten, wie eben die, ob ein bestimmter Spruch auf andere Fälle anwendbar sei. Ähnlich schwer durch Regeln zu lösen war auch die Frage der Geltung von Schiedssprüchen, wenn Mitglieder der jeweiligen Organisationen kurzerhand austraten. Gelangte aber ein unklarer Fall erst einmal vor ein höheres Gericht, gaben ihn die Common Law-Richter so leicht nicht wieder aus der Hand. Den Primat des Common law zu behaupten war für die Richter gleichbedeutend mit der Aufrechterhaltung des rule of law schlechthin; diese Überzeugung pflegten sie gegenüber freiwilligen

245 Zum folgenden wieder die Quarterly Reports (April u. Juli 1858), MRC Mss. 28/CO/1/8/5. $246 \mathrm{Vgl}$. die Erklärung in MRC Mss. 28/CO/1/10/1B.

247 Für Beispiele siehe unten, Kap. III.3. 
Schiedsgerichten ebenso durchzusetzen wie gegenüber den in ihren Augen noch schwächer legitimierten administrativen Spruchinstanzen. ${ }^{248}$

Es waren aber nicht nur die rechtstechnischen Konstruktionsprobleme, die dafür sorgten, daß freiwillige Schieds- und Einigungsinstanzen oft nur eine kurze Existenz hatten oder trotz intensiver Bemühungen einer der beiden Seiten gar nicht erst zustandekamen. Oft fehlte es an der entscheidenden Voraussetzung, nämlich der dauerhaften und verläßlichen Organisation von Arbeitnehmern und Arbeitgebern. So war es etwa in den hochspezialisierten Metallverarbeitungsgewerben Sheffields, wo mehrere Initiativen für conciliation boards von seiten der Gewerkschaften daran scheiterten, daß ihnen keine stabilen Arbeitgebervereinigungen gegenüberstanden. ${ }^{249} \mathrm{An}-$ dernorts verhinderte lange Zeit der Unwille der Arbeitgeber, mit den Gewerkschaften auf gleichem Fuße zu reden, die Errichtung von Einigungsund Schlichtungsgremien. Bekannt ist die Vorgeschichte des Conciliation Board für die Hosiery-Industrie von Nottingham. Dessen Hauptinitiator, der Industrielle A.J. Mundella, rühmte sich später immer wieder, wie er 1860 seine Kollegen mühsam dazu überredet habe, sich zu ,erniedrigen', um mit den Arbeitern zu sprechen. ${ }^{250}$ Mundellas vielgelobter board in Nottingham scheiterte 1884 daran, daß es im Zeichen verschärfter Konkurrenz infolge technischer Neuerungen nicht mehr gelang, alle Arbeitgeber an die Beschlüsse des Gremiums zu binden. Das war kein Einzelfall. Viele boards hielten einer ernsthaften Belastungsprobe in Krisenzeiten nicht stand. ${ }^{251}$ Widerwillen, Mißtrauen und mangelnde Bereitschaft, sich den Beschlüssen der boards zu fügen, gab es aber auch auf seiten der Arbeitnehmer. Dabei unterschieden diese deutlich zwischen conciliation und arbitration. Wäh-

248 Vgl. hierzu allgemein Arthurs, ,Without the Law', bes. S. 67-79. Die Ausführungen von Arthurs beziehen sich vor allem auf die Schiedsgerichte der Geschäftsleute, treffen aber was die abwehrende Haltung der Common lawyers angeht - auch auf die Schieds- und Einigungsstellen der Arbeitnehmer und Arbeitgeber zu.

249 Vgl. Sidney Pollard, A History of Labour in Sheffield, Liverpool 1959, S. 134. Erst im frühen 20. Jahrhundert kam es in Sheffield zur Bildung von festen Verhandlungs- und Schiedsinstanzen, doch blieben auch diese instabil, ebd. S. $238 \mathrm{f}$.

$250 \mathrm{Vgl}$. Schulze-Gaevernitz, Zum socialen Frieden, Bd. 2, S. 291 f. Die Regeln des Hosiery and Glove Board of Arbitration and Conciliation, Nottingham sowie ein allgemein gehaltener Tätigkeitsbericht in: Eleventh and Final Report of the Royal Commissioners appointed to inquire into the Organization and Rules of Trades Unions and Other Associations, PP 1868-69 (4123) XXXI, Bd. 2, Appendix, S. 332 f.

251 Roy Church, Technological Change and the Hosiery Board of Conciliation and Arbitration, 1860-1884, in: Yorkshire Bulletin of Economic and Social Research 15 (1963), S. 52-60. Vgl. Porter, Wage Bargaining, S. 471 für eine ganze Reihe ähnlicher Zusammenbrüche von boards. Siehe auch Royal Commission on Labour, Fifth and Final Report, Part II, PP 1894 (C. 7421.-I.) XXXV, S. 269-272 zu den Erfahrungen mit arbitration und conciliation in verschiedenen Textilgewerben. 
rend die Arbeitnehmer paritätische Gremien zur bloßen Verhandlung über Lohnraten und andere Fragen, also reine conciliation boards, generell befürworteten, verhielten sie sich extrem zurückhaltend gegenüber jeder Art von Verpflichtung, sich im Falle des Scheiterns von Einigungsbemühungen einem verbindlichen Schiedsspruch zu unterwerfen. Aus freien Stücken akzeptierten Gewerkschaften das Prinzip der arbitration, also Schiedsklauseln, normalerweise nur aus einer Position relativer Stärke. Bei der London Society of Compositors war dies der Fall gewesen. In vielen anderen Branchen hingegen, besonders im Baugewerbe, ließen sich die Arbeitervertreter nur in Notlagen, nach den verlorenen Streiks der sechziger und frühen siebziger Jahre des 19. Jahrhunderts, dazu überreden, Schiedsklauseln in Verbindung mit Stillhalteabkommen als Bestandteile tariflicher Abmachungen hinzunehmen. Bei den einfachen Mitgliedern der Baugewerkschaften bestand eine ausgeprägte Abneigung gegen arbitration, weil die Einführung dieses Prinzips zusammenfiel mit der Durchsetzung der von den Arbeitgebern gewünschten stundenweisen Bezahlung. In Manchester kam es 1869 zu einer Riesendemonstration, auf der die Bauarbeiter Spruchbänder mit der Aufschrift „No Hours. No Arbitration“ umhertrugen. ${ }^{252}$ Während der großen Depression führten die Schiedssprüche der Unparteiischen dann häufig zu Lohnsenkungen, was das Verfahren in den Augen der Arbeitnehmer weiter in Verruf brachte. ${ }^{253}$ Es ist daher verständlich, daß die Gewerkschaften mit dem Anziehen der Konjunktur in den neunziger Jahren des 19. Jahrhunderts das ungeliebte Prinzip der arbitration nach Möglichkeit in den Hintergrund zu drängen suchten.

Die Vorbehalte der Arbeitnehmer gegen arbitration bezogen sich im wesentlichen auf Tarifverhandlungen, also den Streit um zukünftige Arbeitsbedingungen. Über größere Proteste gegen die Anwendung des Verfahrens bei Streitigkeiten aus schon bestehenden Verträgen, seien es Tarifverträge oder Einzelarbeitsverträge, ist hingegen nichts bekannt. Weil nun aber zwischen diesen beiden Typen von Disputen in der Regel nicht sorgfältig unterschieden wurde, wirkte sich die Skepsis gegenüber dem Schiedsprinzip auch auf den quasi-gerichtlichen Tätigkeitsbereich der boards aus. Juristisch gesehen gab es bei Streitigkeiten aus bestehenden Verträgen an sich nicht viel zu verhandeln; im wesentlichen waren Fakten und Rechte festzustellen. In der Praxis vieler boards wurden aber auch Rechtsfragen zunächst einmal als Verhandlungssache betrachtet. Für die sogenannten kleineren Dispute bil-

252 Vgl. Richard Price, Masters, unions and men. Work control in building and the rise of labour 1830-1914, Cambridge 1980, S. 111, 116 ff., 309.

253 Porter, Wage Bargaining, S. 465. 
deten sich im Laufe der Zeit bei vielen lokalen und regionalen boards ständige Unterausschüsse heraus, meist zusammengesetzt aus einem oder zwei Vertretern von jeder Seite und teils mit, teils ohne unparteiischem Vorsitzenden. Wenn man nach einem britischen Äquivalent für die deutschen Gewerbegerichte in ihrer Funktion als Rechtsprechungsorgan sucht, so kommen vor allem diese ständigen Unterausschüsse in Frage.

Anders als bei den deutschen Gewerbegerichten war das Verfahren vor diesen Unterausschüssen nur selten detailliert und dauerhaft festgelegt. In der Regel ähnelte es vom Charakter her mehr einer informellen Verhandlung als einem Gerichtsprozeß. Die Praxis sah meist so aus, daß der Gewerkschaftssekretär und der Sekretär der lokalen Arbeitgebervereinigung gemeinsam den strittigen Sachverhalt prüften, Zeugen vernahmen und entweder eine friedliche Lösung herbeiführten oder den so voruntersuchten Fall zur Entscheidung an den board weiterleiteten. Manchmal gab es mehrfach gestufte Verfahren, so bei Mundellas Hosiery board in Nottingham, wo Individualfälle zunächst von den beiden Sekretären geprüft, dann vor einem engeren Ausschuß bestehend aus zwei Arbeitern und zwei Arbeitgebern verhandelt und entschieden wurden. Bei Uneinigkeit oder Unzufriedenheit einer Seite war anfangs Berufung an den großen conciliation board von Nottingham möglich, später ging man hier dazu über, die Individualfälle ganz im engeren Ausschuß zu belassen und nötigenfalls einem ad boc ernannten Schiedsrichter zur Entscheidung zu übergeben. ${ }^{254}$

Sogar bei der vom Grafschaftsrichter Rupert Kettle initiierten Schiedsund Einigungsstelle für das Baugewerbe in Wolverhampton, deren Verfahren von allen britischen Einrichtungen dieser Art am stärksten dem ordentlichen Zivilprozeß angenähert war, entschied man sich schon nach kurzer Zeit, die Individualfälle durch einen kleinen Ausschuß, bestehend aus je einem Vertreter beider Parteien, auf dem Wege friedlicher Einigung lösen zu lassen. ${ }^{255}$ Die gerichtsförmige Prozedur wurde also auch hier als ungeeignet für Individualfälle angesehen, und das obwohl Kettle ansonsten in seinen öffentlichen Vorträgen zum Thema immer wieder betonte, wie wichtig es für das gute Funktionieren von Schieds- und Einigungsstellen sei, daß ihre Sprüche rechtlich bindende Kraft besäßen und zur Not durch die ordentliche Justiz vollstreckbar sein müßten. ${ }^{256}$ Dementsprechend sorgte Kettle

254 Schulze-Gaevernitz, Zum Socialen Frieden, Bd. 2, S. 294; Lujo Brentano, Das Arbeitsverhältnis gemäß dem heutigen Recht, Leipzig 1877, S. 273 ff.; ders., Die Arbeitergilden der Gegenwart, 2 Bde., Leipzig 1871/72, Bd. 2, S. $273 \mathrm{ff}$.

255 Vgl. Henry Crompton, Arbitration and Conciliation, in: Fortnightly Review 5 (1869), S. 622-628, S. 623; Zimmermann, Einigungswesen, S. $21 \mathrm{f}$.

$256 \mathrm{Vgl}$. etwa seine Bemerkungen auf dem Trades Union Congress von 1871: Report of Procee- 
dafür, daß die Verfahrensordnung seines arbitration board im Baugewerbe von Wolverhampton zum Bestandteil der individuellen Arbeitsverträge gemacht wurde. Das geschah, indem man die Statuten des board in den Betriebshöfen und auf den Baustellen aushängte und sie außerdem jedem Arbeiter bei Vertragsschluß persönlich bekanntgab.257 Freilich räumte Kettle ein, daß kein noch so klug konstruiertes freiwilliges Schiedssystem gegen die Übergriffe des Common law gefeit sei. Er dachte dabei vor allem an den anfechtbaren Rechtsstatus der kollektiven Vereinigungen, auf deren Mitwirkung die Schieds- und Einigungstellen nun einmal angewiesen waren. ${ }^{258}$ Um das System auf eine solidere Grundlage zu stellen, forderte Kettle deshalb ein Gesetz, welches die Trade Unions und Arbeitgebervereinigungen zu Körperschaften gemacht hätte, die verbindliche Verträge schließen und dafür auch haftbar gemacht werden konnten.

Mit diesen Überlegungen zur rechtlichen Einhegung des kollektiven Verhandelns ging Kettle weit über das hinaus, was andere Verfechter der Schieds- und Einigungsstellen mitzutragen bereit waren. Allen gemeinsam war jedoch die Auffassung, daß die Schieds- und Einigungsstellen primär für Tarifabschlüsse, Streikvermeidung und die Regulierung der allgemeinen Arbeitsbedingungen von Nutzen seien, hingegen nur nebenbei auch zur Beilegung von alltäglichen Reibereien zwischen Arbeitnehmern und Vorgesetzten dienen könnten. Dieses Prioritätsverständnis äußerte sich darin, daß Konflikte des einzelnen Falles vielerorts aus der dauernden Zuständigkeit der boards ausgegliedert und an die Sekretäre oder kleinere Ausschüsse delegiert wurden. So geschah es beispielsweise in der Schuhindustrie ${ }^{259}$, in der Stahl- und Walzeisenindustrie ${ }^{260}$ oder bei den Dampfkesselherstellern. ${ }^{261} \mathrm{Die}$ arbitration and conciliation boards leisteten also gewissermaßen

dings at the Third Annual Trades Union Congress, London 1871, unpag., Diskussion am 9. März 1871 (Microfilm edition).

257 Zimmermann, Einigungswesen, S. 22.

258 Rupert Kettle, Boards of Conciliation and Arbitration, S. 184: „... I believe that the Common law is so intricate that an arbitration system cannot work freely under it without some danger of illegality."

259 Vgl. Webb, Industrial Democracy, S. 185-192 u. 235 f.; Alan Fox, A History of the National Union of Boot and Shoe Operatives 1874-1957, Oxford 1958, S. 71 f., 158, 222, 295 f.; Elisabeth Brunner, The Origins of Industrial Peace: The Case of the British Boot and Shoe Industry, in: Oxford Economic Papers 1 (1949), S. 247-259.

260 Vgl. Zimmermann, Einigungswesen, S. 78 ff.; Berichte der nach England entsendeten Kommission, S. 19; Lotz, Schieds- und Einigungsverfahren, S. 285 f., 293-302 mit Fallbeispielen; danach waren die Hauptgegenstände von Beschwerden (ebd., S. 301): „angebliche Benachteiligung einer Partei durch technische Umwälzungen, Einführung eines anderen Löhnungssystems, endlich ungerecht erscheinende Fabrikstrafen".

261 Berichte der nach England entsendeten Kommission, S. 25. 
Geburtshilfe für ein darunter liegendes System der Beilegung individueller Streitigkeiten, während sie sich in ihrer eigentlichen Tätigkeit vor allem auf die kollektiven Tarifauseinandersetzungen konzentrierten.

Am stärksten durchgebildet war diese Trennung der Funktionen in den nordostenglischen. Kohlerevieren von Northumberland und Durham. In beiden Grafschaften wurden, nachdem es Anfang der siebziger Jahre des 19. Jahrhunderts zu ersten Tarifabsprachen gekommen war, alsbald sogenannte joint committees eingerichtet. Das waren ständige Ausschüsse, die alle in den einzelnen Gruben vorkommenden Streitfragen um die konkrete Anwendung der Tarife und ,Gewohnheiten' besprechen und ab 1877/79 auch verbindlich entscheiden sollten. ${ }^{262}$ Die Kosten der joint committees wurden zu gleichen Teilen von den Gewerkschaften und den Arbeitgebervereinigungen getragen. Sie tagten etwa ein- bis zweimal pro Monat, also in ähnlich häufigen Abständen wie die lokalen Grafschaftsgerichte. Bei Streitfällen hatte jede Seite für die eigenen Kosten aufzukommen. Von der $\mathrm{Zu}-$ ständigkeit der joint committees ausgenommen waren die sogenannten Grafschaftsfragen, worunter man die Festsetzung der durchschnittlichen Lohnraten per geförderter Tonne Kohle sowie Anträge auf Abänderung von, Gewohnheiten' verstand. Für diese Fragen existierten in beiden Grafschaften boards of conciliation, die ihrer Funktion entsprechend jeweils nur wenige Male pro Jahr zu tagen brauchten. Dieses zweigleisige System der Konfliktlösung und -vorbeugung hielt sich im nordostenglischen Kohlenbergbau bis über den Ersten Weltkrieg hinaus.

Die Bandbreite der von den joint committees in Durham und Northumberland bearbeiteten Einzelfälle war weitgestreut. Den größten Raum nahmen Klagen und Beschwerden über die Lohnzahlung bei besonders schwierigen Arbeitsbedingungen unter Tage ein. War zum Beispiel die Kohle sehr hart oder das Flöz extrem niedrig, pflegten die Häuer unter Verweis auf die ,Gewohnheit' einen über der Durchschnittsrate liegenden Lohn zu verlangen. Umgekehrt fühlten sich auch die Arbeitgeber berechtigt, eine Herabsetzung des Lohns per geförderter Tonne zu fordern, wenn die Kohle weich war oder mit Sprengungen gearbeitet werden konnte. Hierbei handelte es sich um Fragen, die eine genaue Kenntnis der Verhältnisse unter Tage voraussetzten. Grundlagen der Entscheidung waren einmal die Fakten, wie sie

262 Hierzu und zum folgenden ausführlich, Royal Commission on Labour, Fifth and Final Report, Part II, PP 1894 (C. 7421.-I.) XXXV, S. 66-71; Schulze-Gaevernitz, Zum socialen Frieden, Bd. 2, S. 333-347, dort auf S. 348-350 eine deutsche Übersetzung der Statuten des ständigen Ausschusses von Northumberland. Vgl. außerdem: Auerbach, Ordnung des Arbeitsverhältnisses, S. 34-37, dort auf S. 37-40 eine deutsche Übersetzung der Statuten des ständigen Ausschusses von Durham; Webb, Industrial Democracy, S. 192-195, $311 \mathrm{f}$. 
von den Vertretern beider Seiten vor Ort ermittelt wurden, sodann die ,Gewohnheiten', die sich teils aus dem Herkommen, teils aus früheren Entscheidungen der joint committees ergaben, schließlich die Durchschnittslohnrate als Berechnungsbasis für die festzulegende Abweichung. Es ist unschwer zu erkennen, daß ein normaler Friedens- oder Grafschaftsrichter mit derartigen Streitfragen überfordert war und daß sich das law of master and servant zu ihrer Lösung nicht eignete. Ähnliches gilt für die ebenfalls recht häufigen Konflikte um die Einschätzung der Sicherheit an bestimmten Örtern, um die Anrechenbarkeit bestimmter Tätigkeiten auf die effektive Arbeitszeit, um die Aufteilung des Lohns unter die in Doppelschichten zusammenarbeitenden Häuer. Hingegen scheinen sich die joint committees kaum mit Kontraktbrüchen oder Entlassungen einzelner Arbeiter wegen angeblicher Disziplinlosigkeit, mangelnder Leistung oder Krankheit beschäftigt zu haben. Für diese vertraglichen Streitigkeiten sowie für die Klärung von Ansprüchen bei Unfällen zog man weiterhin vor die Gerichte. Die ordentliche Justiz wurde also durch die joint committees nur teilweise ersetzt, nämlich in den Bereichen, in denen es primär darauf ankam, die ,Gewohnheiten' und Tarifabsprachen mit den ,Fakten' vor Ort in Einklang zu bringen.

Von allen Schieds- und Einigungsstellen, die dem britischen Handelsministerium bekannt wurden, waren die joint committees von Durham und Northumberland die bei weitem aktivsten und konstantesten Gremien. Der offiziellen Statistik zufolge behandelten sie zwischen 1895 und 1910 stets mehr als die Hälfte, oft sogar mehr als zwei Drittel sämtlicher Fälle aus ganz Großbritannien, die überhaupt an das Ministerium gemeldet wurden (Grafik 4.1). Selbst in den Streikjahren 1892 und 1911-12 kam die Tätigkeit der beiden joint committees nicht zum Erliegen. Bedeutende Fallzahlen wurden sonst nur von den auf verschiedene Orte verteilten Schiedsstellen in der Schuhfabrikation und ab 1911 vom Arbitration Board der südwalisischen Weißblech-Industrie erreicht. Wie im nordostenglischen Kohlenbergbau gelangten auch in diesen beiden Industrien überwiegend Dispute zwischen einzelnen Arbeitnehmern und ihren Arbeitgebern vor die Schiedsstellen, wobei es häufig um die Fertigungsqualität der abgelieferten Produkte ging. Gerade für derartige Fragen eigneten sich die mit Fachleuten beider Seiten besetzten Schiedsstellen besser als die ordentliche Justiz. Die Schiedsgerichte in der Schuhindustrie erwiesen sich jedoch als weniger stabil als die joint committees von Durham und Northumberland (Grafik 4.1).

Die bemerkenswerte Aktivität der joint committees von Durham und Northumberland hatte offenbar nicht zur Folge, daß dort die Zahl der Arbeitsstreitigkeiten vor den ordentlichen Gerichten abnahm. Im Gegenteil, 
Grafik 4.1: Schieds- und Einigungsstellen in Großbritannien 1881-1913: bearbeitete Fälle

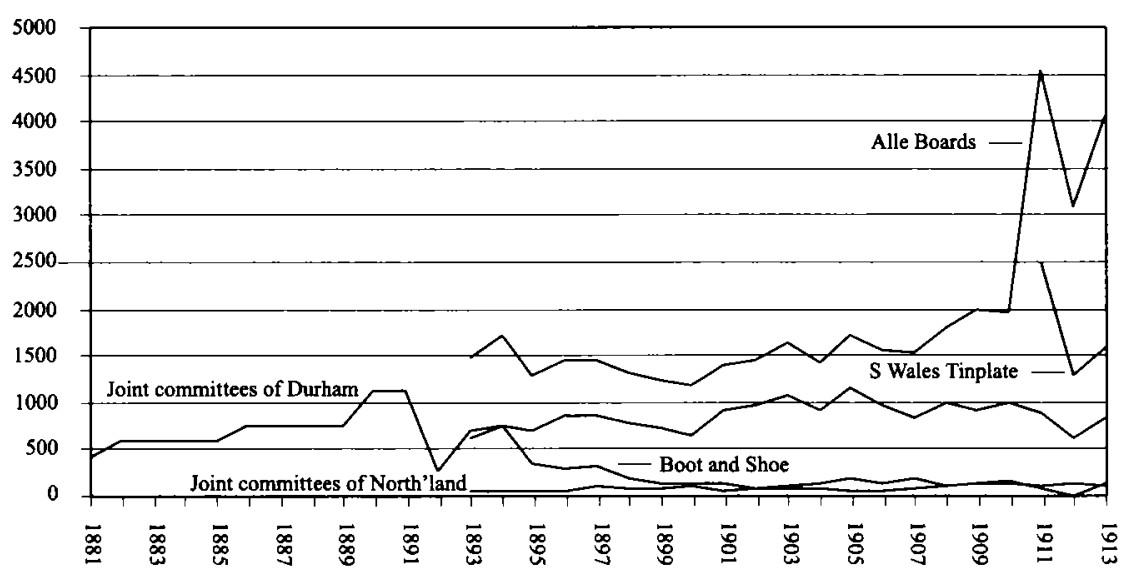

Quellen: Für Durham 1881: Schulze-Gaevernitz, Bd. 2, S. 335; für Durham 1882-1893: Report on Strikes and Lock-Outs of 1893, PP 1894 [C. 7566] LXXXI, Pt. I, S. 225 f.; für die übrigen Zahlen: jährliche Reports on Strikes and Lock-Outs 1893-1911 in den Parliamentary Papers (1894-1914/16).

es sieht geradezu so aus, als hätte die Einrichtung der joint committees zumindest bis zum Anfang der neunziger Jahre sogar zu einer vermehrten Klagetätigkeit von Arbeitgebern und Arbeitnehmern vor den örtlichen Friedensgerichten geführt. Seit den frühen siebziger Jahren, also etwa zeitgleich mit der beginnenden Tätigkeit der joint committees, nahmen in Durham die Klagen unter den Master and Servant-Gesetzen zu, und entgegen dem nationalen Trend blieben die Zahlen dort - bei teilweise erratischen Ausschlägen nach oben - auch nach 1875 weiterhin hoch. ${ }^{263}$ Ein ursächlicher Zusammenhang zwischen der Existenz der joint committees und den verhältnismäßig hohen Klagezahlen vor den Friedensgerichten in Durham wird sich kaum nachweisen lassen; denkbar wäre immerhin, daß die Arbeit der freiwilligen Einigungsstellen neue Streitpunkte produzierte, die in der Folge dann auch die Gerichte beschäftigten. Sicher ist jedenfalls, daß die Konkurrenz der joint committees in den nordostenglischen Kohlerevieren zunächst keine Flucht aus der ordentlichen Gerichtsbarkeit auslöste. Vielmehr scheint die Konkurrenz das Geschäft für die Friedensgerichte in Durham und Northumberland belebt zu haben.

263 Vgl. Grafik 2.4, S. 196. 
Auch in den mittelenglischen Zentren der Strumpfwirkerei und Schuhindustrie ist in den Zeiten, in denen dort arbitration boards besonders aktiv waren, also in den sechziger und siebziger Jahren in Nottinghamshire und in den frühen neunziger Jahren in Northamptonshire, kein auffälliger Rückgang der Klagen vor den Friedensgerichten zu verzeichnen. Die Existenz freiwilliger Einigungsstellen führte somit keineswegs automatisch zu einer Verminderung der Konflikte, sondern ließ anscheinend manche individuellen Streitigkeiten nur um so schärfer hervortreten. Angesichts dieser Befunde fällt es schwer, in der Tätigkeit der Schieds- und Einigungsstellen den Hauptgrund für die Abkehr der Arbeitnehmer und Arbeitgeber von der ordentlichen Justiz zu sehen. Zumindest bis zu den neunziger Jahren des 19. Jahrhunderts finden sich dafür wenig Anhaltspunkte.

\section{DeR STAAT ALS HELFENDER BEOBACHTER: DIE WEITERE ENTWICKLUNG BIS ZUM ERSTEN WELTKRIEG}

Bis 1896 hatte sich das Schieds- und Einigungswesen weitgehend ohne Mithilfe des Staates entwickelt. Zwar verabschiedete das Parlament in den Jahren 1824, 1867 und 1872 Gesetze, deren Zweck die friedliche Beilegung von Arbeitskonflikten durch behördlich lizensierte Schieds- und Einigungsverfahren sein sollte, doch blieben diese Versuche, wie zeitgenössische Beobachter übereinstimmend feststellten, allesamt folgenlos. ${ }^{264}$ Weder Arbeitgeber noch Arbeitnehmer machten von den durch die Gesetzgebung gebotenen Möglichkeiten Gebrauch. Die Gründe dafür waren im einzelnen verschieden, der gemeinsame Mangel der fehlgeschlagenen Gesetze bestand aber in den Augen der potentiellen Nutznießer darin, daß sie zu detaillierte Vorschriften enthielten und so den Gestaltungsspielraum für Verhandlungen zu sehr einengten. ${ }^{265}$ Erst mit dem Conciliation Act von 1896 fand der Gesetzgeber eine Formel, die dem Bedürfnis von Gewerkschaften und Arbeitgebervereinigungen nach zwangloser und autonomer Regulierung ihrer Konflikte so weit entgegenkam, daß etliche schon bestehende und neugegründete conciliation and arbitration boards an das Handelsministerium

264 Masters and Workmen Arbitration Act, 5 Geo. 4, c. 96 (1824); An Act to establish Equitable Councils of Conciliation to adjust Differences between Masters and Workmen, 30 \& 31 Vict c. 105 (1867); Arbitration (Masters and Workmen) Act, 35 \& 36 Vict. c. 46 (1872). Einen Überblick über wesentliche Inhalte dieser älteren Gesetzgebungsversuche und zeitgenössische Stimmen dazu vermittelt: Royal Commission on Labour, Fifth and Final Report, Part I, PP 1894 (C. 7421) XXXV, S. 163 f., Memorandum by Sir Frederick Pollock on the Statute Law as to Arbitration in Trade Disputes.

$265 \mathrm{Vgl}$. etwa die Kritik von Kettle, Boards of Conciliation and Arbitration, S. $178 \mathrm{ff}$. 
über ihre Aktivitäten berichteten und bei einzelnen, besonders heftigen oder langwierigen Konflikten sogar um die Hilfe des Ministeriums bei der Schlichtung nachsuchten. ${ }^{266}$ Dies konnte laut Gesetz jeweils nur bei beiderseitiger Zustimmung geschehen. Im Hinblick auf innere Organisation und Entscheidungsabläufe behielten die boards ihre Satzungsautonomie. Das Ministerium sollte vermitteln und helfen, es konnte aus eigener Initiative eine Untersuchung einleiten, aber es durfte nichts erzwingen. So lag die Bedeutung des Gesetzes von 1896 nicht so sehr in vermehrten Eingriffsbefugnissen des Staates, sondern vor allem in einem verbesserten Informationsfluß. Die Regierung gewann erstmals einen genaueren und regelmäßigen Einblick in einen signifikanten Ausschnitt des freiwilligen Schieds- und Einigungswesens in der gewerblichen Wirtschaft. Durch die Labour Gazette und die in den Parliamentary Papers publizierten Berichte und Statistiken wurden diese Informationen einer breiten Öffentlichkeit zugänglich gemacht und sollten, so die Hoffnung der Ministerialbeamten, zur Nachahmung anregen. Dieses Programm war in Maßen erfolgreich, wie sowohl die Zunahme der dem Ministerium bekannten boards und joint committees als auch die Zahl der von diesen Einrichtungen insgesamt behandelten Dispute belegt. ${ }^{267}$ Gemessen an den Erwartungen blieb der Erfolg aber doch begrenzt, denn einmal gab es in manchen wichtigen Industrien Arrangements der Streitbeilegung, die nicht als feste boards institutionalisiert wurden, und zum anderen offenbarten die jährlichen Berichte, daß unter den gemeldeten Disputen viele waren, die aus behördlicher Sicht als Bagatellsachen einzustufen waren.

Das freiwillige Streitschlichtungswesen blieb somit weiterhin partiell dem kontrollierenden Blick des Staates verborgen, und es erschien zudem in seinen Zielsetzungen und Auswirkungen disparat. Die Beamten und Statistiker im Ministerium beurteilten das System vor allem danach, wie weit es größere Arbeitsniederlegungen beenden oder vermeiden half. Entsprechend waren die Fragenkataloge angelegt, die an die bekannten boards und joint committees versandt wurden. ${ }^{268}$ Was als Rückmeldung kam, paßte sich die-

266 Conciliation (Trade Disputes) Act, 59 \& 60 Vict., c. 30 (1896). Vgl. zu den Inhalten und Hintergründen dieses Gesetzes Cornelißen, Das „Innere Kabinett“, S. 340 ff.; dort auf S. 342 auch eine tabellarische Übersicht über die Zahl der durch ministerielle Unterstützung geschlichteten ,Dispute` zwischen 1897 und 1913. Ergänzend dazu mit Angaben von 1896 bis 1920 die Tabelle in: Report on Conciliation and Arbitration, 1920 (185), S. 7.

267 Siehe oben Fn. 235 für die Zahl der boards und Grafik 4.1, S. 280, für die insgesamt gemeldeten ,Dispute.

268 Vgl. Report on Strikes and Lock-Outs in the United Kingdom in 1903, and on Conciliation and Arbitration Boards, London 1904, PP 1904 (Cd. 2112) LXXXIX, S. 131 (Form of Inquiry sent to Secretaries of Conciliation and Arbitration Boards). 
sem behördlichen Frageinteresse an mit der Folge, daß die offiziellen $R e-$ ports möglicherweise nur ein ungenaues Bild von der tatsächlichen Wirkungsweise der einzelnen Einrichtungen vermitteln. Für uns entsteht daraus das Problem, daß gerade der hier interessierende Bereich des Umgangs mit Individualfällen im Dunklen bleibt.

Geht man davon aus, daß sich die Tätigkeit der boards und committees auf die gemeldeten Dispute beschränkte, kann der Geschäftsrückgang bei den ordentlichen Gerichten allenfalls zum Teil auf das Wirken der freiwilligen Einrichtungen zurückgeführt werden. Bis 1913 bewältigten die dem Staat bekannten Schieds- und Einigungsstellen nie mehr als 5000 Fälle pro Jahr, und das Gros dieser Fälle entfiel auf wenige, zudem regional begrenzte Industrien. ${ }^{269}$ Auch wenn man die nicht fest institutionalisierten Streitbeilegungsorgane in die Betrachtung einbezieht, ergibt sich kein wesentlich anderes Bild: Im Jahr 1905 zum Beispiel befaßten sich die überregionalen Einigungsgremien der Maschinenbauer und der Baumwollweber mit 16 und 12 Fällen, die lokalen Sekretäre und committees der Baumwollspinner von Lancashire und Manchester mit 427 Fällen. ${ }^{270}$ In den unruhigen Jahren von 1911 bis 1913 erreichte die Tätigkeit der committees der Baumwollspinner einen Höhepunkt mit 2045 bearbeiteten Fällen, also etwa 680 pro Jahr. ${ }^{271}$ Die Streitschlichtungsmechanismen im Maschinenbau und in der Baumwollspinnerei wurden von Zeitgenossen des öfteren als vorbildlich und besonders effizient herausgehoben. ${ }^{272}$ Daher wird man für andere behördlich nicht erfaßte Einrichtungen mit ähnlichen Größenordnungen zwischen einem Dutzend Fällen für überregionale Gremien und maximal einigen hundert Fällen für Einigungsausschüsse und informelle Gespräche auf regionaler Ebene rechnen können. Alles in allem waren also die Fallzahlen - verglichen mit dem Klageaufkommen vor den Friedens- und Grafschaftsgerichten - nicht eben hoch. Berücksichtigt man ferner, daß viele dieser Fälle wirtschaftliche Interessenkonflikte waren, die sich ohnehin einer justizförmigen Lösung entzogen, reduziert sich der Bereich, in dem die Schieds- und Einigungsstellen direkt mit der ordentlichen Justiz konkurrierten, noch weiter.

Die Wirkung des britischen Schieds- und Einigungswesens wird freilich nur unzureichend beschrieben, wenn lediglich Fälle gezählt werden. „Gute

269 Siehe Grafik 4.1, S. 280.

270 Report on Strikes and Lock-Outs 1905, S. 45. Ähnliche Zahlen für 1907: Labour Gazette, Okt. 1908, S. 303.

271 Siehe Porter, Wage Bargaining, S. 472; ders., Industrial Peace in the Cotton Trade, 1875-1913, in Yorkshire Bulletin of Economic and Social Research 19 (1967), S. 49-61.

272 Vgl. Zimmermann, Einigungswesen, S. 37 f; dort auch weitere Zahlenangaben, die sich in ähnlichen Größenordnungen bewegen. Siehe auch Webb, Industrial Democracy, S. 195-203. 
Einigungsämter haben die Tendenz, sich selbst in gewissem Sinne überflüssig zu machen." 273 So schrieb der eingangs zitierte deutsche Beobachter, Waldemar Zimmermann, und er meinte damit, daß die Praxis der Verständigung und die tarifliche Normierung der Arbeitsverträge auf Dauer das Konfliktpotential selber verringern würden. Zum Beweis führte er unter anderem das Einigungsamt der nordenglischen Stahl- und Walzeisenindustrie an, das in den Jahren vor 1905 kaum noch habe in Aktion treten müssen, weil „die Streitfälle jetzt fast regelmäßig unter vier Augen im Werk selbst geschlichtet" würden. ${ }^{274}$ Eine wesentliche Funktion der ständigen gemeinsamen Ausschüsse und Einigungskammern bestand somit für Zimmermann darin, daß die vielen kleinen Konflikte gar nicht erst bis in jenes kritische Stadium vordrangen, das die Einschaltung der förmlichen Verhandlungsprozeduren notwendig machte.

Die Schlüsselrolle fiel dabei den lokalen Organisationen der Arbeitgeber und Arbeitnehmer zu. Hier waren es insbesondere die jeweiligen Ortssekretäre, die in den Betrieben schon im Vorfeld vermittelnd eingreifen sollten. Den Sekretären und den internen Komitees der beiden Organisationen oblag es, die wichtigen, das heißt über den Einzelfall hinausweisenden Fälle von denjenigen zu trennen, die nur einzelne Personen betrafen und deshalb als weniger wichtig galten. Die Sekretäre mußten entscheiden, ob es sich lohnte, wegen einer individuellen Beschwerde den umständlichen Schiedsund Einigungsapparat in Gang zu setzen. Für den einzelnen Arbeitnehmer bedeutete dies, daß sein Fall zunächst vor allem daraufhin geprüft wurde, ob er ein hinreichend allgemeines Problem berührte, das sich bei Nicht-Beachtung zu einem größeren Konflikt auswachsen könnte. Nicht der mögliche Rechtsanspruch des Einzelnen, sondern die potentielle Konflikthaltigkeit der Situation bildete also das Kriterium, nach dem die Streitigkeiten am Arbeitsplatz in erster Linie beurteilt wurden. Die Konflikte wurden damit schon auf der untersten Ebene der Betriebe gewissermaßen entindividualisiert und antizipierend in die Sphäre der kollektiven Auseinandersetzungen gehoben. Dem einzelnen Arbeitnehmer blieb kaum etwas anderes übrig, als sich dieser Vorprüfung seines Falles zu unterziehen, wollte er nicht riskieren, im Falle eines Scheiterns der Bemühungen sein Anrecht auf Unterstützungszahlungen seitens der Gewerkschaft (sogenanntes victim's pay) zu verlieren. Ähnliches galt, wenn auch weniger ausgeprägt, für den einzelnen Arbeitgeber. Die kollektiven Vereinbarungen und die Regeln der Schiedsund Einigungsstellen enthielten detaillierte Vorschriften über das bei indivi-

273 Zimmermann, Einigungswesen, S. 39.

274 Ebd., S. 80. 
duellen Beschwerden einzuhaltende Verfahren. Durch ihre Mitgliedschaft in den jeweiligen Organisationen waren Arbeitnehmer und Arbeitgeber im Konfliktfall an diese Verfahrensregeln gebunden. So legte zum Beispiel das berühmte Brooklands Agreement, der 1893 geschlossene Tarifvertrag in der Baumwollspinnerei, in einem Zusatzartikel fest:

Klagt der Arbeiter über Mängel im Faden oder an der Mule und erhält dafür vom Unternehmer keinen Entgelt, so ist der Fall binnen drei Tagen von den beiderseitigen Ortssekretären zu prüfen und durch eine Vereinbarung zu erledigen. Gelingt das nicht, ist eine gemeinsame Sitzung des Ortsausschusses binnen 3 Tagen zu berufen .....$^{275}$

Der hier ausgemalte typische Konflikt - vorenthaltener Lohn wegen mangelhafter Arbeit auf der einen Seite, Klage wegen fehlerhaften Materials auf der anderen Seite - konnte seiner Natur nach durchaus ein Gegenstand von Gerichtsverhandlungen werden. Juristisch gesehen handelte es sich um eine Entscheidung über gegenseitige Ansprüche: Konnte der Arbeitgeber beweisen, daß der Arbeiter nachlässig oder fahrlässig gehandelt hatte, stand ihm Schadensersatz zu; konnte der Arbeitnehmer beweisen, daß der Fehler auf schlechtes Material zurückzuführen war, behielt er seinen Lohnanspruch. In dem Moment jedoch, wo eine kollektive Vereinbarung wie das Brooklands Agreement für derartige Fälle eine mehrfach gestufte Verhandlungsprozedur vorschrieb, wurde aus der potentiellen Rechtsfrage zunächst eine Angelegenheit des gütlichen Ausgleichs. Die harte Alternativfrage, wer im Recht war und wer im Unrecht, wurde in einer solchen Situation tunlichst eliminiert, zumindest in den Anfangsstadien des Einigungsversuchs. Der Konflikt wurde seiner juristischen Dimensionen entkleidet, er wurde gewissermaßen entrechtlicht, um eine vorschnelle Eskalation zu vermeiden.

\section{FAZIT UND AUSBLICK AUF DIE ZWISCHENKRIEGSZEIT}

Entindividualisierung und Entrechtlichung - mit diesen beiden Stichworten läßt sich die Rückwirkung des Schieds- und Einigungswesens auf das Konfliktverhalten am Arbeitsplatz beschreiben. Ein einzelner Arbeiter oder Arbeitgeber, der in dieses System des Streitschlichtens hineinwuchs, hatte im Prinzip keine Veranlassung, es in Frage zu stellen. Der wenig anziehende Charakter der ordentlichen Rechtsprechung in den Friedens- und Grafschaftsgerichten mag dazu beigetragen haben, eine relative Zufriedenheit mit den Resultaten der außergerichtlichen Einigungsverfahren zu fördern.

275 Brooklands Agreement vom 24. 3. 1893, Zusatzartikel vom 22.12. 1900, zit. nach der deutschen Übersetzung bei Zimmermann, Einigungswesen, S. 97. 
Für die ordentliche Justiz hatte das zur Folge, daß sie seltener, als es theoretisch möglich gewesen wäre - wieviel seltener, läßt sich nicht feststellen mit Arbeitsstreitigkeiten konfrontiert wurde. Vielleicht ist das ein Grund dafür, daß das materielle Arbeitsvertragsrecht in Großbritannien so lange ein Stiefkind des Common law blieb. Für die Streitenden selbst mögen die Resultate in vielen Fällen günstiger gewesen sein als das, was nach einem Rechtsstreit zu erwarten gewesen wäre. Im Einzelfall konnte es jedoch auch dazu kommen, daß die Beschwerdeführenden auf ihr, gutes Recht' im juristischen Sinne verzichten mußten, damit die als vorrangig geltenden kollektiven Verhandlungsprozeduren nicht gestört oder gar aufs Spiel gesetzt wurden.

Wie man das Schieds- und Einigungssystem insgesamt bewerten will, hängt vom Standpunkt ab und ist nicht Gegenstand dieser Untersuchung. Wer sich als Historiker die Perspektive eines Funktionsträgers in der organisierten Arbeiterbewegung zu eigen macht, wird die Konzentration auf das kollektiv Verhandelbare und die damit einhergehende Machtsteigerung der Gewerkschaften begrüßen. Wer sich hingegen in die Lage eines in seinen Rechten geschädigten Individuums versetzt, wird eher die beschwichtigenden und entmündigenden Aspekte des Systems hervorkehren. Ungeachtet aller Bewertungsfragen ist festzuhalten, daß der Ausbau des freiwilligen Schieds- und Einigungswesens in Großbritannien zur Entrechtlichung der britischen Arbeitsbeziehungen beigetragen hat. Das geschah allerdings, wie die niedrigen Fallzahlen belegen, weniger durch eine direkt mit der Justiz konkurrierende quasi-gerichtliche Tätigkeit der arbitration and conciliation boards, sondern vielmehr in der Weise, daß Konflikte am Ort ihrer Entstehung von allen Beteiligten primär als Verhandlungssache und nicht als Rechtsstreit begriffen und sehr oft auch auf dem Verhandlungswege endgültig gelöst wurden. Das institutionelle Arrangement der Schieds- und Einigungsstellen beförderte diese unjuristische Sichtweise, indem es den lokalen und betrieblichen Arbeitnehmer- und Arbeitgebervertretern die Definitionsmacht über, wichtige' und ,unwichtige' Konflikte zuspielte.

Der Erste Weltkrieg und die legislativen Maßnahmen der unmittelbaren Nachkriegszeit änderten an den Grundzügen des britischen Schieds- und Einigungswesens, wie es hier geschildert wurde, nur wenig. Die weitere Entwicklung braucht daher nur noch kurz skizziert zu werden. Die Erfahrungen mit der Zwangsschlichtung in den Jahren 1915 bis 1919 wurden von den Beteiligten überwiegend negativ beurteilt. ${ }^{276} \mathrm{Nach}$ dem Krieg war man

276 Die Zwangsschlichtung von Arbeitsstreitigkeiten durch einen vom Ministerium gestellten Unparteiischen wurde (unter bestimmten Bedingungen und begrenzt auf kriegswichtige In- 
überall bestrebt, schnell zu den Vorkriegsinstitutionen und -praktiken zurückzufinden. Das System differenzierte sich weiter aus, es erfaßte neben der Industrie zunehmend auch den Dienstleistungsbereich, und der Staat griff dort, wo die Selbstorganisation der Beteiligten zu schwach war, unterstützend ein. Neue Strukturen des Verhandelns und Streitschlichtens kamen hinzu, sie reichten von den shop stewards und works committees auf betrieblicher Ebene ${ }^{277}$ bis hinauf zum Industrial Court an der Spitze als gleichsam letzter Instanz des Schieds- und Einigungswesens. ${ }^{278}$ Leitendes Prinzip bei alldem blieb aber stets die Freiwilligkeit. ${ }^{279}$ Die ordentliche Justiz wurde nicht in das System einbezogen. Der Industrial Court konnte nur bei $\mathrm{Zu}-$ stimmung beider Parteien und nur nachdem alle in dem betreffenden Gewerbe etablierten freiwilligen Schlichtungsprozeduren ausgeschöpft waren, angerufen werden. Das Urteil war ein Schiedsspruch ohne zwingende Wirkung; es war juristisch nicht vollstreckbar, galt nur für den einzelnen Fall und schuf keine allgemeine Regel. Weder von seiner Stellung im Rechtssystem noch vom seinem (bescheidenen) Geschäftsumfang her war der britische Industrial Court mit dem 1926 geschaffenen deutschen Reichsarbeitsgericht vergleichbar. ${ }^{280}$ Auch das von den Whitley-Komitees der Jahre 1917-18 empfohlene Instrument der staatlich geförderten joint industrial councils sollte von der Intention her den voluntaristischen Charakter des

dustrien, die sogenannten controlled establishments) ermöglicht durch den Munitions of War Act, $5 \& 6$ Geo. 5 , c. 78 (1915), s. 1. Wieder abgeschafft wurde die Zwangsschlichtung durch den Wages (Temporary Regulation) Act, 8 \& 9 Geo. 5 (1918), s. 6. Der Industrial Courts Act, $9 \& 10$ Geo. 5, c. 69 (1919) etablierte eine neue, freiwillige Schlichtungsprozedur. Während des Krieges stieg die Zahl der durch staatliche Intervention beigelegten Arbeitskonflikte steil an, von 81 Fällen (1914) auf 3583 Fälle (1918), um dann schnell wieder zu sinken auf 920 (1920). Siehe Report on Conciliation and Arbitration, 1920, S. 7.

277 Hierzu, auch zu den Anfängen der shop steward-Bewegung vor dem Ersten Weltkrieg ausführlich: Joachim Rückert u. Wolfgang Friedrich, Betriebliche Arbeiterausschüsse in Deutschland, Großbritannien und Frankreich im späten 19. und frühen 20. Jahrhundert. Eine vergleichende Studie zur Entwicklung des kollektiven Arbeitsrechts, Frankfurt/Main 1979 , bes. S. 32-62.

278 Im Überblick zu den Reformversuchen der Nachkriegszeit: Fox, History and Heritage, S. 290-308; Brodie, Evolution of British Labour Law.

279 Vgl. Report on Conciliation and Arbitration, 1919 (221), S. III. Dort wird als Maxime der Regierungspolitik formuliert „... that trades should be encouraged to discuss and settle their wages and other questions without the intervention of the State, but that the Government should provide means for conciliation and arbitration if the ordinary negotiations between employers and employed have broken down and the parties desire assistance, or the case is one in which, in the general interest, some action by the Government is desirable."

${ }^{280}$ Zum Industrial Court siehe Wolf Dittler, Die amtliche Schlichtung und die staatliche Lohnfestsetzung in England. Zugleich ein Beitrag zur Rechtsvergleichung im Arbeitsrecht, Stuttgart 1931, S. 50-55; M. Turner-Samuels, Industrial Negotiation and Arbitration, London 1951, S. 266-279. 
britischen Systems nicht ändern, sondern stärken. ${ }^{281}$ Ebenso auch die Trade boards, die nun in größerer Zahl nach ähnlichen Grundsätzen wie unter dem Trade Boards Act von 1909 in Niedriglohngewerben ins Leben gerufen wurden. ${ }^{282}$

Auf allen Ebenen dieses komplexen Streitschlichtungssystems trafen die Akteure weiterhin keine strenge Unterscheidung zwischen Rechts- und Interessenkonflikten sowie zwischen Individual- und Kollektivstreitigkeiten. Anders als in Deutschland beurteilte man den einzelnen Disput nicht nach juristischen Kriterien, sondern primär unter dem Gesichtspunkt des ihm innewohnenden Gefahrenpotentials für die zukünftigen Beziehungen zwischen den Arbeitnehmern und Arbeitgebern eines Betriebs oder einer ganzen Branche. Danach entschied sich, wie mit den Fällen verfahren wurde, wobei den Ortssekretären und innerbetrieblichen Verhandlungspartnern die Schlüsselrolle zufiel. Insgesamt verstärkten sich in den Nachkriegsjahren die schon vorher beobachtbaren Tendenzen der Entindividualisierung und Entrechtlichung bei der Beilegung von Arbeitsstreitigkeiten. Damit nahm die britische Entwicklung einen anderen Weg als die deutsche, die sich im gleichen Zeitraum durch eine zunehmend scharfe rechtsdogmatische und institutionelle Trennung zwischen individuellem und kollektivem Arbeitsrecht auszeichnete und die sich insgesamt als Prozeß der Verrechtlichung darstellen läßt. Die Gewerbegerichte besaßen dabei, wie im folgenden zu zeigen sein wird, eine Scharnierfunktion. Sie trugen die Maßstäbe und Begriffe der ordentlichen Justiz in die Arbeitsbeziehungen hinein, sie stellten aber auch ein Angebot dar, das es den Arbeitnehmern und Arbeitgebern ermöglichte, ihre Vorstellungen von materieller Gerechtigkeit und angemessenem Verfahren in die Rechtsprechung und bald auch in die Rechtswissenschaft einzuschleusen.

${ }^{281}$ Ebd., S. $10 \mathrm{ff}$;; Bernd-Jürgen Wendt, Whitleyism. Versuch einer Institutionalisierung des Sozialkonfliktes in England am Ausgang des Ersten Weltkrieges, in: Dirk Stegmann u. a. (Hg.), Industrielle Gesellschaft und politisches System. Beiträge zur politischen Sozialgeschichte. Festschrift für Fritz Fischer zum 70. Geburtstag, Bonn 1978, S. 337-353.

282 Zur Praxis unter dem Trade Boards Act von 1909 siehe oben, Kap. I.4. 


\section{VERGLEICH MIT DEN DEUTSCHEN GEWERBE- UND KAUFMANNSGERICHTEN}

\section{DAS GEWERBEGERICHTSGESETZ VON 1890 - „VERRECHTLICHUNGS- BEGINN OHNE BERUFSJURISTEN" $“ 283$}

Im Juni 1894 erschien in der Labour Gazette, dem Organ der Abteilung für Arbeiterfragen im britischen Handelsministerium, eine Notiz über „Industrial Courts" in Deutschland. ${ }^{284}$ Der Artikel informierte über die wichtigsten Bestimmungen des deutschen Gewerbegerichtsgesetzes vom 29. Juli 1890 und gab einige Zahlen zur Nutzung der neu geschaffenen Einrichtung. Erwähnenswert schien dem Redakteur unter anderem, daß nur wenige Klagen von Arbeitgebern, die meisten hingegen von Arbeitnehmern ausgingen und daß überwiegend geringfügige Summen im Spiel waren. Kommentare oder Wertungen enthielt der Artikel nicht. Den Titel des Gesetzes „betreffend die Gewerbegerichte“ übersetzte der Redakteur recht frei mit „Arbitration and Conciliation Law". Damit ist angedeutet, in welchem Kontext die Rezeption der neuen deutschen Institution stattfand. Die Gewerbegerichte wurden als Versuch interpretiert, in Deutschland etwas einzuführen, was in Großbritannien schon lange, allerdings auf freiwilliger Basis existierte, nämlich Schiedsgerichte und Einigungsstellen. In britischen Regierungskreisen und bei Sozialreformern dachte man zu dieser Zeit verstärkt darüber nach, wie der industrielle Frieden staatlicherseits gefördert werden könne. Ein Resultat des Nachdenkens war der Conciliation Act von 1896. Im Rahmen der dahin führenden Diskussionen bestand ein gewisses Interesse an vergleichbaren Bestrebungen im Ausland. Nicht nur die deutschen Gewerbegerichte, auch die französischen Conseils de prud'bommes und die Experimente mit staatlicher Zwangsschlichtung in Neuseeland und Australien wurden unter diesem Gesichtspunkt beobachtet. ${ }^{285}$ Das ohnehin nur

283 Reichold, Der „Neue Kurs“, S. 25.

284 Industrial Courts, in: Labour Gazette, Juni 1894, S. 190. Als Quelle wurden die Blätter für Soziale Praxis vom 24. Mai 1894 angegeben. Eine weitere Kurzmeldung über Gewerbegerichte in der Labour Gazette, Okt. 1894, S. 318.

285 Vgl. David F. Schloss, State Promotion of Industrial Peace, in: Economic Journal 3 (1893), S. 218-225. Seine Kenntnisse über die Gewerbegerichte bezog der Autor, damals außerplanmäßiger Mitarbeiter im Board of Trade, aus einem Bericht des Foreign Office. Zu Schloss vgl. Cornelißen, Das „Innere Kabinett“, S. $56 \mathrm{ff}$. Vgl. ferner den auf deutsche Quellen gestützten Bericht über die Gewerbegerichtsgesetzgebung und ihre ersten Auswirkungen in: Royal Commission on Labour, Foreign Reports, Bd. V: Germany, PP 1893-94 (C. 7063 - VII.) XXXIX, Part II, hier S. 35-38. Schon die Überschrift des entsprechenden Abschnitts („Prevention and Settlement of Strikes") deutet auf das Hauptinteresse der britischen Beobachter. Aus dem Bericht selbst spricht eine gewisse Enttäuschung über die geringe Nutzung der Ge- 
verhaltene Interesse an den deutschen Gewerbegerichten schwand jedoch rasch, als sich herausstellte, daß diese Gerichte auch nach mehrjährigem Bestehen fast ausschließlich mit kleinen Streitigkeiten aus Individualarbeitsverträgen beschäftigt blieben, während die Wirksamkeit als Einigungsamt $\mathrm{zu}$ vernachlässigen war. ${ }^{286}$ Nur 44 Anrufungen im Jahr 1896, und das bei schon 284 bestehenden Gewerbegerichten: diese Bilanz erschien den britischen Beobachtern im Handelsministerium denn doch zu dürftig, um sich noch länger mit dieser deutschen Einrichtung zu befassen. Daß im gleichen Jahr, 1896, bereits 68798 Individualklagen vor die Gewerbegerichte gebracht wurden, davon 63462 von Arbeitnehmern, war der Labour Gazette nur eine unscheinbare Meldung wert. ${ }^{287}$ Nach 1897 wurde über diesen zentralen Aspekt der Gewerbegerichtsbarkeit nicht mehr berichtet, die Funktion als Einigungsamt wurde in den folgenden zehn Jahren nur noch wenige Male erwähnt.288

Für das schwache und zudem nur selektive britische Interesse an den Gewerbegerichten lassen sich verschiedene Gründe nennen. Generell hatten Sozialpolitiker und Gewerkschaftler in Großbritannien um 1890 das Gefühl, in allen Dingen, die mit industriellen Beziehungen und Arbeiterschutz zu tun hatten, den kontinentaleuropäischen Nationen weit voraus zu sein. Der Gedanke, daß man im Bereich des Arbeitsrechts ausgerechnet vom Deutschen Kaiserreich etwas lernen oder gar übernehmen könne,

werbegerichte und ihrer Vorläufer für die kollektive Streitschlichtung. Kritisch zur fehlenden Würdigung des politischen Kampfes der deutschen Arbeiterbewegung durch den britischen Berichterstatter: Eduard Bernstein, Der Bericht der englischen Arbeitskommission über die Arbeiterfrage in Deutschland, in: Die Neue Zeit 12 (1894), S. 493-499.

286 Vgl. die Artikel: Conciliation and Arbitration in Germany in 1896, in: Labour Gazette, Okt. 1897, S. 293; Settlement of Labour Disputes by Industrial Courts in Germany, in: ebd., Aug. 1898, S. 230f.; Work of the Berlin Industrial Court as an agency for averting and settling Strikes and Lock-outs, in: ebd., Jan. 1899, S. 11.

287 Labour Gazette, Juni 1897, S. 169.

288 Labour Gazette, Aug. 1901, S. 234; ebd., Sept. 1906, S. 260. Auch sonst finden sich kaum Spuren einer nennenswerten Rezeption. Die Webbs zeigten sich gegen ihre sonstige Gewohnheit bemerkenswert uninformiert: Webb, Industrial Democracy, S. 226, Fn. 1. Sogar William Harbutt Dawson, der als Mitarbeiter in verschiedenen Ministerien eifrig bemüht war, deutsche Einrichtungen bekannt zu machen, würdigte die rechtsprechende Funktion der Gewerbegerichte nur in vagen Worten. Siehe: William H. Dawson, The German Workman: A Study in National Efficiency, London 1906, S. VIII; ders., Industrial Germany, London u. Glasgow 1912, S. 224. Vgl. zu Dawson allgemein: Jörg Filthaut, Dawson und Deutschland. Das deutsche Vorbild und die Reformen im Bildungswesen, in der Stadtverwaltung und in der Sozialversicherung Großbritanniens, 1880-1914, Frankfurt/Main 1994. Auch bei Günter Hollenberg, Englisches Interesse am Kaiserreich. Die Attraktivität PreuBen-Deutschlands für konservative und liberale Kreise in Großbritannien 1860-1914, Wiesbaden 1974, finden sich außer einem Hinweis auf Dawson (S. 234) keine Belege für eine Rezeption. 
mußte einem britischen Arbeiter oder fortschrittlichen Sozialreformer damals in der Tat abwegig erscheinen. Warum sollte man nach vorbildlichen Gesetzen in einem Land suchen, in dem es noch Gesindeordnungen gab, die Gefängnis- und Prügelstrafen für widerspenstige Knechte und Hausbedienstete vorsahen? ${ }^{289}$ Was war von einem Staat zu erwarten, der es immer noch zuließ, daß streikende Arbeiter und Gewerkschaftsmitglieder wegen harmloser Unmutsbekundungen gegenüber Arbeitswilligen, ja sogar wegen der bloßen Ankündigung eines Streiks zu Haftstrafen verurteilt wurden, obwohl die Koalitionsfreiheit gesetzlich seit 1869 verbrieft war?290 Nationale Stereotypen über ,englische Freiheit' und kontinentale ,Despotie‘ mögen bisweilen zu einer Übertreibung der Unterschiede geführt haben, doch ist es tatsächlich schwer vorstellbar, daß eine englische Regierung um die Jahrhundertwende noch gewagt hätte, einen Gesetzentwurf wie die deutsche Zuchthausvorlage von 1899 einzubringen, die eine Verschärfung der Strafen

289 Thomas Vormbaum, Politik und Gesinderecht im 19. Jahrhundert (vornehmlich in Preußen 1810-1918), Berlin 1980, hier S. 86-92 zur körperlichen Züchtigung. Das Züchtigungsrecht wurde im Jahr 1900 durch Art. 95 des Einführungsgesetzes zum BGB abgeschafft, aber für einen Dienstboten, der geschlagen wurde, gab es dennoch weiterhin keine Möglichkeit, seinen Dienstherrn straf- oder zivilrechtlich zur Rechenschaft zu ziehen. Vgl. zur „Bizarrerie des gesinderechtlichen Zustandes" um 1900: Hermann Jastrow, Das Gesinderecht nach dem Bürgerlichen Gesetzbuch, in: Soziale Praxis 6 (1897), Sp. 1254-1257 (das Zitat Sp. 1257). Die Rückständigkeit der einzelstaatlichen deutschen Gesinderechte war in England zwar kein Thema, aber doch vage bewußt; vgl. etwa die Notiz „Law relating to Breach of Contract by Agricultural Labourers" in: Labour Gazette, Juli 1900, S. 201, über ein Kontraktbruchgesetz vom gleichen Jahr aus dem Herzogtum Anhalt.

290 Die richterliche Bekämpfung der Gewerkschaften und ihrer Aktivitäten war in Deutschland eine Angelegenheit der Strafjustiz, die sich dazu unter anderem des preußischen Vereinsgesetzes, verschiedener Paragraphen des Strafgesetzbuchs (Beleidigung, Nötigung, Erpressung) und des $\$ 153$ der Gewerbeordnung (Ausübung des Koalitionszwangs) bediente. Die Zivilsenate des Reichsgerichts kritisierten des öfteren sogar öffentlich die Rechtsprechung ihrer Kollegen von den Strafsenaten. Siehe Rainer Schröder, Die strafrechtliche Bewältigung der Streiks durch Obergerichtliche Rechtsprechung zwischen 1870 und 1914, in: Archiv für Sozialgeschichte 31 (1991), S. 85-102. Vgl. außerdem: Klaus Saul, Zwischen Repression und Integration. Staat, Gewerkschaften und Arbeitskampf im kaiserlichen Deutschland 1884-1914, in: Klaus Tenfelde u. Heinrich Volkmann (Hg.), Streik. Zur Geschichte des Arbeitskampfes während der Industrialisierung, München 1981, S. 209-236; ders., Gewerkschaften zwischen Repression und Integration. Staat und Arbeitskampf im Kaiserreich 1884-1914, in: Wolfgang J. Mommsen u. Hans-Gerhard Husung (Hg.), Auf dem Wege zur Massengewerkschaft. Die Entwicklung der Gewerkschaften in Deutschland und Großbritannien 1880-1914, Stuttgart 1984, S. 433-453; Gerd Bender, Die industrielle Ordnung und das Reichsgericht, in: Rechtshistorisches Journal 8 (1989), S. 109-119; ders., Strukturen des kollektiven Arbeitsrechts; Hans-Joachim Bieber, Die Rolle von Gewerkschaften und Wirtschaftsverbänden bei der Entstehung des Arbeitsrechts, in: Hans G. Nutzinger (Hg.), Die Entstehung des Arbeitsrechts in Deutschland. Eine aktuelle Problematik in historischer Perspektive, Marburg 1998, S. 15-69, hier S. 32-37. 
unter anderem für das Aufstellen von Streikposten vorsah. ${ }^{291}$ Bei der Bismarckschen Sozialversicherung schließlich, dem einzigen sozialpolitischen Experiment, dem in Großbritannien größere Aufmerksamkeit zuteil wurde, waren die Zwangselemente und die gegen die Selbstorganisation der Arbeiter gerichtete Zielsetzung zu offensichtlich, um den Wunsch nach einer Nachahmung aufkommen zu lassen. ${ }^{292}$ Es war bekannt, daß die deutschen Arbeiter selbst aus diesen Gründen der Sozialversicherung anfangs skeptisch bis ablehnend gegenüberstanden. Im übrigen konnten sich die britischen Beamten und Gewerkschaftsführer in ihrem Überlegenheitsgefühl durch die deutschen Sozialreformer, Kathedersozialisten und auch viele Sozialdemokraten bestätigt fühlen, die (mit verschiedener Akzentuierung) immer wieder betonten, wie fortschrittlich und vorbildlich das auf Selbsthilfe, Verhandlungen und Autonomie gegründete britische Tarif- und Einigungswesen sei. $\mathrm{Da} ß$ unter diesen Umständen das Zukunftsweisende an den deutschen Gewerbegerichten, ihre kreative Rechtsprechung zum Individualarbeitsverhältnis, in Großbritannien nicht erkannt wurde, kann kaum verwundern.

Ein weiterer Grund für das britische Desinteresse lag darin, daß eine Konstruktion wie die Gewerbegerichte mit der gewachsenen englischen Gerichtsverfassung und der Ideologie des Common law unvereinbar war. Spezielle Gerichte mit eigenen Verfahrensregeln nur für bestimmte Personenkreise widersprachen der britischen Vorstellung von Gleichheit vor dem Gesetz. Problematisch erschienen Sondergerichtsbarkeiten insbesondere dann, wenn ihnen gestattet sein sollte, rechtsgültige Urteile ohne Berufungsmöglichkeit an die ordentliche Justiz zu fällen. Genau das aber sah das Gewerbegerichtsgesetz von 1890 vor, und es bestimmte außerdem, daß Rechtsanwälte vom Verfahren ausgeschlossen bleiben mußten. ${ }^{293}$ So sympathisch und anziehend gerade diese Bestimmungen die Gewerbegerichte für deutsche Arbeitnehmer machten, so wenig paßten sie zu den Erfahrungen englischer Arbeitnehmer mit ihrer eigenen Justiz. Zwar waren professionelle Juristen und Berufungen an höhere Instanzen bei englischen Ar-

$291 \mathrm{Zu}$ Inhait und Kontext der Zuchthausvorlage: Ernst Rudolf Huber, Deutsche Verfassungsgeschichte seit 1789, Bd. 4: Struktur und Krisen des Kaiserreichs, 2. Aufl., Stuttgart 1969, S. 1235 f. Die Position der SPD und der anderen Parteien mit Debattenauszügen in: Max Schippel, Sozialdemokratisches Reichstags-Handbuch. Ein Führer durch die Zeit- und Streitfragen der Reichsgesetzgebung, Berlin o.J. [1902], S. 154-163 u. 746-752.

$292 \mathrm{Vgl}$. Hennock, British Social Reform. Siehe auch oben, Kap. I.2., zur Rezeption der Unfallversicherungsgesetzgebung.

293 Gewerbegerichtsgesetz 1890, $\$$ 29, 44, RGBl. Jg. 1890, S. 147 u. 154. 
beitnehmern nicht gerade beliebt, andererseits bestand ohne sie oft überhaupt keine Chance, berechtigte Ansprüche durchzusetzen.

All dies macht es verständlich, daß die Gewerbegerichte des Kaiserreichs und ihr späterer Ausbau zur Arbeitsgerichtsbarkeit der Weimarer Republik in Großbritannien nahezu unbemerkt blieben. Wenn man sich darüber wundert, sollte man bedenken, daß um 1890 auch in Deutschland niemand ahnen konnte, in welche Richtung und mit welcher Geschwindigkeit sich die Gewerbegerichte entwickeln würden. Aus der Rückschau erscheint es geradezu unwahrscheinlich, daß noch unter der Amtszeit Bismarcks, also vor dem Beginn des sogenannten ,Neuen Kurses', in den Bundesratsausschüssen und im Handelsministerium an einem Gesetzentwurf gearbeitet wurde, der die ordentlichen Gerichte und die professionellen Juristen von einem so wichtigen Feld wie dem Individualarbeitsrecht weitgehend ausschalten sollte und der dazu die Wahl von Beisitzern aus dem Kreis der Arbeitgeber und Arbeitnehmer auf paritätischer Basis vorsah. ${ }^{294}$ Wenn sich auch an den Einzelheiten des Planes im Laufe des Gesetzgebungsverfahrens manches änderte, herrschte doch über die Wünschbarkeit und die Grundzüge der neuen Institution ein bemerkenswerter Konsens, der im Reichstag mindestens von den Nationalliberalen bis zu den Sozialdemokraten reichte. Zwar verweigerten letztere dem Gesetz am Ende die Zustimmung, doch geschah dies nicht, weil die SPD Gewerbegerichte an sich ablehnte, sondern weil ihre weitergehenden Forderungen vor allem im Hinblick auf das aktive Wahlrecht und die Wählbarkeit für das Beisitzeramt nicht erfüllt wurden. Die Sozialdemokraten kritisierten außerdem, daß bestimmte Arbeitergruppen, insbesondere die Land- und Forstarbeiter, das kaufmännische Hilfspersonal sowie die in staatlichen Betrieben beschäftigten Arbeiter, nicht unter den Wirkungsbereich der Gewerbegerichte fallen sollten. ${ }^{295}$ Immerhin gelang es, die pseudo-selbständigen Heimgewerbetreibenden durch eine geschickte Formulierung des freisinnigen Abgeordneten Eberty in die Jurisdiktion der Gewerbegerichte einzubeziehen.296 Das Prinzip einer geson-

294 Ein Resümee der Ereignisse, die zum Gesetzentwurf führten, bei Günter Graf, Das Arbeitsgerichtsgesetz von 1926. Weimarer Verfassungsvollzug auf justizpolitischen Irrwegen des Kaiserreichs?, Goldbach 1993, S. 32-38. Vgl. außerdem zu den Intentionen führender Akteure: Hans Jörg von Berlepsch, „Neuer Kurs“ im Kaiserreich? Die Arbeiterpolitik des Freiherrn von Berlepsch 1890-1896, Bonn 1987, S. 15-53 u. 84-101.

295 Zu den Debatten im Reichstag vgl. Graf, Arbeitsgerichtsgesetz, S. 38-43; Berlepsch, „Neuer Kurs", S. 101-111. Weitere Aufschlüsse zu den Beratungen im Plenum und im Ausschuß des Reichstags verdanke ich auch einem unveröffentlichten Diskussionspapier von Gyu-Jung Park, Das Gewerbegerichtsgesetz und die Sozialdemokratie, Bochum 1998, (30 S).

296 Gewerbegerichtsgesetz 1890, $\$ 4$, RGBl. Jg. 1890, S. 142f. Park, Gewerbegerichtsgesetz, S. 10 u. $17 \mathrm{f}$. Nicht ganz korrekt in diesem Punkt: Johannes Bähr, Entstehung und Folgen des 
derten, von der allgemeinen Justiz abgetrennten Gerichtsbarkeit für die Streitigkeiten von Arbeitern wurde zu diesem Zeitpunkt aber auch von der SPD und den Freisinnigen anerkannt. Die Vorstellung, daß es ein ,einheitliches Arbeitsrecht' für alle Arbeitnehmer geben solle, begann erst um die Jahrhundertwende in die politische Debatte einzudringen und ist bereits als Resultat des Erfolgs der Gewerbegerichte zu sehen.

Die unmittelbare Vorgeschichte des Gesetzes von 1890 und die Positionen der Parteien sind bekannt und müssen hier nicht wiederholt werden.297 Wichtiger als die unterschiedlichen Forderungen im Detail erscheint die Übereinstimmung im Grundsätzlichen. Das gilt zumal aus vergleichender Perspektive. Wesentliche Punkte des Entwurfs der verbündeten Regierungen passierten den Reichstag ohne nennenswerten Widerstand und aufgeregte Debatten. Dazu gehörten die kommunale Trägerschaft der Gewerbegerichte und ihre zunächst fakultative Einführung überall dort, wo eine entsprechende Einigung auf lokaler Ebene erzielt werden konnte. Mit der Wahl der Gemeinde als Gerichtsbezirk wurde zugleich branchenspezifischen Lösungen, wie sie für England typisch waren, eine Absage erteilt. Größere Diskussionen über diesen Punkt gab es nicht. Den Besonderheiten der örtlichen Gewerbestruktur konnte durch ein Ortsstatut Rechnung getragen werden, in dem zum Beispiel die Bildung von Fachkammern oder die Wahl von Beisitzern aus den am Ort stark vertretenen Industrien vorgesehen sein konnte. ${ }^{298}$

Keine unüberwindlichen Meinungsverschiedenheiten gab es auch hinsichtlich der Zusammensetzung. Das Gewerbegericht sollte bestehen aus einem vom Magistrat oder der Gemeindevertretung zu bestellenden Vorsitzenden, der weder Arbeitnehmer noch Arbeitgeber sein durfte, und Beisitzern, die in je gleicher Zahl und geheim durch alle unter die Rechtsprechung des Gerichts fallenden Arbeitnehmer und Arbeitgeber zu wählen waren. Umstritten waren lediglich das Wahlrecht für die Beisitzer und das behördliche Bestätigungsrecht des Vorsitzenden, das der Staat sich vorbehielt, von

Arbeitsgerichtsgesetzes von 1926. Zum Verhältnis von Arbeiterschaft, Arbeiterbewegung und Justiz zwischen Kaiserreich und Nationalsozialismus, in: Klaus Tenfelde (Hg.), Arbeiter im 20. Jahrhundert, Stuttgart 1991, S. 507-532, S. 511 u. 519.

$297 \mathrm{Vgl}$. neben der bereits genannten Literatur: Adelheid v. Saldern, Gewerbegerichte im wilhelminischen Deutschland, in: Karl-Heinz Manegold ( $\mathrm{Hg}$.$) , Wissenschaft, Wirtschaft und$ Technik. Studien zur Geschichte. Wilhelm Treue zum 60. Geburtstag, München 1969, S. 190-203; Jochen Weiß, Arbeitsgerichtsbarkeit und Arbeitsgerichtsverband im Kaiserreich und in der Weimarer Republik, Frankfurt/Main 1994, S. 13-16.

298 Von der Möglichkeit, durch Ortsstatut besondere Strukturen und Verfahren einzuführen, wurde wenig Gebrauch gemacht. In Preußen folgten die meisten Ortsstatuten einem vom Ministerium ausgegebenen Musterstatut: vgl. v. Saldern, Gewerbegerichte, S. 193. 
dem er aber später in der Praxis nie Gebrauch machte. ${ }^{299}$ Diese Differenzen verblassen jedoch zunächst hinter der Tatsache, daß der deutsche Gesetzgeber mit großer Mehrheit gewählten Arbeitnehmervertretern ein Mitspracherecht in einer Institution einräumte, die staatliche Hoheitsaufgaben erfüllte. ${ }^{300}$ Damit wurde den Gewerkschaften nach den Selbstverwaltungsgremien der Sozialversicherung ein zweites gesetzlich legitimiertes Betätigungsfeld eröffnet. ${ }^{301}$

Breite Zustimmung fand auch die neuartige Verknüpfung von gerichtlicher und schlichtender Tätigkeit in einer Institution. Die vor $1890 \mathrm{im}$ Deutschen Reich bestehenden gewerblichen Schiedsgerichte waren mit wenigen Ausnahmen nur für Streitigkeiten aus Individualarbeitsverträgen zuständig gewesen. Hier folgte das Gewerbegerichtsgesetz einer Tradition, die teils auf deutschen Erfahrungen beruhte, teils auf die im Rheinland übernommenen und später umgeformten französischen Conseils de prud'bommes zurückging. ${ }^{302} \mathrm{Im}$ Jahr 1890 kam nun die Funktion als Einigungsamt bei kollektiven Konflikten um zukünftige Arbeitsbedingungen hinzu. Für diese Teilfunktion spielte bei der Vorbereitung des Gesetzes das englische Vorbild der con-

299 Vgl. v. Saldern, Gewerbegerichte, S. 194; Ignaz Jastrow, Die Erfahrungen in den deutschen Gewerbegerichten, in: Jahrbücher für Nationalökonomie und Statistik 69 (1897), S. 321-395, S. 334f.

300 Zum Problem des staatlichen Charakters der Gewerbegerichtsbarkeit trotz kommunaler Trägerschaft: Reichold, Der „Neue Kurs“, S. 19; Graf, Arbeitsgerichtsgesetz, S. 43.

$301 \mathrm{Vgl}$. Klaus Tenfelde, Arbeitersekretäre. Karrieren in der deutschen Arbeiterbewegung vor 1914, Heidelberg 1996, S. 19-23.

302 Zu den, Vorläufer'-Institutionen der Gewerbegerichte gibt es eine inzwischen recht umfangreiche Literatur, die hier nicht im einzelnen kommentiert werden kann. Als verfehlt müssen alle Versuche gelten, die Wurzel der Arbeitsgerichtsbarkeit des späten Kaiserreichs lediglich in einer bestimmten Traditionslinie, etwa den französischen Conseils de prud'bommes, zu suchen. Auf diese Linie konzentriert sich die Darstellung von Klaus Globig, Gerichtsbarkeit als Mittel sozialer Befriedung, dargestellt am Beispiel der Entstehung der Arbeitsgerichtsbarkeit in Deutschland, Frankfurt/Main 1985. Dagegen ist zu Recht darauf hingewiesen worden, daß es schon vor der napoleonischen Ära gewerbliche Schiedsgerichte in verschiedenen Regionen Deutschlands gab, darunter auch im rheinischen Raum (Solingen), die ihre Einrichtung vor allem dem Bedürfnis von Unternehmern und Verlegern nach Fertigungskontrolle verdankten. Hierzu: Jürgen Brand, Untersuchungen zur Entstehung der Arbeitsgerichtsbarkeit in Deutschland. Erster Teilband: Zwischen genossenschaftlicher Standesgerichtsbarkeit und kapitalistischer Fertigungskontrolle, Pfaffenweiler 1990. Freilich geht auch Brand zu weit, wenn er behauptet, daß „der Warenkontrolle und der Schaffung gleichartiger Konkurrenzbedingungen für die Verleger/Unternehmer die entscheidende Rolle bei der Herausbildung einer eigenständigen Arbeitsgerichtsbarkeit" zukam (S. 11f., Hervorhebung von mir). Vielmehr ist von einer vielfältigen und in manchen Regionen, besonders im Rheinland, mehrfach überformten Tradition auszugehen. Grundlegend zur Arbeitsweise der rheinischen Fabrikengerichte sind die Publikationen von Peter Schöttler. Das Gewerbegerichtsgesetz von 1890 bediente sich relativ frei aus einem Vorrat erprobter Struktur- und Verfahrenselemente, fügte aber auch Neues hinzu. 
ciliation boards eine gewisse Rolle. ${ }^{303}$ Voraussetzung dafür war ein bis ins liberale Lager reichender Konsens, daß ein, wie Gustav Schmoller sich ausdrückte, „Mitreden der Arbeiter in Form der englischen Gewerkvereine“ notwendig sei, wenn man der sonst sicher „kommenden socialen Revolution“ entgehen wolle. ${ }^{304}$ Auch die Februarerlasse Kaiser Wilhelms II. enthielten mit der Erwähnung von „Formen ..., in denen die Arbeiter durch Vertreter, welche ihr Vertrauen besitzen, an der Regelung gemeinsamer Angelegenheiten beteiligt und zur Wahrnehmung ihrer Interessen bei Verhandlungen mit den Arbeitgebern und den Organen meiner Regierung befähigt werden ", ein in diese Richtung weisendes, freilich sehr vage formuliertes Versprechen. 305 Als Einigungsamt konnte das Gewerbegericht nur auf Initiative beider Parteien in Aktion treten. Um rechtswirksam zu werden, mußten die erzielten Vereinbarungen oder Schiedssprüche von beiden Seiten binnen einer bestimmten Frist angenommen werden. Freiwillige Mitwirkung war also hierähnlich wie in England - erforderlich, während das Gewerbegericht bei Individualfällen wie ein normales Gericht rechtsverbindliche Urteile fällte. Sowohl die Zulassung gewählter Beisitzer als auch das staatliche Angebot eines Einigungsamts bedeuteten de facto eine Stärkung des gewerkschaftlichen Einflusses in der deutschen Arbeiterschaft. Diese nicht nur symbolische Anerkennung durch die Legislative war bedeutsam angesichts der Tatsache, daß Strafjustiz, Polizei und der private Betriebsschutz der Unternehmer fortfuhren, das praktische Wirken der Gewerkschaften vor allem in der Schwerindustrie nach Kräften zu behindern. 306

303 Vgl. die Hinweise bei Reichold, Der „Neue Kurs“, S. 19; Graf, Arbeitsgerichtsgesetz, S. 35.

304 Gustav Schmoller, Über Wesen und Verfassung der großen Unternehmungen (1889), in: ders., Zur Social- und Gewerbepolitik der Gegenwart, Leipzig 1890, S. 372-440, S. 436. Zur Diskussion um Streikbekämpfung und Einigungswesen unter deutschen bürgerlichen Sozialreformern: Rüdiger vom Bruch, Streiks und Konfliktregelung im Urteil bürgerlicher Sozialreformer 1872-1914, in: Klaus Tenfelde u. Heinrich Volkmann, Streik. Zur Geschichte des Arbeitskampfes in Deutschland während der Industrialisierung, München 1981, S. 253-270.

305 Der Text der Februarerlasse bei Ernst Rudolf Huber, Dokumente zur Deutschen Verfassungsgeschichte, Bd. 2: 1851-1918, Stuttgart 1964, S. 413 f., hier S. 414. Ausführlich zur Entstehungsgeschichte des Textes und seiner Wirkung: Karl Heinrich Kaufhold, Die Diskussion um die Neugestaltung des Arbeitsrechts im Deutschen Reich 1890 und die Novelle zur Reichsgewerbeordnung 1891, in: Zeitschrift für Arbeitsrecht 22 (1991), S. 277-322, S. 292-300. In der öffentlichen Diskussion um 1890 wurde vielfach nicht klar unterschieden zwischen Arbeiterausschüssen, Einigungsämtern, gewerblichen Schiedsgerichten und Arbeiterkammern; vgl. Heinrich Herkner, Zur Kritik und Reform der deutschen Arbeiterschutzgesetzgebung, in: Archiv für Soziale Gesetzgebung und Statistik 3 (1890), S. 209-261, S. 248 ff. u. $257-260$.

306 Zur Streikbekämpfung durch unternehmerische Privatpolizei: Ralph Jessen, Unternehmerherrschaft und staatliches Gewaltmonopol. Hüttenpolizisten und Zechenwehren im Ruhr- 
Ein weiteres, um 1890 ebenfalls kaum umstrittenes Merkmal des Gewerbegerichtsgesetzes verdient aus vergleichender Perspektive Beachtung. Es ist das in England in dieser Form undenkbare Prinzip der Sondergerichtsbarkeit, das mit den Gewerbegerichten seine bis dahin deutlichste Ausprägung erfuhr. Schon vor 1890 gab es in Deutschland besondere Gerichte und Spruchkammern, deren Zuständigkeit sachlich und personell begrenzt war und die für ihren Zweck die Zuständigkeit der ordentlichen Gerichte ausschlossen. $\mathrm{Zu}$ nennen sind die Kammern für Handelssachen bei den Landgerichten und die Verwaltungsgerichte. ${ }^{307}$ Die konkurrierende Rechtsprechung der ordentlichen Gerichte wurde auch durch das Gewerbegerichtsgesetz beseitigt. Darüber hinaus wurde hier nun auch die Berufung eingeschränkt auf diejenigen Verfahren, bei denen der Streitwert über 100 Mark lag. Des weiteren wurden professionelle Juristen weitgehend aus den Gewerbegerichten verbannt: Rechtsanwälte waren nicht zugelassen, und der Vorsitzende mußte keine juristische Ausbildung genossen haben, wenn er auch in der Praxis meist ein Verwaltungsjurist war. Das Gewerbegericht war somit mehr als andere Sondergerichte in Deutschland von der ordentlichen Justiz und ihren Maßstäben abgekoppelt, ohne daß die Rechtskräftigkeit und Vollstreckbarkeit der Urteile deswegen in Frage gestellt wurde. Der Gewerberichter und seine Beisitzer waren mithin in ihrer Spruchtätigkeit mindestens ebenso autonom wie die englischen Friedensrichter, jedoch mit dem Unterschied, daß sie durch indirekte beziehungsweise direkte Wahl viel näher mit den Erwartungen der Rechtssuchenden in Berührung standen als die undemokratisch, von oben' ernannten Friedensrichter. Die englischen magistrates waren zudem in erster Linie Vollstrecker des allgemeinen Strafgesetzes, die deutschen Gewerberichter konnten hingegen in stärkerem Maße selbst rechtsschöpferisch tätig werden.

$\mathrm{Zu}$ den weithin akzeptierten Punkten des Gesetzes von 1890 gehörten schließlich auch die verfahrensrechtlichen Bestimmungen. Neben dem Ausschluß der Anwälte war hier vor allem der obligatorische Sühneversuch von

gebiet (1870-1914), in: Alf Lüdtke (Hg.), „Sicherheit“ und „Wohlfahrt“. Polizei, Gesellschaft und Herrschaft im 19. und 20. Jahrhundert, Frankfurt/Main 1992, S. 161-186.

307 Gerichtsverfassungsgesetz 1877, RGBI. Jg. 1877, S. 41-76, S. 60 ff. (Kammern für Handelssachen). Vgl. Wilhelm Silberschmidt, Die deutsche Sondergerichtsbarkeit in Handels- und Gewerbesachen, insbesondere seit der französischen Revolution. Ein Beitrag zur Geschichte der Laiengerichte, Stuttgart 1904 (Zeitschrift für Handelsrecht, Beilagenheft 55), bes. S. $189 \mathrm{ff}$.; Werner Schubert, Die deutsche Gerichtsverfassung (1869-1877). Entstehung und Quellen, Frankfurt/Main 1981, S. 181-200. Zur Verwaltungsgerichtsbarkeit: Wolfgang Rüfner, Die Entwicklung der Verwaltungsgerichtsbarkeit, in: Deutsche Verwaltungsgeschichte, hrsg. v. Kurt G.A. Jeserich u.a., Bd. 3: Das Deutsche Reich bis zum Ende der Monarchie, Stuttgart 1984, S. 909-930. 
Bedeutung. Der Gewerberichter war gehalten, „thunlichst auf eine gütliche Erledigung des Rechtsstreits hinzuwirken" ${ }^{308}$ Erst wenn ein Vergleich nicht zustandekam, sollte eine kontradiktorische Verhandlung unter Hinzuziehung der Beisitzer anberaumt werden. Die Gebührenfreiheit für den Fall, daß sich die Streitenden tatsächlich auf einen Vergleich verständigten, unterstützte den auf Befriedung statt Konfrontation zielenden Charakter des Gewerbegerichtsverfahrens. Der prozeßrechtliche Vorrang des Vergleichs, die niedrigen Gebühren, Vorschußfreiheit für die Kläger, Ausschluß der Anwälte, beschränkte Berufungsmöglichkeit, paritätische Laienbeteiligung und lokale Verankerung: all diese Elemente waren geeignet, eine, wie es in der Begründung des Gesetzentwurfs hieß, „in besonderem Maße des Vertrauens der Betheiligten versicherte und besonders schleunige Rechtspflege" zu gewährleisten. ${ }^{309}$ Zugleich trugen diese Elemente der Tatsache Rechnung, daß die Arbeitnehmer als schwächere Vertragspartner auf eine schnelle, unkomplizierte und finanziell risikoarme Justiz angewiesen waren, um ihre Ansprüche überhaupt durchsetzen zu können. Anders als der englische Gesetzgeber und das Common law gingen Regierung und Reichstagsmehrheit nicht von einer fiktiven Gleichheit der vor Gericht erscheinenden Parteien aus. Das Verfahren vor dem Gewerbegericht kalkulierte vielmehr ein, daß die Arbeitgeber als finanziell stärkere und durchhaltefähigere Partei durch längere und teurere Verfahren begünstigt worden wären. Indem das Gewerbegerichtsgesetz diesen Vorteil mithilfe prozeßrechtlicher Vorschriften kompensierte, war es auch ein Stück Arbeiterschutz. Der nationalliberale Abgeordnete Johannes von Miquel, Frankfurter Oberbürgermeister und als solcher vertraut mit den Erfordernissen eines gewerblichen Schiedsgerichts wie es in Frankfurt schon vor 1890 existierte, brachte diesen Gedanken zum Ausdruck, wenn er erklärte, es sei „für den Arbeiter weit wichtiger, eine schnelle Entscheidung zu haben, als eine übermäßig gründliche und skrupulöse Behandlung der Sache. Denn er kann nicht auf das Resultat einer günstigen Entscheidung in vielen Fällen warten. “310 In der Plenardebatte des Reichstags war es lediglich der Industrielle Freiherr v. Stumm, der für eine Berufung an die ordentliche Justiz eintrat und dies damit begründete, daß „ein gerechtes Urteil für den Arbeiter noch wichtiger als ein billiges" sei. ${ }^{311}$ Auch wenn die Motive v. Stumms allzu durchsichtig

308 Gewerbegerichtsgesetz 1890, §39, RGBl. Jg. 1890, S. 150.

309 Amtliche Begründung zum Gewerbegerichtsgesetz 1890, in: RT-Protokolle Bd. 121, Drucksache 5/1890, S. 38, zit. nach Reichold, Der „Neue Kurs“, S. $18 \mathrm{f}$.

310 Sten. Ber. RT 8. LP 1. Sess., Bd. 1, S. 463; zit. nach Park, Gewerbegerichtsgesetz, S. 24.

311 Sten. Ber. RT 8. LP 1. Sess., Bd. 1, S. 493; zit. nach Park, Gewerbegerichtsgesetz, S. 25. Dort weitere Stimmen zu dieser Frage. Der sozialdemokratische Rechtsexperte Arthur Stadtha- 
waren, um zu überzeugen, begab sogar er sich mit diesem Argument auf die Ebene derer, die den Arbeiterschutz als einen wesentlichen Zweck der Gewerbegerichtsbarkeit anerkannten.

Daß der Ausschluß der Anwälte und die Beschränkung der Rechtsmittel so reibungslos den Reichstag passierten und auch von der Regierung akzeptiert wurden, hing freilich nicht nur mit der Einsicht in die Schutzbedürftigkeit der Arbeitnehmer zusammen. Vielmehr lag dem auch die damals verbreitete Auffassung zugrunde, daß die gewerblichen Streitigkeiten kaum juristische Fragen berührten und daher leicht zu lösen seien. Allein die Konkurrenzklauseln hielt man schon 1890 für schwierig genug, um sie von der Zuständigkeit der Gewerbegerichte auszunehmen. ${ }^{312}$ Andeutungsweise kam 1890 noch ein weiteres Motiv für den Ausschluß der Anwälte zur Sprache; es war die Sorge vor einer Spezialisierung professioneller Juristen auf Arbeitsstreitigkeiten mit der unerwünschten Nebenfolge, daß dadurch juristisches Anspruchsdenken und unnötige Streitsucht in die Arbeitswelt Einzug halten könnten. So ist wohl der Ausspruch des freisinnigen Abgeordneten Gustav Kauffmann zu verstehen, der vor der Zulassung der Anwälte mit der Bemerkung warnte, man würde damit „geradezu den juristischen Hecht in den gewerblichen Karpfenteich" hineinsetzen. ${ }^{313}$ Eine Verrechtlichung der alltäglichen Beziehungen zwischen Arbeitnehmern und Arbeitgebern lag somit 1890 keineswegs in der Intention des deutschen Gesetzgebers. Berufsjuristen sollten draußen bleiben. Die Gewerbegerichte sollten dazu dienen, Arbeitskonflikte so weit wie möglich mit den unjuristischen Mitteln des Vergleichs und der gütlichen Einigung beizulegen.

Diese Hoffnung sollte sich in den folgenden Jahren nur teilweise erfüllen. Zwar zeigten die ersten Statistiken, daß annähernd die Hälfte der Verfahren durch Vergleich und weniger als ein Drittel durch streitiges Urteil abgeschlossen wurden, wichtiger jedoch und für viele überraschend war zunächst einmal der sprunghafte Anstieg der Klagen überhaupt, vor allem von seiten der Arbeiter. ${ }^{314}$ Dieser Anstieg war natürlich zum Teil darauf zurück-

gen regte bereits in dieser Debatte einen eigenen Instanzenzug der Gewerbegerichtsbarkeit an, doch wurde sein dahingehender Antrag von Regierungsseite mit dem Kostenargument zurückgewiesen.

312 Gewerbegerichtsgesetz 1890, \$3, RGBl. Jg. 1890, S. 142.

313 Sten. Ber. RT 8. LP 1. Sess, Bd. 1, S. 442 B; zit. nach Graf, Arbeitsgerichtsgesetz, S. 41.

314 Im Jahr 1896 wurden 45,6 Prozent der Fälle durch Vergleich, 23,8 Prozent durch Zurücknahme, 7,7 Prozent durch Versäumnisurteil, 21,6 Prozent durch Endurteil und der Rest auf andere Weise erledigt. 92,2 Prozent der Klagen kamen von Arbeitern gegen ihre Arbeitgeber, 7,5 Prozent von Arbeitgebern gegen Arbeiter; der Rest waren Klagen von Arbeitern untereinander. Vgl. Das Gewerbegericht, 2. Jg. (1897), S. 95. Für die Klagezahlen siehe Grafik 5.1, S. 320 . 
zuführen, daß in immer mehr Städten Gewerbegerichte entstanden, aber auch das konnte wiederum als Zeichen für eine bedenklich zunehmende Streitlust der Arbeiter gedeutet werden. So sahen es jedenfalls viele Arbeitgeber, deren anfängliche Zustimmung bald in Ablehnung umschlug und die sich mancherorts gegen die Errichtung von Gewerbegerichten zu wehren versuchten. Dabei konnten sie sich hinter dem Kostenargument verschanzen, das auch in den Kommunalverwaltungen Anklang fand. Die Befürworter der Gewerbegerichte - Gewerkschaftler, arbeiterfreundliche Kommunalbeamte, bürgerliche Sozialreformer und vor allem die mitwirkenden Richter und Besitzer selbst - werteten dagegen die Zahlen anders. Für diese Gruppen, die sich schon bald in einem Verband zusammenschlossen und mit der Zeitschrift „Das Gewerbegericht“ ein eigenes Presseorgan schufen, stellte die neue Institution die längst überfällige Antwort auf einen offensichtlichen Bedarf dar, der sich in den Klagezahlen manifestierte. ${ }^{315}$ Wer in diesem Streit recht hatte, läßt sich kaum entscheiden. Gewiß wären ohne die Gewerbegerichte viele berechtigte Klagen aus Angst vor den Kosten unterdrückt, viele unzulässige Praktiken in den Betrieben niemals aufgedeckt worden, insofern traf die Bedarfstheorie zweifellos zu. Andererseits kann nicht ausgeschlossen werden, daß durch die neue und risikoarme Klagemöglichkeit in manchen Fällen erst die Streitlust geweckt wurde, wo es vorher vielleicht bei einer diffusen Unmutsäußerung geblieben wäre. So oder so bewirkte erst das ,Angebot' der neuen Institution, daß ein etwa vorhandener ,Bedarf' artikuliert und aktiviert werden konnte.

Tatsache ist also, und dies ist für den deutsch-englischen Vergleich hervorzuheben, daß die Gewerbegerichte das Konfliktverhalten deutscher Arbeitnehmer und Arbeitgeber entscheidend veränderten. Das relativ attraktive Verfahren lud dazu ein, Streitigkeiten am Arbeitsplatz zunächst unter dem Blickwinkel einer möglichen Klage zu betrachten. Das Modell der Gerichtsverhandlung, nicht wie in England das Modell des kollektiven Verhandelns stand den Beteiligten vor Augen, wenn sie sich eine Lösung, ihres‘ Falles vorzustellen versuchten. Dies führte dazu, daß in Deutschland viele Dispute von vornherein als individuelle Rechtsstreitigkeiten begriffen und behandelt wurden, die in England als Gegenstand eines potentiellen kollektiven Konflikts gegolten hätten. Insofern kam es also in Deutschland, trotz (oder gerade wegen) des unjuristischen Charakters der Gewerbegerichte, zu

315 Zum Verband deutscher Gewerbegerichte und seiner Zeitschrift: Weiß, Arbeitsgerichtsbarkeit und Arbeitsgerichtsverband. Vgl. auch die Beiträge in der Festschrift zum 100jährigen Bestehen des Verbands: Die Arbeitsgerichtsbarkeit. Festschrift zum 100jährigen Bestehen des Deutschen Arbeitsgerichtsverbandes, Neuwied u. Berlin 1994. 
einer Verrechtlichung der Arbeitsbeziehungen. Darüber hinaus kam es auch zu einer Individualisierung der Konflikte, während sich die englische Entwicklung, wie wir im Abschnitt über die Schieds- und Einigungsstellen gesehen haben, mit den Stichworten Entindividualisierung und Entrechtlichung beschreiben läßt.

\section{DIE ENTWICKLUNG BIS ZUM ARBEITSGERICHTSGESETZ VON 1926: ANNÄHERUNG AN DIE ORDENTLICHE JUSTIZ}

Als das Gewerbegerichtsgesetz 1890 verabschiedet wurde, konnte niemand ahnen, daß die neuen Gerichte bei den Arbeitern binnen kurzer Zeit populär werden würden. Auch waren sich Politiker und Juristen nicht darüber im klaren, wie sehr die Rechtsprechung zum Arbeitsvertrag an Umfang und Komplexität zunehmen würde, wenn erst eine Institution bestand, vor der die Konflikte am Arbeitsplatz tatsächlich zur Verhandlung gelangten anstatt wie vorher unterdrückt oder auf andere Weise erledigt zu werden. Vollends unvoraussehbar war schließlich, daß die Gewerbegerichte einmal die Grundlage und das Vorbild für eine fast alle Arbeitnehmergruppen erfassende eigenständige Gerichtsbarkeit abgeben würden. Nur so ist zu erklären, daß eine aus heutiger Sicht höchst folgenreiche Veränderung der Gerichtsverfassung damals so relativ unbemerkt und ohne großen Streit $\mathrm{zwischen}$ Parteien und Interessengruppen vonstatten ging. Vor allem das Desinteresse der Berufsjuristen und der Rechtswissenschaft war eine wesentliche Voraussetzung für das Zustandekommen der Reform. Soweit sich deutsche Juristen um 1890 überhaupt mit dem Arbeitsverhältnis beschäftigten, subsumierten sie dessen rechtliche Aspekte unter die Normen des allgemeinen Vertragsrechts. ${ }^{316}$ Im übrigen hielten sie die Regulierung des Arbeitslebens für ein polizeiliches Problem, mit dem die Gerichte allenfalls als Berufungsinstanz bei Strafsachen in Berührung kamen. Die anfallenden Rechtsfragen galten insgesamt als so einfach, daß von juristischer Seite 1890 praktisch kein Einspruch gegen die Abkopplung der Gewerbegerichte von der ordentlichen Justiz erhoben wurde.

316 Sowohl der romanistische als auch der germanistische Zweig der akademischen Jurisprudenz des 19. Jahrhunderts zeigten sich am Arbeitsverhältnis wenig interessiert. Vgl. Alfred Söllner, Der industrielle Arbeitsvertrag in der deutschen Rechtswissenschaft des 19. Jahrhunderts, in: Walter Wilhelm (Hg.), Studien zur Europäischen Rechtsgeschichte, Frankfurt/ Main 1972, S. 288-303; Becker, Arbeitsvertrag und Arbeitsverhältnis, S. 115-141, 316f. Eine hervorhebenswerte Ausnahme unter den Juristen vor 1890 war der schweizer Staats- und Zivilrechtler Johann Caspar Bluntschli, siehe ebd., S. 130-134. 
Schon zehn Jahre später hatte sich dies gründlich geändert. Anläßlich der Gewerbegerichtsnovelle von 1901, durch die die Errichtung von Gewerbegerichten in allen Gemeinden mit mehr als 20000 Einwohnern obligatorisch wurde ${ }^{317}$, und dann verstärkt im Zusammenhang mit Plänen für eine Ausdehnung des Gewerbegerichtsverfahrens auf weitere Arbeitnehmergruppen, insbesondere die kaufmännischen Angestellten, kam es unter Juristen, Politikern und Interessenvertretern zu heftigen und anhaltenden Grundsatzdiskussionen. Diese betrafen das Prinzip der Sondergerichtsbarkeit als solches und kreisten um die Frage, ob man es ausweiten solle oder ob nicht vielmehr eine stärkere Rückbindung der schon bestehenden Gewerbegerichte an die ordentliche Justiz vonnöten sei. ${ }^{318}$ Damit stand zugleich die Stellung des nunmehr immer häufiger so genannten ,Arbeitsrechts' in der Rechtsordnung zur Debatte. Es bahnte sich die Streitfrage an, ob man es zulassen solle, daß das Arbeitsrecht zum Sonderrecht aller Arbeitnehmer mutierte, oder ob die Rechtsprobleme des Arbeitsverhältnisses nicht besser in einem (entsprechend zu reformierenden) allgemeinen Privatrecht aufgehoben blieben. ${ }^{319}$ Beunruhigt durch den Aufschwung der populären Gewerbegerichte und sensibilisiert durch die Kritik am ,unsozialen' Charakter des 1900 in Kraft getretenen Bürgerlichen Gesetzbuchs schalteten sich nun immer mehr Richter, Anwälte und Rechtswissenschaftler in die Diskussion über die Zukunft des Arbeitsrechts und seiner Institutionen ein. ${ }^{320}$ Das Arbeitsrecht war aus seinem Dornröschenschlaf erwacht und entwickelte sich

317 Gewerbegerichtsgesetz $1901 \$ 1$ a, RGBl. Jg. 1901, S. 249. In der ab 1. Januar 1902 geltenden Fassung: Gewerbegerichtsgesetz $1901 \$ 2$, RGBl. Jg. 1901, S. 353-375, S. 354.

318 So äußerte sich z. B. ein Amtsrichter aus Langenberg, der die Gewerbegerichte als „Mißbildungen“ bezeichnete und meinte, „daß keine Veranlassung zur Neuschaffung von kaufmännischen Schiedsgerichten vorliegt, daß vielmehr eine Rückübertragung der den Gewerbegerichten überwiesenen Rechtsstreitigkeiten an die ordentlichen Gerichte, wohin sie gehören, eher am Platze ist, als die Einrichtung neuer Sondergerichte nach Art der Gewerbegerichte." Metzges, Gewerbegerichte und kaufmännische Schiedsgerichte in ihrer Berechtigung als Sondergerichte, in: Deutsche Juristen-Zeitung 2 (1897), S. 353-355, S. 355.

319 Letzteres war die Position Philipp Lotmars, dessen Pionierrolle unter Arbeitsrechtlern lange nicht gebührend gewürdigt worden ist; vgl. Rückert, „Frei“ und „sozial“, bes. $245 \mathrm{f}$. Kritisch $z u$ Rückerts polarisierender Typologie, in der nahezu alle privatrechtskritischen Positionen als „antiliberal“ verdammt und teilweise sogar in eine Kontinuitätslinie zum Nationalsozialismus eingeordnet werden: Becker, Arbeitsvertrag und Arbeitsverhältnis, S. 326.

320 Zur Kritik an den Bestimmungen zum Dienstvertrag im BGB: Becker, Arbeitsvertrag und Arbeitsverhältnis, S. 219-239; Martin Martiny, Integration oder Konfrontation? Studien zur Geschichte der sozialdemokratischen Rechts- und Verfassungspolitik, Bonn-Bad Godesberg 1976, S. 56-71; Hans-Peter Benöhr, Fast vier Tropfen sozialen Öls - Zum Arbeitsrecht im BGB, in: Wirkungen europäischer Rechtskultur. Festschrift für Karl Kroeschell zum 70. Geburtstag, hrsg. v. Gerhard Köbler u. Hermann Nehlsen, München 1997, S. 17-38. 
- viel früher als in England - zur ernst genommenen juristischen Disziplin. 321

Die Verabschiedung des Gesetzes "betreffend die Kaufmannsgerichte“ vom 6. Juli 1904, das für Streitigkeiten zwischen Handlungsgehilfen und ihren Prinzipalen eine an das Vorbild der Gewerbegerichte angelehnte Jurisdiktion schuf, war unter diesen Umständen alles andere als selbstverständlich. ${ }^{322}$ Trug das Gewerbegerichtsgesetz von 1890 noch den Charakter eines von allen Seiten freundlich aufgenommenen Experiments, hatten sich die Positionen zehn Jahre später aufgrund der inzwischen gesammelten Erfahrungen verhärtet. Dem Kaufmannsgerichtsgesetz von 1904 ging ein jahrelanges Tauziehen zwischen den Regierungen im Bundesrat, den Ministerien, den Parteien, Sozialpolitikern, Arbeitgebern, verschiedenen Juristen-Fraktionen und den betroffenen Berufsverbänden voraus. Das Resultat war ein von taktischen Rücksichten geprägter Kompromiß, der fast niemanden zufriedenstellte. Zu den wenigen Zufriedenen zählte der Deutschnationale Handlungsgehilfenverband (DNHV), der schon seit 1901 für eigenständige kaufmännische Schiedsgerichte nach dem Modell der Gewerbegerichte eingetreten war. ${ }^{323}$ Dies geschah wohl auch in der nicht uneigennützigen Hoffnung, bei den Beisitzerwahlen die Mehrheit der Arbeitnehmervertreter erringen zu können. Voraussetzung dafür war einmal, daß die zu schaffende Sondergerichtsbarkeit allein auf das kaufmännische Hilfspersonal beschränkt blieb, nicht aber auf andere, politisch ,unzuverlässigere' Klassen von Angestellten ausgedehnt wurde. ${ }^{324}$ Zum anderen mußte sichergestellt werden, daß die Kaufmannsgerichte, was ihre Zusammensetzung anging,

321 Vgl. Heinz Potthoff, Probleme des Arbeitsrechts. Rechtspolitische Betrachtungen eines Volkswirts, Jena 1912, S. 247: „Erst durch die Gewerbegerichte wurde man aufmerksam auf die bedeutsamen Probleme und begann die wissenschaftliche Erörterung einzelner Fragen. Das große Werk von Professor Lotmar, dessen erster Band 1902 herauskam, wirkte wie eine Offenbarung. Gegenwärtig findet eine umfassende Bearbeitung vieler Fragen durch eine Reihe von Juristen statt, die wohl den Weg zu einem einheitlichen Arbeitsrecht bahnen wird." Die erste arbeitsrechtliche Professur wurde 1920 an der Universität Frankfurt für Hugo Sinzheimer eingerichtet.

322 Kaufmannsgerichtsgesetz 1904, RGBI. Jg. 1904, S. 266-272.

$323 \mathrm{Vgl}$. Graf, Arbeitsgerichtsgesetz, S. 63 f.; ausführlich: Hermann Schuon, Der Deutschnationale Handlungsgehilfen-Verband zu Hamburg. Sein Werdegang und seine Arbeit (Abhandlungen des staatswissenschaftlichen Seminars zu Jena, Bd. 13, 3. Heft) Jena 1914, S. 149-160; der DNHV unterhielt auch eine eigene Rechtsschutzabteilung, vgl. mit statistischen Angaben ebd., S. $209 \mathrm{ff}$. Im Jahr 1911 wurden 16514 Rechtsauskünfte erteilt, in 1076 Fällen half der DNHV bei einer gütlichen Einigung und in 191 Fällen führte er Prozesse für Mitglieder.

324 Einen rechtlich klar definierten Begriff des, Angestellten' gab es zu dieser Zeit noch nicht. Er bürgerte sich erst im Anschluß an das Versicherungsgesetz für Angestelite von 1911 ein. Vgl. Jürgen Kocka, Angestellter, in: Geschichtliche Grundbegriffe, Bd. 1, Stuttgart 1972, S. 110-128. 
unabhängig von den Gewerbegerichten mit ihren von den sozialistischen Freien Gewerkschaften dominierten Beisitzern blieben. Die verfahrensrechtlichen Vorschriften der Gewerbegerichte konnten und sollten hingegen nach dem Wunsch des DNHV im ganzen unverändert übernommen werden.

Das Gesetz von 1904 entsprach im wesentlichen den Vorstellungen des Handlungsgehilfenverbands, obwohl regierungsintern zunächst an einem völlig anderen Plan gearbeitet worden war. Das vor allem von Posadowsky, Staatssekretär im Reichsamt des Innern, und Justizminister Schönstedt favorisierte Modell griff die Bedenken der Justizverwaltungen mehrerer Länder gegen das Prinzip der Sondergerichtsbarkeit auf und wollte die Zuständigkeit für Streitigkeiten zwischen Angestellten und ihren Vorgesetzten ganz bei den ordentlichen Gerichten belassen. ${ }^{325}$ Allerdings sollten großzügige Verfahrenserleichterungen in den Amtsgerichten eintreten, mit denen man den Wünschen der Kaufmannsgehilfen und anderer Angestellter nach einem schnellen und billigen Klageweg entgegenzukommen gedachte. Geplant waren unter anderem der Ausschluß von Rechtsanwälten, Verkürzung von Fristen, Berufungsmöglichkeit nur bei Streitwerten über 100 Mark, Gebührenermäßigung, Verzicht auf Vorschuß der Gerichtskosten durch den Kläger sowie vollständige Gebührenfreiheit bei einem Vergleich - alles Elemente, die dem Gewerbergerichtsverfahren entlehnt waren und die nun in der untersten Ebene der ordentlichen Justiz, in den Amtsgerichten, Anwendung finden sollten. Um möglichen Forderungen nach weiteren Sondergerichten für andere Beschäftigtengruppen von vornherein die Spitze abzubrechen, sollten diese Verfahrenserleichterungen nach dem Willen Posadowskys nicht nur den Handlungsgehilfen, sondern sofort allen abhängig Beschäftigten (sogar den Landarbeitern und dem Gesinde) zugute kommen; die gewerblichen Arbeiter sollten aber weiterhin der Gewerbegerichtsbarkeit unterstehen. Ein wesentliches Element, das die Gewerbegerichte populär gemacht hatte, sparte Posadowsky freilich wohlweislich aus seinen Überlegungen zur Reform des Amtsgerichtsverfahrens aus: die Beteiligung gewählter Laien. Beisitzer wie im Gewerbegericht sollte es in den Amtsgerichten nicht geben. ${ }^{326}$ Das hatte in erster Linie politische Gründe;

325 Hierzu und zum folgenden die auf den Akten basierende Darstellung von Graf, Arbeitsgerichtsgesetz, S. 65-73. Graf bewertet die Pläne Posadowskys als „zukunftsweisend“ in dem Sinne, daß damit der spätere ,Irrweg' einer gesonderten Arbeitsgerichtsbarkeit möglicherweise vermeidbar gewesen wäre.

326 Lediglich den als politisch ,zuverlässig' geltenden Handlungsgehilfen wollte Posadowsky zugestehen, für ihre Streitsachen Laienbeisitzer hinzuzuziehen, die jedoch nicht direkt, son- 
Posadowsky und seine Regierungskollegen fürchteten nichts so sehr wie einen weiteren Einflußgewinn der SPD und sozialistischer Gewerkschaften. Die Nicht-Zulassung von Laien-Beisitzern deckte sich aber auch mit dem Interesse der Richter und Justizverwaltungen, die sich gegen weitere Aufweichungen des Monopols der Berufsjuristen wandten.

Posadowskys Vorhaben scheiterte regierungsintern am Einspruch des preußischen und anderer Finanzministerien, die glaubten, den Gebührenausfall an den Gerichten nicht verkraften zu können, und die darüber hinaus befürchteten, daß andere bisher benachteiligte Klägergruppen (zum Beispiel Mieter) für ihre Streitigkeiten ähnliche Forderungen nach Prozeßkostenreduktion oder -befreiung erheben würden. Das Veto der Finanzminister machte es Posadowsky und Schönstedt unmöglich, ihre Ideen weiterzuverfolgen, und so machten sie sich nun - als zweitbeste Lösung - den Plan einer allein auf die Kaufmannsgehilfen beschränkten berufsständischen Sondergerichtsbarkeit zu eigen. Ein entsprechender Bundesratsentwurf wurde nach heftigen Auseinandersetzungen im Reichstag, insbesondere über das von einer Ausschußmehrheit zunächst geforderte Frauenwahlrecht, und nach mehreren Abänderungen, die auf eine institutionelle Annäherung an die Gewerbegerichte hinausliefen, am 6. Juli 1904 Gesetz. Eindeutiger Gewinner der Debatte waren die Handlungsgehilfen, die in den Genuß einer allein ihnen vorbehaltenen und von ihnen mitgestalteten Sondergerichtsbarkeit kamen. Verlierer der Debatte war zunächst die SPD, deren Maximalziel, die vollständige Eingliederung der kaufmännischen Arbeitsstreitigkeiten in die Kompetenz der Gewerbegerichte, zu keiner Zeit mehrheitsfähig war. Ein Rückschlag war das Gesetz von 1904 auch für die wenigen Theoretiker und Sozialreformer, die zu diesem Zeitpunkt bereits eine möglichst weitgehende Vereinheitlichung des Arbeitsrechts als Sonderrecht aller Arbeitnehmer zu konzipieren begannen. Gescheitert waren vorerst aber auch alle Bestrebungen der Richter, Anwälte und Justizpolitiker, die aus standespolitischen oder prinzipiellen Gründen den Primat der ordentlichen Gerichte und des allgemeinen Privatrechts aufrechterhalten wollten. Schließlich blieben auch die Arbeitgeber ohne Erfolg, die aus ganz anderen Gründen, nämlich um die Schwellen vor dem Gang zum Gericht für die Arbeitnehmer möglichst hoch zu halten, für eine Alleinzuständigkeit der ordentlichen Justiz eingetreten waren.

Kurzfristig stärkte das Kaufmannsgerichtsgesetz die Tendenz zur berufsständischen Segmentierung der Arbeitsgerichtsbarkeit im Deutschen Kai-

dern nach Art des Schöffenwahlrechts gewählt werden sollten; vgl. Graf, Arbeitsgerichtsgesetz, S. 68. 
serreich, eine Tendenz, die zuvor schon durch die Gewerbeordnungsnovelle von 1897 gefördert worden war, mit der die Innungsschiedsgerichte der Handwerker eine Kompetenzerweiterung erfahren hatten. ${ }^{327}$ Auf lange Sicht folgenreicher war jedoch die Tatsache, daß mit den Handlungsgehilfen eine politisch zum Teil weit rechts stehende Gruppierung die Vorzüge einer von der ordentlichen Justiz abgekoppelten Arbeitsgerichtsbarkeit kennenlernte. Damit erweiterte sich der Kreis der Befürworter von gesonderten Arbeitsgerichten. Die Gewerbegerichte erlebten durch die enge institutionelle und teilweise personelle Verflechtung mit den Kaufmannsgerichten Personalunion der Vorsitzenden war zulässig - einen Prestigezuwachs und traten politisch aus dem sozialistisch-gewerkschaftsnahen Umkreis heraus, in dem sie bis dahin jedenfalls in den Augen ihrer Gegner angesiedelt waren. Die Arbeitsgerichtsbarkeit war nun politisch und sozial breiter verankert. Das verbesserte die Chancen derer, die für ihre Ausdehnung auf weitere Beschäftigtengruppen und langfristig für ihre Vereinheitlichung eintraten.

Das vaterländische Hilfsdienstgesetz vom 5. Dezember 1916 bedeutete einen Schritt in diese Richtung, auch wenn es mit den staatlichen Schlichtungsausschüssen eine vorübergehend mit den Gewerbe- und Kaufmannsgerichten konkurrierende Institution schuf. ${ }^{328}$ Die Schlichtungsausschüsse setzten sich zusammen aus einem Beauftragten des Kriegsamts als Vorsitzendem und einer je gleichen Zahl von Arbeitnehmer- und Arbeitgebervertretern, welche aus Vorschlagslisten der Arbeitgeberverbände und Gewerkschaften $z u$ berufen waren. Die Ausschüsse erfüllten eine zweifache Funktion. Zum einen operierten sie konkurrierend zu den Gewerbe- und Kaufmannsgerichten als Einigungsamt bei kollektiven Streitigkeiten um Löhne und Arbeitsbedingungen, wobei die Schiedssprüche der Schlichtungsaus-

327 Gesetz, betreffend die Abänderung der Gewerbeordnung 1897, RGBl. Jg. 1897, S. 663-706. Das Gesetz ermöglichte die Einführung von Zwangsinnungen und brachte so viele Handwerksgesellen und ihre Arbeitgeber unfreiwillig in den Zuständigkeitsbereich der Inungsschiedsgerichte. Außerdem gelangten nun auch Streitigkeiten der Innungsmitglieder mit ihren ungelernten Arbeitern vor die Innungsschiedsgerichte. Zur Kritik der entspechenden Bestimmungen: Paul Voigt, Die neue deutsche Handwerker-Gesetzgebung, in: Archiv für Soziale Gesetzgebung und Statistik 11 (1897), S. 39-87, S. 63-65; hier auch Angaben zur Anzahl und (vom Autor gering eingeschätzten) Bedeutung der damals bestehenden Innungsschiedsgerichte.

328 Gesetz über den vaterländischen Hilfsdienst 1916, $\mathbb{S} 9$, 10, 13, RGBl. Jg. 1916, S. 1333-1339. Allgemein zu den Hintergründen des Gesetzes und seiner Auswirkung auf die kollektiven Arbeitsbeziehungen: Gerald D. Feldman, Army, Industry and Labor in Germany, 1914-1918, Princeton 1966, ND Providence u. Oxford 1992, S. 197-249, 303-321, 409-420; Hans-Joachim Bieber, Gewerkschaften in Krieg und Revolution: Arbeiterbewegung, Industrie, Staat und Militär in Deutschland 1914-1920, 2 Bde., Hamburg 1981, Bd. 1, S. $296 \mathrm{ff}$. 
schüsse einen de facto zwingenden Charakter erhielten. ${ }^{329}$ Zum anderen konnten die Schlichtungsausschüsse von einzelnen hilfsdienstpflichtigen Arbeitnehmern angerufen werden. Dies war speziell für den Fall vorgesehen, daß ein Arbeitgeber sich weigerte, die für einen Arbeitsplatzwechsel erforderliche Entlassungsbescheinigung auszuhändigen. In diesen Fällen konnte der Ausschuß selbst die Bescheinigung ausstellen, wenn er zur Auffassung gelangte, daß für den Arbeitnehmer ein „wichtiger Grund“ für seinen Wunsch nach Veränderung vorlag; als ein solcher "wichtiger Grund" sollte insbesondere die „angemessene Verbesserung der Arbeitsbedingungen " gelten. ${ }^{330}$ Die Schlichtungsausschüsse erfüllten also in Deutschland eine ähnliche arbeitskräftelenkende Aufgabe wie die britischen Munitions Tribunals unter dem Munitions of War Act von 1915, jedoch mit dem Unterschied, daß die Rechtsgrundlage und die Spruchpraxis der britischen Tribunale zu den leaving certificates entschieden arbeitnehmerfeindlicher ausfiel als diejenige der deutschen Schlichtungsausschüsse zu den Entlassungsbescheinigungen. ${ }^{331} \mathrm{Da}$ nun die Schlichtungsausschüsse flächendeckend im ganzen Deutschen Reich eingeführt wurden und zudem für nahezu alle im weitesten Sinne kriegswichtig beschäftigten Personen entscheidungsbefugt waren, war hier für einen Teilaspekt des Individualarbeitsverhältnisses (Kündigung und Entlassung) die erstrebte einheitliche Arbeitsgerichtsbarkeit schon im Ersten Weltkrieg vorweggenommen. ${ }^{332}$ Das Hilfsdienstgesetz

329 Dieser kam dadurch zustande, daß bei Nicht-Unterwerfung des Arbeitgebers die Arbeitnehmer kündigungsberechtigt waren, während im umgekehrten Fall den nicht unterwürfigen Arbeitnehmern die Entlassungsbescheinigung vorenthalten werden mußte.

330 Arbeiter scheinen sich diese Bestimmungen vor allem in der Anfangsphase bis Mitte 1917 in größerem Umfang bei Stellenwechseln zunutze gemacht zu haben; indirekt entstand dadurch auch zusätzlicher Druck auf die Betriebe, ihre Arbeitsbedingungen entsprechend zu verbessern: Hans-Joachim Bieber, Die Entwicklung der Arbeitsbeziehungen auf den Hamburger Großwerften zwischen Hilfsdienstgesetz und Betriebsrätegesetz (1916-1920), in: Gunther Mai (Hg.), Arbeiterschaft in Deutschland 1914-1918. Studien zu Arbeitskampf und Arbeitsmarkt im Ersten Weltkrieg, Düsseldorf 1985, S. 77-153, bes. S. 96-102; Dirk H. Müller, Gewerkschaften, Arbeiterausschüsse und Arbeiterräte in der Berliner Kriegsindustrie 1914-1918, in: ebd., S. 155-178, bes. S. 167. In der chemischen Industrie scheint die Praxis weniger arbeitnehmerfreundlich gewesen zu sein: Gottfried Plumpe, Chemische Industrie und Hilfsdienstgesetz am Beispiel der Farbenfabriken, vorm. Bayer \& Co., in: ebd., S. 179-209, S. 197-201.

331 Vgl. zur britischen Praxis die Studie von Rubin, War, Law and Labour. Zum Vergleich der Handlungsspielräume der beiden Arbeiterbewegungen im Ersten Weltkrieg siehe auch den Literaturbericht von Hans-Gerd Husung, Arbeiterschaft und Arbeiterbewegung im Ersten Weltkrieg: Neue Forschungen über Deutschland und England, in: Klaus Tenfelde ( $\mathrm{Hg}$.), Arbeiter und Arbeiterbewegung im Vergleich. Berichte zur internationalen historischen Forschung (= Historische Zeitschrift, Sonderhefte, Bd. 15), München 1986, S. 611-664.

332 Allerdings blieb der weibliche Arbeitsmarkt von den Bestimmungen des Hilfsdienstgesetzes 
bescherte somit nicht nur, worauf schon des öfteren hingewiesen worden ist, den deutschen Gewerkschaften auch in der Schwerindustrie endlich die ersehnte Anerkennung, ${ }^{333}$ sondern es trug darüber hinaus zur Vereinheitlichung individualarbeitsrechtlicher Normen und Verfahren bei, und das in einer Weise, die durchaus als arbeitnehmerfreundlich bezeichnet werden kann.

Die Schlichtungsausschüsse verdankten ihre Existenz der Ausnahmesituation des Krieges. Anders als die analogen Institutionen in Großbritannien wurden sie aber nach Kriegsende nicht sofort wieder suspendiert. Vielmehr blieben sie nach dem Krieg bis 1923 für bestimmte Einzelstreitigkeiten zwischen Arbeitnehmern und Arbeitgebern zuständig, ja sie erhielten in dieser Zeit durch verschiedene Demobilmachungsverordnungen von 1919 und das Betriebsrätegesetz von 1920 sogar noch zusätzliche Entscheidungsbefugnisse bei Wiedereinstellungen von Kriegsteilnehmern und Entlassungen. ${ }^{334}$ Ein Grund dafür war die weitgehende Zufriedenheit der Arbeiterschaft mit der Jurisdiktion dieser Ausschüsse, ein anderer Grund war die Tatsache, daß die Gewerbe- und Kaufmannsgerichte, die man sonst mit dieser Rechtsprechung hätte betrauen können, nicht überall existierten und nicht für die gesamte Arbeiter- und Angestelltenschaft zuständig waren. Je länger dieser Zustand andauerte, desto offenkundiger wurde der Anachronismus einer berufständisch segmentierten und nicht flächendeckenden Arbeitsgerichtsbarkeit. Die Schlichtungsverordnung vom 30. Oktober 1923

ausgenommen. Vgl Ute Daniel, Arbeiterfrauen in der Kriegsgesellschaft. Beruf, Familie und Politik im Ersten Weltkrieg, Göttingen 1986, S. 88-99.

333 Gerd Bender, Vom Hilfsdienstgesetz zum Betriebsrätegesetz. Zur rechtlichen Regulierung des industriellen Verhandlungssystems zwischen Reform und Revolution (1916-1920), in: Heinz Mohnhaupt (Hg.), Revolution, Reform, Restauration. Formen der Veränderung von Recht und Gesellschaft, Frankfurt/Main 1988, S. 191-210, S. 199 ff.

334 Vgl. Johannes Bähr, Staatliche Schlichtung in der Weimarer Republik. Tarifpolitik, Korporatismus und industrieller Konflikt zwischen Inflation und Deflation 1919-1932, Berlin 1989, S. 24f. Allgemein zu den Demobilmachungsverordnungen des Jahres 1919 betreffend Entlassungen: Richard Bessel, Germany After the First World War, Oxford 1993, S. 133 ff. Über die Rechtslage nach den Verordnungen bestand zeitweise erhebliche Unklarheit, so daß sogar der Reichswirtschaftsminister Wissell sich genötigt sah, die Bestimmungen zu erläutern; vgl.: Justus Wilhelm Hedemann, Zur Frage der Entlassung von Arbeitern und Angestellten, in: Recht und Wirtschaft 8 (1919), S. 188-193, und die Antwort von Rudolf Wissell, Zur Frage der schiedsgerichtlichen Beilegung von Arbeitsstreitigkeiten, in: Recht und Wirtschaft 9 (1920), S. 36-39. Zu den besonderen Bestimmungen für Schwerbeschädigte: Christopher R. Jackson, Infirmative Action: The Law of the Severely Disabled in Germany, in: Central European History 26 (1993), S. 417-455, S. 429 ff. Zur Bedeutung des Betriebsrätegesetzes für das kollektive Verhandlungssystem: Bender, Vom Hilfsdienstgesetz zum Betriebsrätegesetz, S. $208 \mathrm{ff}$. Das Einspruchsrecht der Betriebsräte bei Entlassungen regelten die \$\$ 84-87 des Betriebsrätegesetzes, RGBl. Jg. 1920, S. 147-174, S. $167 \mathrm{ff}$. 
beendete die unbefriedigende Situation, indem sie im Vorgriff auf künftige Gesetzgebung die Gewerbe- und Kaufmannsgerichte zu vorläufigen Arbeitsgerichten erklärte und ihnen alle rechtsprechenden Funktionen der alten Schlichtungsausschüsse übertrug. ${ }^{335} \mathrm{Die}$ Schlichtungsausschüsse sollten nur dort noch provisorisch als Arbeitsgerichte weiter fungieren, wo kein Gewerbe- oder Kaufmannsgericht bestand. Ansonsten wurde ihre Funktion auf die Hilfe beim Abschluß von Tarifverträgen reduziert.

Spätestens ab 1923 war somit vorgezeichnet, welche Richtung die kommende Reform der Arbeitsgerichtsbarkeit nehmen würde. Mit der Schlichtungsverordnung zog man institutionell eine klare Trennlinie zwischen individuellen Rechtsstreitigkeiten einerseits und kollektiven Verhandlungsangelegenheiten andererseits. Für erstere sollten in Zukunft die Arbeitsgerichte, für letztere bei Versagen freiwilliger Gremien die staatlichen Schlichtungsausschüsse zuständig sein. Ein System wie das englische, das individuelle Dispute und kollektive Arbeitskämpfe unterschiedslos durch Verhandlungen und freiwillige Schiedsverfahren lösen wollte, hatte nach 1923 in Deutschland keine Chance auf Realisierung mehr. Es wurde auch vorher schon von niemandem mehr ernsthaft propagiert. Die industriellen Beziehungen Englands waren nur noch ein Thema für wissenschaftliche Abhandlungen, als nachahmenswertes Vorbild spielten sie in der Weimarer Republik anders als im Kaiserreich praktisch keine Rolle mehr. Deutsche Gewerkschaftler, Arbeitgeber, Politiker und Juristen hatten sich in jahrzehntelanger Übung daran gewöhnt, daß Streitigkeiten aus individuellen Arbeitsverträgen am besten durch besondere gerichtsförmige Verfahren beizulegen waren. Als ebenso selbstverständlich galten mittlerweile die öffentliche Trägerschaft und die branchenübergreifende Organisation der für diesen Zweck zu bildenden Gerichte. Die Tätigkeit der gewerkschaftlichen Arbeitersekretariate war auf diese Struktur zugeschnitten. All diese Organisationsprinzipien hätten unter britischen Gewerkschaftlern, Politikern und Arbeitgebern großen Streit ausgelöst, wenn sie überhaupt jemals in Erwägung gezogen worden wären. Tatsächlich blieb aber die deutsche Arbeitsgerichtsbarkeit in England völlig unbeachtet. Im Umgang mit individuellen Arbeitsstreitigkeiten hatten sich also die in den beiden Ländern angewandten Methoden nach dem Ersten Weltkrieg so weit auseinanderentwickelt, daß eine gegenseitige Befruchtung oder gar ein Transfer von Ideen und Praktiken nicht mehr möglich schien.

335 Verordnung über das Schlichtungswesen 1923, RGBl. Jg. 1923, S. 1043-1045 u. 1191-1192 (Ausführungsverordnung). Vgl. Bähr, Staatliche Schlichtung, S. 78. 
Ähnlich unrealistisch wie eine Übernahme britischer Methoden war in der Weimarer Republik auch eine bloße Restauration der berufsständisch begrenzten Arbeitsgerichtsbarkeiten des Kaiserreichs. Der Krieg, die Sofortmaßnahmen der Novemberrevolution und die Nachkriegsgesetzgebung hatten Erwartungen geschaffen, die eine Reform der personellen Zuständigkeit der Gewerbe- und Kaufmannsgerichte unausweichlich machten. $\mathrm{Zu}$ den ersten Taten des Rats der Volksbeauftragten gehörte 1918 die Beseitigung der einzelstaatlichen Gesindeordnungen. ${ }^{336}$ Damit wurde das letzte Überbleibsel einer paternalistischen Herr-Diener-Beziehung aus dem deutschen Arbeitsrecht getilgt, wenn man das Beamtenverhältnis einmal außer Betracht läßt. Für die Streitigkeiten der Landarbeiter mit ihren ehemaligen „Herren“ waren nun bis auf weiteres die ordentlichen Gerichte zuständig. ${ }^{337}$ Diese prozeßrechtliche Benachteiligung wurde als ebenso unhaltbar empfunden wie der Ausschluß der nicht ,kaufmännischen' Angestellten von den Vorzügen des arbeitsgerichtlichen Verfahrens. Überdies machten es die komplizierter gewordenen betrieblichen Strukturen in vielen Fällen auch für spitzfindige Juristen schwierig zu entscheiden, wer ein ,Arbeiter' im Sinne des Gewerbegerichtsgesetzes, wer ein ,Handlungsgehilfe' im Sinne des Kaufmannsgerichtsgesetzes war und wer nicht. ${ }^{338}$ Die gesetzlichen

336 Aufruf des Rats der Volksbeauftragten an das deutsche Volk vom 12. November 1918, RGBl. Jg. 1918, S. 1303-1304, Abs. 8: „Die Gesindeordnungen werden außer Kraft gesetzt, ebenso die Ausnahmegesetze gegen die Landarbeiter."

337 Grundlage der Rechtsprechung war neben dem BGB die vorläufige Landarbeitsordnung vom 24. Januar 1919, RGBl. Jg. 1919, S. 111-114. Vgl. dazu den Kommentar des Vorsitzenden des Deutschen Landarbeiterverbandes mit der Forderung, Schlichtungsausschüsse und Gewerbegerichte auch in der Landwirtschaft einzuführen, eventuell in Gestalt besonderer "Landarbeitsgerichte": Georg Schmidt, Neues Landarbeiterrecht, in: Recht und Wirtschaft 8 (1919), S. 75-78, S. 78.

338 Die Schwierigkeiten bei der Abgrenzung der personellen Zuständigkeit begannen von Anfang an. Zahlreiche, zum Teil kuriose Beispiele aus der Praxis bei: Jastrow, Erfahrungen in den deutschen Gewerbegerichten, S. 337-346 u. 391-393. Schon nach wenigen Jahren kam eine stattliche Liste von Berufen zusammen, bei denen die Kompetenz umstritten war und zum Teil widersprüchliche Entscheidungen ergingen: Bilderverkäufer, kaufmännische Angestellte in Fabrikbetrieben, Kaltmamsells, Hausdiener u. Köchinnen bei Restaurateuren, Gehilfen in Gärtnereien, Gehilfen im Zeichenbüro eines Architekten, Schauspieler, Tierbändiger, Musiker, Kunstgymnastiker, Artisten, Clowns, Büglerinnen und Bügellehrerinnen, Pferdebahnschaffner, Arbeiter in Gasanstalten, Arbeiter für Reparatur- und Reinigungszwecke in Eisenbahnbetrieben, Bauarbeiter, Kolonnenführer einer Baukolonne, Maurerpoliere, Ober-Maschinenmeister in Druckereien, Gehilfen und Lehrlinge von Meistern, die Mitglieder einer Innung mit Innungsschiedsgericht waren, usw. Die unendlichen Kompetenzstreitigkeiten bildeten den Hauptkritikpunkt derer, die schon vor dem Ersten Weltkrieg für eine Vereinheitlichung des Arbeitsrechts eintraten. Vgl. mit weiteren Beispielen: Hugo Sinzheimer, Über den Grundgedanken und die Möglichkeit eines einheitlichen Arbeitsrechts für Deutschland (1914), in: ders., Arbeitsrecht und Rechtssoziologie. Gesammelte 
Definitionen erschienen zunehmend willkürlich und waren juristisch kaum mehr zu handhaben. Wenig populär und nur noch als Übergangslösung toleriert wurden auch die besonderen Berggewerbegerichte. Sie wurden 1926 ebenso beseitigt wie die Innungsschiedsgerichte der Handwerker, für deren Fortexistenz sich allerdings die Mittelstandpolitiker verschiedener Parteien nachdrücklich, wenngleich vergeblich einsetzten. ${ }^{339}$ Des ausdrücklichen Verfassungsversprechens der Weimarer Reichsverfassung (Art. 157: „Das Reich schafft ein einheitliches Arbeitsrecht.") hätte es unter diesen Umständen gar nicht bedurft, um zumindest eine Reform der arbeitsgerichtlichen Institutionen anzustoßen. ${ }^{340} \mathrm{Zu}$ mehr ist es dann aber in der Weimarer Republik auch nicht gekommen. Das materielle Arbeitsrecht blieb unkodifiziert. Es setzt sich bis heute nur aus Teilgesetzen und einzelnen Paragraphen anderer Kodifikationen zusammen, und es ist wie kaum ein anderes Rechtsgebiet in Deutschland weiterhin Gegenstand der freien Rechtsschöpfung durch die Arbeitsgerichte.

Warum die arbeitsrechtlichen Kodifizierungspläne schon bald nach 1919 im Sande verliefen und auf welch verschlungenen Wegen es nach langem Hin und Her im Jahr 1926 wenigstens gelang, ein Arbeitsgerichtsgesetz zu verabschieden, ist in letzter Zeit mehrmals dargestellt worden. ${ }^{341}$ Hier genügt es daher, die Positionen der Debatte und die wesentlichen Bestimmungen des Gesetzes mit Blick auf den deutsch-englischen Vergleich zusammenzufassen. Im Zentrum der Auseinandersetzung stand das Verhältnis der Arbeitsgerichte zur ordentlichen Justiz; untergeordnete Streitpunkte waren die Frage der Zulassung von Rechtsanwälten in der untersten Instanz und die genaue Verortung des Instanzenzugs in der Gerichtsverfassung. In der

Aufsätze und Reden, hrsg. v. Otto Kahn-Freund u. Thilo Ramm, 2 Bde. Frankfurt u. Köln 1976, Bd. 1, S. 35-61, S. 37-43.

339 Vgl. Graf, Arbeitsgerichtsgesetz, S. 293 u. 299 f.

340 Zur Problematik der arbeitsrechtlichen Verfassungsaufträge in der Weimarer Republik: Knut Wolfgang Nörr, Arbeitsrecht und Verfassung. Das Beispiel der Weimarer Reichsverfassung von 1919, in: Zeitschrift für Arbeitsrecht 23 (1992), S. 361-377; Joachim Rückert, Soziale Grundrechte und Arbeitsbeziehungen in der Weimarer Reichsverfassung, in: Mitteilungsblatt des Instituts zur Erforschung der europäischen Arbeiterbewegung 18 (1997), S. 23-35.

341 Vgl. Thomas Bohle, Einheitliches Arbeitsrecht in der Weimarer Republik. Bemühungen um ein deutsches Arbeitsgesetzbuch, Tübingen 1990; Bertram Michel, Der Kampf der Gewerkschaften um die einheitliche Arbeitsgerichtsbarkeit (1926), in: Klaus Feser u.a., Arbeitsgerichtsprotokolle, Neuwied u. Darmstadt 1978, S. 28-53; Jochen Weiss, Von den Gewerbegerichten zu den Arbeitsgerichten, in: Die Arbeitsgerichtsbarkeit. Festschrift zum 100jährigen Bestehen des Deutschen Arbeitsgerichtsverbands, Neuwied u. Berlin 1994, S. 75-87; sowie die bereits erwähnten Studien von Graf, Arbeitsgerichtsbarkeit; Bähr, Entstehung und Folgen des Arbeitsgerichtsgesetzes; Martiny, Integration oder Konfrontation. 
Hauptfrage gab es zwei Extrempositionen. Große Teile der SPD, die Freien Gewerkschaften, mit Abstrichen auch die nicht-sozialistischen Gewerkschaften, der Verband der Gewerbe- und Kaufmannsgerichte sowie eine kleine Zahl von Arbeitsrechtlern plädierten für die Ausdehnung des aus ihrer Sicht bewährten Modells der Gewerbe- und Kaufmannsgerichte auf alle Arbeitnehmer. Demgegenüber traten die Mehrheit der Arbeitgeber, nahezu die gesamte Richterschaft, die meisten anderen Juristen, die Kommunen, die Justizverwaltungen der Länder und auch einige sozialdemokratische Rechtswissenschaftler und Politiker, vor allem Gustav Radbruch, für eine mehr oder weniger weitgehende Angliederung an die ordentliche Justiz ein.

Bei Befürwortern wie bei Gegnern der eigenständigen Arbeitsgerichtsbarkeit spielten leicht zu durchschauende verbandspolitische und wirtschaftliche Interessen eine erhebliche Rolle. Die Intentionen der für eine Angliederung an die ordentliche Justiz eintretenden Koalition lagen dabei jedoch weiter auseinander, zum Teil widersprachen sie einander sogar. Während etwa die Arbeitgeber vor allem an einer Verminderung der gegen sie gerichteten Prozeßflut interessiert waren und für diesen Zweck die ordentliche Justiz, so wie sie war, als geeignetes abschreckendes Mittel ansahen, kritisierten Kommunen und Rechtsanwälte lediglich partielle Aspekte der bisherigen Arbeitsgerichtsbarkeit. Die Städte und Gemeinden waren in erster Linie aus Kostengründen gegen die einfache Fortschreibung des Modells der Gewerbe- und Kaufmannsgerichte. Sobald nur die Trägerschaft auf die Länder und das Reich abgewälzt wurde, wie es schließlich geschah, hatten sie gegen eine Sondergerichtsbarkeit keine prinzipiellen Einwände mehr. Ebenso hätten sich wohl viele Rechtsanwälte mit einer eigenständigen Arbeitsgerichtsbarkeit abgefunden, wenn die Befürworter nur bereit gewesen wären, ihnen die Vertretungsbefugnis auch in der untersten Instanz einzuräumen.

Daß die Freien Gewerkschaften in der Anwaltsfrage hart blieben und damit eine große bürgerliche Berufsgruppe geschlossen ins gegnerische Lager trieben, ist ihnen von Historikern als kurzsichtig-egoistische Interessenpolitik angekreidet worden. ${ }^{342}$ Die Gewerkschaften der Weimarer Republik hätten, so heißt es, die Beisitzerwahlen, die Arbeitersekretariate und die Gewerbegerichte wie einen Besitzstand verteidigt. Sie hätten diese Institutionen lediglich unter dem Gesichtspunkt der Mitglieder- und Organisationsstabilisierung betrachtet und so die Möglichkeit verspielt, die verknöcherte und rückwärtsgewandte Weimarer Justiz im ganzen zu reformieren. ${ }^{343}$

342 Martiny, Integration oder Konfrontation, S. 115-125.

343 Martiny, Integration oder Konfrontation, S. $109 \mathrm{ff}$. 
Diese Kritik befindet sich im Einklang mit der Position Radbruchs, der sich von einem Eindringen der, sozialen' Arbeitsrechtssprechung in die ordentlichen Gerichte eine Änderung des Geistes der Richterschaft insgesamt erhoffte. ${ }^{344}$ Abgesehen davon, daß diese Kritik den Handlungsspielraum und die damaligen Einflußmöglichkeiten sozialdemokratischer Rechtspolitik auf die Justiz überschätzt, scheint sie mir auch aus einem anderen Grund verfehlt: Sie geht mit einer gewissen Arroganz über die vielen hundertausend Einzelschicksale klagender oder beklagter Arbeitnehmer hinweg, für die eine Rückführung des Arbeitsgerichtsverfahrens in die ordentliche Justiz zweifellos eine Verschlechterung ihrer Klage- und Erfolgschancen bedeutet hätte. Den gewerkschaftlichen Arbeitersekretären und den Mitwirkenden in den Gewerbegerichten stand diese Problematik lebhafter vor Augen als Politikern wie Radbruch. Ihr Handeln orientierte sich an dem konkreten Ziel, Einzelfallgerechtigkeit herzustellen, deshalb ist es verfehlt, ihr Eintreten für eigenständige, ,unjuristische' Arbeitsgerichte bloß als defensive Interessenpolitik zu werten. Die Position der Gewerkschaftsfunktionäre mag aus der Sicht eines Historikers, der das Scheitern der Weimarer Republik unter anderem auf die mangelnde Republiktreue der Justiz zurückführt, kurzsichtig und naiv gewesen sein, eine legitime und auf den Zweck der Arbeitsgerichte bezogen sachlich angemessene Haltung war es gewiß. Man konnte allerdings mit Blick auf die erstrebte Einzelfallgerechtigkeit durchaus auch für die Zulassung von Rechtsanwälten eintreten, wie es etwa die gewerkschaftsfreundlichen Juristen Hugo Sinzheimer, Alwin Sänger und Georg Flatow taten, letzterer mit dem Argument, daß auf Arbeitgeberseite mit einer dauernden Präsenz professioneller juristischer Beratung (durch Firmenanwälte, Justiziare, Rechtsabteilungen) ohnehin zu rechnen sei, weshalb man dem einzelnen Arbeitnehmer oder der Gewerkschaft die entsprechende Möglichkeit nicht leichtfertig versagen solle. 345 Auch die zunehmende Komplexität des Arbeitsrechts und die sich abzeichnende Vermehrung der Berufungsfälle nach der Reform ließen sich als Argument für die Anwaltszulassung schon in der ersten Instanz geltend machen.

Zu warnen ist im übrigen vor einer historischen Schwarz-Weiß-Malerei, die im Kampf der Weimarer Juristenschaft für den Primat der ordentlichen Justiz ausschließlich enge standespolitische und arbeitgeberfreundliche

344 Bähr, Entstehung und Folgen des Arbeitsgerichtsgesetzes, S. 515.

345 Bähr, Entstehung und Folgen des Arbeitsgerichtsgesetzs, S. 515. Zur Tätigkeit von Anwälten für Firmen: Hannes Siegrist, Advokat, Bürger und Staat. Sozialgeschichte der Rechtsanwälte in Deutschland, Italien und der Schweiz, Frankfurt/Main 1996, S. 571-582. 
oder anti-sozialistische Motive ans Licht treten sieht. Solche Motive gab es zweifellos, aber ähnlich wie bei den englischen Common law-Juristen war es auch bei den deutschen Juristen nicht nur eine hohle Phrase, wenn sie auf einer einheitlichen Rechtsordnung als notwendiger Bedingung für Gleichheit vor dem Gesetz und Voraussehbarkeit von Entscheidungen insistierten. Eine Sondergerichtsbarkeit wie die bisherigen Gewerbe- und Kaufmannsgerichte, die relativ autonom, einzelfallbezogen und frei Recht schöpften, ohne daß zumindest in einer höheren Instanz auf Konsistenz der Urteile geachtet wurde, war mit der Vorstellung von Rechtssicherheit und gleicher Rechtsanwendung im ganzen Land, also einem Grundprinzip der Rechtsstaatlichkeit, tatsächlich nicht leicht zu vereinbaren. Daher erklärt es sich, daß in der Schlußphase der politischen Auseinandersetzung um das Arbeitsgerichtsgesetz die Organisation des Instanzenzugs immer stärker in den Vordergrund rückte. Als es im Zuge der Beratungen klar wurde, daß die untere Instanz aufgrund der Hartnäckigkeit der Gewerkschaften dem Modell der bisherigen Gewerbegerichte verpflichtet bleiben würde, konzentrierten sich die Berufsverbände der Juristen auf das Ziel, wenigstens die höheren Instanzen so eng wie möglich an die ordentliche Justiz zu binden. In diesem Bestreben waren sie weitgehend erfolgreich.

Das Arbeitsgerichtsgesetz vom 23. Dezember 1926 war ein Kompromiß zwischen Gewerkschaften und Justizjuristen. ${ }^{346}$ Für die untere Instanz folgte das Gesetz in allen entscheidenden verfahrensrechtlichen Fragen dem Vorbild der Gewerbe- und Kaufmannsgerichte. Bei der Wahl der Beisitzer wurde aber das für die Gewerkschaften als Organisation günstigere Modell der Schlichtungsausschüsse übernommen. Es gab somit keine Direktwahl durch die im Gerichtsbezirk ansässigen Arbeitnehmer und Arbeitgeber mehr, sondern Vorschlagslisten der jeweiligen "wirtschaftlichen Vereinigungen", aus denen die höhere Verwaltungsbehörde die Beisitzer auswählte. Von der Zusammensetzung her waren die neuen Arbeitsgerichte der Weimarer Republik damit weniger demokratisch als die Gewerbegerichte des Kaiserreichs: Den unorganisierten Arbeitnehmern wurde ihr bisheriges Mitspracherecht genommen. In den höheren Instanzen, den Landesarbeitsgerichten und dem Reichsarbeitsgericht, dominierten klar die Berufsjuristen. Die Vorsitzenden mußten aus dem Kreis der am jeweiligen Landgericht oder dem Reichsgericht tätigen Richter genommen werden. Berufung an die Landesarbeitsgerichte war möglich bei Streitwerten über 300 Reichsmark oder wenn das Arbeitsgericht auf einen Fall von "grundsätzlicher Be-

346 Arbeitsgerichtsgesetz 1926, RGBI. Jg. 1926, Bd. 1, S. 507-524. 
deutung" erkannte; für die Revision vor dem Reichsarbeitsgericht galten die gleichen Streitwertgrenzen wie für normale zivilrechtliche Verfahren. Vor beiden höheren Instanzen bestand Anwaltszwang, in der ersten Instanz blieben hingegen die Anwälte ausgeschlossen.

Durch die Rückkopplung der höheren arbeitsgerichtlichen Instanzen an die ordentliche Justiz veränderte sich auch die Rechtsprechung in den lokalen Arbeitsgerichten. Sie waren fortan in ihrer Entscheidungsfindung an die ,von oben' kommenden Präzedenzfälle gebunden. Ihre rechtsschöpferische Tätigkeit engte sich auf die Fälle ein, zu denen keine höchstrichterlichen Urteile vorlagen. Die Arbeitsrichter und Beisitzer in der untersten Instanz wandelten sich zwangsläufig mehr und mehr zu bloßen Normanwendern. Ihr Bild näherte sich also zunehmend dem des normalen Richters an. Als Gegengewicht gegen diese Tendenz blieben die hohen Berufungsgrenzen und das weiterhin obligatorisch vor die streitige Verhandlung einzuschaltende Güteverfahren. Hier behielten die Arbeitsgerichte einen Rest von Autonomie, der sich gerade bei der Lösung der kleinen Streitigkeiten bemerkbar machte. Über die tatsächlichen Vorgänge in den Arbeitsgerichten der späten Weimarer Republik wissen wir allerdings erstaunlich wenig, erheblich weniger als über den Gerichtsalltag in den Gewerbegerichten des Kaiserreichs. Die Aufmerksamkeit der Zeitgenossen und der rechtshistorischen Forschung konzentrierte sich verständlicherweise auf die Entscheidungen des neuen Reichsarbeitsgerichts und hier vor allem auf diejenigen, die den kollektiven Arbeitskampf betrafen. Während die lokalen Arbeitsgerichte überwiegend nur noch Rechtsanwendung betrieben, fiel nun die rechtsschöpferische Rolle in erster Linie dem Reichsarbeitsgericht zu. ${ }^{347}$ Besonders das von den Reichsarbeitsrichtern vertretene Ideal der ,Betriebsgemeinschaft' geriet schnell ins Kreuzfeuer der Kritik und trug dem Gericht den Vorwurf ein, sich einem „faschistischen Sozialideal“ anzunähern. ${ }^{348} \mathrm{Ob}$

347 Das betont Thilo Ramm, Die Arbeitsverfassung der Weimarer Republik, in: Franz Gamillscheg u. a. (Hg.), In Memoriam Sir Otto Kahn-Freund, München 1980, S. 225-246, S. 240.

348 Hierzu zuletzt: Gabriele Metzler, Justiz im Schatten der Weltwirtschaftskrise. Das Konzept der Arbeitsbeziehungen und der innerbetrieblichen Ordnung nach der Rechtsprechung des Reichsarbeitsgerichts (1927-1932), in: Vorträge zur Justizforschung Bd. 2, hrsg. von Heinz Mohnhaupt u. Dieter Simon, Frankfurt/Main 1993, S. 471-497. Der Faschismus-Vorwurf wurde von Otto Kahn-Freund erhoben: Otto Kahn-Freund, Das soziale Ideal des Reichsarbeitsgerichts. Eine kritische Untersuchung zur Rechtsprechung des Reichsarbeitsgerichts (1931), wieder in: Thilo Ramm, Arbeitsrecht und Politik. Quellentexte 1918-1933, Neuwied u. Berlin 1966, S. 149-210. Unter "Faschismus" verstand Kahn-Freund hier nicht die tatsächlichen Zustände im Italien Mussolinis, sondern ein Ideal, das vom Liberalismus die „ablehnende Haltung gegenüber staatlicher Wirtschaft“, vom Konservativismus "den Gedanken der staatlichen Fürsorge und des nationalen Interesses" und vom Kollektivismus „die 
sich freilich die im Ideal der ,Betriebsgemeinschaft ' implizierte arbeitgeberfreundliche Tendenz auch in den erstinstanzlichen Gerichten auswirkte, ist keineswegs sicher. Sogar das Reichsarbeitsgericht selbst entschied „in Einzelfällen häufig zugunsten der Arbeitnehmer. “349 Von einem Vertrauenseinbruch seitens der Arbeitnehmer in die Arbeitsgerichte kann jedenfalls nicht die Rede sein. Schon in den beiden ersten Jahren ihrer Tätigkeit stieg die Zahl der bearbeiteten Fälle sprunghaft an, von 379689 im Jahr 1928 auf 427614 im Jahr 1929, und es blieb dabei, daß weitaus die meisten dieser Fälle auf Arbeitnehmerklagen zurückgingen.

Hält man sich die aus englischer Sicht geradezu unglaubliche Steigerung der Klagezahlen vor deutschen Arbeitsgerichten seit 1890 vor Augen, wird deutlich, wie sehr das Konfliktverhalten auf institutionelle Angebote reagierte. Es kann nicht allein die Kampfkraft der britischen Gewerkschaften, es können nicht allein die relativ effizienten innerbetrieblichen, lokalen und brancheninternen Verhandlungsmechanismen gewesen sein, die britische Arbeitnehmer davon abhielten, den Klageweg zu beschreiten. Betriebsräte, regelmäßige Gesprächsrunden, und Versuche, Konflikte durch Verhandlung oder wenn nötig durch Streik zu lösen, gab es schließlich auch in Deutschland, ohne daß dies die Arbeitsgerichte überflüssig gemacht hätte. ${ }^{350}$ Man kann es auch anders herum wenden: Die Arbeitsgerichte stellten eine Institution bereit, die es den deutschen Gewerkschaften und Arbeitgebern möglich machte, kleine alltägliche Reibereien und Konflikte am Arbeitsplatz aus den großen, kollektiven Konflikten herauszuhalten. Dies mag dazu beigetragen haben, daß Arbeitskämpfe in der Weimarer Republik oft sofort ins Grundsätzlich-Politische gingen und eine verbal schärfere Note annahmen als in Großbritannien. Auf der anderen Seite mag die größere Häufigkeit und längere Dauer der Streiks im Großbritannien der Zwi-

Idee der Verbandsbildung und der Verbände als Träger der sozialen Aktionen“ übernahm (S. 153).

349 Metzler, Justiz im Schatten der Weltwirtschaftskrise, S. 480. Vgl. jedoch auch die kritischere Einschätzung von Martiny, Integration oder Konfrontation?, S. 145-148.

350 Nach 1900 wuchs die Zahl der Tarifverträge in Deutschland in beeindruckendem Tempo, obwohl die Schwerindustriellen bis zum Ende des Ersten Weltkriegs nicht mitmachten. Vgl. Ullmann, Tarifverträge, S. 97-100. Siehe auch Martiny, Integration oder Konfrontation, S. 74. Wenn die deutschen Gewerkschaften in der späten Weimarer Republik vor Arbeitskampfmaßnahmen häufiger zurückschreckten als die britischen, so war dies eher eine Folge der tiefer einschneidenden Wirtschaftskrise als eines prinzipiell harmoniesüchtigeren Kurses gegenüber Arbeitgebern; allerdings machte die starke Staatsorientierung die deutschen Gewerkschaften im Moment der NS-Machtergreifung unfähig zum politischen Kampf. Vgl. Sidney Pollard, German Trade Union Policy 1929-1933 in the Light of the British Experience, in: J. Baron von Kruedener (Hg.), Economic Crisis and Political Collapse. The Weimar Republic 1924-1933, New York 1990, S. 21-44. 
schenkriegszeit, kulminierend im Generalstreik von 1926, damit zusammenhängen, daß dort auch kleine Konflikte (Entlassung eines Gewerkschaftsmitglieds, Verletzung von Job-Demarkationen) mangels eines gerichtlichen Lösungsweges schnell zu unüberbrückbaren Gegensätzen eskalierten. Die beiden unteren Instanzen der englischen Gerichtsbarkeit, die Friedens- und Grafschaftsgerichte, konnten wegen ihrer primär strafenden und schuldeneintreibenden Funktionen, wegen ihrer Überlastung und ihrer zum Teil wenig vertrauenerweckenden Zusammensetzung nicht die befriedende Rolle bei Einzelfällen spielen, die in Deutschland von den Arbeitsgerichten wahrgenommen wurde.

Die unterschiedliche Struktur der Institutionen führte aber nicht nur zu einem divergierenden Konfliktverhalten der Arbeitnehmer und Arbeitgeber beider Länder; sie hinterließ auch im Bewußtsein der Streitparteien und in den Begriffen der Jurisprudenz ihre Spuren. Es war der stets mögliche Gang zum Arbeitsgericht, der das Beharren auf individuellen Rechtsansprüchen und den Ruf nach entsprechenden gesetzlichen Regelungen in der deutschen Arbeitnehmerschaft lebendig hielt. Und es war die Spruchpraxis der Gewerbe- und späteren Arbeitsgerichte, die in Deutschland das Individualarbeitsrecht gleichsam von unten herauf entstehen ließ und die Rechtswissenschaft zu relativ frühen Systematisierungsanstregungen herausforderte. Eine vergleichbare Herausforderung von den unteren Rängen der Justiz hat es in England bis zur Errichtung der industrial tribunals 1964/71 nicht gegeben, und das ist ein Grund dafür, warum das Individualarbeitsrecht dort erst spät von den Juristen entdeckt wurde und ein Fremdkörper im Common law geblieben ist. Dem Fehlen eines geeigneten Tribunals für Arbeitsstreitigkeiten ist es auch zuzuschreiben, daß britische Arbeitnehmer und Arbeitgeber dem Recht als Konfliktlöser lange Zeit wenig zutrauten und gesetzlichen Regulierungen, seien sie britischen oder europäischen Ursprungs, bis heute verhältnismäßig gleichgültig gegenüberstehen.

\section{GERICHTSFLUCHT IN ENGLAND, PROZESSFLUT IN DEUTSCHLAND: EIN VERSUCH, UNTERSCHIEDE ZU ERKLÄREN}

Es ist nicht ganz unproblematisch, statistische Angaben miteinander zu vergleichen, wenn die institutionellen Kontexte und zugrundeliegenden Begriffe so verschieden sind wie im Fall der deutschen Arbeitsgerichtsbarkeit einerseits, der englischen Friedens- und Grafschaftsgerichte andererseits. ${ }^{351}$

351 Grundsätzliches zur Vergleichbarkeit von Klageaufkommen und Zivilprozeßstatistiken bei: Erhard Blankenburg, Prozeßflut und Prozeßebbe. Über die Fähigkeit der Gerichte, mit 
Was zunächst die personelle Zuständigkeit angeht, so entsprach die Definition von ,Arbeitern' im Sinne des Gewerbegerichtsgesetzes nicht exakt derjenigen von servants oder workmen im Sinne der Master and Servant-Gesetze. ,Arbeiter' waren nach der deutschen gesetzlichen Definition auch Betriebsbeamte, Werkmeister und höhere technische Angestellte - Beschäftigte, die in England nicht als workmen galten und folglich wegen ihrer Arbeitsstreitigkeiten nicht vor die Friedensgerichte zitiert werden konnten. Die Landarbeiter durften (oder mußten) dort jedoch erscheinen, während sie von den deutschen Gewerbegerichten ausgeschlossen waren. Der soziale Einzugsbereich der Gewerbegerichte war also ein anderer als bei den englischen Friedensgerichten. Auf der anderen Seite kannten die englischen Grafschaftsgerichte keinerlei personelle Zuständigkeitsbegrenzung; ihre Jurisdiktion ging erheblich über diejenige aller berufständischen Arbeitsgerichte des Kaiserreichs hinaus. Auch die sachlichen Zuständigkeiten stimmten nicht genau überein: Anders als die Friedensgerichte besaßen die deutschen Gewerbe- und Kaufmannsgerichte keine Strafgewalt und sie hatten auch mit der Durchsetzung von Arbeiterschutzbestimmungen nichts zu tun. Haftpflicht- und Entschädigungsfragen bei Arbeitsunfällen wurden in Deutschland durch die berufsgenossenschaftlichen Spruchkammern abgewickelt, in England war dies hingegen ein wichtiges Betätigungsfeld der Grafschaftsgerichte. In räumlicher Hinsicht bestand vor allem in den Jahren bis 1901, als die Gewerbegerichte noch fakultativ waren, eine erhebliche Differenz: Die Gewerbegerichtsbezirke waren nicht flächendeckend; im Jahr 1896 zum Beispiel deckten die Bezirke erst 31 Prozent der Reichsbevölkerung ab. ${ }^{352}$ Friedens- und Grafschaftsgerichte konnten hingegen selbst in der entlegensten englischen Provinz angerufen werden. Einen Unterschied gab es schließlich auch bei den Streitwerten: Sie waren bei den Friedens- und Grafschaftsgerichten in der Höhe begrenzt, bei den Gewerbe- und Kaufmannsgerichten dagegen unbegrenzt. Kurzum, eine Gegenüberstellung der absoluten Klagezahlen vor den genannten deutschen und englischen Gerichten besitzt aufgrund des unterschiedlichen $\mathrm{Zu}$ schnitts der Institutionen nur eine grobe Indikatorfunktion.

Dennoch ist nicht zu erkennen, was man sonst sinnvoll vergleichen könnte, um überhaupt einen quantitativen Anhaltspunkt für die relative Be-

Rechtsstreitigkeiten fertig zu werden, in: ders. (Hg.), Prozeßflut?, S. 9-20; Christian Wollschläger, Die Arbeit der europäischen Zivilgerichte im historischen und internationalen Vergleich, in: ebd., S. 21-114, hier bes. S. 28-37.

352 Vgl. Willi Cuno, Die Rechtsprechung der deutschen Gewerbegerichte. Statistische Ergebnisse, in: Das Gewerbegericht 2 (1897), Außerordentliche Beilage, Sp. 81-96, Sp. 83. 
deutung des Rechts im Bereich der Arbeitsstreitigkeiten in den beiden Ländern zu gewinnen. Auch sind, läßt man einmal die Arbeiterschutz- und Unfallsachen in England beiseite, die Differenzen bei der sachlichen Zuständigkeit nicht allzu groß. Sowohl in den Friedens- und Grafschaftsgerichten als auch in den Gewerbe- und Kaufmannsgerichten betraf das Gros der Arbeitnehmer- und Arbeitgeberklagen zum einen den Lohn und sonstige gegenseitige Ansprüche, zum anderen den Beginn und das Ende des Arbeitsverhältnisses, also Versagungen der Anstellung, Kontraktbrüche, Kündigungen, Zeugnisse und dergleichen. ${ }^{353}$ Quantitativ wenig ins Gewicht fällt auch der Unterschied bei den Streitwerten. Die Masse der Klagen vor den Gewerbe- und Kaufmannsgerichten betraf nur geringfügige Summen, die weit unter den zulässigen Grenzwerten bei den Grafschaftsgerichten ( $£ 50$ und $£ 100$ ab 1903) lagen. ${ }^{354}$ Was also bei der Interpretation der Zahlenreihen zu beachten bleibt, ist vor allem die räumlich und personell beschränktere Zuständigkeit der deutschen Gewerbe- und Kaufmannsgerichte bis in die frühen Weimarer Jahre. Gerade das aber läßt den entscheidenden Befund, die viel größere und zudem schnell steigende Klagetätigkeit in Deutschland, nur um so stärker hervortreten. Denn zusätzlich zu den Fällen vor den Gewerbe- und Kaufmannsgerichten müßte man in Deutschland noch eine zwar unbestimmte, aber gewiß nicht unbedeutende Zahl von gerichtsförmigen Verfahren vor örtlichen Polizeibehörden (Gesinde und Hauspersonal bis 1918), vor Innungsschiedsgerichten (Handwerker bis 1926), vor Gemeindevorstehern (gewerbliche Arbeiter in Regionen ohne Gewerbegerichte bis 1916/23), vor Schlichtungsausschüssen (Arbeiter und Angestellte 1916 bis 1923) und vor Amts- und Landgerichten (alle übrigen Arbeitnehmer bis 1926) in die Rechnung einbeziehen. Die Divergenz zwischen den beiden nationalen Streitkulturen ist also in Wirklichkeit noch viel größer als sie im Vergleich der grafischen Darstellungen erscheint (Grafik 5.1, zu vergleichen mit Grafiken 2.1, 2.3 und 3.1).

Die gegenläufige Entwicklung ist eklatant. Zur gleichen Zeit, als in England die Flucht der Arbeitnehmer und Arbeitgeber aus den Gerichten ein-

353 Im Gewerbegericht Frankfurt waren im Geschäftsjahr 1894/95 insgesamt 1859 Rechtsstreitigkeiten anhängig. Davon entfielen auf Zahlung rückständigen Lohns $1160(62,4 \%)$ und auf Schadensersatz wegen einseitiger Lösung des Arbeitsverhältnisses 451 (24,3\%); siehe Frankfurter Zeitung und Handelsblatt, 26. Nov. 1895, Rubrik „Frankfurter Angelegenheiten“.

354 Vor den Gewerbegerichten betrug der Anteil der Klagen mit Streitwerten über 100 Mark 4,5\% im Jahr 1896, 3,8\% im Jahr 1913 und 44,5\% im Jahr 1919. Vor den Kaufmannsgerichten betrug der Anteil der Klagen mit Streitwerten über 300 Mark 16,9\% im Jahr 1905, 19,6\% im Jahr 1913 und 44,5\% im Jahr 1919. 100 Pfund entsprachen 1913 etwa 2080 Reichsmark und 1919 etwa 22700 Reichsmark; vgl. B. R. Mitchell, British Historical Statistics, Cambridge 1988, S. 703. 
Grafik 5.1: Gewerbe-, Kaufmanns- und Arbeitsgerichte im Deutschen Reich 1892-1929: Zabl der Klagen

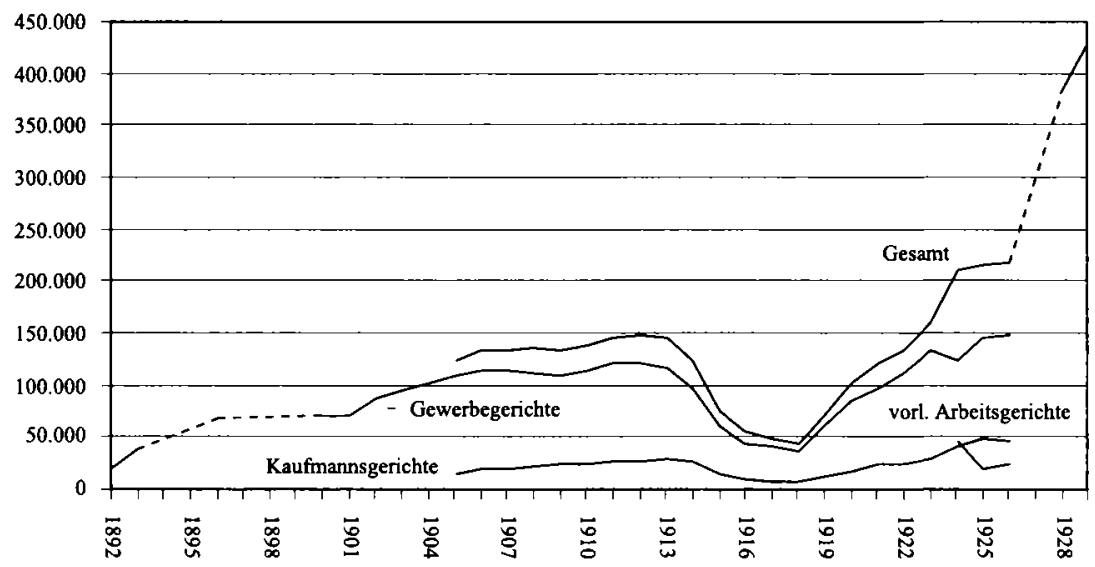

Quellen: Für 1892 und 1893: Labour Gazette, Okt. 1894, S. 318 (unter Berufung auf eine Meldung in Blätter für Sociale Praxis); für 1896: Das Gewerbegericht, 2. Jg. (1897), S. 83-96; für 1900-1913: Reichs-Arbeitsblatt ab 1. Jg. (1903-04); für 1914-18: Reichs-Arbeitsblatt 18. Jg. (1920), Sonderbeilage Nr. 1, Jan. 1920; für 1919-1929: Statistisches Jahrbuch für das Deutsche Reich ab 41. Jg. (1920), Sonderbeilage Nr. 1, Jan. 1920; für 1919-1929: Statistisches Jahrbuch für das Deutsche Reich ab 41. Jg. (1920) - hier werden nur die Zahlen für ,anhängige Sachen“ gegeben, ohne daß die vom Vorjahr übriggebliebenen Fälle subtrahiert werden, daher müssen die tatsächlichen Zahlen um bis zu $10 \%$ niedriger angesetzt werden; vgl. Hubert Rottleuthner, Aspekte der Rechtsentwicklung in Deutschland - Ein soziologischer Vergleich deutscher Rechtskulturen, in: Zeitschrift für Rechtssoziologie 6 (1985), S. 206-254, S. 240.

setzte, also im frühen 20. Jahrhundert, kam es in Deutschland zu einer wahren Prozeßflut. Diese wurde durch den Ersten Weltkrieg zwar kurzzeitig eingedämmt, aber nicht gebrochen. Die Klagezahlen stiegen in den frühen zwanziger Jahren schnell wieder an und hatten schon 1923 den VorkriegsHöchststand überschritten, während sie in England auf niedrigstem Niveau stagnierten. Die historisch wohl einmalige Prozeßexplosion vor den deutschen Arbeitsgerichten in den späten zwanziger Jahren, die sich bis zum Höhepunkt der Weltwirtschaftskrise fortsetzte und auch im Bereich der normalen Zivilgerichtsbarkeit ihre Parallele fand, ist sicher zum Teil auf die in Deutschland stärker als in anderen Ländern einschneidende Arbeitslosigkeit zurückzuführen: Die Entlassungen sorgten für zahlreiche Kündigungsstreitigkeiten, und der plötzliche Absturz vieler in die Arbeitslosigkeit zog anschließend massenhaft zivile Mahnverfahren und Schuldsachen nach 
sich. ${ }^{355}$ Selbst wenn man diesen Effekt abstreicht, bleibt aber der Unterschied zur englischen Entwicklung bestehen. Auch in England gab es in den zwanziger und frühen dreißiger Jahren stark erhöhte Arbeitslosigkeit. Anders als in Deutschland stagnierte dort jedoch die Zahl der Zivilprozesse insgesamt und nahm - relativ zur Bevölkerungszahl - sogar ab. 356 Was die Arbeitsstreitigkeiten bis 1923 angeht, so waren es nicht das Konfliktniveau (Entlassungen) und der davon ausgehende ,Bedarf an gerichtlichen Problemlösungen, sondern primär die unterschiedlichen Institutionen, die in Deutschland zum Anstieg, in England zu Rückgang und Stagnation der Klagetätigkeit führten.

Setzt man die Klagezahlen für Deutschland in Beziehung zur Zahl der potentiellen Kläger und Beklagten, so kamen auf 100000 gewerblich Beschäftigte am Ende des 19. Jahrhunderts etwa 750 Fälle, um 1907 annähernd 900 Fälle und Mitte der zwanziger Jahre über 1150 Fälle vor den Gewerbegerichten und vorläufigen Arbeitsgerichten (Grafik 5.2, zu vergleichen mit Grafik 2.3). Die Wahrscheinlichkeit für einen einzelnen gewerblichen Arbeiter oder Arbeitgeber, in einen Streitfall vor einem Gewerbegericht oder vorläufigen Arbeitsgericht verwickelt zu werden, lag damit Ende des 19. Jahrhunderts bei 132 zu 1, um 1907 bei 112 zu 1 und Mitte der zwanziger Jahre bei $87 \mathrm{zu}$ 1. Diese Wahrscheinlichkeit war also gegen Ende des 19. Jahrhunderts etwa zehn mal so hoch und in den zwanziger Jahren sogar fast fünfzig mal so hoch wie die Wahrscheinlichkeit für englische Arbeiter und Arbeitgeber, wegen einer Streitigkeit aus dem Arbeitsvertrag vor die Friedensrichter zitiert zu werden. Noch drastischer fällt der Unterschied aus, wenn man die Kaufmannsgerichte und Grafschaftsgerichte in den Vergleich der Klageraten pro 100000 Beschäftigte einbezieht. Vor den Kaufmannsgerichten kamen bereits 1907 auf 100000 kaufmännisch Beschäftigte annähernd $1500 \mathrm{Klagen}$, und Mitte der zwanziger Jahre waren es mehr als 2000. Um 1925 mußte jeder fünfzigste kaufmännische Angestellte oder Arbeitgeber in Deutschland damit rechnen, im Laufe eines Jahres in einen Prozeß vor dem Kaufmannsgericht verwickelt zu werden. Vor den englischen Grafschaftsgerichten war es Anfang der zwanziger Jahre nur jeder viertausendzweihundertste Arbeitnehmer oder Arbeitgeber (Grafik 5.2, zu vergleichen mit Grafik 3.1). Mit unterschiedlichen Konjunkturverläufen und

355 Vgl. Hubert Rottleuthner, Aspekte der Rechtsentwicklung in Deutschland - Ein soziologischer Vergleich der deutschen Rechtskulturen, in: Zeitschrift für Rechtssoziologie 6 (1985), S. 206-254, S. 237-241; vgl. auch Wollschläger, Arbeit der europäischen Zivilgerichte, S. $60 \mathrm{ff}$.

356 Vgl. das Schaubild und die Erläuterungen ebd., S. $64 \mathrm{ff}$. 
Grafik 5.2: Gewerbe-, Kaufmanns- und Arbeitsgerichte im Deutschen Reich 1892-1925: Klagen pro 100000 , gewerblich ' bzw. ,kaufmännisch'Beschäftigte

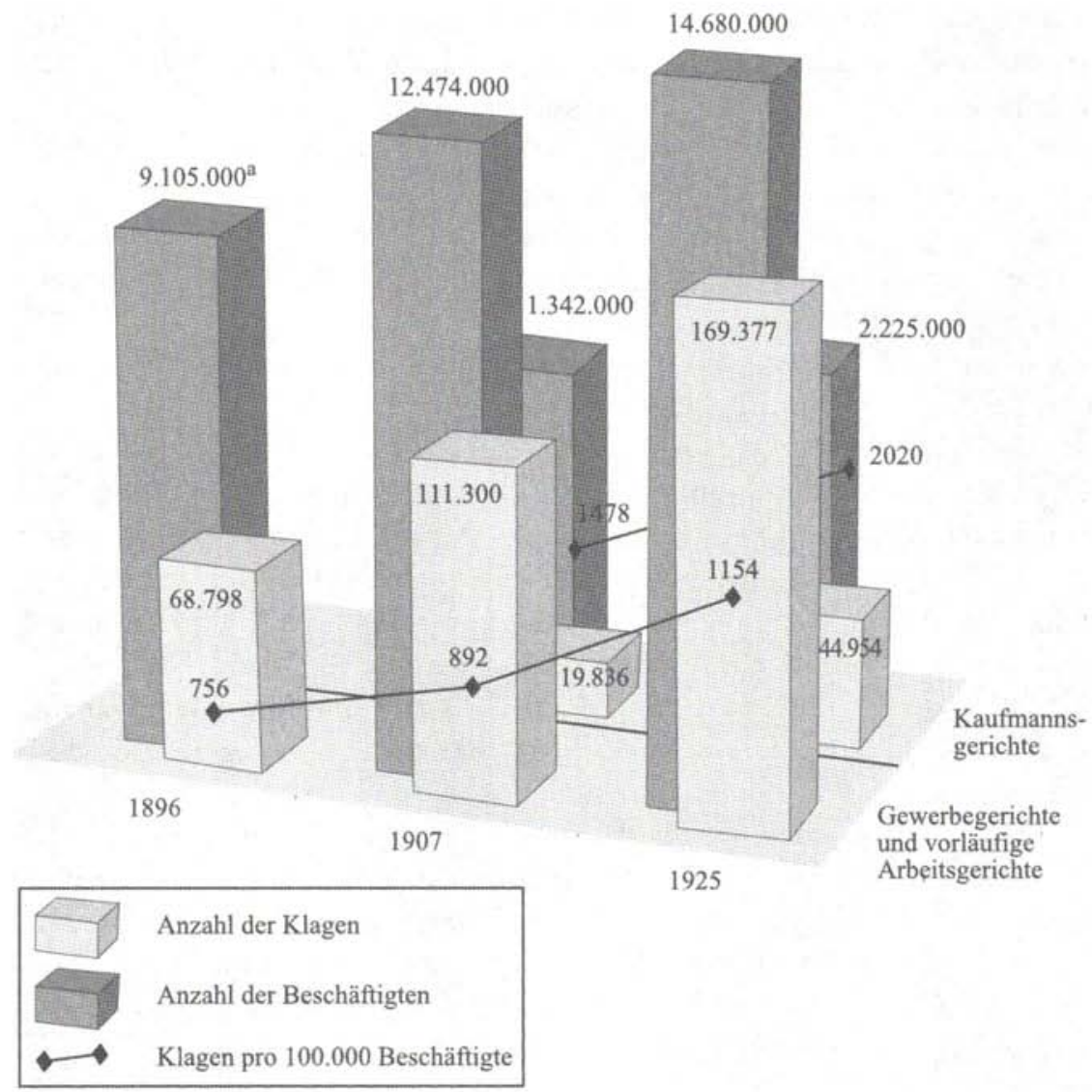

a Berufszählung 1895

Erläuterung: 1. Die Zahlen für "Klagen“ 1907 sind Fünfjahresdurchschnitte, zentriert auf das Jahr der Berufszählung. Die Zahlen für Klagen 1925 sind Dreijahresdurchschnitte, zentriert auf das Jahr der Berufszählung.

2. Für die Zahl der, gewerblich ' Beschäftigten wurden aus den Berufsstatistiken die Zahlen für „Erwerbstätige überhaupt “ in Industrie, Bergbau und Handwerk und für „Gehilfen“ bzw. „Arbeiter" in Handel und Verkehr addiert. Damit trifft man ungefähr die Gruppe derer, die unter die Jurisdiktion der Gewerbegerichte und vorläufigen Arbeitsgerichte fielen. Für die Zahl der ,kaufmännisch' Beschäftigten wurde die Zahl für „Angestellte“ in Handel und Verkehr genommen. Tatsächlich waren hierunter auch manche, die nicht unter die Jurisdiktion der Kaufmannsgerichte fielen, auf der anderen Seite muß man sich einen Teil der Selbständigen als Arbeitgeber und somit potentielle Kläger oder Beklagte hinzudenken.

Quellen: Für die Klagezahlen wie Grafik 5.1; für die Zahl der ,gewerblich ' bzw. ,kaufmännisch“ Beschäftigten: Statistisches Jahrbuch für das Deutsche Reich, Jg. 18 (1897), S. 7; Jg. 30 (1909), S. 10 f.; Jg. 46 (1927), S. 25: Ergebnisse der Berufszählungen von 1895, 1907 u. 1925. 
anderen wirtschaftlichen Daten können diese enormen Diskrepanzen nicht erklärt werden.

Wie ist die Prozeßflut in Deutschland zu erklären? Was sind die Gründe für die Streitlust der deutschen Arbeitnehmer - denn sie waren es, die durchweg zu mehr als 90 Prozent für die Prozesse verantwortlich waren?357 Will man sich nicht mit der zweifelhaften Zuschreibung angeblicher Nationalcharaktere begnügen - der ,rechthaberische Deutsche und der ,geduldige' Engländer -, kommt als Erklärung vor allem eine institutionenbezogene Angebotstheorie des Streitverhaltens in Frage. Die Justizeinrichtungen konnten zum Rechtsstreit ermutigen, indem sie ihn unkompliziert und risikoarm gestalteten, wie es bei den Gewerbegerichten offensichtlich der Fall war; die Institutionen konnten aber auch, wie im Fall der englischen Friedens- und Grafschaftsgerichte, durch hohe Kosten, abschreckende Verfahren und ungewisse Erfolgsaussichten entmutigend wirken. Wenig plausibel ist hingegen eine Erklärung von der Nachfrageseite her. Die Konflikte an deutschen und englischen Arbeitsplätzen waren im Prinzip gleichartig. Hier wie dort gab es Entlassungen, die als unfair empfunden wurden; hier wie dort gab es mangelhafte Leistung, unentschuldigtes Fehlen, Arbeitsverweigerung, Kontraktbrüche, unbezahlte oder nicht tarifgemäße Löhne. Es gibt keinen Grund, anzunehmen, daß derartige Streitfälle in England grundsätzlich seltener vorkamen als in Deutschland. Sie wurden aber viel seltener auf dem Rechtsweg gelöst, und das lag, so wird hier argumentiert, primär an der mangelnden Attraktivität der dafür in Frage kommenden Gerichte und ihrer Prozeduren, also am institutionellen Angebot.

Denkbar wäre allerdings auch eine Erklärung, die auf Unterschiede im materiellen Arbeitsrecht selber abhebt. Wenn man zum Beispiel nachweisen könnte, daß die Rechtsbestimmungen zum Kündigungsschutz, zur Entschädigung bei ungerechtfertigter Entlassung, zu Strafgeldern oder Lohneinbehaltungen im wilhelminischen Deutschland wesentlich arbeitnehmerfreundlicher ausfielen als im viktorianischen England, würde dies die vergleichsweise große Prozeßfreudigkeit der deutschen Arbeitnehmer wenigstens zum Teil erklären. Tatsächlich enthielten die deutschen Kodifikationen - die Gewerbeordnung, das Handelsgesetzbuch und auch das BGB insbesondere in den Bereichen Kündigung und Entlassung eine Reihe von Vorschriften und Klauseln, die den deutschen Arbeitnehmer tendenziell besser stellten als sein englisches Gegenüber. Die günstigere Rechtslage be-

357 Die deutsche Statistik unterschied von Anfang an zwischen Arbeitnehmer- und Arbeitgeberklagen und erspart dem Historiker somit aufwendige Forschungen, wie ich sie für England durchgeführt habe. 
stand aber vor allem darin, daß es überhaupt präzise und zwingende Normen zu diesem Konfliktfeld gab. Das machte es im Einzelfall möglich, einen Prozeß mit einiger Sicherheit über den Ausgang zu beginnen und durchzufechten. Zu nennen sind etwa Vorschriften wie die, daß Kündigungsfristen auf beiden Seiten gleich lang sein mußten ${ }^{358}$, oder daß eine bestimmte Kündigungsfrist (zum Beispiel sechs Wochen bei Handlungsgehilfen) automatisch als vereinbart galt, falls die Vertragsparteien nicht ausdrücklich etwas anderes festgelegt hatten ${ }^{359}$, oder daß ein Arbeitnehmer bei Vorliegen eines ,wichtigen Grundes' (zum Beispiel Nicht-Beachtung von Arbeiterschutzbestimmungen durch den Arbeitgeber) das Recht hatte, seinen Arbeitsplatz ohne vorherige Kündigung zu verlassen. ${ }^{360}$ Für derartige gesetzliche Bestimmungen fand sich in England keine Parallele. Fragen dieser Art waren in England nur durch Common law und custom geregelt. Das führte im konkreten Fall, wie noch zu zeigen sein wird, sehr oft zu einer völligen Unvoraussehbarkeit, ja Beliebigkeit des Prozeßausgangs. ${ }^{361}$ Blickt man nur auf die Substanz der höchstrichterlichen Entscheidungen, ergibt sich zwar auch in England ein halbwegs konsistent erscheinender Komplex von Normen zu Kündigung und Entlassung; auch unterscheidet sich dieser Normkomplex, wenn man genau hinsieht, nicht einmal so sehr von den zeitgleich in Deutschland geltenden gesetzlichen Vorschriften. Jedoch war es für einen durchschnittlichen englischen Anwalt, von einem Laien gar nicht zu reden, viel schwerer zu erkennen, was das geltende Recht in einer konkreten Frage

358 Gewerbeordnung 1891, $\$ 122$, RGBl. Jg. 1891, S. 261-290, S. 272: „Das Arbeitsverhältniß zwischen den Gesellen oder Gehülfen und ihren Arbeitgebern kann, wenn nicht ein Anderes verabredet ist, durch eine jedem Theile freistehende, vierzehn Tage vorher erklärte Aufkündigung gelöst werden. Werden andere Aufkündigungsfristen vereinbart, so müssen sie für beide Theile gleich sein. Vereinbarungen, welche dieser Bestimmung zuwiderlaufen, sind nichtig."

359 Das Handelsgesetzbuch von 1897 legte außerdem eine gesetzliche Mindestkündigungsfrist von einem Monat fest. HGB 1897, $\$ \$ 66-67$, RGBl. Jg. 1897, S. 219-436, S. 233: „\$66. Das Dienstverhältniß zwischen dem Prinzipal und dem Handlungsgehülfen kann, wenn es für unbestimmte Zeit eingegangen ist, von jedem Theile für den Schluß eines Kalendervierteljahrs unter Einhaltung einer Kündigungsfrist von sechs Wochen gekündigt werden. $\$ 67$. Wird durch Vertrag eine kürzere oder längere Kündigungsfrist bedungen, so muß sie für beide Theile gleich sein; sie darf nicht weniger als einen Monat betragen. ... Eine Vereinbarung, die diesen Vorschriften zuwiderläuft, ist nichtig." Zu den weiteren Einzelheiten des Kündigungsrechts für Handlungsgehilfen: Wolfgang Heine, Die Sozialpolitik des Handelsstandes und das deutsche Handelsgesetzbuch, in: Archiv für Soziale Gesetzgebung und Statistik 11 (1897), S. 279-322, S. 303-309.

360 Vgl. zu den je nach „Arbeiterkategorieen“ unterschiedlichen Bestimmungen in dieser Frage: Hermann Jastrow, Der Arbeiterschutz nach dem Bürgerlichen Gesetzbuch, in: Soziale Praxis 6 (1897), Sp. 1030-1034.

361 Siehe unten Kap. V.3. 
jeweils war. Folglich war jeder Prozeß, der in England vor einer unteren Instanz über eine Kündigung oder Entlassung begonnen wurde, mit einem viel höheren Risiko behaftet als in Deutschland, wo es einem gewerkschaftlichen Arbeitersekretär mithilfe des Gesetzbuchs und eines gelehrten Kommentars in der Regel möglich war, den Ausgang vorherzusagen und seinem Klienten dementsprechend zu- oder abzuraten. ${ }^{362}$ Es war mithin weniger die Substanz des Individualarbeitsrechts als vielmehr seine besondere Form - Kodifikation und Kommentar hier, Common law und custom dort -, die es im deutschen Fall für Arbeitnehmer leichter und risikoloser machte, einen Prozeß zu beginnen. Die deutschen Rechtsnormen selbst waren zwar ebenfalls in dem einen oder anderen Punkt arbeitnehmerfreundlicher als in England, besonders nach 1918, aufs Ganze gesehen waren die Unterschiede hier aber nicht allzu groß.

Die beste und klarste Kodifikation nützt freilich einem armen Kläger wenig, wenn auf der untersten Ebene der Rechtspflege hohe Schwellen vor dem Gericht und hohe prozeßrechtliche Hürden im Gericht aufgebaut werden. Damit sind wir erneut bei der institutionellen Erklärung angelangt. Das in Teilbereichen arbeitnehmerfreundlichere deutsche Arbeitsvertragsrecht mag als sekundäre Erklärung für die Prozeßflut in Frage kommen, an erster Stelle stand jedoch das günstige institutionelle Angebot der Gewerbeund Kaufmannsgerichte, das in jedem Fall eine Klage lohnender erscheinen ließ als vor den ordentlichen Gerichten in England.

Die Untersuchung der Erfolgsquoten von 1850 bis in die zwanziger Jahre hat im Fall der englischen Friedens- und Grafschaftsgerichte keine starken Ausschläge und keinen anhaltenden Trend zugunsten der einen oder anderen Seite gezeigt. Diesem Faktor konnte daher bei der Erklärung der Flucht aus den Gerichten in England keine große Bedeutung beigemessen werden. Wie stand es mit den Erfolgen klagender Arbeitnehmer vor den Gewerbeund Kaufmannsgerichten? Liegt hier ein weiterer Schlüssel für die Flut arbeitsrechtlicher Prozesse in Deutschland? Glaubt man vereinzelten Stimmen aus Arbeitgeberkreisen und der ihnen nahestehenden Presse, zeichnete sich die Rechtsprechung der Gewerbegerichte von Anfang an durch eine gewisse Parteinahme zugunsten der Arbeiter aus. Manche Kommentare zu einzelnen Urteilen lesen sich beinahe so, als hätten die Gewerberichter und ihre Beisitzer eine Klassenjustiz in umgekehrter Richtung betrieben. So berichtete das Baugewerks-Blatt im Jahr 1895 mit offenkundiger Empörung über einen Fall aus Berlin, bei dem „die Mehrheit des Gerichts“ unter Beru-

362 Eine Ausnahme bildeten hierbei allerdings die unaufhörlichen personellen Kompetenzstreitigkeiten; siehe oben Fn. 338. 
fung auf ein allgemeines „Gerechtigkeitsgefühl“ einen Arbeitgeber verurteilte, weil er einen vom örtlichen Arbeitsnachweis zu ihm geschickten Bauarbeiter nicht eingestellt hatte. ${ }^{363}$ Und das Central-Blatt für die Deutsche Papier-Fabrikation sah anläßlich eines Falls aus Gleiwitz die Gewerbegerichtsbarkeit in Gefahr, „zu einer Parteijustiz zu entarten“, und forderte die „Einführung der Berufung für alle Streitsachen“; hier hatte sich ein Schlosser, der sich von einem Konkurrenzbetrieb hatte anwerben lassen, geweigert, in der ihm im alten Betrieb verbleibenden vierzehntägigen Frist in einem anderen Fabrikationszweig (ohne Lohnschmälerung) zu arbeiten. Er verließ den Betrieb. Das Gericht gab dennoch seiner Klage auf Entschädigung von $4 \mathrm{M}$. pro Tag statt. Das Arbeitgeberblatt machte dagegen die "natürlichen Rechtsanschauungen" geltend, nach denen es einem Brotherrn freistehen müsse, seine Arbeiter innerhalb des Berufsgebiets nach Ermessen $z u$ beschäftigen, und wonach es kein „Recht auf eine ganz bestimmte Art von Thätigkeit" geben könne. ${ }^{364}$

Verteidiger der Gewerbegerichte, allen voran Karl Flesch, Mitbegründer des Verbandes deutscher Gewerbegerichte, und Ignaz Jastrow, Sozialreformer, Publizist und erster Herausgeber der Zeitschrift „Das Gewerbegericht“, beeilten sich, den Vorwurf der Parteilichkeit durch konkrete Zahlen und Beispiele aus der Spruchpraxis zu widerlegen. ${ }^{365}$ Jastrow meinte, daß viele Unternehmer den Tit. 7 der Gewerbeordnung vor Einführung der Gewerbegerichte einfach nie zur Kenntnis genommen hätten und nun, da die Arbeiter erstmals eine realistische Klagechance erhalten hätten, überrascht festellen müßten, welche Bestimmungen das Gesetz enthalte. ${ }^{366}$ Den Angaben von Flesch zufolge waren Berliner Arbeitnehmer 1895/96 in den Fällen, die durch streitiges Urteil entschieden wurden, nur zu knapp 20 Prozent erfolgreich,

363 Deutsches Baugewerks-Blatt 14 (1895), 1. Aug. 1895, Sp. 348 f.; vgl. auch den scharf mit den sozialdemokratischen Beisitzern ins Gericht gehenden Artikel in der folgenden Nummer vom 10. Aug. 1895, Sp. 362-65, „Zur Reform der Gewerbegerichte“. Gefordert wurden hier u. a. eine Berufungsmöglichkeit gegen alle Urteile und eine Änderung des Wahlmodus der Beisitzer: Diese sollten künftig aus einer Vorschlagsliste von der Behörde ausgewählt werden.

364 Centralblatt für die Deutsche Papier-Fabrikation 47 (1896), 16. Dez. 1896, S. 603.

365 Karl Flesch, Der Jahresbericht des Gewerbegerichts Berlin, in: Das Gewerbegericht 2 (1897), Sp. 53-56, Sp. 54; Jastrow, Erfahrungen in den deutschen Gewerbegerichten, S. 361-374; ders., Sozialpolitik und Verwaltungswissenschaft, Bd. 1: Arbeitsmarkt und Arbeitsnachweis. Gewerbegerichte und Einigungsämter, Berlin 1902, S. 466-481. Zu Karl Flesch vgl.: Hugo Sinzheimer, Der Sozialpolitiker Karl Flesch und seine literarisch-wissenschaftliche Tätigkeit (1915), in: ders., Arbeitsrecht und Rechtssoziologie. Gesammelte Aufsätze und Reden, hrsg. v. Otto Kahn-Freund u. Thilo Ramm, 2 Bde. Frankfurt u. Köln 1976, Bd. 1, S. 387-387.

366 Jastrow, Sozialpolitik, S. 468. 
während Arbeitgeber bei den durch Endurteil entschiedenen Fällen viel häufiger, nämlich zu etwa 50 Prozent Erfolg hatten. Der Jahresbericht des Gewerbegerichts Frankfurt für 1894/95 wies ausdrücklich auf die Zahl der abweisenden oder teilweise abweisenden Urteile hin (215 von 373, also Mißerfolge in $58 \%$ der durch Endurteil entschiedenen Fälle) und knüpfte daran den Wunsch „daß angesichts der Thatsachen endlich einmal die vage Behauptung, der Arbeiter bekäme, doch immer Recht', verstummen möchte. “367 Spätere Erhebungen kamen zu ähnlichen Resultaten. ${ }^{368}$ Nach diesen Zahlen lag die Erfolgsquote deutscher Arbeiter vor den Gewerbegerichten noch unter derjenigen englischer Arbeiter vor den Friedensgerichten. Selbst vor den als extrem parteiisch verschrieenen magistrates waren englische Arbeiter meinen Berechnungen zufolge seit der Mitte des 19. Jahrhunderts durchweg in etwa der Hälfte ihrer Fälle erfolgreich. Bei den Grafschaftsgerichten wurde die 50 Prozent-Marke im späten 19. Jahrhundert sogar deutlich überschritten. An den ,objektiv' meßbaren Erfolgsraten kann es demnach kaum gelegen haben, daß deutsche Arbeitnehmer so viel bereitwilliger als ihre englischen Kollegen vor Gericht zogen.

Nun beziehen sich allerdings die eben zitierten Angaben von Flesch und anderen zu den Klageerfolgen in Deutschland allein auf streitige Urteile. Durch Endurteil wurde aber vor den Arbeitsgerichten lediglich ein kleinerer Teil der Streitigkeiten entschieden. Der entsprechende Anteil sank bei den Gewerbegerichten zwischen 1896 und 1918 von 21,2 auf 11,8 Prozent, um dann bis 1926 wieder auf 17,8 Prozent zu steigen; bei den Kaufmannsgerichten ging der Anteil der Endurteile von 18,5 Prozent im Jahr 1905 auf 12,2 Prozent im Jahr 1918 zurück und stieg bis 1926 wieder auf 14,9 Prozent an. Der größte Teil der Fälle wurde also anderweitig, das heißt durch Vergleich, Zurücknahme, Ausbleiben der Parteien, Verzicht, Anerkenntnis und Versäumnisurteil erledigt; unter diesen Prozeßausgängen nahmen die Vergleiche stets den ersten Platz ein. Ihr Anteil sank bei den Gewerbegerichten zwischen 1896 und 1926 von 45,6 auf 32,8 Prozent, bei den Kaufmannsgerichten zwischen 1905 und 1926 von 44,0 auf 33,8 Prozent. Wie die Praxis hier aussah, ob es vor allem bei den Vergleichen zu einer spürbaren Begünstigung der Arbeitnehmer kam, könnte nur durch eine breit angelegte Analyse von Einzelfällen auf der Basis von Gerichtsakten und Presseartikeln

367 Frankfurter Zeitung und Handelsblatt, 26. Nov. 1895, Rubrik „Frankfurter Angelegenheiten".

368 Vgl. die Angaben bei Bähr, Entstehung und Folgen des Arbeitsgerichtsgesetzes, S. 510: „In Berlin gewannen die Arbeitgeber im Durchschnitt der Jahre 1895-1904 60\% der von ihnen beim Gewerbegericht angestrengten Verfahren, die Arbeitnehmer dagegen nur 40\%." 
geklärt werden, wie sie hier für die englischen Friedens- und Grafschaftsgerichte vorgelegt wird. Für ein solches Vorhaben fehlt bisher in Deutschland jede empirische Grundlage. Es wäre ein aufwendiges Quellenerschließungsprojekt erforderlich, das insbesondere auch die Kommunalarchive sowie die Lokal- und Gewerbepresse einbeziehen müßte. ${ }^{369}$ Dies kann von einem einzelnen Forscher in vertretbarer Zeit nicht für zwei Länder gleichzeitig bewältigt werden. Die Frage nach Erfolg und Mißerfolg bei Vergleichen und anderweitig erledigten Fällen muß also vorerst offen bleiben. Ohnehin läßt sich außer bei Urteilen aus Aktennotizen nachträglich selten mit Gewißheit feststellen, ob das Ergebnis von den Beteiligten als Erfolg oder Mißerfolg bewertet wurde. Wir haben es hier mit einem subjektiven Bereich zu tun, der sich einer historisch-quantifizierenden Analyse entzieht.

Folgt man jedoch rechtssoziologischen Untersuchungen zur Arbeitsgerichtsbarkeit der Gegenwart, so ist für die meisten Arbeitnehmer die begründete Aussicht, durch einen gerichtlich herbeigeführten Vergleich zumindest an eine Teilsumme zu gelangen, völlig ausreichend für eine Klage. 370 Es spricht nichts gegen die Annahme, daß rechtssuchende Arbeitnehmer im Kaiserreich ein ähnliches Kalkül anstellten. Ihnen war bewußt, daß die Gewerberichter versuchen mußten, beide Parteien zu einem Vergleich zu überreden. Wer also von vornherein die Absicht hegte, sich mit einem Teilerfolg zu begnügen, war mit dem Gewerbegerichtsverfahren bestens bedient. Für ihn bot das Gericht kostenlose argumentative Schützenhilfe. Vorausgesetzt, das Arbeitsverhältnis selbst war bereits zerbrochen, konnte ein Arbeitnehmer unter diesen Vorgaben eigentlich nur gewinnen. Dies dürfte ein Grund für den großen Zulauf zu den Gewerbegerichten gewesen sein. Sehr plastisch zeigt dies die folgende von Jastrow mitgeteilte Begebenheit:

Ein erfahrener Gewerbegerichts-Vorsitzender erzählte, daß er in der ersten Zeit seiner Praxis die hohen Vergleichziffern für den bedeutendsten Erfolg seiner Thätigkeit hielt, bis er eines Tages einem Gespräch zweier halbwüchsiger Burschen zu-

369 Die Bestände zu Gewerbe- und Kaufmannsgerichten in staatlichen deutschen und polnischen Archiven sind minimal, etwas besser sieht es für die Arbeitsgerichte seit 1927 aus. Vgl. Barbara Dölemeyer (Hg.), Repertorium ungedruckter Quellen zur Rechtsprechung. Deutschland 1800-1945, 2 Halbbände, Frankfurt/Main 1995. Kleine Bestände (vor allem Generalia, seltener Einzelfallakten) befinden sich demnach in den Staatsarchiven von Poznan (Posen), Torun (Thorn), Coburg, München, Ludwigsburg, Karlsruhe, Hamburg, Bremen und im Landesarchiv Schleswig-Holstein.

370 Vgl. Siegfried Schönholz, Bedingungen und Merkmale der Erledigungsweise im Arbeitsgerichtsverfahren, insbesondere des Abschlusses von Prozeßvergleichen und der Thematik in der Verhandlung, in: Hubert Rottleuthner ( $\mathrm{Hg}$.), Rechtssoziologische Studien zur Arbeitsgerichtsbarkeit, Baden-Baden 1984, S. 263-290, S. 266; Klaus Feser u. a., Arbeitsgerichtsprotokolle, Neuwied u. Darmstadt 1978, S. $90 \mathrm{ff}$. 
hörte, von denen der eine behauptete, irgend einen Anspruch an seinen Arbeitgeber zu haben. Der andere, ohne erst lange die Gründe für den Anspruch anzuhören, gab ihm den Rat: ,Geh nur ans Gewerbegericht, Etwas kriegst Du sicher!' Dies machte ihn stutzig. Wenn die Folge seiner Sühnethätigkeit war, daß sein Gericht in den Ruf kam, ,Etwas' sicher zu beschaffen, so mußte das ein Fingerzeig sein, nicht allzu sehr auf Vergleiche hinzuwirken. ${ }^{371}$

Erneut erweist sich hier die besondere institutionelle Struktur, in diesem Fall der prozeßrechtliche Vorrang des Vergleichs, als ausschlaggebender Faktor für die Prozeßflut.

Was die Arbeitgeber angeht, so läßt sich aus publizistischen Kommentaren und Erfahrungsberichten einzelner Beteiligter ablesen, daß es für sie gar nicht so sehr die Prozeßresultate waren, die als unfair wahrgenommen wurden. Vielmehr richtete sich die Kritik meist gegen die Art und Weise, in der die Verhandlungen geführt wurden. Arbeitgeber empfanden es als lästig oder auch empörend, daß man sie nötigte, persönlich vor den Gewerberichtern zu erscheinen. ${ }^{372}$ Es störte sie, daß sie sich nicht durch Anwälte oder einen Justiziar vertreten lassen durften. Sie beschwerten sich darüber, daß man ihnen keine Zeit zur Beschaffung von Beweisen einräumte, daß man sie für ihren Zeitverlust und Verdienstausfall aufgrund der Warterei und Lauferei nicht angemessen entschädigte. Kurzum, viele Arbeitgeber ärgerten sich, daß man sie vor dem Gewerbegericht auf eine Stufe mit ihren Arbeitern herabwürdigte. Stein des Anstoßes war also die für einen ,Herrn im Hause، ungewohnte Erfahrung der Gleichbehandlung vor Gericht, weniger ein ungünstiges Urteil im einen oder anderen Fall. Es ist nicht auszuschließen, daß es Arbeitern hin und wieder Genugtuung verschaffte, ihren Arbeitgeber auf diese Weise zu etwas zu nötigen, was ihm unangenehm sein mußte. Manchem klagenden Arbeiter mag diese Form der Rache sogar soviel wert gewesen sein, daß ihm der Prozeßausgang gleichgültig war. Sehr viel verlieren konnte er ja in aller Regel nicht. Genau auf dieses Motiv des Klagens um der bloßen Belästigung des Gegners willen, also auf das, was man im Englischen nuisance litigation nennt, zielte die Kritik der Arbeitgeberseite am Gewerbegerichtsverfahren. Die zu niedrigen Schwellen, nicht etwaige Sympathien der Richter, verlockten dieser Auffassung zufolge die Arbeiter zu einer an-

371 Jastrow, Erfahrungen in den deutschen Gewerbegerichten, S. 354.

372 Vgl. Flesch, Jahresbericht des Gewerbegerichts Berlin, Sp. 53f.: „Wer diese Angriffe verfolgt, weiß, daß sie fast immer sich nicht gegen ergangene Urtheile richten, sondern dem Aerger darüber Ausdruck geben, daß der Prinzipal, wegen der geringsten Kleinigkeit' von dem Arbeiter mehrfach aufs Gericht citiert werden könne, und schließlich, schon um der Lauferei zu entgehen, einen Vergleich machen müsse." Flesch fordert daher an dieser Stelle dazu auf, „die Parteien, die Urtheil haben wollen, nicht zum Vergleich zu drängen.“ 
maßenden und überzogenen Strategie des Konflikts mit juristischen Mitteln.

Ein letzter Punkt sollte in die vergleichende Betrachtung des Klageverhaltens einbezogen werden; es ist das Image der jeweiligen Gerichte in den Augen der potentiellen Nutzer. Dieses Image resultierte natürlich in erster Linie aus konkret erfahrenen und meßbaren Faktoren: Gerichtsgebühren und Anwaltskosten, Verfahrensdauer, Zusammensetzung der Richterbänke und Erfolgsraten. Darüber hinaus prägten aber auch kollektive Erinnerungen und Erzählungen über vergangene Zustände das Bild der betreffenden Institutionen. Das war in besonderem Maße bei den englischen Laien-Friedensrichtern der Fall, denen der Ruf, arbeiterfeindlich und strafversessen zu sein, auch im späten 19. und frühen 20. Jahrhundert noch nachhing, als die Praxis längst nicht mehr so einseitig wie in früh- und mittelviktorianischer Zeit war. Die ,Meistererzählung' der englischen Arbeiterbewegung wurde selbst zum Faktor der Abwendung von der Justiz. Damit verglichen hatten die deutschen Gewerbegerichte als institutionelle Neuschöpfung einen Vorteil. Zwar gab es in vielen deutschen Städten schon vor 1890 gewerbliche Schiedsgerichte, deren Wurzeln im Rheinland bis in die napoleonische Ära und mancherorts sogar weiter zurück reichten. ${ }^{373}$ Die Gewerbegerichte wurden aber als etwas Neues wahrgenommen, und tatsächlich bestand zwischen ihnen und den älteren Schiedsgerichten bis auf wenige Ausnahmen im Rheinland, in Elsaß-Lothringen, Sachsen und den Hansestädten keine direkte institutionelle Kontinuität. ${ }^{374}$ Eine Übertragung des Image der alten auf die neue Institution fand daher allenfalls vereinzelt auf lokaler Ebene statt. Außerdem gab es in Deutschland um 1890 bezogen auf die alten gewerblichen Schiedsgerichte nichts, was auch nur annähernd mit den suggestiven Klassenjustiz-Erzählungen über die englischen Friedensrichter vergleichbar war. Außerhalb des unmittelbaren Einzugsbereichs wußte man allgemein nur wenig über diese Vorläufer der Gewerbegerichte, und was sich aus den wenigen Publikationen über diese Einrichtungen entnehmen ließ, war aus Arbeitnehmersicht keineswegs so negativ, daß es Anlaß zu Mißtrauen gegen die neuen Gerichte gab. Denn sowohl aus den damals publizierten Zahlen als auch aus neueren historischen Forschungen geht her-

373 Vgl. Wilhelm Stieda, Das Gewerbegericht, Leipzig 1890, mit statistischen Angaben im Anhang. Danach wurden neben den älteren Gerichten im Rheinland, in Berlin, in den Hansestädten und anderen größeren Städten zwischen 1869 und 1889 insgesamt 78 weitere gewerbliche Schiedsgerichte eingerichtet (S. $192 \mathrm{ff}$.).

$374 \mathrm{Vgl}$. die Angaben bei Jastrow, Erfahrungen in den deutschen Gewerbegerichten, S. 325 f. Die fortbestehenden älteren Schiedsgerichte wurden durch Landesgesetze in Zusammensetzung und Verfahren den neuen Gewerbegerichten nahezu vollständig angeglichen. 
vor, daß die Vorläufer-Gerichte mehrheitlich von Arbeitnehmern angerufen wurden und daß die Fälle in ähnlicher Weise wie später bei den Gewerbegerichten erledigt wurden, also überwiegend durch Vergleich und nur zum geringen Teil durch streitiges Urteil. ${ }^{375}$ Die absoluten Klagezahlen lagen zwar, wie sich etwa an den Beispielen Elberfelds und Berlins zeigen läßt, erheblich niedriger als in den Gewerbegerichten nach 1890; verglichen mit englischen Friedensgerichten in vergleichbar bedeutenden Industriezentren war der Zulauf zu diesen Institutionen aber schon vor 1890 recht hoch. ${ }^{376}$

Die Kritik an den alten gewerblichen Schiedsgerichten ging hauptsächlich von den Sozialdemokraten und bürgerlichen Sozialreformern aus. Sie setzte nicht so sehr an ihrer konkreten Tätigkeit in den einzelnen Städten an, sondern richtete sich bei der SPD in erster Linie gegen die Zusammensetzung, bei den bürgerlichen Reformern vor allem gegen die mangelnde Einheitlichkeit in Prozedur und Zuständigkeit auf nationaler Ebene. Der Wunsch nach innerer Einheit des Rechtssystems und des Gerichtswesens im neuen deutschen Kaiserreich, der die großen Kodifikationen hervorbrachte, trieb auch die Reform der Gewerbegerichtsbarkeit voran. Ohne dieses Motiv der nationalen Rechtseinheit, über das ein breiter Konsens herrschte, wäre ein so weitreichendes Reformexperiment wie die Einrichtung der Gewerbegerichte nicht zustandegekommen. Einen vergleichbaren Impetus, das vorgefundene Rechts- und Justizsystem auf den Prüfstand zu stellen und nach neuen Lösungen zu suchen, hat es in England nie gegeben. ${ }^{377}$

375 Vgl. vor allem: Schöttler, Die rheinischen Fabrikengerichte; ders., Mikrogeschichte der Arbeitsgerichtsbarkeit; ders., Aufstieg und Fall eines Fabrikengerichtspräsidenten: Die Karriere des Johann Caspar van der Beeck 1803-1861, in: Archiv für Sozialgeschichte 31, 1991, S. 27-60. Vgl. außerdem die statistischen Angaben zu den Gerichten in Posen, Elbing, Bremen, Hamburg, Stuttgart, Nürnberg, Erfurt, Apolda, Leipzig, Dresden und Kempten bei Stieda, Gewerbegericht, S. 131-142; ferner: Eugen Stahlhacke, Die Entwicklung der Gerichtsbarkeit in Arbeitssachen bis 1890, in: Die Arbeitsgerichtsbarkeit, S. 59-73.

376 In Elberfeld wurden in den Jahren von 1858 bis 1867 im Durchschnitt 781 Fälle pro Jahr verhandeit, in der Mitte der neunziger Jahre waren es dann mit 1321 (1896) und 1469 (1897). annähernd doppelt so viele (zum Vergleich Sheffield: im Durchschnitt 166 Fälle pro Jahr zwischen 1858 und 1867); die Zahlen für Elberfeld nach Stahlhacke, Entwicklung, S. 67, und G. Pabst, Gewerbegerichte, in: Statistisches Jahrbuch Deutscher Städte, 7. Jg. (1898), S. 130-138; für Sheffield vgl. Grafik 2.5, S. 197. In Berlin stieg das Klageaufkommen vor der städtischen Gewerbe-Deputation - bei starken Schwankungen - von 964 Fällen im Jahr 1871 auf 7410 Fälle im Jahr 1885, im Durchschnitt dieser 15 Jahre waren es 4356 Fälle pro Jahr (zum Vergleich London: im Durchschnitt 692 Fälle pro Jahr zwischen 1871 und 1885). In den acht Jahren zwischen 1906 und 1913 lagen dann die Zahlen für Berlin bei über 10000, für London nur bei 800 pro Jahr; die Angaben für Berlin aus: Statistisches Jahrbuch der Stadt Berlin, 6. Jg. (1880) - 13. Jg. (1888) und Reichs-Arbeitsblatt, 5. Jg. (1907) - 12. Jg. (1914); die genauen Zahlen für London in: London Statistics, hrsg. v. London County Council, Bd. 18 (1907-08) - Bd. 25 (1914-15).

377 Allgemein zum Motiv der nationalen Vereinheitlichung für die Kodifikationsbewegung und 
So entstand in Deutschland eine Institution, die sich von den VorläuferEinrichtungen weit entfernte und deren Auswirkungen und Folgen um 1890 niemand voraussehen konnte. Daß sich die Gewerbegerichte zu einer berufsständeübergreifenden Arbeitsgerichtsbarkeit weiterentwickeln würden, lag keineswegs in einer vermeintlichen Logik der Geschichte. Einer der engagiertesten Verteidiger der neuen Institution, der bereits erwähnte Ignaz Jastrow, plädierte zum Beispiel 1897 dafür, aus den Gewerbegerichten die unterste Stufe der Zivilrechtsprechung schlechthin zu machen. Gerade weil sich diese Gerichte bei Lohnstreitigkeiten so glänzend bewährt hätten, solle man sie zur ersten Instanz für zivile Bagatellstreitigkeiten aller Art ausbauen. Die Nebenfunktion als Einigungsamt könne dann verselbständigt werden. ${ }^{378}$ Ähnliche Überlegungen spielten, wie gesehen, auch in den Diskussionen, die zum Kaufmannsgerichtsgesetz führten, eine Rolle. Wären um 1900 die Vorstellungen Posadowskys und anderer Justizpolitiker realisiert worden (und das lag durchaus im Bereich des Möglichen), hätte sich das deutsche System der Beilegung von Arbeitsstreitigkeiten dem englischen System wieder angenähert. Man hätte die ,juristischen' Streitigkeiten aus dem Arbeitsvertrag in die ordentliche Justiz zurückgeholt und alle sonstigen Dispute in die vorjuristische Sphäre freiwilliger, staatlich geförderter Schieds- und Einigungsinstanzen abgedrängt. Knapp zwanzig Jahre später hatte sich dann aber die Praxis der Gewerbe- und Kaufmannsgerichte so sehr verfestigt, daß eine eigenständige Streitkultur im Bereich des Arbeitslebens und ein eigenes Rechtsgebiet entstanden waren. Spätestens seit der Novemberrevolution konnten Theorie und Praxis des Arbeitsrechts vom allgemeinen bürgerlichen Recht und seinen Institutionen weder vollständig eingefangen noch konsequent ausgegrenzt werden. Recht und industrielle Beziehungen bilden seitdem in Deutschland nicht - wie in England bis in die siebziger Jahre des 20. Jahrhunderts - zwei schroff voneinander abgegrenzte Systeme, sondern haben sich in der Arbeitsgerichtsbarkeit eine Institution geschaffen, die beiden Systemen angehört und eine gegenseitige Wahrnehmung ermöglicht.

die Reform der Gerichtsverfassung im Kaiserreich: Michael John, Politics and the Law in Late Nineteenth-Century Germany. The Origins of the Civil Code, Oxford 1989.

378 Jastrow, Erfahrungen in den deutschen Gewerbegerichten, S. $393 \mathrm{ff}$. 